Prepared for the U.S. Department of Energy

under Contract DE-AC05-76RL01830

\title{
Advanced Rooftop Control (ARC) Retrofit: Field-Test Results
}

\section{W. Wang}

S Katipamula, Principal Investigator

$\mathrm{H} \mathrm{Ngo}$

$\mathrm{R}$ Underhill

$D$ Taasevigen

R Lutes

July 2013

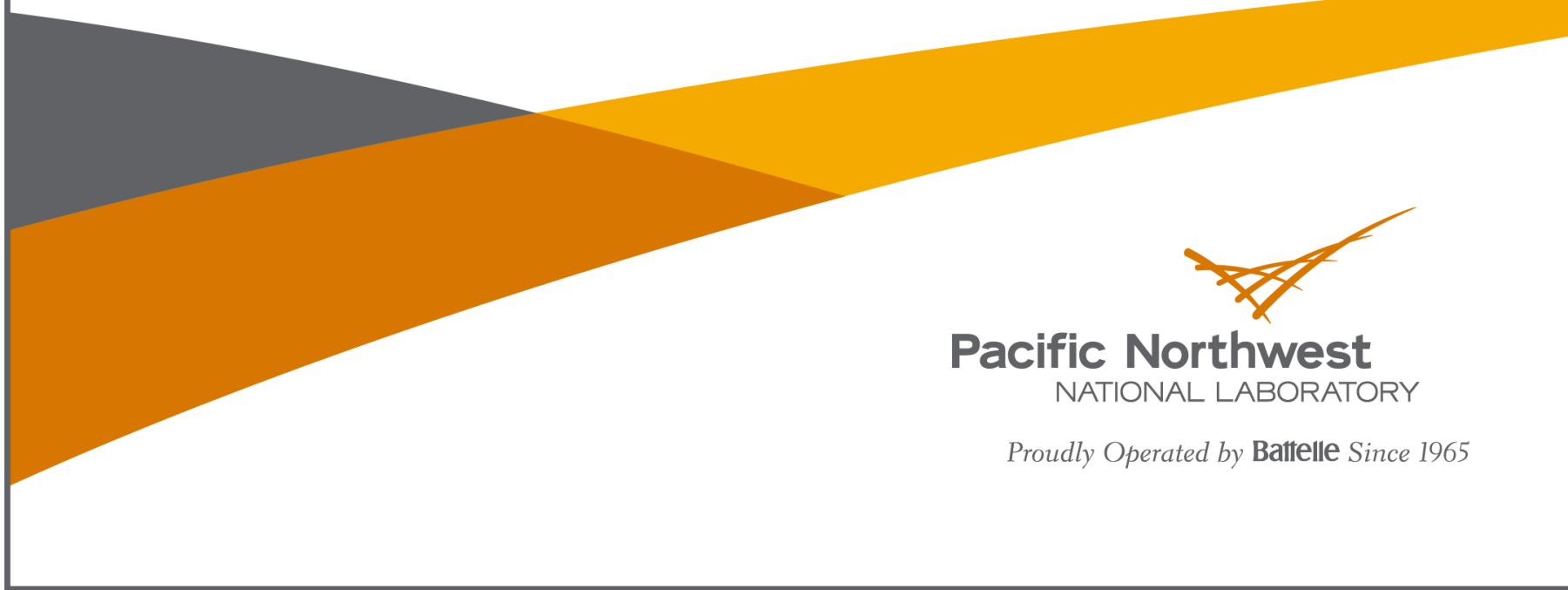




\title{
DISCLAIMER
}

United States Government. Neither the United States Government nor any agency thereof, nor Battelle Memorial Institute, nor any of their employees, makes any warranty, express or implied, or assumes any legal liability or responsibility for the accuracy, completeness, or usefulness of any information, apparatus, product, or process disclosed, or represents that its use would not infringe privately owned rights. Reference herein to any specific commercial product, process, or service by trade name, trademark, manufacturer, or otherwise does not necessarily constitute or imply its endorsement, recommendation, or favoring by the United States Government or any agency thereof, or Battelle Memorial Institute. The views and opinions of authors expressed herein do not necessarily state or reflect those of the United States Government or any agency thereof.

\author{
PACIFIC NORTHWEST NATIONAL LABORATORY \\ operated by \\ BATTELLE \\ for the \\ UNITED STATES DEPARTMENT OF ENERGY \\ under Contract DE-AC05-76RL01830 \\ Printed in the United States of America \\ Available to DOE and DOE contractors from the \\ Office of Scientific and Technical Information, \\ P.O. Box 62, Oak Ridge, TN 37831-0062; \\ ph: (865) 576-8401, fax: (865) 576-5728 \\ email: reports@adonis.osti.gov \\ Available to the public from the National Technical Information Service, \\ U.S. Department of Commerce, 5285 Port Royal Rd., Springfield, VA 22161 \\ ph: (800) 553-6847, fax: (703) 605-6900 \\ email: orders@ntis.fedworld.gov \\ online ordering: http://www.ntis.gov/ordering.htm
}

This document was printed on recycled paper. 
PNNL-22656

\title{
Advanced Rooftop Control (ARC) Retrofit: Field-Test Results
}

\author{
W Wang \\ S Katipamula, Principal Investigator \\ H Ngo \\ R Underhill \\ D Taasevigen \\ R Lutes
}

July 2013

Prepared for

U.S. Department of Energy

under Contract DE-AC05-76RL01830

Pacific Northwest National Laboratory

Richland, Washington 99352 



\section{ABSTRACT}

This multi-year research study was initiated to find solutions to improve packaged heating and cooling equipment operating efficiency in the field. Pacific Northwest National Laboratory (PNNL), with funding from the U.S. Department of Energy's (DOE's) Building Technologies Office (BTO) and Bonneville Power Administration (BPA) conducted this research, development and demonstration (RD\&D) study.

Packaged heating and cooling equipment with constant speed supply fans is designed to provide ventilation at the design rate at all times when the fan is operating and when the building is occupied as required by building code. Although there are a number of hours during the day when a building may not be fully occupied or the need for ventilation is lower than designed, the ventilation rate cannot be adjusted easily with a constant speed fan. Therefore, modulating the supply fan in conjunction with demand controlled ventilation (DCV) will not only reduce the heating/cooling energy but also reduce the fan energy.

The objective of this multi-year RD\&D project was to determine the magnitude of energy savings achievable by retrofitting existing packaged rooftop air units (RTUs) with advanced control strategies not ordinarily used for RTUs. First, in FY11, through detailed simulation analysis, it was shown that significant energy (between $24 \%$ and $35 \%$ ) and cost savings (38\%) from fan, cooling and heating energy consumption could be realized when RTUs with gas furnaces are retrofitted with advanced control packages (combining multi-speed fan control, integrated economizer controls and DCV). The simulation analysis also showed significant savings for heat pumps (between $20 \%$ and $60 \%$ ). The simulation analysis was followed by an extensive field test of a retrofittable advanced RTU controller.

In FY12, a total of 66 RTUs on 8 different buildings were retrofitted with a commercially available advanced controller for improving RTU operational efficiency. Of the 66 RTUs, 17 were packaged heat pumps and the rest were packaged air conditioners with gas heat. The eight buildings cover four building types, including mercantile (both retail and shopping malls), office, food sales, and healthcare. These buildings are located in four different climate zones, including warm and coastal climate, mixed and humid climate, mixed and marine climate, and cool and moist climate. One-minute interval data was collected from these 66 units over a 12-month period. During the 12 months of monitoring period, the controls on the RTUs were alternated between standard (pre-retrofit mode) and advanced control modes on a daily basis. The measured actual savings, the normalized annual energy savings, and the savings uncertainties were calculated using the methods described in the American Society of Heating, Refrigeration and Air Conditioning Engineers (ASHRAE) Guideline 14. Major findings from this work are highlighted below:

- The advanced controller reduced the normalized annual RTU energy consumption between $22 \%$ and $90 \%$, with an average of $57 \%$ for all RTUs. The fractions savings uncertainty was $12 \%$ for normalized savings, significantly lower than the average savings.

- Normalized annual electricity savings were in the range between $0.47 \mathrm{kWh} / \mathrm{h}$ (kWh per hour of fan/unit operation) and $7.21 \mathrm{kWh} / \mathrm{h}$, with an average of $2.39 \mathrm{kWh} / \mathrm{h}$.

- Fan energy savings made a dominant contribution to the total RTU electricity savings, while the heating and cooling energy savings varied with units and were relatively smaller in comparison 
with fan energy savings. In general, fan energy savings had much less uncertainty than heating and cooling energy savings.

- As expected, savings increased with the RTU size. The electricity savings increased from about $1.0 \mathrm{kWh} / \mathrm{h}$ for the group with RTU cooling capacity less than 10 tons, to $1.9 \mathrm{kWh} / \mathrm{h}$ for the group with RTU capacity between 10 and 15 tons, and then to $3.9 \mathrm{kWh} / \mathrm{h}$ for the group with RTU capacity greater than 15 tons.

- On average, packaged air conditioners (AC units) with gas heat achieved more electricity savings than heat pumps (HP units). The AC units saved $2.60 \mathrm{kWh} / \mathrm{h}$, while the HP group saved 1.75 $\mathrm{kWh} / \mathrm{h}$. The reason for this is that the average size of HPs was smaller than the average size of the ACs.

- Normalizing the annual savings with unit runtime and fan horse power appeared to be a better indicator of the potential savings from this retrofit. The variation of annual normalized RTU electricity savings were between 500 and $800 \mathrm{Wh} / \mathrm{h} / \mathrm{hp}$, with average savings of approximately $703 \mathrm{Wh} / \mathrm{h} / \mathrm{hp}$ across all eight sites.

Based on the normalized annual electricity savings and the installed cost of the advanced controller, the simple payback period was calculated for three arbitrary electricity rates including $0.05 \$ / \mathrm{kWh}, 0.10$ $\$ / \mathrm{kWh}$, and $0.15 \$ / \mathrm{kWh}$. Note that the gas energy savings were not considered in estimating the payback periods because gas consumption was not directly measured. Major findings from the economic analysis include the following:

- For all RTUs, the average payback period was 6,3 , and 2 years, respectively for the three utility rates. These payback periods account for the controller cost and labor to install the controller. The simple payback period for individual units varied from 9 months to 10 years for the electricity rate of $0.15 \$ / \mathrm{kWh}$. The units with the shortest payback period were either large units (e.g., greater than 15 tons) or had the longest runtime (e.g., 24/7 operations).

For all eight building sites, the simple payback period from the advanced controller installation ranged between 1 to 4 years for the utility rate of $0.15 \$ / \mathrm{kWh}$, between $11 / 2$ years and $61 / 2$ years for the utility rate of $0.10 \$ / \mathrm{kWh}$, and between 3 years and 13 years for the utility rate of $0.05 \$ / \mathrm{kWh}$. Based on the analysis of the over 60 units in 4 different building types and 4 climate locations, RTUs greater than 20 cooling tons capacity and runtime greater than 14 hours a day will have payback periods less than 3 years even at $\$ 0.05 / \mathrm{kWh}$, while units with 7.5 ton capacity that run less than 10 hours a day will need $50 \%$ utility incentive even at $\$ 0.15 / \mathrm{kWh}$ to have a 3-year payback. Although the number of climate locations covered by this demonstration study was small, the results are applicable to other climate locations as well. Because significant savings from this retrofit were associated with fan electricity savings, which are dependent on unit runtime and fan size, the savings in other climate locations should be similar.

The total source energy consumption associated with RTUs (air conditioners and heat pumps) is over 1,000 trillion Btus. Based on the measured savings, even if one-half of the packaged RTUs in the field are retrofitted with the advanced RTU controller, it will result in annual savings of approximately 285 trillion Btus of source energy. These energy savings are equivalent to removing over 70 coal-powered (200 MW each) power plants or over 10 nuclear power plants (1,000 MW each). 


\section{EXECUTIVE SUMMARY}

The multi-year research study was initiated to find solutions to improve packaged heating and cooling equipment operating efficiency in the field. Pacific Northwest National Laboratory (PNNL), with funding from the U.S. Department of Energy's (DOE's) Building Technologies Office (BTO) and Bonneville Power Administration (BPA) conducted this research, development and demonstration (RD\&D) study.

Packaged rooftop units (RTUs) are used in $46 \%$ (2.1 million) of all commercial buildings, serving over $60 \%$ (39 billion square feet) of the commercial building floor space in the U.S. (EIA 2003). The site cooling energy consumption associated with RTUs is about 160 trillion Btus annually. Packaged heat pumps account for an additional 70 trillion Btus annually. The source energy consumption of these units is over 1,000 trillion Btus. Therefore, even a small improvement in part-load operation of these units can lead to significant reductions of energy use and carbon emissions.

Packaged heating and cooling equipment with constant-speed supply fans is designed to provide ventilation at the design rate at all times when the fan is operating as required by building code. Although there are a number of hours during the day when a building may not be fully occupied or the need for ventilation is lower than designed, the ventilation rate cannot be adjusted easily with a constant speed fan. Studies have shown that demand-based ventilation control can save significant energy in climates that are not favorable for economizing or have significant heating energy loads. Therefore, modulating the supply fan in conjunction with demand controlled ventilation (DCV) will not only reduce the fan energy consumption but also will reduce the heating/cooling energy consumption.

Therefore, the objective of this multi-year RD\&D project was to determine the magnitude of energy savings achievable by retrofitting existing packaged rooftop units (RTUs) with advanced control strategies not ordinarily used for packaged units. First, in FY11, through detailed simulation analysis, it was shown that significant energy (between $24 \%$ and $35 \%$ ) and cost savings (38\%) from fan, cooling and heating energy consumption could be realized when RTUs with gas furnaces were retrofitted with advanced controls (combining multi-speed fan control, integrated economizer controls and DCV). The simulation analysis also showed significant savings for heat pumps (between $20 \%$ and $60 \%$ ). In FY11, the simulation analysis was followed by an extensive field test of a retrofittable advanced RTU controller.

A review of available products identified three potential products to choose from: 1) Catalyst, 2) Enerfit, and 3) Digi-RTU Optimizes. All vendors retrofit the supply fan with a variable-frequency drive (VFD) that can vary their speed based upon the RTU mode (heating mode, cooling mode or ventilation-only mode). All of the vendors provide advanced air-side economizer controls and DCV capabilities. The air-side economizer was integrated with mechanical cooling and economizer activation was based upon differential dry-bulb temperature or differential enthalpy. One vendor also provided the capability to modulate the compressor speed to control cooling capacity. All of these vendor retrofits came with new instrumentation to support the new control sequence strategies. Along with the additional instrumentation, most of these vendors claimed to have some level of fault detection diagnostics (FDD). After a detailed review of features of all available products and the maturity of products, PNNL chose to evaluate the Catalyst product in the field.

\section{ADVANCED RTU CONTROLler DESCRIPTION}

In most packaged units, a zone thermostat controls the operation of the compressor or the gas furnace, depending on whether the zone thermostat is calling for cooling or heating. All units tested in the field 
used "standard" conventional control strategies, the compressor or furnace was turned on or off to maintain the zone thermostat set point with the supply fan operating continuously (when the building is occupied) to provide sufficient ventilation air and provide comfort heating and cooling for the space. In addition, the conventional controls tested in the field, before the RTUs were retrofitted with advanced controllers, used a fixed dry-bulb high-limit for economizer controls. When the outdoor-air temperature was less than $55^{\circ} \mathrm{F}$ and the thermostat called for cooling, the outdoor-air damper opened fully (100\%). When there was a call for cooling and the outdoor-air temperature was greater than $55^{\circ} \mathrm{F}$, the outdoorair damper was set to its minimum position and mechanical cooling was enabled. The supply-fan speed could not be modulated under the conventional RTU control, so it supplied constant air volume under all modes of operations (ventilation, heating or cooling).

In contrast, the advanced controller tested in the field had the following features: integrated air-side economizers, supply-fan speed controls, and demand-controlled ventilation. If the units had multiple compressors, compressors were staged. The integrated economizer controls used differential dry-bulb temperature control to control the flow of outdoor air. The advanced RTU controller used the outdoorair temperature as the trigger point to determine when the air-side economizer cooling mode begins, when the economizer is integrated with mechanical cooling, and when the mechanical cooling is allowed to operate. The supply-fan speed options were determined primarily by the RTU operational mode. There were three primary modes of operation: ventilation, heating and cooling. The fan speed in ventilation mode was set at $40 \%$, while the speed during cooling and heating was either $75 \%$ or $90 \%$, depending on the number of stages of operation. The DCV option in the advanced controller used the return-air $\mathrm{CO}_{2}$ as the trigger point to determine how to regulate the outdoor-air damper and fan speed controls to ensure that the maximum allowable $\mathrm{CO}_{2}$ levels (high $\mathrm{CO}_{2}$ set point $=1000 \mathrm{ppm}$ ) was not exceeded.

\section{Field Measurement Metering ANd Monitoring}

The advanced controller was tested on 66 RTUs on 8 different buildings and 8 different climate locations. The same metering and monitoring plan was used on all RTUs to: 1 ) verify the operations of the advanced controller, 2) estimate the energy savings resulting from retrofitting the RTUs with the advanced controller and 3) estimate of simple payback periods. .

A thermistor-type temperature sensor was used to measure the outdoor-air temperature, the air temperature in the return duct, the mixed-air temperature right after the dampers, and the dischargeair temperature downstream of the supply fan and the cooling coil. The total true power consumption of the RTU was also measured using a power transducer. The $\mathrm{CO}_{2}$ concentration in the return-air duct was monitored using a $\mathrm{CO}_{2}$ sensor. In addition to the temperature, power and $\mathrm{CO}_{2}$ sensor measurements, a number of control signals were monitored (damper, cooling status, heating status, fan speed, etc.).

The monitoring plan consisted of collection of data at each RTU at 1-minute intervals, aggregating the data from all RTUs on a site, storing it locally on the roof, and streaming the data in real time to the Cloud for analysis. The cellular network was used to upload data from each site to the Cloud. In case of loss of communication between the site and Cloud, the logged data stored locally at each site had a maximum storage capacity to store between 4 and 8 hours of data (depending the number of units on the roof). 
The advanced RTU controller had a "soft" service switch to change the RTU control logic between the standard (conventional) control and the advanced energy saving control. During the standard control operation, the supply-fan speed was always at $100 \%$ when the RTU was in operation; the air-side economizer was not integrated with mechanical cooling and it was controlled with a fixed dry-bulb temperature; and the demand-controlled ventilation was disabled. During the advanced energy saving control operation, the supply fan runs at different speeds depending on the RTU operation modes such as ventilation, $1^{\text {st }}$ stage cooling and $2^{\text {nd }}$ stage cooling; the air-side economizer was integrated with mechanical cooling and it was controlled with a differential dry-bulb temperature controls; and the demand-controlled ventilation was enabled. During the field tests, the standard control and the advanced control were alternated daily. The standard control was intended to emulate the RTU operation before retrofitting the controller. Thus, the test days with the standard control operation represent the pre-retrofit period while the days with the advanced control represent the post-retrofit period. The alternating RTU operations between the standard control and the advanced control continued until sufficient test data covering different weather conditions were collected, which was approximately 12 months for most units.

\section{SITE AND EQUIPMENT DESCRIPTION}

A total of 66 RTUs on 8 different buildings were metered and monitored:

- The buildings were located in four states: Washington (WA), Ohio (OH), California (CA), and Pennsylvania (PA). These locations fall into the following climate zones: Cleveland, $\mathrm{OH}(5 \mathrm{~A})$; Oaks, PA (4A), Valencia, CA (3B), and all the sites in WA fall under Seattle (4C). Details on the climate zone definition can be found in ASHRAE Standard 90.1 (ASHRAE 2010b).

- The building types cover mercantile (both retail and shopping malls), office, food sales, and healthcare.

- Of the 66 tested RTUs, 17 were packaged heat pumps (HP) and the rest were packaged air conditioners $(\mathrm{AC})$ with gas heating.

\section{EnERgy SaVings Estimation Methodology}

The energy savings estimation methodology used was similar to that defined in ASHRAE Guideline 142002. The first step in the process involved developing regression models based on the measured energy consumption data during the pre-retrofit period (i.e., when the standard controls were used) and the post-retrofit period (i.e., when the advanced RTU controls were used). Regression models were used to correlate the daily heating, cooling and total energy consumption with the average outdoor-air temperature. Theoretically, these regression models can have one to five parameters depending on building type and the energy-use pattern. After a quick look at several RTUs' scatter charts showing the relationship between RTU's energy use and outdoor-air temperature, it was found that the threeparameter (3-P) and the five-parameter (5-P) change-point models were appropriate for most RTUs. The change point is a threshold below (above) which mechanical cooling (heating) was not needed to maintain the space temperature in its deadband. The 5-P change-point model was applied to the total electricity for heat pumps. For air conditioners with gas furnace, the 3-P change-point model is applied to cooling only, heating only, and the total electricity consumption. 
The second step estimated the energy consumption of the RTU using the pre-retrofit model (standard controls) under the post-retrofit conditions (e.g., post-retrofit outdoor-air conditions, etc.). The actual energy savings were then computed as the differences between the estimated energy use and the measured actual energy use over the post-retrofit period. In addition to the actual savings, normalized annual savings were also calculated using the typical meteorological year (TMY) weather data. To calculate normalized savings, the pre- and post-retrofit models were used to estimate the pre- and postretrofit energy consumption using TMY weather data. The difference between the pre- and post-retrofit energy consumption estimates was the normalized annual energy savings.

Because there can be errors in measurements (sensors) and also errors associated with models, the saving estimates will have some uncertainty. ASHRAE Guideline 14 recommend the following three primary sources of quantifiable uncertainty when estimating savings:

- Sampling uncertainty generated from not having a large enough sample to cover all possible combination of units. Although the RTUs selected for retrofits were by no means the random sample of the entire population, the sample was large enough so the sampling uncertainty was considered to be zero.

- Measurement error associated with the mis-calibration, range, and repeatability of the sensor and installation effects. In the current work the sources of measurement errors were primarily from the electric power meter and the outdoor-air temperature sensor.

- Modeling uncertainty generated from the prediction error of the regression models. Because gas consumption was not measured, uncertainty associated with heating models was not calculated.

- The fractional savings uncertainty, expressed as the ratio of the expected savings uncertainty to the total savings, was estimated for both the actual savings and the normalized savings.

\section{Advanced Control Validation}

One of the major objectives of this study was to validate the advanced RTU controller functions in the field. In comparison with the pre-retrofit RTU operation, the advanced controller used in this field test study had three major energy efficiency features: the supply-fan speed control, DCV, and integrated airside economizer control. Therefore, the validation process concentrated on these three features.

When the advanced RTU control was activated, the supply fan ran at different speeds depending on the mode that the RTU operated. Based on the control sequence, the supply-fan speed normally varied according to the following rules:

Rule 1: If an RTU ran in the ventilation mode, supply-fan speed was $40 \%$.

Rule 2: If an RTU ran in the economizing only mode and the outdoor-air temperature was less than $58^{\circ} \mathrm{F}$, supply-fan speed was $75 \%$ for the $1^{\text {st }}$ stage cooling and supply-fan speed was $90 \%$ for the $2^{\text {nd }}$ stage cooling.

Rule 3: If an RTU ran in the economizing only mode and the outdoor-air temperature was greater than $58^{\circ} \mathrm{F}$, supply-fan speed was $90 \%$. 
Rule 4: If an RTU ran in the $1^{\text {st }}$ stage cooling and the outdoor-air temperature was in between 58 and $70^{\circ} \mathrm{F}$, supply-fan speed was $90 \%$.

Rule 5: If an RTU ran in the $1^{\text {st }}$ stage cooling and the outdoor-air temperature was greater than $70^{\circ} \mathrm{F}$, supply-fan speed was $75 \%$.

Rule 6: If an RTU ran in the $2^{\text {nd }}$ stage cooling and the outdoor-air temperature was greater than $70^{\circ} \mathrm{F}$, supply-fan speed was $90 \%$.

Rule 7: If an RTU ran in the $1^{\text {st }}$ stage heating, supply-fan speed was $75 \%$.

Rule 8: If an RTU ran in the $2^{\text {nd }}$ stage heating, supply-fan speed was $90 \%$.

Database queries representing each of the eight rules described above were used on all RTUs to provide statistics on the number of records violating the supply-fan speed rule corresponding to that RTU operating condition. Overall, based on the analysis of the monitored data, the supply-fan speed control worked correctly according to the control sequence. There were a few instances when the data points got "stuck" for a period of time. Based on the feedback from the controller manufacturer, the stuck points primarily occurred in the transfer from the input/output of the controller to monitoring platform. The stuck point issue was related to data collection and not equipment operation. When a point was "stuck," it generally recovered quickly.

With demand-controlled ventilation, the outdoor-air damper was modulated based on the measured $\mathrm{CO}_{2}$ concentration in the return-air stream. DCV operation was validated using the same approach as that for the supply-fan control. Database queries were used to generate statistics on the number of records for two situations: $\mathrm{CO}_{2}$ concentration less than $1,000 \mathrm{ppm}$; and $\mathrm{CO}_{2}$ concentration greater than $1,000 \mathrm{ppm}$. The rules for the above two situations were as follows:

Rule 9: If the measured $\mathrm{CO}_{2}$ concentration was less than $1,000 \mathrm{ppm}$ and the unit was not running in the economizer mode, then the percentage of outdoor air should be at the minimum.

Rule 10: If the measured $\mathrm{CO}_{2}$ concentration was greater than $1,000 \mathrm{ppm}$ and the unit was not running in the economizer mode, then the percentage of outdoor air should lie between the minimum and the maximum outdoor air.

Like supply-fan speed controls, the DCV control in the advanced RTU controller worked correctly according to the control sequence.

When the space temperature was above the cooling set point, cooling was needed. The cooling needs could be met by outdoor air alone (economizing), combination of outdoor air and mechanical cooling (integrated economizing) or mechanical cooling. There are a number of rules that govern the economizer controls. The measured outdoor-, return-, mixed- and discharge-air temperatures, and the outdoor-air damper and cooling signals were used together to validate the economizer operation. In addition to the outdoor-air damper signal, the outdoor-air fraction (OAF) was computed from the measured temperatures and compared to its expected OAF value.

Economizer control was validated using the same approach as the supply-fan control and DCV. Database queries were used to generate statistics on the number of records for three situations: the outdoor-air damper did not fully open when it should; the outdoor-air damper opened more than the minimum position; and the system economized when there was no call for cooling. The rules for the above three situations were formulated as below: 
Rule 11: If the advanced controller received a cooling call and the outdoor-air condition was favorable for economizing, the damper must be in a fully open position (or to maintain a fixed discharge-air temperature).

Rule 12: If the advanced controller received a call for cooling and the outdoor condition was not favorable for economizing, the damper must be at the minimum position to meet ventilation needs.

Rule 13: If the advanced controller did not receive cooling call, the damper must be at the minimum position to satisfy ventilation needs.

Although there were a few exceptions, the query results showed that a majority of RTUs had very low percentages of data records that violated the above three rules on economizer control. In addition to the three economizer rules, there could be other potential faults that cannot be detected with simple rules. To identify those faults, a diagnostics tool (AirDx) was used. Using the measured temperatures and RTU operation schedules, AirDx can identify certain faults that potentially reduce energy savings or cause ventilation problems. OAF is the fraction of actual outdoor-air volume relative to the RTU's total supply air volume. For all RTUs, the desired OAF is between $5 \%$ and $100 \%$, corresponding to the minimum and the maximum damper position, respectively. Thus, with the aid of AirDx, the relative effectiveness of the economizer was determined by comparing the desired OAF and the OAF calculated from the temperature measurements.

First, the diagnostic tool was used to check whether over-ventilation was a potential problem. Some sites consistently had higher OAF than expected. This was not a control problem, but was most likely caused by damper leakage, non-linear relationship of damper position to the OAF and sensor measurement accuracy or biases. Over-ventilation occurred when the outdoor-air damper opened wider when it was commanded to the minimum position or when OAF exceeded the expected minimum OAF even when the outdoor-air damper was at the minimum position. Because the OAF was calculated from the measured return- , outdoor-, and mixed-air temperatures, any inaccuracies or biases in temperature sensors made the calculated OAF unreliable. Small biases (less than $2^{\circ} \mathrm{F}$ ) were difficult to detect. Therefore, the reported over-ventilation may be caused by either real damper problems (leakage) or temperature sensor faults. The AirDx tool identified that five RTUs at one site had faults associated with the mixed-air temperature sensor. However, the temperature sensors were checked before installation, so the problem may not be associated with sensing elements but the location of the sensors. Accurate measurement of mixed-air temperature is difficult in RTUs because of stratification of air. Some units had more stratification than others either because of the design or site construction (position of return-air ducts).

Second, the diagnostic tool was used to check if the OAF was approximately $100 \%$ when the outdoor-air damper was fully open. Most sites (with exception of two) had issues bringing in $100 \%$ outdoor air even when the damper was fully open. Again, this was not a control problem, but was most likely caused by damper leakage, non-linear relationship of damper position to the OAF and inaccuracies or biases in temperature sensors. This condition can be caused by several reasons including the damper actuator faults, the damper leakage, and the sensor faults. Based on these findings, maintenance work was performed on some RTUs at one site to seal return-air leakage. The sealing led to the OAF being closer to $100 \%$ when the outdoor-air damper was fully open. 


\section{Summary OF EnERgy SAVINGS ANALYSIS}

Actual energy savings and normalized annual energy savings and uncertainties associated with energy savings were calculated for each RTU.

- The actual RTU electricity savings ranged between $22 \%$ and $91 \%$, with an average of $56 \%$. The fractional uncertainty for actual RTU electricity savings ranged between $2 \%$ and $77 \%$, with an average of $25 \%$.

- The percentage of actual fan energy savings ranged between $26 \%$ and $94 \%$, with an average of $74 \%$.

- Many RTUs had negative heating and cooling energy savings, although the advanced controller was not expected to increase heating energy and cooling energy. The problem of negative heating and cooling energy savings was most likely caused by the following three reasons. First, the magnitude of heating and cooling savings was small. In extremely hot or cold climates, use of DCV will produce heating and cooling savings and integrated economizer would also produce additional cooling savings, albeit small. Because most of the demonstration sites were not in extreme climates, the heating and cooling savings were modest. Second, heating energy was not measured for air conditioning units with natural gas heating. Instead, the nominal furnace capacity was used together with the control signals to calculate heating energy consumption. Thus, any misinterpretations of the control signals (i.e., static data and mode transition period) decreased the reliability of the source data for regression model development. Third, for some units, the number of data points for RTU heating or cooling was not sufficient to develop robust regression models, causing high uncertainty associated with the heating or cooling energy savings.

The percentage actual savings and the uncertainty range at $95 \%$ confidence for all RTUs are shown in Figure ES - 1. This figure shows the following general trend: the higher the percentage of electricity savings, the smaller the uncertainty and thereby the shorter the error bar. Units with higher percentage of savings usually have most of their time running only the fan (either ventilation mode or economizing mode) when they are on. Because there was little variation in fan energy vs. outdoor-air temperature, the modeling uncertainty was low for those units.

The percentage of normalized annual energy savings and the normalized savings uncertainty for all RTUs is similar to that of actual savings. Some findings specific to normalized savings are listed as follows:

- Most units had normalized savings uncertainty lower than the actual savings uncertainty. This is because the post-retrofit period had more data points when calculating the normalized savings uncertainty.

- The percentage of normalized annual RTU electricity savings was in the range between $22 \%$ and $90 \%$, with an average of $57 \%$. The fractional uncertainty for normalized RTU electricity savings ranged between $1 \%$ and $51 \%$, with an average of $12 \%$.

- A few units had unreasonable results for either fan or cooling energy savings. Possible causes include the following. First, the baseline cooling energy was small so dividing a small number may cause high percentage values. Second, the normalized fan energy was calculated from the regression models for total RTU electricity, heating and cooling. Because the focus of this work was total RTU electricity savings, these RTUs were not excluded from our analysis, even though they had unreasonable percentage values of fan or cooling savings. 
The percentage of normalized annual savings and uncertainties (at 95\% confidence interval) for each RTU, as shown in Figure ES - 2 . Across all RTUs, the minimum normalized electricity savings at $95 \%$ confidence was between $12 \%$ and $89 \%$. In comparison with actual savings (Figure ES - 1), the error bars are much shorter for most units because of the smaller normalized savings uncertainty.

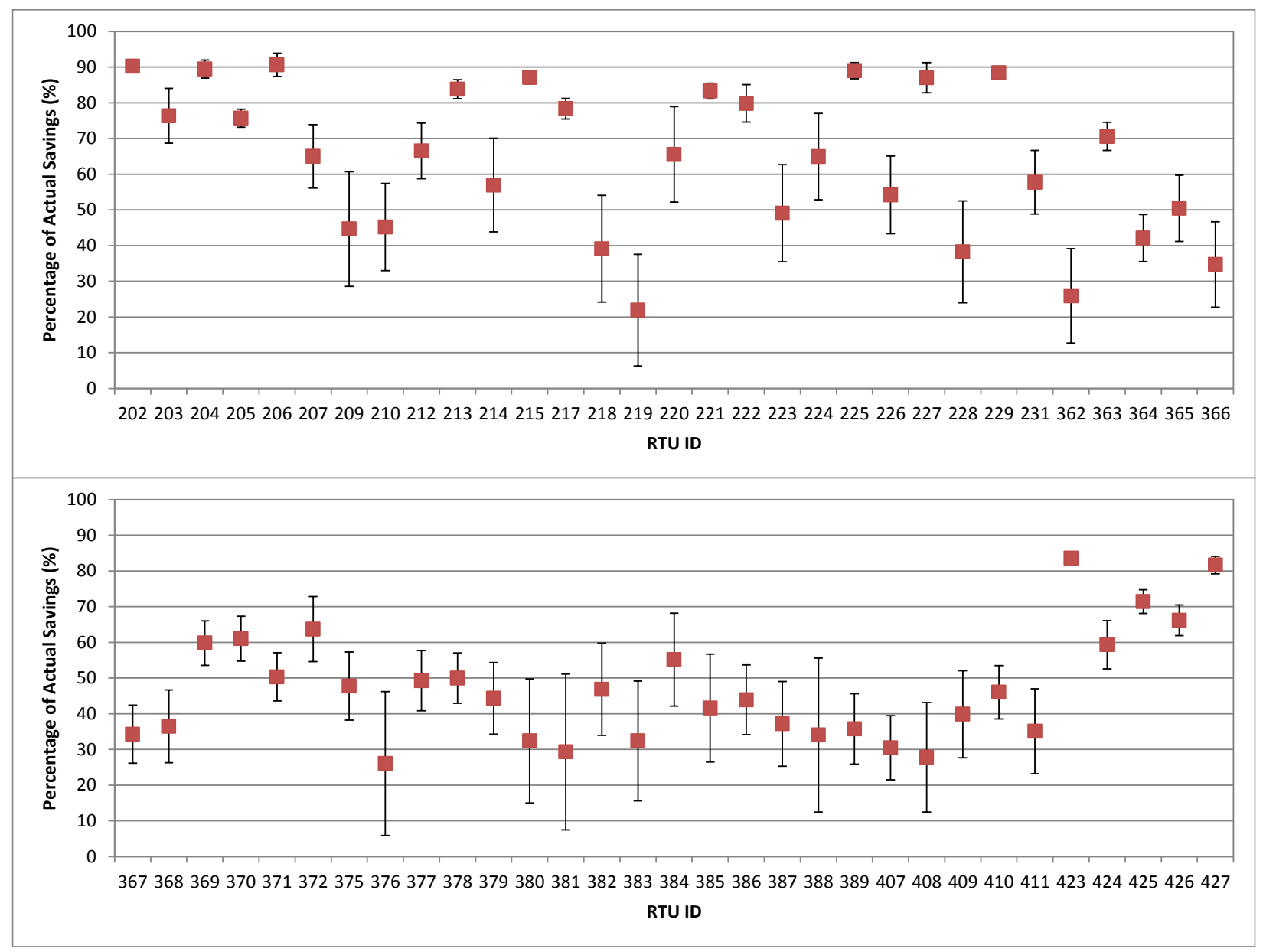

Figure ES - 1: Percentage of actual energy savings and uncertainty range at 95\% confidence for each RTU 


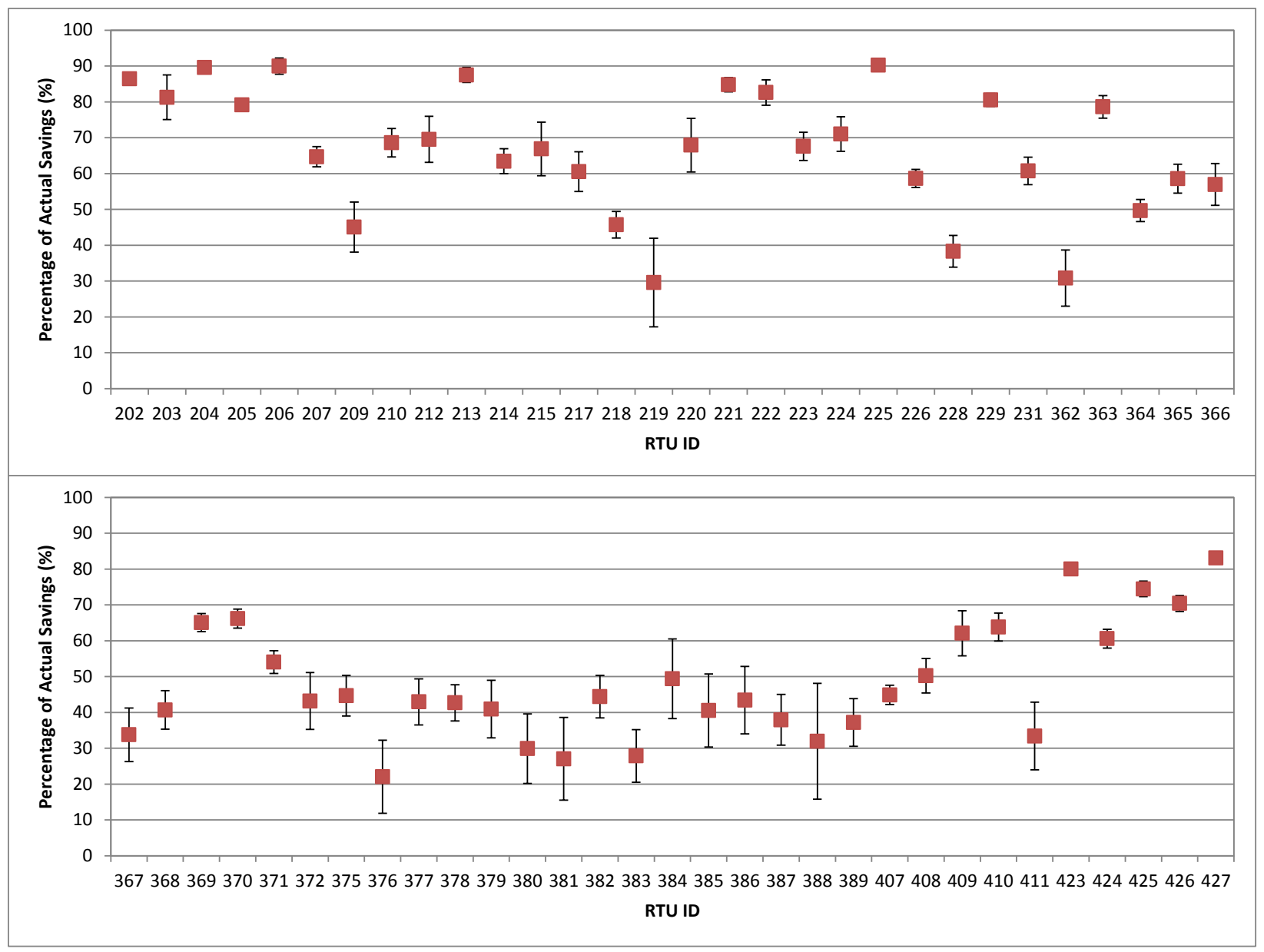

Figure ES - 2: Percent of normalized annual energy savings and uncertainty range at 95\% confidence for each RTU

Figure ES - 3 shows the frequency distribution of actual and normalized RTU electricity savings. The majority are in the range between $40 \%$ and $90 \%$. Because the electricity savings mostly came from fan energy reduction, the units with lower savings usually had longer compressor runtimes, while the units with higher savings had shorter compressor runtimes. 


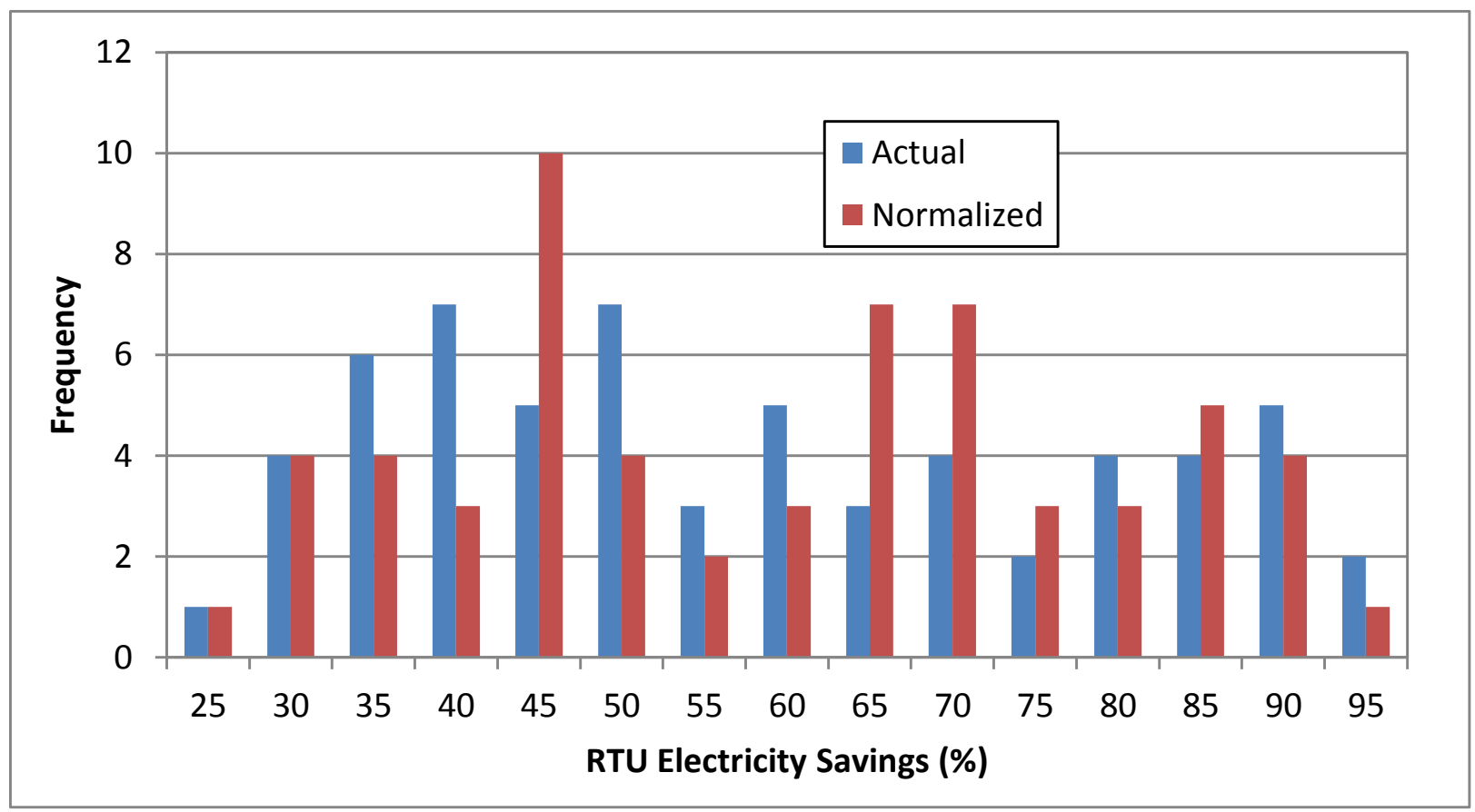

Figure ES - 3: Frequency distribution of actual and normalized RTU electricity savings

In addition to the percentage of RTU electricity savings, review of the absolute savings and absolute savings normalized by variables that had significant impact on the savings was also conducted. The variables that had significant effect on the savings included: building type (static pressure and occupancy variations), climate location, unit runtime (total runtime and compressor runtime versus supply fan runtime) and the unit size (supply fan motor).

The summary of the absolute actual savings includes:

- As expected, actual fan energy savings made a dominant contribution to the total RTU electricity savings.

- Actual RTU electricity savings was in the range between $0.35 \mathrm{kWh} / \mathrm{h}$ and $7.68 \mathrm{kWh} / \mathrm{h}$ ( $\mathrm{kWh}$ per unit run hour), with an average of $2.41 \mathrm{kWh} / \mathrm{h}$, while the fan only electricity savings range between $0.32 \mathrm{kWh} / \mathrm{h}$ to $6.64 \mathrm{kWh} / \mathrm{h}$ with an average of $1.95 \mathrm{kWh} / \mathrm{h}$.

- Actual RTU electricity savings was in the range between $197 \mathrm{Wh} / \mathrm{h} / \mathrm{hp}$ and 1,300 Wh/h/hp (Wh per unit run hour and per unit fan $\mathrm{hp}$ ) with an average of $709 \mathrm{Wh} / \mathrm{h} / \mathrm{hp}$, while the fan only electricity savings range between $194 \mathrm{Wh} / \mathrm{h} / \mathrm{hp}$ and $702 \mathrm{Wh} / \mathrm{h} / \mathrm{hp}$ with an average of 556 Wh/h/hp.

The summary of the absolute normalized annual savings includes:

- The RTU runtime was based on the operation schedule derived from the monitored data.

- Annual TMY weather normalized savings was in the range between $0.47 \mathrm{kWh} / \mathrm{h}$ and $7.21 \mathrm{kWh} / \mathrm{h}$, with an average of $2.39 \mathrm{kWh} / \mathrm{h}$, while the fan only electricity savings range between $0.36 \mathrm{kWh} / \mathrm{h}$ to $7.37 \mathrm{kWh} / \mathrm{h}$ with an average of $2.18 \mathrm{kWh} / \mathrm{h}$. 
- Annual TMY weather normalized RTU electricity savings was in the range between $218 \mathrm{Wh} / \mathrm{h} / \mathrm{hp}$ and 1,086 Wh/h/hp with an average of $695 \mathrm{Wh} / \mathrm{h} / \mathrm{hp}$, while the fan only electricity savings range between $201 \mathrm{Wh} / \mathrm{h} / \mathrm{hp}$ to $929 \mathrm{Wh} / \mathrm{h} / \mathrm{hp}$ with an average of $595 \mathrm{Wh} / \mathrm{h} / \mathrm{hp}$.

Both the actual and normalized annual savings showed significant variation of the electricity savings per hour, but it generally increased with the size of the unit. The variations for any given size of unit were likely caused by particular building and unit characteristics such as building type, climate conditions, and the supply-fan static pressure. The trend was consistent with both air conditioners (ACs) and heat pumps (HPs).

Figure ES -4 shows the variation of normalized RTU electricity savings per unit run hour and per supplyfan motor hp as a function of RTU size. Although there was some scatter just like the similar actual savings plot, there was no obvious trend with the size of the unit. It appears that normalizing savings with the unit run hours and the fan motor size, correlates well with the annual savings across the eight sites. Most units had savings between $500 \mathrm{Wh} / \mathrm{h} / \mathrm{hp}$ and $800 \mathrm{Wh} / \mathrm{h} / \mathrm{hp}$, with an average savings across all sites being $703 \mathrm{Wh} / \mathrm{h} / \mathrm{hp}$.

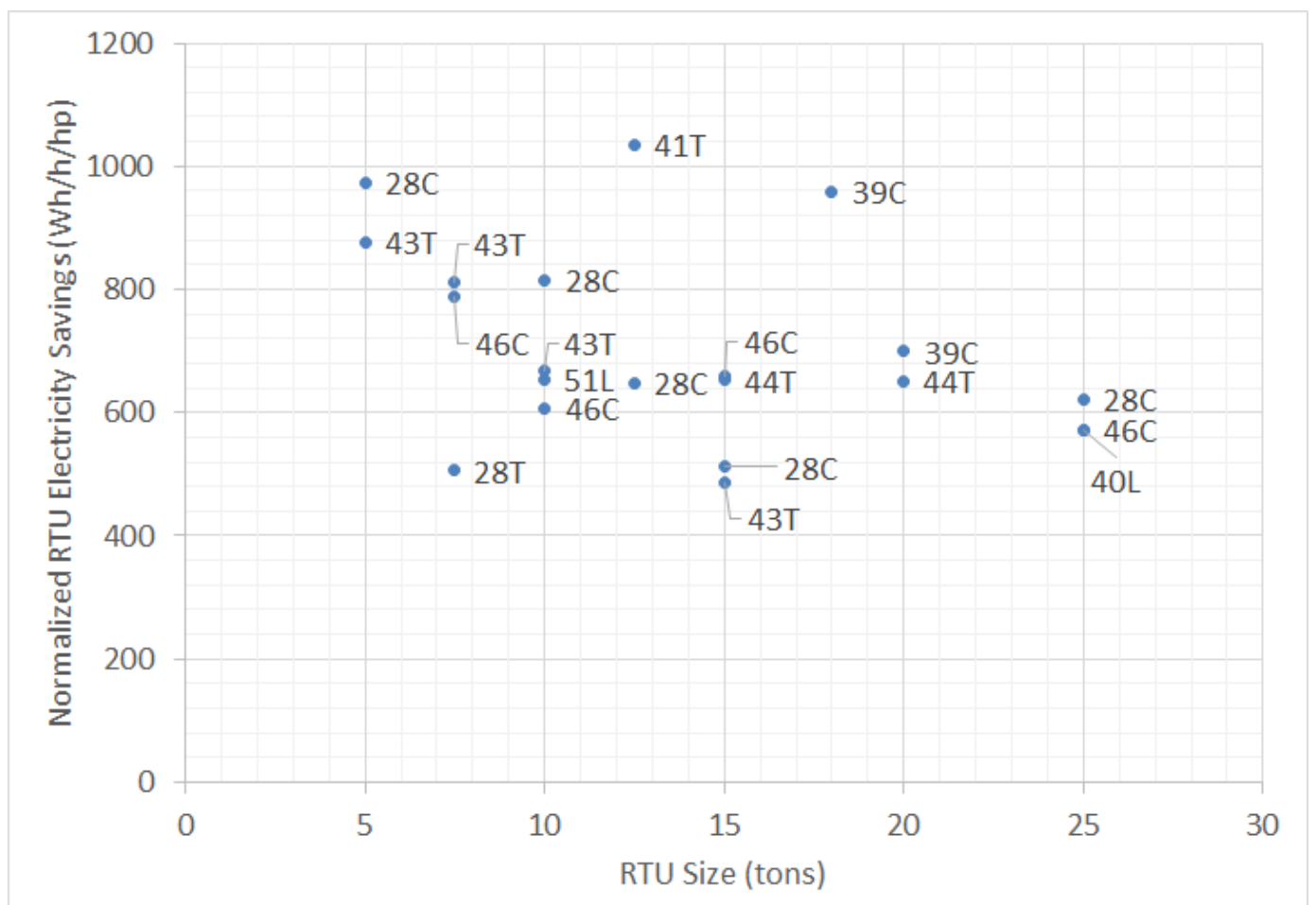

Figure ES - 4: Variation of average normalized RTU electricity savings per unit run hour and per fan motor hp with RTU size

The results presented in this section demonstrate retrofitting an RTU with an advanced controller can lead to significant RTU energy savings.

\section{ECONOMIC ANALYSIS}

The simple payback analysis helps building owners understand the financial impact of RTU controller retrofits and justify their investment. Table ES - 1 breaks down the costs associated with the advanced controller retrofit by metering and monitoring for a single RTU at varying capacities and corresponding 
supply-fan sizes. While the metering costs are fixed upfront, the monitoring is broken down into fixed and variable cost ( $\$ /$ month for internet subscription and hosting fees). The metering and monitoring costs are not essential to the retrofit but allow for monitoring of the persistence of the RTU operations.

Table ES - 1: RTU advanced controller costs broken down by metering and monitoring

\begin{tabular}{|c|r|r|r|r|r|r|r|}
\hline $\begin{array}{c}\text { RTU Capacity } \\
\text { (tons) }\end{array}$ & $\begin{array}{c}\text { Supply } \\
\text { Fan } \\
\text { Size } \\
(\mathrm{hp})\end{array}$ & $\begin{array}{c}\text { Controller } \\
(\$)\end{array}$ & $\begin{array}{c}\text { Controller Labor } \\
(\$)\end{array}$ & $\begin{array}{c}\text { Metering } \\
(\$)\end{array}$ & $\begin{array}{c}\text { Metering } \\
\text { Labor }(\$)\end{array}$ & $\begin{array}{c}\text { Fixed } \\
\text { Monitoring } \\
(\$)\end{array}$ & $\begin{array}{c}\text { Variable } \\
\text { Monitoring } \\
(\$ / \text { Month) }\end{array}$ \\
\hline$\leq 5$ & 1 & 2,200 & 750 & 1,071 & 375 & 2,403 & 50 \\
\hline$>5$ and $\leq 10$ & 2 & 2,600 & 750 & 1,071 & 375 & 2,403 & 50 \\
\hline$>10$ and $\leq 15$ & 3 & 3,500 & 750 & 1,071 & 375 & 2,403 & 50 \\
\hline$>15$ and $\leq 20$ & 5 & 4,000 & 750 & 1,071 & 375 & 2,403 & 50 \\
\hline$>20$ and $\leq 25$ & 7.5 & 4,142 & 750 & 1,071 & 375 & 2,403 & 50 \\
\hline
\end{tabular}

- Controller cost varied because the size of the variable frequency drive (VFD) depended on the size of the supply fan motor, which was included in the controller cost.

- Labor rate assumed to be $\$ 125 / \mathrm{h}$. This may vary based on market conditions.

- Metering included a total RTU power measurement device, a mixed-air sensor and cost to install the two sensors.

- Fixed monitoring cost included a monitoring unit, cellular modem, radio, and wireless client transmitter. This cost was for one RTU, and each additional RTU monitored at a site will increase the cost of fixed monitoring by an additional $\$ 150$.

- Variable monitoring included web hosting and internet access.

Based on the costs outlined in Table ES - 1, a simple payback period was calculated for the advanced controller, based on the projected normalized annual energy savings. Three utility rates were used: 0.05 $\$ / \mathrm{kWh}, 0.10 \$ / \mathrm{kWh}$ and $0.15 \$ / \mathrm{kWh}$. Across all units, the annual average cost savings were $\$ 744$, $\$ 1,489$ and $\$ 2,233$ for the three considered utility rates, with a corresponding average installed cost of $\$ 4,172$ resulting in average payback period of 6,3 , and 2 years, respectively. This payback period was only for the controller and labor to install the controller. It did not include any of the metering and monitoring packages.

For individual units, the simple payback period varied from 9 months to 10 years at a utility rate of $\$ 0.15 / \mathrm{kWh}$. This variation in payback period was largely dependent on RTU size and RTU runtime. The units with the shortest payback period were either large units (e.g., greater than 15 tons) or had the largest annual runtime (operating hours per year).

Figure ES - 5 shows the frequency of units at varying payback periods and capacity ranges for (a) all capacities at a $\$ 0.10 / \mathrm{kWh}$ utility rate; (b) all capacities at a $\$ 0.15 / \mathrm{kWh}$ utility rate; (c) two capacity ranges at a $\$ 0.10 / \mathrm{kWh}$ utility rate; and (d) two capacity ranges at a $\$ 0.15 / \mathrm{kWh}$ utility rate. Figure ES - 5 shows that as the utility rate increased, the frequency of units with less than 3 years of payback period also increased, with the majority of the units less than 3 years of payback period having capacities greater than 20 tons. 


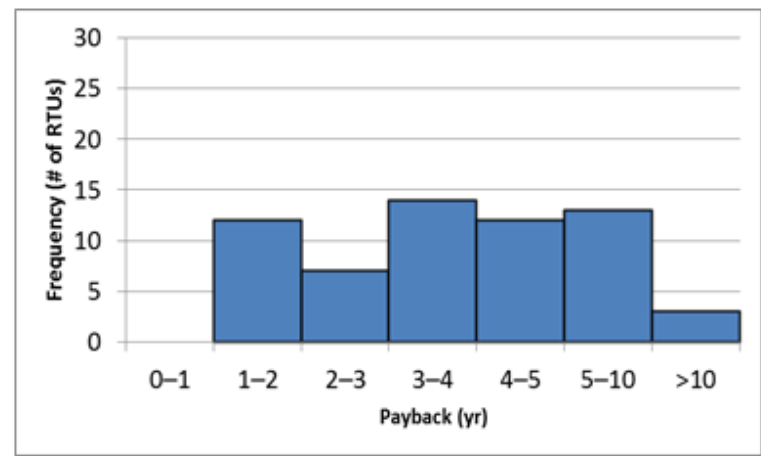

(a)

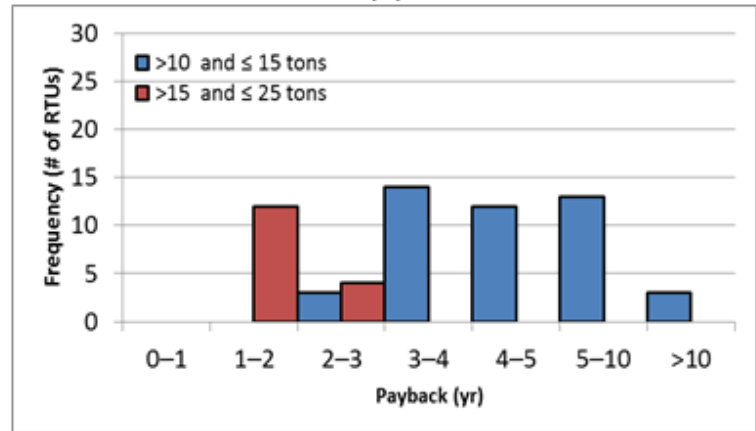

(c)

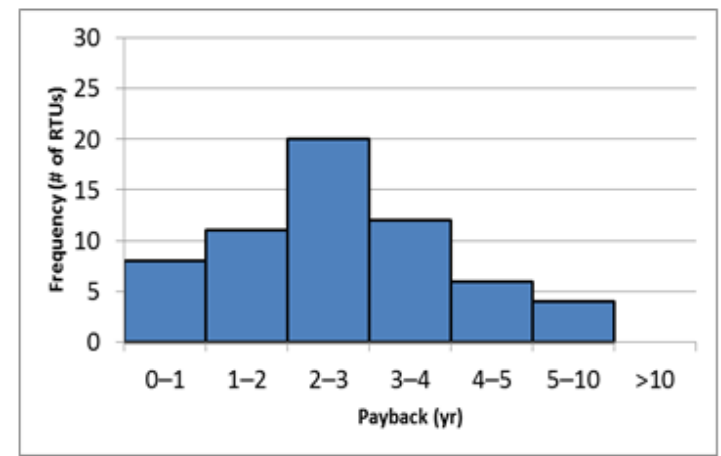

(b)

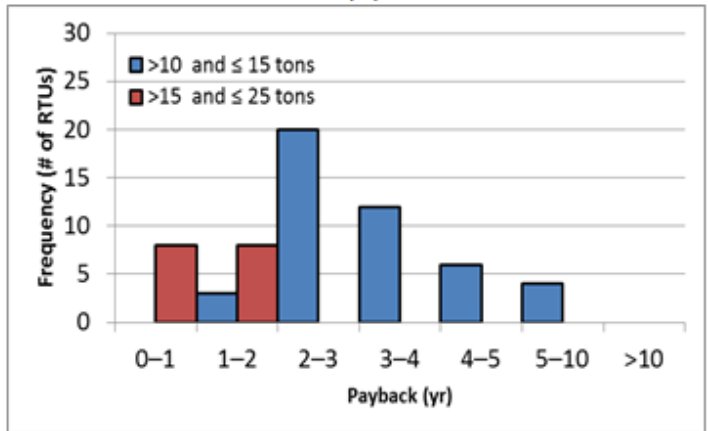

(d)

Figure ES - 5: Histogram charts showing the frequency of units at varying payback periods for (a) all capacities at a $\$ 0.10 / \mathrm{kWh}$ utility rate; (b) all capacities at a $\$ 0.15 / \mathrm{kWh}$ utility rate; (c) two capacity ranges at a $\$ 0.10 / \mathrm{kWh}$ utility rate; and (d) two capacity ranges at a $\$ 0.15 / \mathrm{kWh}$ utility rate

\section{SUMMARY, DISCUSSION AND RECOMMENDATIONS}

A total of 66 RTUs on 8 different buildings were retrofitted with a commercially available advanced controller for improving RTU operational efficiency. Of the 66 tested RTUs, 17 were packaged heat pumps and the rest were packaged air conditioners with gas heat. The eight buildings covered four building types, including mercantile (both retail and shopping malls), office, food sales, and healthcare. These buildings were located in four different climate zones including warm and coastal climate, mixed and humid climate, mixed and marine climate, and cool and humid climate. The measured actual savings, the normalized annual energy savings, and the savings uncertainties were calculated using the methods described in the ASHRAE Guideline 14. Major findings from this work are highlighted below:

- The advanced controller reduced both actual consumption and normalized consumption by between $22 \%$ and $90 \%$, with an average of $55 \%$ for all RTUs.

- On average, the fractional savings uncertainty was $25 \%$ for actual savings and $12 \%$ for normalized savings.

- Fan energy savings made a dominant contribution to the total RTU electricity savings, while the heating and cooling energy savings varied with units and were relatively smaller in comparison with fan energy savings. In general, fan energy savings had much less uncertainty than heating and cooling energy savings. 
- At the building level (total of all monitored RTU electricity consumption), the percentage of RTU electricity savings was in the range between $37 \%$ and $73 \%$ for both actual and normalized savings. The absolute electricity savings were in the range between 1.4 and $3.9 \mathrm{kWh}$ per hour of unit operation.

- As expected, both actual and normalized savings increased with the RTU size. The electricity savings increased from about $1.0 \mathrm{kWh} / \mathrm{h}$ for the group with RTU cooling capacity less than 10 tons, to $1.8 \mathrm{kWh} / \mathrm{h}$ for the group with RTU capacity between 10 and 15 tons, and then to 4.2 $\mathrm{kWh} / \mathrm{h}$ for the group with RTU capacity greater than 15 tons.

- On average, packaged air conditioners with gas heat (AC units) achieved more electricity savings than heat pumps (HP units). For both actual and normalized savings, the AC group saved 2.60 $\mathrm{kWh} / \mathrm{h}$ per running hour, while the HP group saved $1.75 \mathrm{kWh} / \mathrm{h}$. This was because the average size of HPs was smaller than the average size of the ACs.

- The variation of annual normalized RTU electricity savings were between 400 and $700 \mathrm{Wh} / \mathrm{h} / \mathrm{hp}$ with average savings approximately $515 \mathrm{Wh} / \mathrm{h} / \mathrm{hp}$ across all eight sites.

Based on the normalized annual electricity savings and the installed cost of the advanced controller, the simple payback period was calculated for three electricity rates including $0.05 \$ / \mathrm{kWh}, 0.10 \$ / \mathrm{kWh}$, and $0.15 \$ / \mathrm{kWh}$. Note that the gas energy savings were not considered in estimating the payback periods because gas consumption was not directly measured. Major findings from the economic analysis included the following:

- For all RTUs, the average payback period is 6, 3, and 2 years, respectively for the three utility rates. These paybacks accounted for the controller cost and labor to install the controller, but did not include the metering and monitoring packages. The simple payback period for individual units varied from 9 months to 10 years for the electricity rate of $0.15 \$ / \mathrm{kWh}$. The units with the shortest payback period were either large units (e.g., greater than 15 tons) or had the longest runtime (e.g., 24/7 operations).

- For all eight building sites, the simple payback period from the advanced controller installation ranged between 1 to 5 years for the utility rate of $0.15 \$ / \mathrm{kWh}$, between $11 / 2$ years and $61 / 2$ years for the utility rate of $0.10 \$ / \mathrm{kWh}$, and between 3 years and 13 years for the utility rate of 0.05 $\$ / k W h$.

When applying the project findings to a specific project, some factors not sufficiently considered in this work may affect the energy savings or the simple payback period. The following items need to be taken into account for RTU controller retrofits:

- Equipment maintenance and reparation should be an integrated part of the RTU controller retrofit. If some parts of the RTU do not function properly, the potential of energy savings cannot be fully realized.

- Because significant demand reductions were not expected from advanced RTU controller retrofit, demand reduction and demand cost savings were not considered in the work. For many commercial buildings with demand cost (a big portion of the energy bills), demand reduction could have significant impact on the simple payback period. This may be a more salient feature for those advanced controllers capable of modulating the compressor speed. 
- The simple payback period could be significantly reduced if utility incentives are available and considered in the economic analysis. In this respect, utility incentives are important to expand the market acceptance of the RTU advanced controller.

- Cost savings on natural gas were not considered in this work for simple payback period calculation. The gas cost savings are expected to become important in cold climates and buildings with high fluctuation of occupancy profiles.

Based on the project team's experience, the following recommendations are made for possible improvement of the control algorithm:

- The advanced controller demonstrated in the field changed the supply-fan control from constant speed to multi-speed with use of a VFD. More savings could be achieved if the supplyfan speed was modulated continuously.

- The current control sequence implemented two-stage economizing when the outdoor-air temperature was $58^{\circ} \mathrm{F}$ and below. The supply fan ran at $75 \%$ and $90 \%$ of its full speed for the two stages of economizing. Although the intent was to reduce fan energy by running the supply fan at low speeds, a tradeoff existed between the fan running time and the fan running speed. Efforts are needed to compare the current approach with other alternative approaches such as running the supply fan at its full speed for economizing.

- When the outdoor-air temperature was above $70^{\circ} \mathrm{F}$ and there is a call for cooling, the current control sequence implemented two stages of DX (direct expansion) cooling if the RTU had staged capacity controls. The supply fan ran at $75 \%$ and $90 \%$ of its full speed for the two stages. To save more fan energy, it might be worthwhile to maintain the fan speed at $75 \%$ for the $2^{\text {nd }}$ stage cooling. Once the advantage of running the supply fan at low speed was verified, similar changes could be made for the DX cooling stage when the outdoor-air temperature was between $58^{\circ} \mathrm{F}$ and $70^{\circ} \mathrm{F}$ and there was a call for cooling.

- When the outdoor-air temperature was between $58^{\circ} \mathrm{F}$ and $70^{\circ} \mathrm{F}$, the current control sequence required that the $2^{\text {nd }}$ stage of DX cooling be initiated if the discharge-air temperature was above $58^{\circ} \mathrm{F}$ after running the $1^{\text {st }}$ stage of DX cooling for 10 minutes. In this respect, the current control sequence could be improved in several possible aspects: 1) consider using a time delay longer than 10 minutes; 2 ) consider raising the discharge-air temperature threshold value; 3 ) if the advanced controller has access to the space temperature, use the space temperature deviation from the cooling set point instead of the discharge-air temperature as the criterion to initiate the $2^{\text {nd }}$ stage of DX cooling; and 4) swap internally the $1^{\text {st }}$ and $2^{\text {nd }}$ stages of DX cooling and determine if the $2^{\text {nd }}$ stage is able to satisfy the internal requirements (discharge-temperature and space set points).

- The discharge-air temperature sensor was used as a safety device to increase fan speeds when the discharge-air temperature was too high (discharge $>150^{\circ} \mathrm{F}$ ) or too low (discharge $<48^{\circ} \mathrm{F}$ ). If the discharge-air temperature sensor is reliable, it can be used to modulate the fan speed. Fan speeds could be based upon the target discharge set point (leaving air temperature) after the fan.

- The controller had heat pump lockouts that determine when compression heat was disabled (only electric heating is allowed) and when electric heat is disabled (only compression heat is allowed). Suggested improvements include lowering the electric strip lockout maximum value 
(it is still adjustable, but limit the maximum value to not exceed $42^{\circ} \mathrm{F}$ ); and limit the minimum night set back temperature value that the space(s) can be allowed to float down to. The idea is that the tradeoff for energy efficiency and savings is quickly lost when the RTU is a heat pump configuration with electric auxiliary heating. The $\mathrm{kW}$ demand costs from having to activate electric heating wipes out a significant portion of the kWh savings from extended night set back hours. This results in many owners setting their schedules to longer occupied periods. The solution is to have aggressive set back schedules (shorter occupancy periods), but limit the night set back temperature values $\left(65^{\circ} \mathrm{F}\right.$ would be the minimum setting that would be allowed). This means that nighttime actions might show the RTU activating between one and five times to maintain the minimum setting, but the recovery period would be much shorter and hopefully results in a short-lived use of the $2^{\text {nd }}$ stage auxiliary electric strip heater.

- The advanced controller can be enhanced by adding more capabilities, such as optimal start and stop, demand response strategies, and automatic fault diagnostics.

Based on the analysis of the over 60 units in 4 different building types and 4 climate locations, it was clear that the building type, unit runtime and supply-fan motor size were significant contributors to the energy savings potential. Although savings associated with DCV will be high in extreme climate locations, most of the climate locations in the study were not extreme. Consider retrofitting an existing RTU with advanced controller under the following conditions, which will yield a 3-year payback period (Table ES - 2):

Table ES - 2: Recommendations on when to consider advanced RTU control retrofits that yield 3-year payback

\begin{tabular}{|l|l|l|}
\hline \multicolumn{1}{|c|}{ RTU Size } & Average Run Hours per Day & Utilities Rates and Incentives \\
\hline$>20$ tons & $>14$ & At any utility rates and with no incentive \\
\hline$>20$ tons & 12 to 14 & $\$ 0.10 / \mathrm{kWh}$ with no incentive \\
\hline$>20$ tons & $<10$ & $\$ 0.10 / \mathrm{kWh}$ with moderate $(25 \%)$ incentive \\
\hline 15 to 18 tons & $>14$ & $\$ 0.12 / \mathrm{kWh}$ with no incentive \\
\hline 15 to 18 tons & $<10$ & $\$ 0.10 / \mathrm{kWh}$ with high $(50 \%)$ incentive \\
\hline 7.5 to 12.5 tons & $>14$ & $\$ 0.15 / \mathrm{kWh}$ with no incentive \\
\hline 7.5 to 12.5 tons & $<10$ & $\$ 0.15 / \mathrm{kWh}$ with high $(50 \%)$ incentive \\
\hline$>7.5$ tons & $>14$ & $\$ 0.10 / \mathrm{kWh}$ with high $(50 \%)$ incentive \\
\hline$>7.5$ tons & $>14$ & $\$ 0.12 / \mathrm{kWh}$ with moderate $(25 \%)$ incentive \\
\hline$>7.5$ tons & $<10$ & $\$ 0.15 / \mathrm{kWh}$ with high $(50 \%)$ incentive \\
\hline
\end{tabular}

The above rules-of-thumb can be used for screening purposes, but a more thorough analysis based on site-specific conditions may be necessary. For units that are 5 tons and smaller, which typically use a single-phase fan motors, this technology is not going to be cost-effective; however, there are other options for those single-phase units that are cost-effective. Those options were not considered in this study. 


\section{ACKNOWLEDGEMENT}

The authors would like to acknowledge the Buildings Technologies Office of the U.S. Department of Energy (DOE) Office of Energy Efficiency and Renewable Energy and Bonneville Power Administration (BPA) for supporting the research, development and demonstration effort. The authors would also like to thank Jason Koman and Alan Schroeder, Technology Development Managers, at DOE and Mira Vowles Project Manager at BPA, Nick Fernandez for providing the technical review, Linda Sandahl (Program Manager at PNNL) for thoughtful comments and insights, Sue Arey for editorial support, Loren Ruiz for help in preparing this document and Nicholas Denegre, summer intern, for helping validate the economizer operations and Transformative Wave Technologies Inc., who provided significant cost share and helped recruit organizations to participate in the demonstration. Finally, the authors would like to thank a number of external reviewers who provided valuable comments: Jack Callahan, Janice Peterson, Peter Criscione, Jay Stein, Jerry Scott, Ian Doebber, Jessie Dean, Fred Gordon and Curt Nichols. 


\section{Contents}

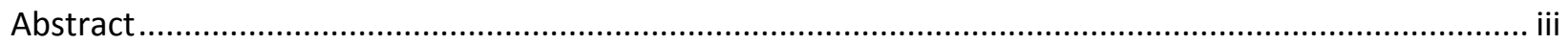

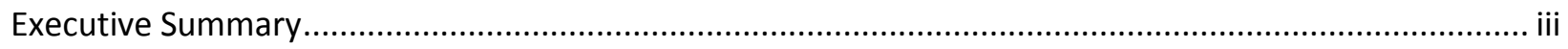

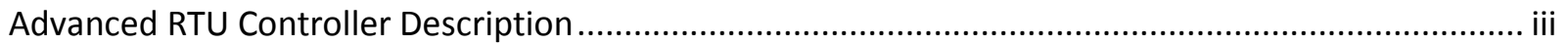

Field Measurement Metering and Monitoring............................................................................... iv

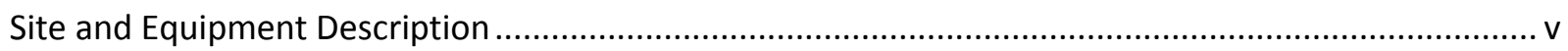

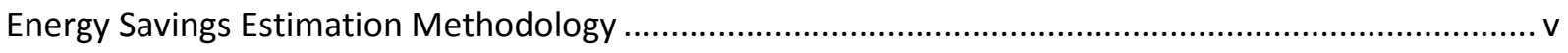

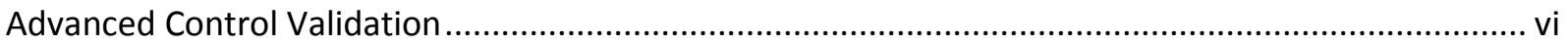

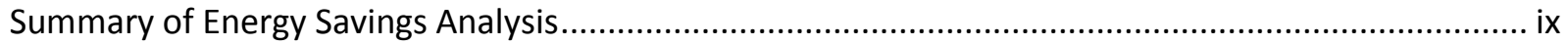

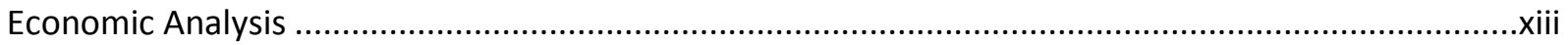

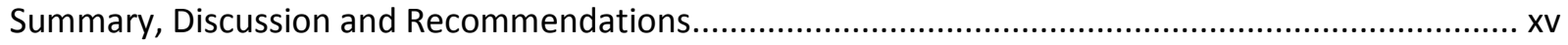

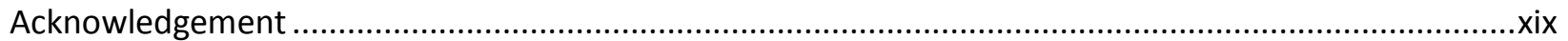

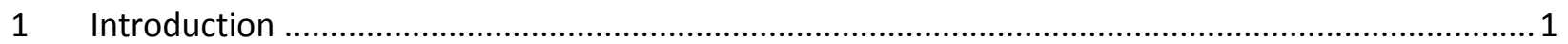

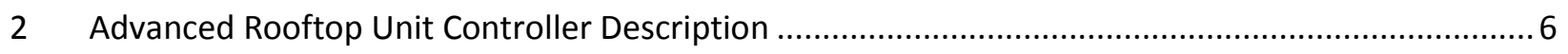

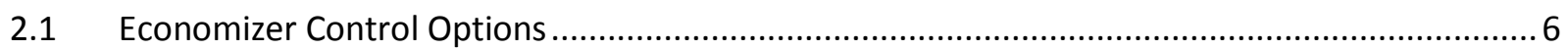

2.2 Conventional Control for Packaged RTUs ...............................................................................

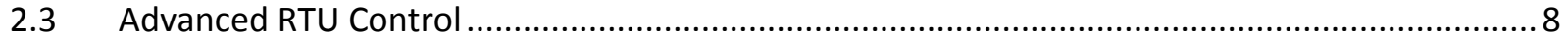

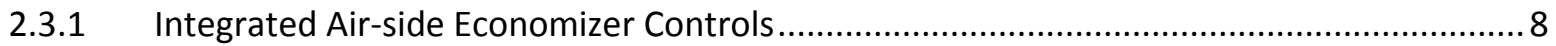

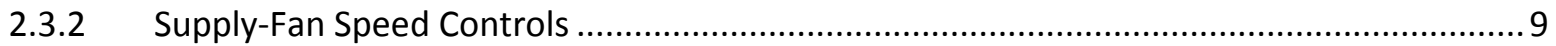

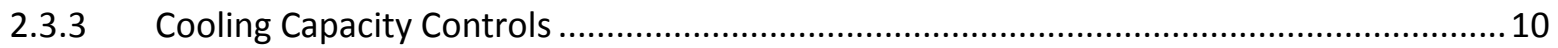

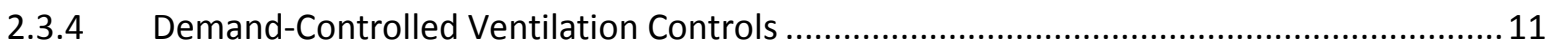

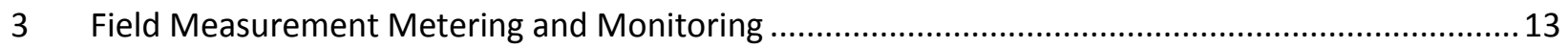

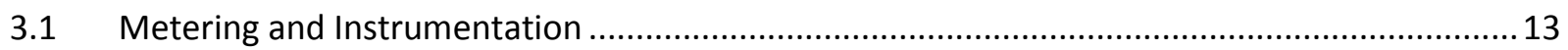

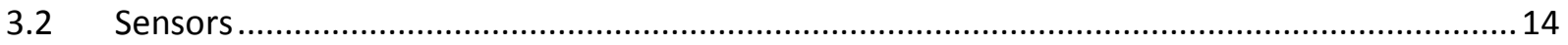

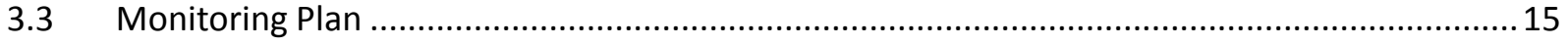

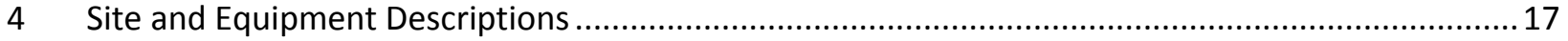

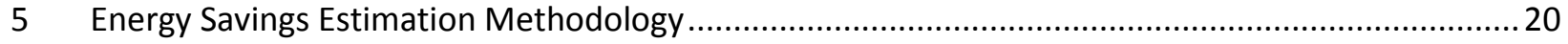

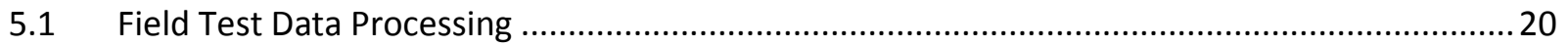

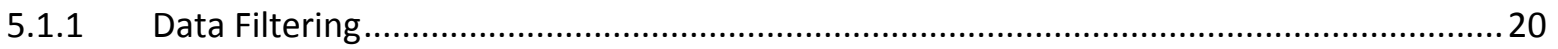

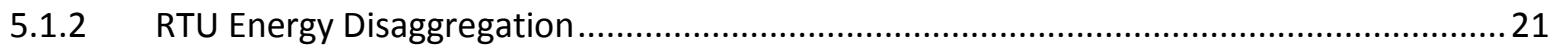

5.1.3 Determination of RTU Actual Heating and Cooling Status ............................................. 24

5.1.4 Data Aggregation and Normalization in Daily Format ................................................. 25

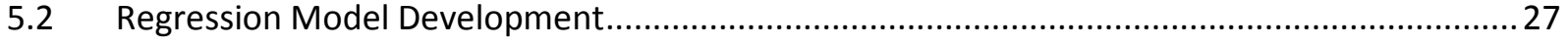




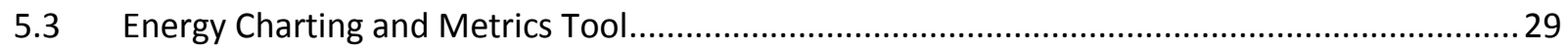

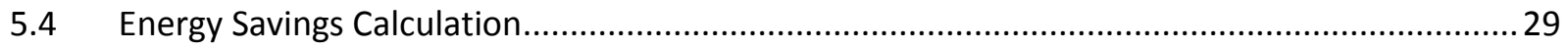

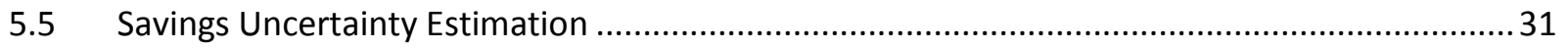

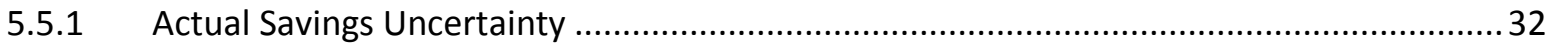

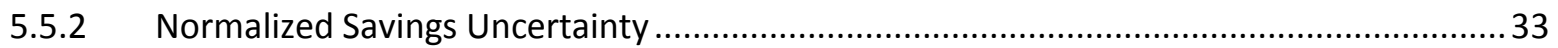

6 Advanced Controls And Economizer Controls Validation .............................................................. 34

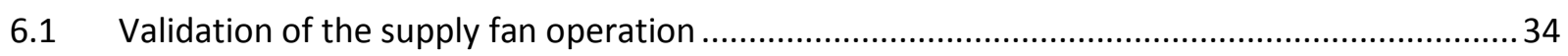

6.2 Validation of the demand-controlled ventilation (DCV) operation ........................................... 37

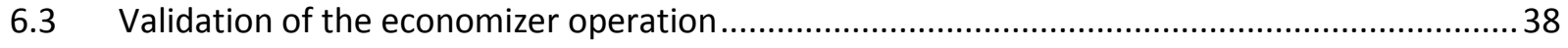

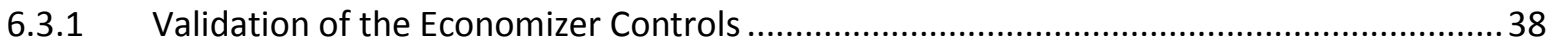

6.3.2 Validation of the Economizer Operations........................................................................... 39

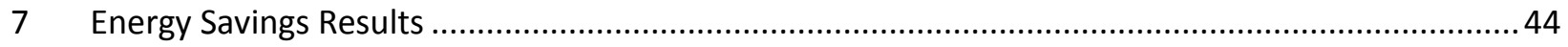

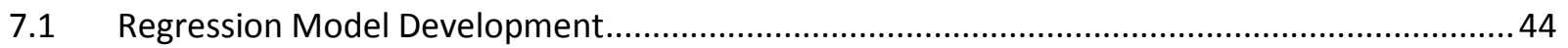

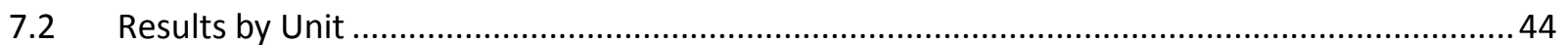

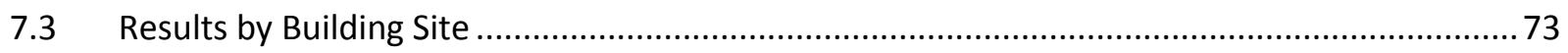

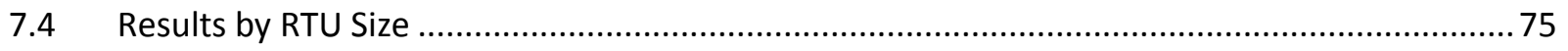

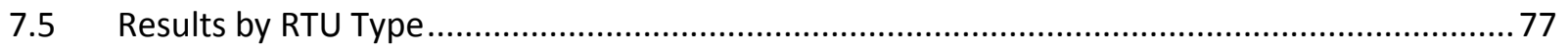

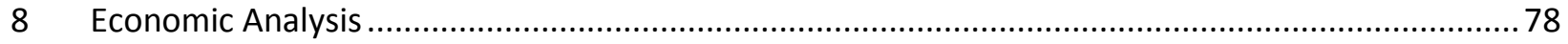

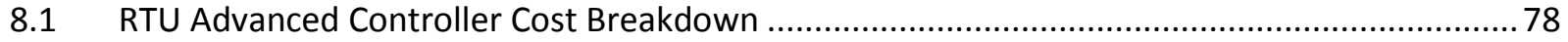

8.2 Advanced RTU Controller Payback Analysis........................................................................... 79

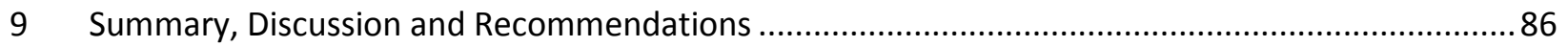

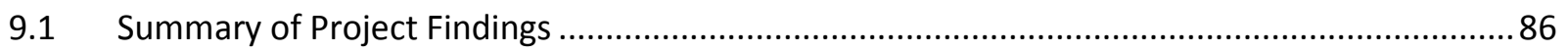

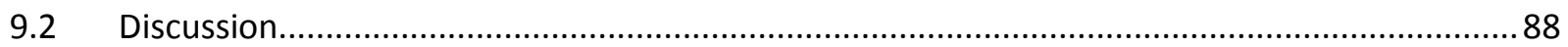

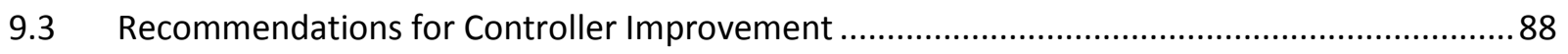

9.4 Recommendations on When to Consider the Advanced RTU Controller Retrofit.....................90

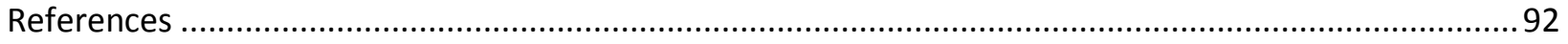

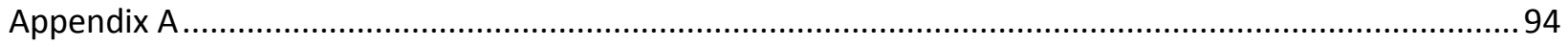




\section{Figures}

Figure ES - 1: Percentage of actual energy savings and uncertainty range at $95 \%$ confidence for each RTU.

Figure ES - 2: Percent of normalized annual energy savings and uncertainty range at $95 \%$ confidence for each RTU .....

Figure ES - 3: Frequency distribution of actual and normalized RTU electricity savings ........................... xii

Figure ES - 4: Variation of average normalized RTU electricity savings per unit run hour and per fan motor hp with RTU size

Figure ES - 5: Histogram charts showing the frequency of units at varying payback periods for (a) all capacities at a $\$ 0.10 / \mathrm{kWh}$ utility rate; (b) all capacities at a $\$ 0.15 / \mathrm{kWh}$ utility rate; (c) two capacity ranges at a $\$ 0.10 / \mathrm{kWh}$ utility rate; and (d) two capacity ranges at a $\$ 0.15 / \mathrm{kWh}$ utility rate. $\mathrm{xV}$

Figure 1: Example of a packaged rooftop unit economizer, cooling and heating coil and fan arrangement.

Figure 2: Schematic diagram showing sensors used to measurement critical parameters in the field test

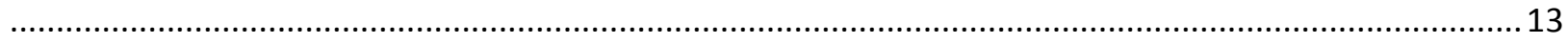

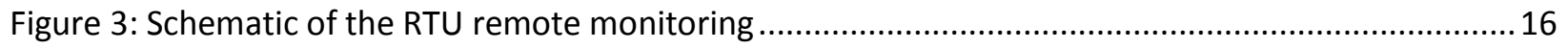

Figure 4: Distribution of tested RTUs by manufacturer .................................................................... 19

Figure 5: Distribution of tested RTUs by size ................................................................................. 19

Figure 6: Flow chart for determining the RTU actual heating and cooling status based on the measured

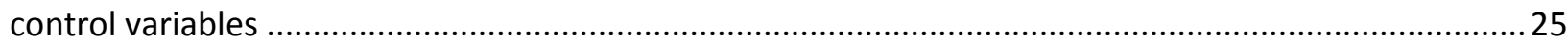

Figure 7: A representation of a 3-parameter regression model for cooling only or the total electricity of

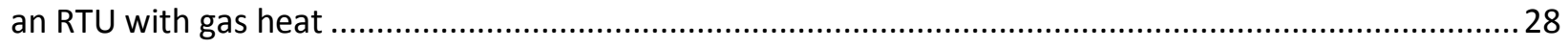

Figure 8: A representation of a 3-parameter regression model for RTU heating only............................28

Figure 9: A representation of a 5-P regression model total electricity of a heat pump ...........................29

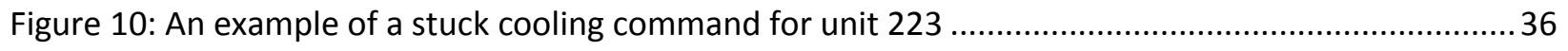

Figure 11: An example of heat spikes during cooling mode for heat pumps .......................................... 37

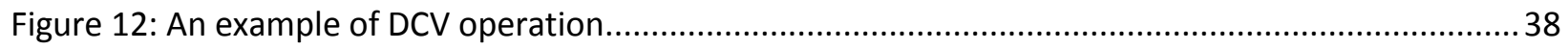

Figure 13: AirDx output for RTU 370 in July, 2012 ........................................................................... 40

Figure 14: Mixed- and return-air temperatures versus outdoor-air temperature for RTU 363 when the

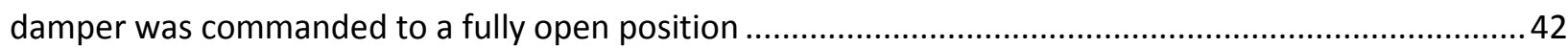

Figure 15: Mixed- and return-air temperatures versus outdoor-air temperature for RTU 381 when the damper was commanded to a fully open position ..............................................................................43

Figure 16: Percentage of actual energy savings and uncertainty range at $95 \%$ confidence for each RTU 47 Figure 17: Percent of normalized annual energy savings and uncertainty range at $95 \%$ confidence for

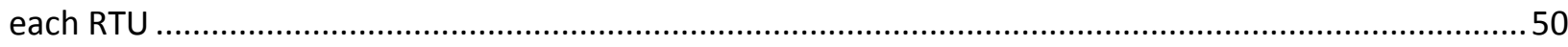

Figure 18: Frequency distribution of actual and normalized RTU electricity savings...............................5 51

Figure 19: Variation of actual RTU electricity savings per unit run hour with RTU size ...........................58

Figure 20: Variation of average actual RTU electricity savings per unit run hour with RTU size................58

Figure 21: Variation of average actual RTU electricity savings per unit run hour and per ton with RTU size

Figure 22: Variation of average actual RTU electricity savings per unit run hour and per fan motor hp with RTU size...... 
Figure 23: Variation of average normalized RTU electricity savings per unit run hour and per ton with RTU size.

Figure 24: Variation of average normalized RTU electricity savings per unit run hour and per fan motor hp with RTU size.

Figure 25: Variation of average normalized fan electricity savings per unit run hour and per fan motor hp

with RTU size

Figure 26: Predicted versus actual normalized annual RTU electricity savings .........................................68

Figure 27: Predicted versus actual normalized annual fan electricity savings ......................................69

Figure 28: Frequency distribution of RTU electricity savings per unit run hour.....

Figure 29: Frequency distribution of RTU electricity savings per unit run hour and supply fan motor hp 70 Figure 30: Monthly contribution to normalized annual electricity savings for different building sites ..... 75

Figure 31: RTU runtime distribution across operational modes for different building sites. .76

Figure 32: Histogram charts showing the frequency of units at varying payback periods for (a) all capacities at a $\$ 0.10 / \mathrm{kWh}$ utility rate; (b) all capacities at a $\$ 0.15 / \mathrm{kWh}$ utility rate; (c) 2 capacity ranges at a $\$ 0.10 / \mathrm{kWh}$ utility rate; and (d) 2 capacity ranges at a $\$ 0.15 / \mathrm{kWh}$ utility rate.

Figure 33: Average payback period for units with largest capacity and runtime for varying utility rates .82 Figure 34: Average payback period for units with capacities less than 10 tons, for varying runtimes and utility rates

Figure 35: Average payback period for units with capacities between 10 tons and 15 tons, for varying runtimes and utility rates.

Figure 36: Average payback period for units with capacities between 15 and 25 tons, for varying runtimes and utility rates. 


\section{Tables}

Table ES - 1: RTU advanced controller costs broken down by metering and monitoring xiv Table ES - 2: Recommendations on when to consider advanced RTU control retrofits that yield 3-year payback xviii

Table 1: List of Sensor Measurements and Monitored Control Signals. .14

Table 2: Summary of buildings participating in the field tests .... 17

Table 3: Calculated RTU parasitic power and supply-fan power 22

Table 4: Example results from the fan-speed control validation process using database query 35

Table 5: Distribution of calculated OAF by site when the damper was commanded to the minimum position 40

Table 6: Distribution of calculated OAF by site when the damper was commanded to the fully open position 41

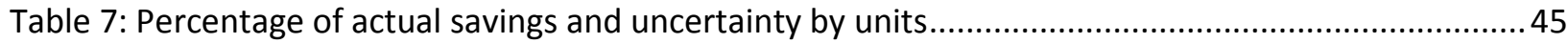

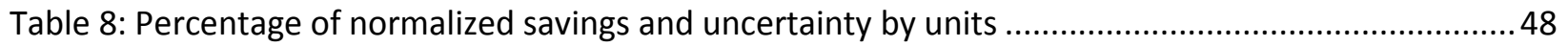

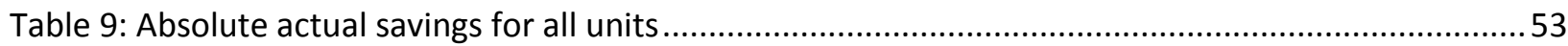

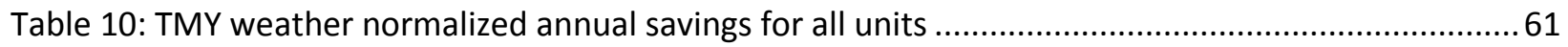

Table 11: RTU operation schedules used for normalized annual RTU savings calculation ......................67

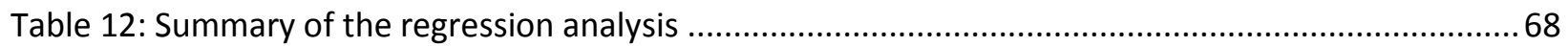

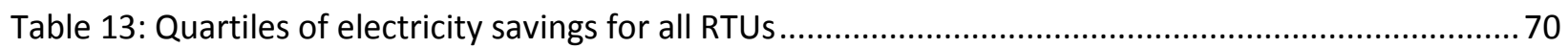

Table 14: Comparison of percentage of runtime in different modes between pre- and post-retrofit ...... 71

Table 15: Percentage of RTU electricity savings and uncertainty by building site ...................................73

Table 16: RTU electricity saving per hour and per ton by building site .................................................74

Table 17: Percentage of electricity savings and uncertainty by RTU size ............................................... 76

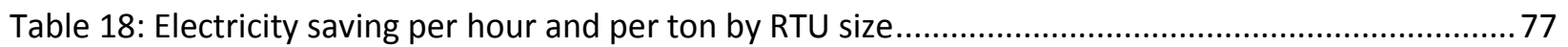

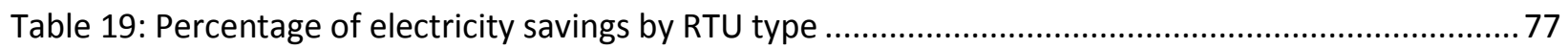

Table 20: Electricity saving per hour and per ton by RTU type .......................................................... 77

Table 21: RTU advanced controller costs broken down by metering and monitoring ...............................78

Table 22: Unit cost savings and payback period based on three different utility rates ............................79

Table 23: Cost savings and payback period by site for controller-only, based on three different utility rates

Table 24: Cost savings and payback period by site for controller and monitoring package based on three

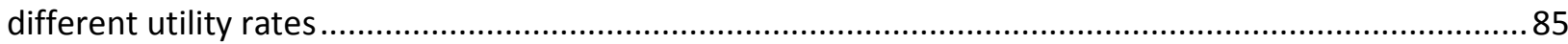

Table 25: Recommendations on when to consider advanced RTU control retrofits that yield 3 year payback 


\section{INTRODUCTION}

Packaged rooftop units (RTUs) are used in $46 \%$ (2.1 million) of all commercial buildings, serving over $60 \%$ (39 billion square feet) of the commercial building floor space in the U.S. (EIA 2003). The site cooling energy consumption associated with RTUs is about 160 trillion Btus annually. Packaged heat pumps account for an additional 70 trillion Btus annually. Therefore, even a small improvement in part-load operation of these units can lead to significant reductions of energy use and carbon emissions.

Efforts to increase the energy efficiency in commercial buildings have focused mainly on improving the efficiency of heating, ventilation and air conditioning (HVAC) equipment at rated (or design) conditions. In addition, focusing on improving the rated efficiency may not yield significant energy savings because systems tend to operate at off-design or part-load conditions for most of their lives. In contrast, approaches that address the improvement in the part-load performance can lead to significant increases in the operating efficiency of equipment and buildings. More importantly, measures that address the operational efficiency apply to both existing and new buildings.

Building codes require that when a building is occupied, the supply fan on packaged units operates continuously to meet the ventilation needs, regardless of whether the unit is providing cooling or heating. A significant portion of the packaged units in the field (over 90\%) have constant speed supply fans. Because the fan is on continuously, the fan energy consumption can be greater than the compressor energy consumption in many locations in the U.S. This implies that there exists a big potential to achieve energy savings from fan speed control.

Packaged equipment with constant-speed supply fans is designed to provide ventilation at the design rate at all times when the fan is operating. Although there are a number of hours during the day when a building may not be fully occupied or the need for ventilation is lower than designed, the ventilation rate cannot be adjusted easily with a constant-speed fan. Studies have shown that demand-based ventilation control can save significant energy in climates that are not favorable for economizing or have a significant heating load (Brandemuehl and Braun 1999; Roth et al. 2003). Traditional demandcontrolled ventilation (DCV) strategies modulate the outdoor-air damper to reduce the rate at which outdoor air enters and the associated energy needed to condition that air. This strategy reduces cooling energy, but the supply fan still runs at full speed.

Supply-fan energy savings can be achieved by modulating the supply-fan speed during the ventilation mode and potentially during mechanical heating/cooling, if the unit has multiple stages of heating/cooling. When the unit is in ventilation mode, the role of the supply fan is to provide fresh air to maintain proper indoor air quality in the spaces that it is serving. Therefore, modulating the supply fan in conjunction with DCV will not only reduce the heating/cooling energy but also reduce the fan energy. The total savings (fan and coil) will depend on a number of factors including control strategy, thermostat set point and characteristics (throttling range and deadband), oversizing of the packaged unit, the efficiency of the packaged unit, and the thermal load profiles.

The objective of this multi-year research and development project was to determine the magnitude of energy savings achievable by retrofitting existing packaged rooftop air conditioners with advanced control strategies not ordinarily used for packaged rooftop units. In FY11, the U.S. Department of Energy's (US DOE's) Building Technologies Office (BTO) funded a study at Pacific Northwest National Laboratory (PNNL) to estimate the potential energy and the associated cost savings from widespread 
use of advanced control strategies with packaged rooftop units. For that study, the savings were estimated based on detailed EnergyPlus (DOE 2010) simulation. Although it is possible to simulate buildings with various combinations of the influencing parameters, the size of simulation runs will become large and unmanageable. Therefore, for this study, only a selected combination of influencing parameters was used to estimate the savings from use of advanced control strategies. The varied parameters included building type (4), building location (16), and various control strategies (22). The FY11 study was limited to air conditioners with gas furnaces (Wang et al. 2011). The results from detailed simulation analysis showed significant energy $(24 \%-35 \%)$ and cost savings (38\%) from fan, cooling and heating energy consumption when packaged units were retrofitted with advanced control packages. In FY12, the simulation analysis was extended to packaged heat pumps but the analysis was limited to 2 building types, 11 climate locations and 3 combinations of control strategies (Wang et al. 2012). The simulation analysis showed that combining multi-speed fan control and DCV lead to between $35 \%$ and $47 \%$ savings across all 11 locations for the retail building and between $20 \%$ and $57 \%$ savings for the office building. Adding an integrated economizer on top of other controls has much smaller marginal impact on energy and cost savings. For example, in comparison with the combination of multi-speed fan control and DCV, the combination of all three control strategies had an additional $0 \%$ to $6.6 \%$ savings, depending on the building type and location.

Because the simulation analysis showed a significant savings potential from advanced RTU controls retrofits, DOE and Bonneville Power Administration (BPA) decided to fund an extensive evaluation of a retrofit advanced RTU controller in the field. PNNL conducted a preliminary study of four advanced RTU controllers (Criscione 2011): 1) Catalyst, 2) Enerfit and 3) Digi-RTU Optimizes. The first three products were commercially available, but the fourth one was still under development when the field test began in 2012.

The products from all vendors included a new variable-frequency drive (VFD), new controller and the required infrastructure to support them (sensors, etc.). All vendors retrofit the supply fan with a VFD that varied their speed based upon the RTU mode (heating mode, cooling mode or ventilation-only mode).

- Catalyst uses discrete (fixed) speeds that vary the supply-fan speed command value based on the mode of operation of the RTU (for example, $75 \%$ speed for $1^{\text {st }}$ stage cooling, $90 \%$ speed for $2^{\text {nd }}$ stage cooling or heating, and $40 \%$ speed when neither cooling or heating).

- The other vendors vary their indoor fan speeds continuously and do not focus on a fixedreduced speed.

- The Digi-RTU Optimizer retrofit applies VFD-driven capability for the compressor(s). The other vendors do not attempt to provide VFD-driven capability for the compressor(s).

- Enerfit includes an option to install an automatic isolation damper on RTUs with split-face coils (upper and lower coils) to isolate air flow to the coil that is active as the $1^{\text {st }}$ stage (usually the upper coil), resulting in further fan-speed reductions. RTUs for multi-staging can be designed for three types of coil design. This includes split-face coil (one coil, with $50 \%$ capacity across $50 \%$ of the duct cross-sectional area), intertwined full face coil (one coil with $50 \%$ capacity across the entire duct cross-sectional area), and split row coil (two coils in series). For constant volume applications, the most common design is the split-face coil, which usually also provides the best dehumidification performance. 
All of the vendors provide advanced air-side economizer controls and demand-controlled ventilation (DCV) capabilities. The air-side economizer is integrated with mechanical cooling and economizer activation is based upon differential dry-bulb temperature or differential enthalpy.

- When it is favorable to cool with outdoor air, the outdoor-air damper will be opened beyond the minimum ventilation setting.

- When it is not favorable to cool with outdoor air, the outdoor-air damper will be held at its minimum ventilation setting.

- The minimum ventilation setting may be calculated according to the required ventilation per floor area (ASHRAE 2010a).

- When the RTU fan is not running (unoccupied mode), the outdoor-air damper is held closed, but may open during night time cooling or during the morning cool-down cycle, when it is favorable to do so.

All of these vendors provide DCV capabilities. The return air stream or space is monitored with a $\mathrm{CO}_{2}$ sensor. As the $\mathrm{CO}_{2}$ concentration in the return air stream increases beyond maximum allowed thresholds, the controllers will initiate different control strategies, all with the same goal - reduce the $\mathrm{CO}_{2}$ levels in the space or as measured in the return air stream.

- In some cases, the outdoor-air damper percent open command will be increased to mitigate high $\mathrm{CO}_{2}$ levels.

- In some cases, the indoor-fan speed will be increased to mitigate high $\mathrm{CO}_{2}$ levels.

- In some cases, both actions will be performed, either in unison or in a sequenced arrangement. Usually, other limits related to comfort and equipment safety may limit the extent to which the DCV controls can open the outdoor-air damper in an attempt to minimize high $\mathrm{CO}_{2}$ levels.

- Enerfit is aligned with solutions to further reduce outdoor-air ventilation requirements by using GPS (Global Plasma Solutions), which they claim to be an "air cleaning" solution (removes contaminants, etc.).

All of these vendors provide retrofits that install at least one new variable frequency drive (VFD), one new digital controller, one new damper actuator (or modified damper actuator that interfaces to the new controller), multiple sensors (discharge-air temperature, return-air temperature, outdoor-air temperature, mixed-air temperature, space temperature, return air or space $\mathrm{CO}_{2}$, power, etc.) and some provide the ability to access the RTU (or network of RTUs) via a web interface.

Additional features of Enerfit include:

- Enerfit provides two versions of control retrofits called "V1" and "V2".

- V1 operates in conjunction with existing HVAC unit controls.

- It monitors heating and cooling calls from the unit controller and integrates them into the proprietary Enerfit control logic.

- V1 operates on open-protocol BACnet and can allow one to view any number of control points and unit information on a Tridium-Jace or similar front-end device with BACnet capabilities. 
- $\quad \mathrm{V} 2$ is a complete direct digital control system.

- V2 can operate as a stand-alone controller for a unit or as open-protocol BACnet HVAC unit controller.

Additional details of the Digi-RTU optimizer include:

- The Digi-RTU controller can be configured for operation using a conventional programmable thermostat or integrated into an existing building automation system (BAS).

- To power the compressor and indoor fan with the Digi-RTU (VFD), a selected rooftop unit must first be rewired. The Digi-RTU must be configured to receive power from the unit's main power supply.

- Start/stop signals from the rooftop unit are sent to the Digi-RTU as inputs, which are then sent by the Digi-RTU to individual components (fan, compressor, etc.) as outputs.

- Implementation requires the installation of a Bes-Tech thermostat utilizing the Modbus RTU communication protocol.

- Additional communication cabling between the Digi-RTU and the Bes-Tech thermostat is also necessary (most likely for the Modbus communications).

- The Digi-WSHP functions similarly to the Digi-RTU and achieves the same energy saving results but is designed for integration with water source heat pumps.

Additional details of the Catalyst controller:

- Catalyst controllers can be configured for two versions of control retrofits.

- The first configuration operates in conjunction with existing thermostat or BAS controls. It monitors heating and cooling signals that originate from the existing thermostat or the existing BAS controller. The controller takes the thermostat signals or the BAS commands and adds intelligence by using proprietary logic, which enables the HVAC unit to make better decisions regarding its operation (fan speed, economizer operations, etc.).

- The second configuration is a complete direct digital control system, which does not rely on a thermostat or existing BAS system.

- Catalyst is designed to work with a VFD that communicates via ModBus RTU communications protocol to the Catalyst controller.

- Catalyst controllers can operate as a stand-alone unit or be wirelessly networked together using the ${ }^{\mathrm{I}} \mathrm{OQ}$ energy intelligence platform. The ${ }^{\mathrm{I}} \mathrm{Q} \mathrm{Q}$ platform can then be integrated with an existing BAS for a total facility solution. This is generally performed using Tridium-Jace as the frontend.

All of these vendor retrofits come with new instrumentation to support the new control sequence strategies. Along with the additional instrumentation, most of these vendors claim to have some level of fault detection diagnostics (FDD).

After a detailed review of features of all available products and the maturity of products, PNNL chose to evaluate the Catalyst product in the field. The demonstrations were first started with funding from DOE 
and then expanded with funding from Bonneville Power Administration. So, the rest of the report documents the results of field evaluation of the Catalyst controller on a number of RTUs.

The advanced RTU controls implemented by the Catalyst controller are summarized in Section 2 . The metering and monitoring plan deployed to assess and characterize the advanced RTU controls in the field are discussed in Section 3. Section 4 provides the details of the sites and the RTUs in those sites. Section 5 provides the details of the methodology used in determining the energy savings from advanced RTU controls retrofit. Validation of the advanced controls features, including the economizer operations and the approaches used in the validation process is described in Section 6. In Section 7, the energy savings results from the advanced RTU control retrofits are presented. Section 8 provides details on labor, metering and monitoring costs associated with the advanced RTU controller and the economic analysis including simple payback period from the retrofits. Discussions, recommendations and future work are discussed in Section 9. 


\section{ADVANCED ROOFTOP UNIT CONTROLLER DESCRIPTION}

Packaged RTUs are factory-made, self-contained units comprising a number of off-the-shelf components available in standard design and cooling capacities. Typically, a packaged RTU consists of a fan and filter section, a mechanical cooling section, and a heating section.

In the fan and filter section, outdoor air is drawn into the RTU through an outdoor-air damper section and is mixed with the air returned from the space through a return-air damper section. These two damper sections are commonly referred to as the "economizer" section of the RTU. If the outdoor air has lower heat content than the return air and the space thermostat is calling for cooling, more outdoor air may be drawn into the RTU through the outdoor-air damper section and less return air may be drawn back through the return-air damper section. The mixed air then passes through filters to protect downstream components from dirt accumulation. As the outdoor-air damper section opens wider, this may cause the building space to become more positively pressurized. A relief fan may also be used to exhaust some return air to the outdoors through a separate damper, to keep the building space from becoming too positively pressurized.

When the outdoor air cannot provide enough cooling, mechanical cooling is used to supplement the cooling needs. The mechanical cooling section provides cooling through a vapor compression cycle, which consists of a compressor (usually reciprocating or scroll), an air-cooled condenser, a direct expansion (DX) evaporator and a thermal expansion valve.

Packaged equipment is divided into three categories depending on the cooling capacity: residential with cooling capacities less than $65,000 \mathrm{Btu} / \mathrm{h}$, light commercial with cooling capacities up to135,000 Btu/h, and commercial with cooling capacities of 135,000 Btu/h or greater (ASHRAE 2008). For light commercial and commercial units, the cooling efficiency is normally measured in terms of the energy efficiency ratio (EER) and integrated energy efficiency ratio (IEER) at standard rated conditions. Although high-efficiency equipment contributes to saving energy, it is not always possible to improve the efficiency of packaged RTUs because of technical and economic constraints. This is especially true for existing building retrofits when the replacement of RTUs is not a viable consideration. On the other hand, as described in the previous section, a number of technologies are commercially available to improve the operational efficiency of existing packaged RTUs. These technologies package a set of advanced control options that include integrated economizer controls, supply-fan speed controls, optimal start and stop controls, and demand-controlled ventilation (DCV).

\subsection{ECONOMIZER ConTrol OPTIONS}

Air-side economizers use cool outdoor air to reduce energy use for mechanical cooling. When the space thermostat calls for cooling and the outdoor conditions are favorable for economizing (as determined by the economizer controls), an air-side economizer brings in outdoor air at a rate greater than the minimum required for ventilation through modulation of the outdoor-air and return-air dampers. This displaces the need for some or all mechanical cooling and reduces mechanical cooling energy consumption of the RTU. Several commonly used economizer-control strategies include fixed (high-limit) dry-bulb temperature, fixed (high-limit) enthalpy, differential dry-bulb temperature, and differential enthalpy. 
With a fixed dry-bulb or enthalpy as the high limit for economizer control, the outdoor-air property (i.e., dry-bulb temperature or enthalpy) is measured and compared to a fixed set point. If the value of the outdoor-air property is less than the set point, outdoor air is used to meet all or part of the cooling demand; otherwise, the air-side economizer is not used (the outdoor-air dampers are positioned at the minimum position to meet ventilation needs). Depending on the climate, and whether the economizer is integrated with mechanical cooling, the fixed dry-bulb set point is usually set between $55^{\circ} \mathrm{F}$ and $75^{\circ} \mathrm{F}$, whereas the fixed enthalpy set point is set around $28 \mathrm{Btu} / \mathrm{lb}$ (Brandemuel and Braun 1999; Taylor and Cheng 2010).

With a differential dry-bulb temperature or differential enthalpy economizer control, the outdoor-air condition is measured and compared with the return-air condition. If the value of the outdoor-air condition (dry-bulb temperature or enthalpy) is less than the condition for the return air, outdoor air is used to meet all or part of the cooling demand; otherwise, the air-side economizer is not used.

Depending on whether air-side economizers work in conjunction with the mechanical cooling, there are two alternatives of economizer operation, respectively referred to as integrated and non-integrated economizers. An integrated economizer, as its name implies, is fully integrated with the mechanical cooling system such that it can use $100 \%$ outdoor air to provide as much cooling as possible, and mechanical cooling is engaged to make up the cooling load not met by use of outdoor air alone. On other hand, a non-integrated economizer does not operate simultaneously with the mechanical cooling system. When the outdoor-air condition is favorable, the economizer provides all necessary cooling. However, when the outdoor-air conditions are not sufficiently favorable to meet all of the cooling demand, the outdoor-air damper returns to its minimum position without the use of economizing, and the mechanical system provides all necessary cooling.

In the following subsection the details of the standard control (pre-retrofit) and the advanced RTU control technology (post-retrofit) that was evaluated in the field are described. The discussion begins by covering conventional controls, and then moves to advanced RTU controls.

\subsection{Conventional Control for Packaged RTUs}

In most packaged units, a zone thermostat controls the operation of the compressor or the gas furnace, depending on whether the zone thermostat is calling for cooling or heating. In conventional control strategies, the compressor or furnace is turned on or off to maintain the zone thermostat set point.

Although the compressor and furnace are cycled on and off based on the space heating and cooling demands, the supply fan runs continuously when the building is occupied. Even though most new packaged units might have air-side economizer controls and staged cooling and heating, many existing packaged units in the market place have thermostats designed to control single-stage cooling and heating with no economizer control. The zone thermostat cycles the compressor and the furnace, with the supply fan operating continuously when the building is occupied to provide ventilation.

The conventional controls tested in the field use a fixed dry-bulb high-limit for economizer controls. When the outdoor-air temperature is less than a preset value, typically about $55^{\circ} \mathrm{F}$, and if the thermostat calls for cooling, the outdoor-air damper is opened fully $(100 \%)$. When there is a call for cooling and the outdoor-air temperature is greater than $55^{\circ} \mathrm{F}$, the outdoor-air damper is set to its minimum position and mechanical cooling is enabled. 
The supply-fan speed cannot be modulated under the conventional RTU control, so it supplies constant air volume under all modes of operations (ventilation, heating or cooling).

\subsection{AdVANCED RTU CONTROL}

There are a number of advanced control options that can be added to RTUs including: integrated air-side economizers, supply-fan speed controls, cooling-capacity controls, and demand-controlled ventilation. The controller that was evaluated in the field had the ability to support all four advanced control options. In this subsection, each of the advanced control options used in the field is described in more detail.

\subsubsection{Integrated Air-side Economizer Controls}

The controller evaluated in the field used an air-side economizer control option that was based primarily upon the use of outdoor air (example in Figure 1) as the trigger point to determine when integration with mechanical cooling begins or ends. Secondary economizer controls to address indoor air quality (IAQ) issues $\left(\mathrm{CO}_{2}\right.$, demand-controlled ventilation) will be discussed later in this document.

- When the outdoor-air temperature was below the compressor lockout set point of $58^{\circ} \mathrm{F}$ (adjustable) and there was a call for cooling, the outdoor-air damper will modulate open to provide free cooling with the use of outdoor air. The target supply-air set point was $54^{\circ} \mathrm{F}$ (adjustable), as measured in the discharge-air (leaving) side of the fan. A proportional-integralderivative (PID) loop for cooling control was used to determine the economizer command value.

- A low limit of $50^{\circ} \mathrm{F}$ was used by a second PID loop to act as a limit control to mitigate low discharge-air temperatures.

- When the outdoor-air temperature was above the compressor lockout set point of $58^{\circ} \mathrm{F}$ and below $70^{\circ} \mathrm{F}$ (adjustable) and there is a call for cooling, the air-side economizer was used for $1^{\text {st }}$ stage of cooling, as determined by the thermostat or BAS. If the thermostat or BAS initiates a call for a $2^{\text {nd }}$ stage of cooling (air-side economizer was unable to reach the cooling set point), the compressor was activated as the $2^{\text {nd }}$ stage of cooling, but the air-side economizer continued to operate, using outdoor air as the lowest heat content air stream.

- When the outdoor-air temperature was greater than $70^{\circ} \mathrm{F}$ (adjustable) and there was a call for cooling, mechanical cooling (compressors) was initiated directly. The air-side economizer will only utilized if the outdoor-air condition (dry-bulb temperature or enthalpy) was lower than the return-air condition (dry-bulb temperature or enthalpy). 


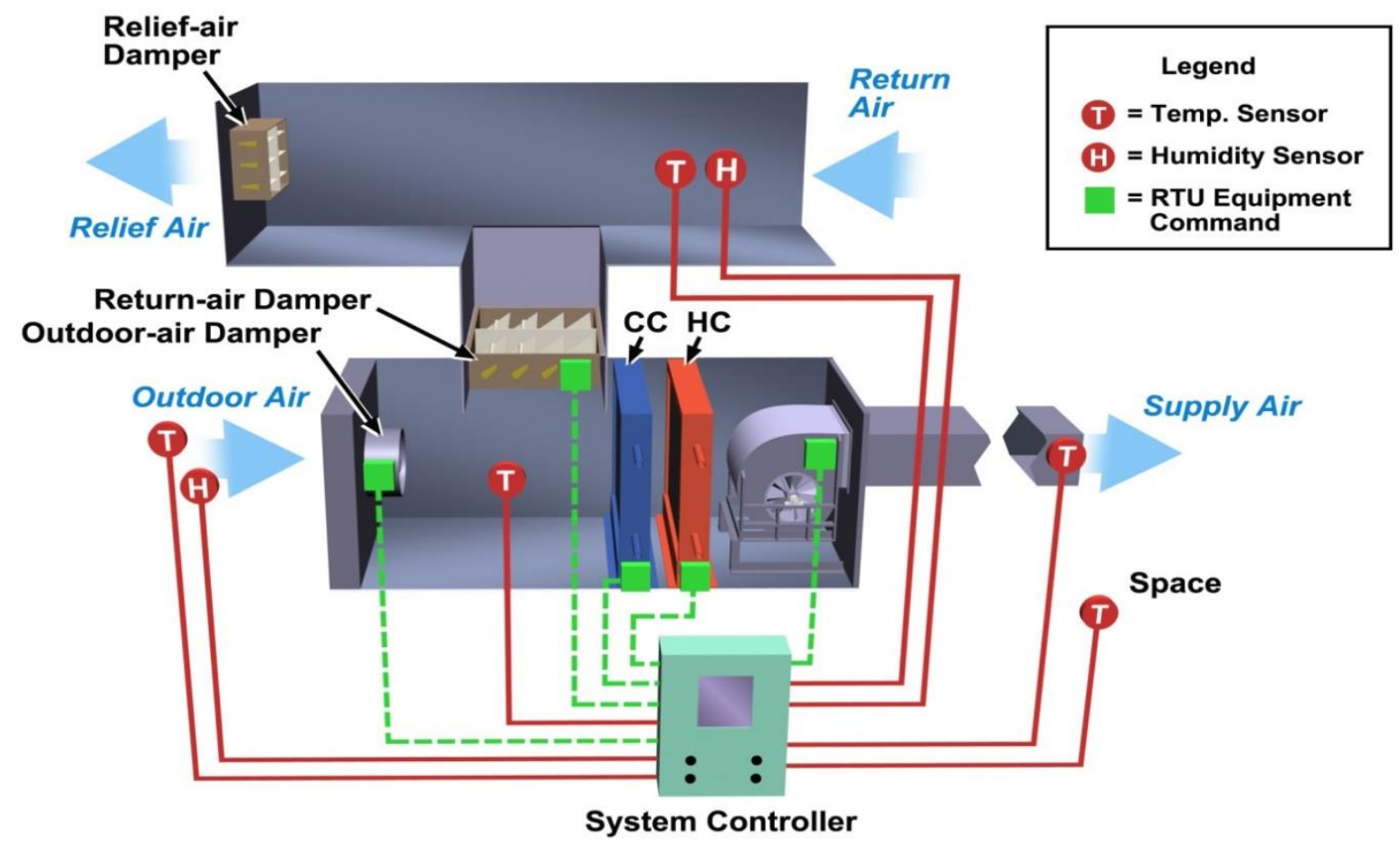

Figure 1: Example of a packaged rooftop unit economizer, cooling and heating coil and fan arrangement.

\subsubsection{Supply-Fan Speed Controls}

The advanced RTU control option had a variable speed drive on the supply fan that was modulated based on the mode of operation of the RTU. The fan-speed control options were based upon the different modes of operation, as determined by the thermostat or BAS as the primary trigger point to determine what speed command signal should be sent to the variable-frequency drive (VFD) for the supply fan. Secondary-speed controls to address temperature safety limits will be discussed in this section of the document. Tertiary-speed controls to address indoor air quality issues such as $\mathrm{CO}_{2}$ and DCV will be addressed in a later section of this document.

The supply-fan speed options were determined primarily by the RTU operational mode. There were three primary modes of operation (ventilation, heating and cooling).

\section{Ventilation Mode}

- When the fan was commanded to run and there was no command for heating or cooling, the RTU operated in the ventilation mode. The supply fan ran at $40 \%$ of its full speed. The outdoorair damper was at its minimum ventilation setting unless DCV otherwise required.

\section{$\underline{\text { Heating Mode }}$}

- When the RTU supply fan was running and there was a call for heating, the supply fan ran at $75 \%$ of its full speed when the $1^{\text {st }}$ stage is activated (for RTUs with two stages of heating).

- When the RTU supply fan was running and there was a call for heating, the supply fan runs at $90 \%$ of its full speed when the $2^{\text {nd }}$ stage was activated (for RTUs with two stages of heating). 
- When the RTU supply fan was running and there was a call for heating, the supply fan ran at $90 \%$ of its full speed when the heating stage was activated (for RTUs with only one stage of heating).

- When the heating stage $\left(1^{\text {st }}\right.$ or $\left.2^{\text {nd }}\right)$ was discontinued, the supply fan remains at the speed corresponding to the stage that just turned off for 2additional minutes, to allow for dissipation of heat, before slowing down to the next speed command.

- When the RTU discharge-air temperature exceeds $150^{\circ} \mathrm{F}$, the supply-fan speed was increased to $100 \%$ in an attempt to lower the discharge-air temperature.

- When the RTU discharge-air temperature exceeds $170^{\circ} \mathrm{F}$, all heating was disabled until the discharge-air temperature is below $135^{\circ} \mathrm{F}$.

- When a stage of heating was activated, it remained active for at least 4 minutes (per stage) before it was allowed to turn off (unless the high temperature limit was exceeded).

\section{Cooling Mode}

- When the outdoor-air temperature was below the compressor lockout set point of $58^{\circ} \mathrm{F}$ (adjustable) and there was a call for cooling ( $1^{\text {st }}$ stage), the outdoor-air damper was modulated open to provide free cooling with the use of outdoor air and the fan speed was commanded to a value of $75 \%$ speed. When the $2^{\text {nd }}$ stage is activated, the fan speed was commanded to a value of $90 \%$ speed but still using only the outdoor air for cooling.

- When the outdoor air temperature was above the compressor lockout set point of $58^{\circ} \mathrm{F}$ and below $70^{\circ} \mathrm{F}$ (adjustable), and there was a call for $1^{\text {st }}$ stage cooling, the air-side economizer was used for the $1^{\text {st }}$ stage of cooling (outdoor-air dampers open) and the fan speed was commanded to a value of $90 \%$ speed. If there is a call for $2^{\text {nd }}$ stage cooling, the $1^{\text {st }}$ stage cooling compressor was activated as the $2^{\text {nd }}$ stage of cooling and the fan speed was remained commanded at a value of $90 \%$ speed.

- When the outdoor-air temperature was above $70^{\circ} \mathrm{F}$ (adjustable) and there was a call for $1^{\text {st }}$ stage cooling, the fan speed was commanded to a value of $75 \%$ speed. If the $2^{\text {nd }}$ stage of cooling was activated in this condition, the supply-fan speed was commanded to a value of $90 \%$ speed.

- When the cooling call terminated, the supply fan remained at the speed corresponding to the stage that just turned off for 2 additional minutes, to allow for dissipation of cooling, before slowing down to the next fan speed command.

- When the RTU discharge-air temperature dropped below $48^{\circ} \mathrm{F}$, the fan speed was increased to $100 \%$ in an attempt to raise the discharge-air temperature.

- All cooling calls were addressed at $90 \%$ fan speed when the RTU was single stage.

- When the RTU discharge-air temperature was drops below $42^{\circ} \mathrm{F}$, all cooling was disabled until the discharge-air temperature is above $50^{\circ} \mathrm{F}$.

\subsubsection{Cooling Capacity Controls}

Packaged RTUs are usually sized to handle the system load at peak design conditions, which are expressed in terms of the weather and the internal loads of the space served. However, because the 
majority of actual operating hours occur at off-peak conditions, the RTU must have some capacity reduction mechanisms to deal with part-load conditions. Two cooling capacity control methods commonly used in packaged RTUs that serve single zones include:

\section{Simple on-off control}

For this case, the compressor is switched on and off as necessary to meet the load requirements. Once the compressor is on, it operates at full capacity, and the RTU provides cool air to the space. When the space temperature drops below the zone temperature set point, the compressor is turned off. This simple on-off control is normally used in RTUs with capacities less than 90,000 Btu/h.

\section{Staged cooling}

Staged cooling is often accomplished by using two or more separate refrigeration circuits, which allows independent operation of the individual circuits. The magnitude of the cooling load (indicated by the deviation of the zone temperature from set point) determines whether the unit operates at its full capacity or a lower capacity. At part-load conditions, using part of the unit's cooling capacity can reduce the compressor's excessive on-off cycling and contribute to better indoor temperature and humidity control.

When the cooling mode begins, the advanced RTU control uses the outdoor-air temperature as the trigger point to determine when the outdoor air-side economizer is integrated with mechanical cooling, and how many stages of mechanical cooling will be allowed to operate.

- When the outdoor-air temperature is above the compressor lockout set point of $58^{\circ} \mathrm{F}$ and below $70^{\circ} \mathrm{F}$ (adjustable) and there is a call for $1^{\text {st }}$ stage cooling, the air-side economizer will be used for the $1^{\text {st }}$ stage of cooling. If there is a call for the $2^{\text {nd }}$ stage of cooling, the $1^{\text {st }}$ stage cooling compressor will be activated. Once the compressor is activated, a 10-minute timer will start. At the end of the 10-minute time period, if the discharge-air temperature is above $58^{\circ} \mathrm{F}$, the $2^{\text {nd }}$ stage compressor will be activated.

- When the outdoor-air temperature is above $70^{\circ} \mathrm{F}$ (adjustable), both stages of mechanical cooling will be used (staged) as required. The economizer (use of outdoor air) will only occur if the outdoor-air temperature is lower than the return-air temperature.

- When the RTU discharge-air temperature drops below $42^{\circ} \mathrm{F}$, all mechanical cooling will be disabled until the discharge-air temperature rises above $50^{\circ} \mathrm{F}$.

- When a stage of cooling is activated, it must remain active for at least 4 minutes (per stage) before being allowed to turn off (unless the low temperature limit is exceeded).

\subsubsection{Demand-Controlled Ventilation Controls}

Demand-controlled ventilation (DCV) adjusts the amount of outdoor air based on the number of occupants and the corresponding ventilation demand. Although a number of options (such as direct people counting, time-of-day schedule tracking, and measuring $\mathrm{CO}_{2}$ concentration) are available to estimate the actual occupancy of spaces, $\mathrm{CO}_{2}$-based DCV is by far the most commonly implemented measure when outdoor air ventilation is dynamically reset (Stanke 2006). $\mathrm{CO}_{2}$-based DCV relies on sensed $\mathrm{CO}_{2}$ concentrations in the space (usually measured in the return air) to regulate the ventilation 
rate. Assuming that the $\mathrm{CO}_{2}$ generation rate is proportional to the number of occupants, the minimum required outdoor-air flow rate for single-zone systems can be calculated from the space $\mathrm{CO}_{2}$ concentration set point and the difference between indoor and outdoor $\mathrm{CO}_{2}$ concentrations (ASHRAE 2010a). By reducing outdoor-air intake (when not economizing), DCV has the potential to reduce the energy associated with conditioning the outdoor air.

The DCV in the advanced controller uses the return-air $\mathrm{CO}_{2}$ as the trigger point to determine how to regulate the outdoor-air damper and fan-speed controls to ensure that the maximum allowable $\mathrm{CO}_{2}$ levels (high $\mathrm{CO}_{2}$ set point $=1000 \mathrm{ppm}$ ) are not exceeded. Based on the return-air $\mathrm{CO}_{2}$ concentration, a PID loop is used to generate a 0 to $100 \%$ ventilation signal, which is then used to adjust the outdoor-air damper command and the supply-fan speed in a sequential and stepped fashion. DCV increases the calculated volume of outdoor air in response to the $\mathrm{CO}_{2}$ levels exceeding the high $\mathrm{CO}_{2}$ set point until the calculated outdoor-air volume matches the "maximum air volume" set point of $30 \%$ (adjustable). This maximum ventilation can be set at the design level because the ventilation Standard (ASHRAE 2010a) does not require the amount of outdoor air to exceed the design ventilation for $\mathrm{CO}_{2}$ control. The following describes this in detail:

- The control algorithm multiplies the damper command value by the supply-fan speed value to estimate the volume of outdoor air. For instance, if the fan speed is $40 \%$ (ventilation mode) and the outdoor-air damper command is $10 \%$, the equation would be $0.40 \times 0.10=0.04$, which means that $4 \%$ of the design supply-air flow is outdoor air.

- If the $\mathrm{CO}_{2}$ level rises to a value that approached or exceeded the high limit $\mathrm{CO}_{2}$ set point (1000 $\mathrm{ppm}$ ), the controller would first increase the outdoor-air damper in an attempt to lower the $\mathrm{CO}_{2}$ levels. So, if the outdoor-air damper signal was increased from $10 \%$ up to $100 \%$ (maximum opening), the equation would show a calculated outdoor-air volume of $40 \%(0.40 \times 1.00=0.40$ or $40 \%)$. Because this exceeds the "maximum air volume" set point (30\%), the maximum damper command would be held at $75 \%$ open, resulting in a calculated outdoor-air volume of $30 \%$.

- If the outdoor-air temperature is cold (less than $48^{\circ} \mathrm{F}$ ), the outdoor-air damper command may not open wider than what the low limit (e.g., $50^{\circ} \mathrm{F}$ ) of discharge-air temperature allows. In this case, the controller will increase the supply fan speed to bring in more outdoor air while meeting the low limit of discharge-air temperature.

- When both air-side economizer and DCV controls are active, the economizer control takes precedence over DCV control. 


\section{Field Measurement Metering AND Monitoring}

The metering and monitoring plan deployed to assess and characterize the advanced controller in the field are discussed in this section. The advanced controller was tested on 66 rooftop units (RTUs) on 8 different buildings and 4 different climate locations. The same metering and monitoring plan was used on all RTUs to: 1) estimate the energy savings resulting from retrofitting the RTUs with the advanced controller and 2) verify the operations of the advanced controller.

\subsection{METERING AND INSTRUMENTATION}

Figure 2 shows the schematic of a typical RTU with sensor locations. Outdoor air enters the RTU through a damper and is mixed with the air returned from the space. The mixed air then passes through an air filter to protect downstream components from dirt accumulation. Depending on the space temperature, the supply air is either cooled by heat exchange with the cooler refrigerant passing through the evaporator coil, or heated by a gas furnace. An exhaust fan may also be used to exhaust some return air to the outdoors through a gravity backdraft damper. A packaged heat pump has the same metering setup but takes a different configuration from Figure 2 because a reverse vapor compression cycle is used for heating. Thus, the heating coil and the DX (direct exchange) cooling coil are combined into one component. A gas burner may be needed for supplemental heating when the DX heating capacity is not sufficient to meet the space heating load.

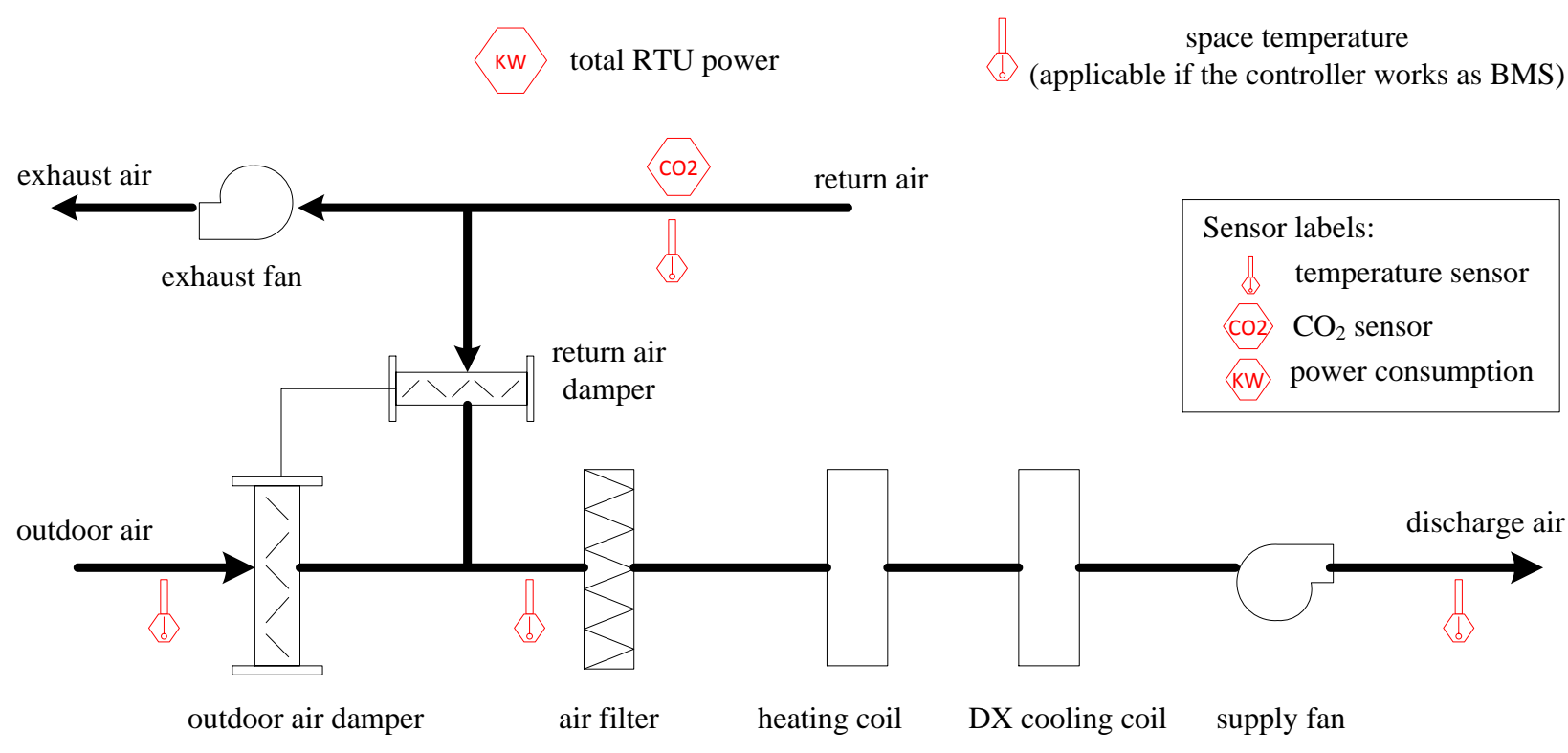

Figure 2: Schematic diagram showing sensors used to measurement critical parameters in the field test 


\subsection{SENSORS}

The following sensors were used for all RTU field tests:

- A thermistor-type temperature sensor made by Automation Components Inc. (ACl) was used to measure the outdoor-air temperature, the air temperature in the return duct, the mixed-air temperature right after the dampers, and the discharge-air temperature downstream of the cooling coil. At some buildings where the advanced controller was used as a building management system (BMS), the space temperature was also monitored. The accuracy of the temperature sensor was $\pm 0.36^{\circ} \mathrm{F}$ in the operating temperature range $\left(40^{\circ} \mathrm{F}\right.$ to $\left.120^{\circ} \mathrm{F}\right)$.

- The total power consumption of the RTU was measured using a power transducer from Continental Control Systems with an accuracy of $\pm 0.5 \%$ of reading.

- The $\mathrm{CO}_{2}$ concentration in the return-air duct was monitored using a sensor from $\mathrm{ACl}$ with an accuracy of $\pm 30 \mathrm{ppm}$ in the operating range (400 to $1500 \mathrm{ppm}$ ). The $\mathrm{CO}_{2}$ concentration in the return duct is considered representative of that in the space and can thus be used in demandcontrolled ventilation.

In addition to the temperature, power and $\mathrm{CO}_{2}$ sensor measurements, a number of control signals were also monitored. Table 1 lists all sensor measurements and control signals monitored.

Table 1: List of Sensor Measurements and Monitored Control Signals

\begin{tabular}{|c|c|c|}
\hline Field Name & Unit & Notes \\
\hline Timestamp & & Local time in the format of yyyy-mm-dd hh:mm \\
\hline Occupied & True/False & Indication of whether the space was occupied based on the building occupancy \\
\hline ESMMode & True/False & True = Advanced control logic; False = Standard control logic \\
\hline FanSpeed & $\%$ & Speed of the variable-speed drive for the supply fan \\
\hline FanPower & kW & Measured from the variable-speed drive \\
\hline OaTemp & ${ }^{\circ} \mathrm{F}$ & Dry-bulb temperature of the outdoor air, measured onsite on each unit \\
\hline RaTemp & ${ }^{\circ} \mathrm{F}$ & Dry-bulb temperature of the return air \\
\hline MaTemp & ${ }^{\circ} \mathrm{F}$ & Dry-bulb temperature of the mixed air \\
\hline DaTemp & ${ }^{\circ} \mathrm{F}$ & Dry-bulb temperature of the discharge air \\
\hline SpaceTemp & ${ }^{\circ} \mathrm{F}$ & $\begin{array}{l}\text { Space temperature, available only for the unit that used the advanced controller } \\
\text { as the BAS }\end{array}$ \\
\hline ActClgStpt & ${ }^{\circ} \mathrm{F}$ & $\begin{array}{l}\text { Cooling set point, available only for the unit that used the advanced controller as } \\
\text { the BMS }\end{array}$ \\
\hline ActHtgStpt & ${ }^{\circ} \mathrm{F}$ & $\begin{array}{l}\text { Heating set point, available only for the unit that used the advanced controller as } \\
\text { the BMS }\end{array}$ \\
\hline VentMode & True/False & $\begin{array}{l}\text { Control signal indicating whether the unit was in ventilation mode (no call for } \\
\text { heating, cooling or dehumidification) }\end{array}$ \\
\hline CoolCall1 & True/False & $1^{\text {st }}$ stage cooling signal from thermostat or BMS \\
\hline CoolCall2 & True/False & $2^{\text {nd }}$ stage cooling signal from thermostat or BMS \\
\hline CoolCmd1 & True/False & The advanced controller initiated command to $1^{\text {st }}$ stage compressor/cooling \\
\hline
\end{tabular}




\begin{tabular}{|c|c|c|}
\hline CoolCmd2 & True/False & The advanced controller initiated command to $2^{\text {nd }}$ stage compressor/cooling \\
\hline AuxHeatCmd & True/False & The advanced controller initiated command to the auxiliary heater for heat \\
\hline EconMode & True/False & The advanced controller initiated command for economizer cooling \\
\hline AdvanceCool & True/False & $\begin{array}{l}\text { Indicated whether the advanced economizer control was used for space } \\
\text { nrernolino }\end{array}$ \\
\hline $\begin{array}{l}\text { DehumidStatu } \\
\text { s }\end{array}$ & True/False & $\begin{array}{l}\text { Indication of call for dehumidification (i.e., compressor was on without a cooling } \\
\text { call). Used only at the site of BJ Wholesale. Dehumidification is not part of the } \\
\text { Catalyst capability, but the Catalyst controller initiated the compressor in } \\
\text { response to space dehumidification request. }\end{array}$ \\
\hline HeatCall1 & True/False & $1^{\text {st }}$ stage heating signal from thermostat or BMS \\
\hline HeatCall2 & True/False & $2^{\text {nd }}$ stage heating signal from thermostat or BMS \\
\hline HeatCmd1 & True/False & The advanced controller initiated command to $1^{\text {st }}$ stage heating \\
\hline HeatCmd2 & True/False & The advanced controller initiated command to $2^{\text {nd }}$ stage heating \\
\hline PowerExCmd & True/False & The advanced controller initiated command for the power exhaust fan, if exists \\
\hline PowerExStpt & $\%$ & Set point to activate the power exhaust fan based on outdoor-air damper \\
\hline Damper & $\%$ & Output command for outdoor-air damper opening position \\
\hline CO2Sensor & PPM & $\mathrm{CO}_{2}$ concentration sensed in return-air duct \\
\hline CO2Stpt & PPM & $\mathrm{CO}_{2}$ set point for demand-controlled ventilation \\
\hline DCVMaxVolu & $\%$ & Maximum outdoor-air damper position in response to high $\mathrm{CO}_{2}$ levels \\
\hline UnitPower & kW & Total electric power for the unit, measured by a power meter \\
\hline ControllerDow & True/False & Indication of loss of communications \\
\hline DriveLock & True/False & $\begin{array}{l}\text { Indicated when the variable-frequency drive was not responding correctly to a } \\
\text { run command }\end{array}$ \\
\hline
\end{tabular}

\subsection{Monitoring Plan}

The monitoring plan consisted of collecting data at each RTU, aggregating the data from all RTUs on a site, storing it locally on the roof, and streaming the data in real time to the Cloud for analysis. All points listed in Table 1 were recorded at 1-minute intervals and stored locally on the roof and also streamed live to be stored in the Cloud for analysis. In case of loss of communication, the data stored locally on the roof were retrieved when the communication was reestablished, so the loss of data was minimized.

Figure 3 schematically shows the entire monitoring process. A building was configured with a Jace-202XPR-24 (Java Application Control Engine) device that wirelessly connected with multiple RTUs and is connected to the cellular network (via the wireless modem). The cellular communication required a small monthly fee to allow for continuous monitoring and data transfer to a hosted web service. The Jace provided the interface to the Catalyst-371 controller and input/output device and also served as a data logger. The logged data was uploaded to the Cloud at regular intervals. In case of loss of communication, the logged data will be stored in the Jace for a maximum of 4 hours, but if a communications outage lasted longer than this, some trended data could have been lost. The Catalyst371 controller connected to the variable-frequency drive (VFD) and the power transducer via its internal Modbus port. 


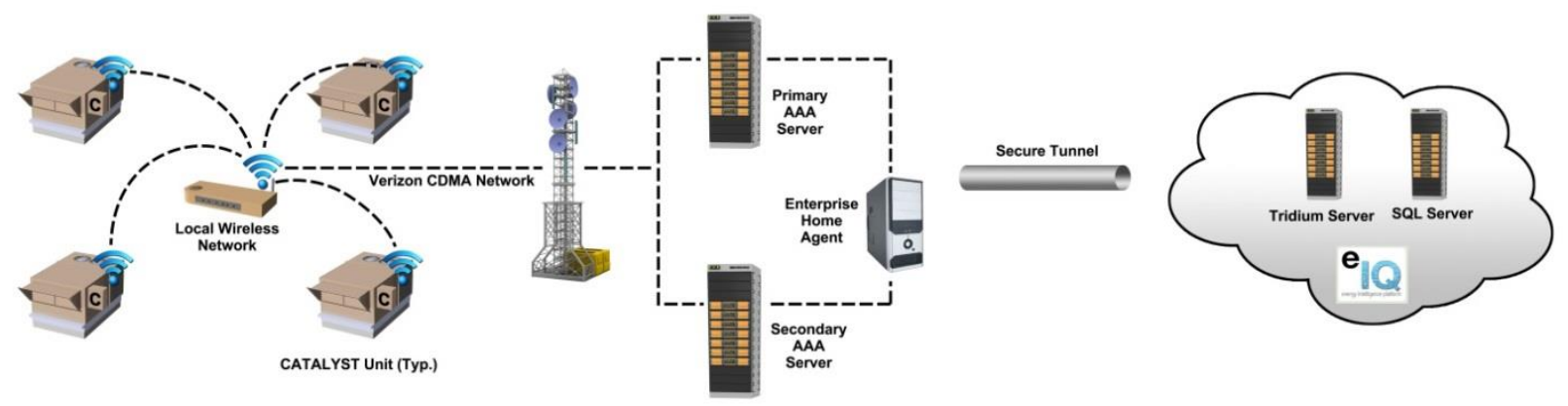

Figure 3: Schematic of the RTU remote monitoring

The Catalyst controller had a service switch to change the RTU control logic between the standard control and the advanced energy saving control. During the standard control operation, the supply-fan speed was always at $100 \%$ when the RTU was in operation; the air-side economizer was not integrated with mechanical cooling and it is controlled with a fixed dry-bulb temperature; and the demandcontrolled ventilation was disabled. During the advanced energy saving control operation, the supply fan ran at different speeds depending on the RTU operation modes such as ventilation, $1^{\text {st }}$ stage cooling and $2^{\text {nd }}$ stage cooling (see Section 2.3.2); the air-side economizer was integrated with mechanical cooling and it was controlled with differential dry-bulb temperature controls; and the demand-controlled ventilation was enabled.

During the field tests, the standard control and the advanced control were alternated daily. The standard control was intended to emulate the RTU operation before retrofitting the controller. Thus, the test days with the standard control operation form the pre-retrofit period while the days with the advanced control form the post-retrofit period. The alternating RTU operations between the standard control and the advanced control continued until sufficient test data covering different weather conditions were collected. 


\section{SITE AND EQUIPMENT DESCRIPTIONS}

A total of 66 RTUs on 8 different buildings were metered and monitored as described in the previous section. Table 2 provides a summary of the building sites, including the location, the building type, number of RTUs tested, the RTU type, and the funding source.

Major characteristics of Table 2 are:

- The buildings are located in four states: Washington (WA), Ohio (OH), California (CA), and Pennsylvania (PA). These locations fall into the following climate zones: Cleveland, $\mathrm{OH}(5 \mathrm{~A})$; Oaks, PA (4A), Valencia, CA (3B), and all the sites in WA fall under Seattle (4C). Details on the climate zone definition can be found in ASHRAE Standard 90.1 (ASHRAE 2010b).

- The building types covered mercantile (both retail and shopping malls), office, food sales, and healthcare.

- Of the 66 tested RTUs, 17 were packaged heat pumps (HP) and the rest were packaged air conditioners with gas heat (AC).

- 20 RTU demonstrations were funded by DOE and the rest were funded by BPA. All DOE-funded RTU tests were located at Better Buildings Alliance (BBA) member's facilities, while BPA-funded RTU tests were located in non-BBA member's facilities.

- At three sites (site ID $=28,41,43$ ), the advanced controller received control signals from the programmable thermostat in the conditioned space. At four sites (site ID $=39,40,46,51$ ), the advanced controller received control signals from the space temperature sensor connected to a local BMS. At site 44, the advanced controller worked as the BMS.

Table 2: Summary of buildings participating in the field tests

\begin{tabular}{|l|l|l|l|l|l|l|}
\hline $\begin{array}{l}\text { Site } \\
\text { ID }\end{array}$ & Location & Building Type & $\begin{array}{l}\text { Funding } \\
\text { Source }\end{array}$ & $\begin{array}{l}\text { Number } \\
\text { of RTUs }\end{array}$ & $\begin{array}{l}\text { RTU } \\
\text { Type }\end{array}$ & RTU Control Configuration \\
\hline 28 & Lynnwood, WA & Mercantile (malls) & BPA & 28 & AC & Programmable thermostat \\
\hline 39 & Cleveland, OH & Healthcare & DOE & 2 & AC & Existing BMS \\
\hline 40 & Oaks, PA & Mercantile (retail) & DOE & 8 & AC & Existing BMS \\
\hline 41 & Kent, WA & Office & BPA & 1 & HP & Programmable thermostat \\
\hline 43 & Everett, WA & Office & BPA & 6 & HP & Programmable thermostat \\
\hline 44 & Federal Way, WA & Mercantile (malls) & BPA & 11 & HP & Advanced controller as BMS \\
\hline 46 & Valencia, CA & Food sales & DOE & 5 & AC & Existing BMS \\
\hline 51 & Bellevue, WA & Mercantile (retail) & DOE & 5 & AC & Existing BMS \\
\hline & & & & & & \\
\hline
\end{tabular}

Tables A-1 and A-2 in Appendix A provide details of each RTU obtained from either the RTU nameplate or spot measurements. The following is a description of each column in these tables.

- Site ID: Building site identification.

- $\quad$ RTU ID: Unique RTU identification number. 
- Make: RTU manufacturer (one of the three) Carrier, Trane, or Lennox.

- Model: RTU model number.

- Tonnage: RTU's rated cooling capacity in tons. RTU size ranged from a minimum cooling capacity of 5 tons to a maximum capacity of 25 tons.

- $\quad$ EER: Rated energy efficiency ratio (EER). The EER ranged from 8.5 to 12.

- COP: Rated heating coefficient of performance (COP), which only applied to heat pumps.

- Auxiliary heating capacity (Aux Ht): The backup heater capacity in $\mathrm{kW}$ for heat pumps.

- Fan power: Fan power in $\mathrm{kW}$, measured at $100 \%$ fan speed.

- $1^{\text {st }}$ stage burner: $1^{\text {st }}$ stage gas furnace capacity in $\mathrm{kBtu} / \mathrm{h}$ for air conditioners with gas furnace.

- $2^{\text {nd }}$ stage burner: $2^{\text {nd }}$ stage gas furnace capacity in $\mathrm{kBtu} / \mathrm{h}$. The $2^{\text {nd }}$ stage furnace capacity refers to the full heating capacity of the gas furnace.

- Economizer changeover temperature: The fixed dry-bulb temperature used to enable air-side economizer control while emulating pre-retrofit operations. For buildings where the fixed drybulb temperature for air-side economizer control was not known, a change over temperature of $55^{\circ} \mathrm{F}$ was used.

- Pre-retrofit minimum outdoor-air damper position: This damper setting was used while emulating pre-retrofit operations.

- Post-retrofit minimum outdoor-air damper position: This damper setting was used during the post-retrofit operations.

- Pre-retrofit fan control strategy: The supply-fan control strategy used to emulate pre-retrofit operations, which was $100 \%$ for all RTUs.

- Occupancy schedule: The occupancy schedule for the spaces served by the RTU. The occupancy schedule was collected from building owners.

- Occupied cooling set point: The space cooling set point during the occupied periods; only applied to buildings where Catalyst controller functions as the BMS or when the Catalyst controller had access to the building BMS.

- Unoccupied heating set point: The space heating set point during the unoccupied periods, only applied to buildings where Catalyst controller functions as the BMS or when the Catalyst controller had access to the building BMS.

- Unoccupied cooling set point: The space cooling set point during the occupied periods, only applies to buildings where Catalyst controller functions as the BMS or when the Catalyst controller has access to the building BMS.

Figure 4 shows the distribution of RTUs by manufacturer. Figure 5 shows the number of RTUs by the size. A majority of the RTUs in the demonstration were between 10 and 15 tons. 


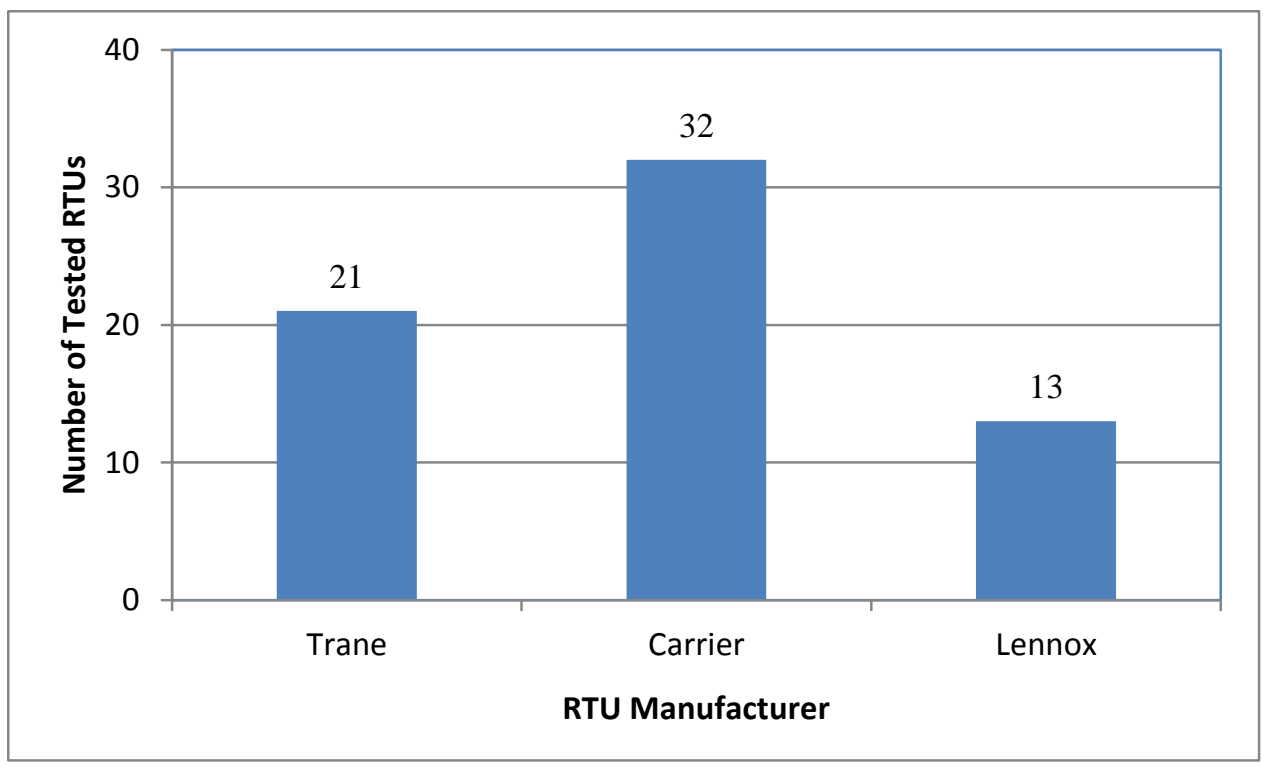

Figure 4: Distribution of tested RTUs by manufacturer

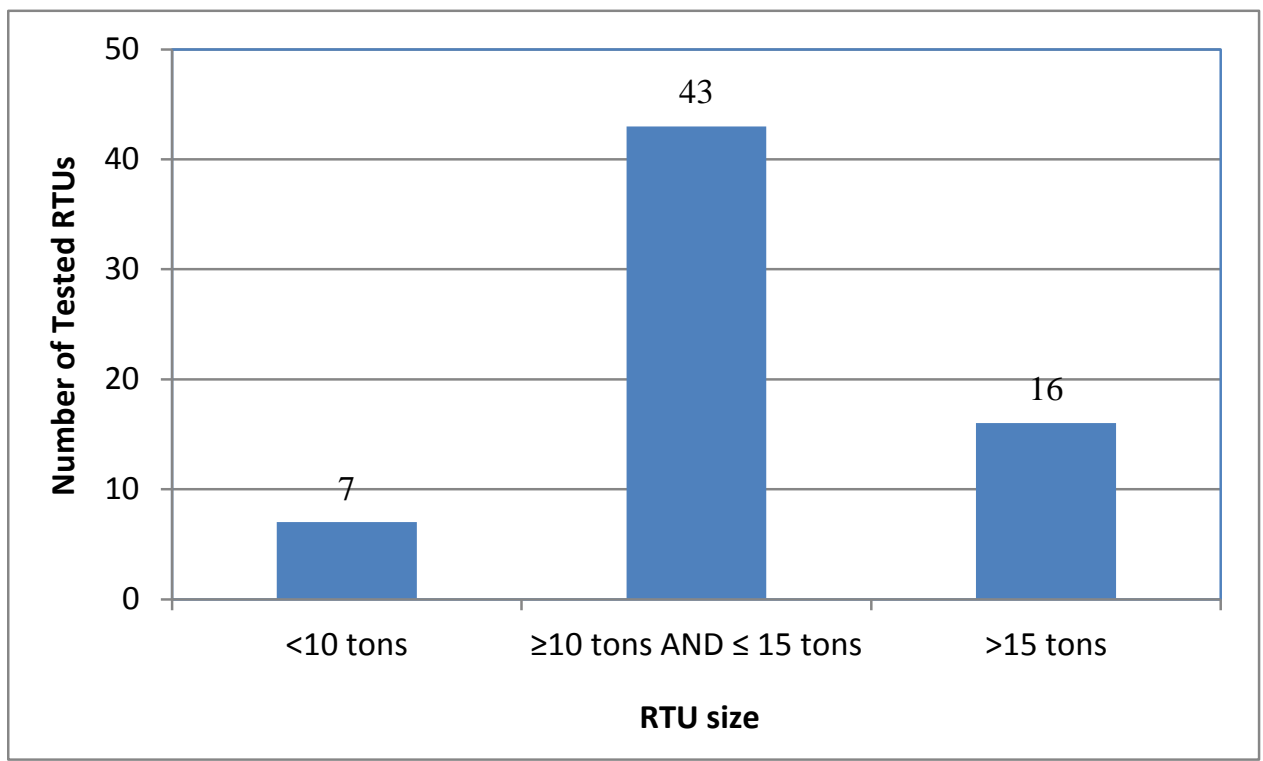

Figure 5: Distribution of tested RTUs by size 


\section{Energy Savings Estimation Methodology}

This section provides the details of the methodology used in determining the energy savings from advanced RTU controls retrofit. The energy savings estimation methodology used is similar to that defined in ASHRAE Guideline 14-2002 (ASHRAE 2002). The first step in the process involves developing regression models based on the measured data during the pre-retrofit period (i.e., when the standard controls were used) and the post-retrofit period (i.e., when the advanced RTU controls were used). The second step is to estimate the energy consumption of the RTU using the pre-retrofit model (standard controls) under the post-retrofit conditions (e.g., post-retrofit outdoor-air conditions, etc.). The energy savings were then computed as the differences between the estimated energy use and the measured actual energy use over the post-retrofit period. In addition to the actual savings, normalized annual savings were also calculated using the typical meteorological year (TMY) weather data. To calculate normalized savings, the pre- and post-retrofit models were used to estimate the pre- and post-retrofit energy consumption using TMY weather data. The difference between the pre- and post-retrofit energy consumption was the normalized annual energy savings. The rest of the section describes the procedures used to preprocess monitored field data for use in modeling, the regression model development, the approach used to develop the energy savings calculation, and the savings uncertainty estimation.

\subsection{Field Test Data Processing}

The high-resolution (1-minute) monitored data cannot be used directly for regression model development because 1) some "bad" data points may exist; 2 ) the 1-minute time resolution is not the best resolution for models used to estimate energy savings (Katipamula et al. 1995) ; and 3) the RTU total energy needs to be disaggregated for heating and cooling model development. Therefore, the raw monitored data were preprocessed in a number of steps, including filtering out "bad" data, disaggregating RTU energy, and aggregating the 1-minute data into daily data suitable for regression model development.

\subsubsection{Data Filtering}

The first step in model development was to filter "bad" data by identifying them and marking them as bad, so they were not used for subsequent data analysis. A data record (set of data associated with one RTU for one time interval) is marked as "error" if one of the following conditions was met:

- Communication is lost between the advanced RTU controller and the archived database. In this case, the logged data variable "ControllerDown" in Table 1 is indicated as TRUE.

- The supply-fan VFD is not responding correctly to a run command. In this case, the logged data variable "DriveLock" in Table 1 is indicated as TRUE.

- The measured unit energy ${ }^{1}(\mathrm{kWh})$ is not available or is not a positive value.

- The sensed space temperature is negative.

\footnotetext{
${ }^{1}$ Although the total electric energy consumption in $\mathrm{kWh}$ is recorded, its consumption is also referred to as average $\mathrm{kW}$ consumption over the recorded interval, which is 1 -minute.
} 
- The supply-fan runs at a speed lower than expected when the space is occupied. According to the control sequence presented in Section 2, the fan speed is not expected to be less than $40 \%$ when the space is occupied and the supply fan is operational. Therefore, when the supply-fan speed is lower than $35 \%$, the data record is marked as an error. The value of $35 \%$ instead of $40 \%$ is set as the low limit to avoid removing those records with fan speeds in between $35 \%$ and $40 \%$ caused by fan speed ramping and round-off error in fan speed recording

- The monitored data gets "stuck" for a period of time. Stuck data means that some key sensor/meter measurements (e.g., outdoor-air temperature and RTU energy) are constant and unchanged. The stuck data occur when there are issues in transferring data from the local controller to the web server. The stuck data were identified manually during the data analysis.

The records marked as error in this step were not considered in the subsequent data analysis.

\subsubsection{RTU Energy Disaggregation}

The total electrical energy consumption was monitored for all RTUs, which included the supply fan, the compressor, the condenser fan and the parasitic power used for RTU control and crankcase heater. The total measured energy needed to be separated into different components to understand the impact of the RTU controller retrofit on RTU energy end uses.

When an RTU was in the idle mode (i.e., when the space was unoccupied and the supply-fan speed was zero), the RTU power was regarded as equal to its parasitic power. It was assumed that the parasitic energy consumption remained constant and was independent of the RTU control modes (i.e., advanced control being on or off). Thus, for each RTU, its parasitic power consumption was calculated as the average of measured RTU power when the unit idled. Table 3 provides the calculated parasitic power for all RTUs. A unit's parasitic power may be reported as not available (NA) because it was operated continuously and never went to the idle mode during the monitoring period. In this case, the unit's parasitic power was assumed to be zero.

The supply-fan power consumption was calculated from the total unit power consumption as follows:

- Step 1: For each unit, the data records satisfying the following conditions were collected i) the unit in ventilation mode; and ii) the space occupied.

- Step 2: When an RTU runs in ventilation mode, the measured power is the sum of the supply-fan power and the parasitic power. Therefore, for each data record collected from the previous step, the supply-fan power was calculated as the difference between the measured total RTU power and the parasitic power shown in Table 3.

- Step 3: For each data record, the supply-fan power from Step 2 was compared with the supplyfan power recorded by the contractor at startup (Tables A-1 and A-2 in Appendix A). Before installing the advanced RTU controller on each RTU, the contractor recorded the supply-fan power at $100 \%$ speed. If the supply-fan power from Step 2 was 1.5 times higher or 0.5 times less than the contractor-recorded fan power, this implies that the estimated fan power from monitored data has some outliers. A possible reason for the outliers was that the control signal from the thermostat commanded a unit in ventilation mode, but the compressor may still be running because of the minimum runtime constraint. 
- Step 4: The fan power from all data records excluding those outliers were averaged. The average was regarded as the fan power at $100 \%$ fan speed.

Using the above steps, the supply-fan power at $100 \%$ fan speed was calculated for all test units, as shown in Table 3.

Table 3: Calculated RTU parasitic power and supply-fan power

\begin{tabular}{|c|c|c|c|}
\hline RTU ID & $\begin{array}{c}\text { Parasitic } \\
\text { Power }(\mathrm{kW})\end{array}$ & $\begin{array}{l}\text { Supply-Fan } \\
\text { Power }(k W)\end{array}$ & $\begin{array}{l}\text { Supply Fan } \\
\text { Power (hp) }\end{array}$ \\
\hline 202 & 0.07 & 2.8 & 3.7 \\
\hline 203 & 0.02 & 1.7 & 2.3 \\
\hline 204 & 0.03 & 2.3 & 3.1 \\
\hline 205 & 0.17 & 1.8 & 2.4 \\
\hline 206 & 0.05 & 2.1 & 2.8 \\
\hline 207 & 0.05 & 6.7 & 8.9 \\
\hline 209 & 0.05 & 0.7 & 0.9 \\
\hline 210 & 0.03 & 8.5 & 11.3 \\
\hline 212 & 0.03 & 7.1 & 9.4 \\
\hline 213 & 0.05 & 2.9 & 3.8 \\
\hline 214 & 0.07 & 1.2 & 1.6 \\
\hline 215 & 0.03 & 1.8 & 2.5 \\
\hline 216 & 0.06 & 2.3 & 3.0 \\
\hline 217 & 0.07 & 1.9 & 2.6 \\
\hline 218 & 0.04 & 2.2 & 2.9 \\
\hline 219 & 0.04 & 1.3 & 1.7 \\
\hline 220 & 0.03 & 1.0 & 1.4 \\
\hline 221 & 0.05 & 1.5 & 2.0 \\
\hline 222 & 0.13 & 1.4 & 1.9 \\
\hline 223 & 0.10 & 1.8 & 2.4 \\
\hline 224 & 0.06 & 1.3 & 1.7 \\
\hline 225 & 0.01 & 1.5 & 2.0 \\
\hline 226 & 0.03 & 2.5 & 3.4 \\
\hline 227 & 0.02 & 1.7 & 2.2 \\
\hline 228 & 0.07 & 2.3 & 3.1 \\
\hline 229 & 0.09 & 3.8 & 5.0 \\
\hline 231 & 0.03 & 1.7 & 2.2 \\
\hline 362 & 0.15 & 2.5 & 3.3 \\
\hline 363 & 0.05 & 5.8 & 7.7 \\
\hline 364 & 0.31 & 4.8 & 6.4 \\
\hline 365 & 0.30 & 5.1 & 6.8 \\
\hline 366 & 0.33 & 5.0 & 6.7 \\
\hline 367 & NA & 6.1 & 8.1 \\
\hline
\end{tabular}




\begin{tabular}{|c|c|c|c|}
\hline RTU ID & $\begin{array}{c}\text { Parasitic } \\
\text { Power }(k W)\end{array}$ & $\begin{array}{l}\text { Supply-Fan } \\
\text { Power (kW) }\end{array}$ & $\begin{array}{l}\text { Supply Fan } \\
\text { Power (hp) }\end{array}$ \\
\hline 368 & 0.31 & 4.8 & 6.4 \\
\hline 369 & NA & 5.2 & 7.0 \\
\hline 370 & NA & 5.1 & 6.9 \\
\hline 371 & NA & 4.8 & 6.4 \\
\hline 372 & 0.61 & 2.4 & 3.1 \\
\hline 375 & 0.17 & 2.6 & 3.4 \\
\hline 376 & 0.08 & 1.0 & 1.4 \\
\hline 377 & 0.07 & 1.1 & 1.4 \\
\hline 378 & 0.13 & 2.5 & 3.3 \\
\hline 379 & 0.08 & 0.4 & 0.6 \\
\hline 380 & 0.08 & 1.1 & 1.4 \\
\hline 381 & 0.70 & 2.0 & 2.6 \\
\hline 382 & 0.12 & 2.0 & 2.7 \\
\hline 383 & 0.17 & 2.0 & 2.7 \\
\hline 384 & 0.05 & 2.2 & 2.9 \\
\hline 385 & 0.18 & 2.0 & 2.7 \\
\hline 386 & 0.15 & 1.7 & 2.2 \\
\hline 387 & 0.24 & 1.8 & 2.4 \\
\hline 388 & 0.18 & 1.8 & 2.4 \\
\hline 389 & 0.05 & 1.9 & 2.5 \\
\hline 390 & 0.22 & 1.7 & 2.2 \\
\hline 391 & 0.18 & 1.9 & 2.5 \\
\hline 407 & 0.06 & 1.0 & 1.4 \\
\hline 408 & 0.04 & 1.4 & 1.9 \\
\hline 409 & 0.08 & 2.5 & 3.4 \\
\hline 410 & NA & 3.0 & 4.0 \\
\hline 411 & 0.18 & 4.4 & 5.9 \\
\hline 423 & 0.16 & 2.0 & 2.6 \\
\hline 424 & 0.15 & 1.8 & 2.4 \\
\hline 425 & 0.15 & 2.3 & 3.0 \\
\hline 426 & 0.15 & 2.1 & 2.7 \\
\hline 427 & 0.14 & 2.3 & 3.0 \\
\hline
\end{tabular}

For the post-retrofit period with advanced RTU controls, the supply fan ran at different speeds depending on the RTU operation mode. Let FanPwr $r_{\text {base }}$ denote the supply-fan power at $100 \%$ speed (see Table 3). For each data record in the post-retrofit period, the supply-fan power was calculated as:

FanPwr $_{\text {adv }}=\left\{\begin{array}{ll}\text { UnitPwr }- \text { ParPwr } & (\text { ActualCool }=0 \text { AND ActualHeat }=0) \\ \left(\frac{\text { Fanspeed }}{100}\right)^{2.5} * \text { FanPwr } & (\text { ActualCool }=1 \text { OR ActualHeat }=1)\end{array}\right.$.

where UnitPwr is the measured total RTU power in $\mathrm{kW}, P a r P w r$ is the parasitic power in $\mathrm{kW}$ from Table 3, FanSpeed is the measured supply-fan speed in the range between 0 and 100, ActualHeat 
indicates the gas furnace or compressor (for heat pumps) status ( 1 indicating heating is on and 0 off), and ActualCool indicates the compressor status ( 1 indicating cooling is on and 0 off). It needs to be noted that both ActualHeat and ActualCool are derived variables, which will be discussed in detail in the next section. For the ideal situation with no power loss on the fan drive and motor, the power is proportional to the cube of the supply-fan speed. Chan (2004) and Ford (2011) have shown that to approximately account for these losses, the supply-fan power can be expressed as being proportional to the fan speed, to a power of between 2.0 and 3.0. Thus, the exponent 2.5 was used to express the supply-fan power law relationship to the supply-fan speed.

For each data record, the cooling power (CoolPower, in kW), which includes the compressor power and the condenser fan power, was calculated as:

$$
\text { CoolPower }=\left\{\begin{array}{ll}
(\text { UnitPwr }- \text { FanPwr }- \text { ParPwr }) & (\text { ActualCool }=1) \\
0 & (\text { ActualCool }=0)
\end{array},\right.
$$

where FanPwr equals to $F a n P w r_{b a s e}$ and $F a n P w r_{a d v}$, respectively, for the pre-retrofit period and the post-retrofit periods.

For each data record, the heating power was calculated differently between heat pumps and RTUs with gas furnaces. For heat pumps, the heating power (HeatPower ${ }_{H P}$, in $\left.\mathrm{kW}\right)$, which included the compressor power and the condenser fan power, was calculated as:

HeatPower $_{H P}=\left\{\begin{array}{ll}(\text { UnitPwr }- \text { FanPwr }- \text { ParPwr }) & (\text { ActualHeat }=1) \\ 0 & (\text { ActualHeat }=0)\end{array}\right.$.

For RTUs with gas furnaces, the heating power $\left(\right.$ HeatPower $_{\text {Gas }}$, in $\mathrm{kBtu} / \mathrm{h}$ ), which is simply the gas burner's input capacity, was calculated as:

$$
\text { HeatPower }_{\text {Gas }}= \begin{cases}\text { FurnaceCap }_{1} & \text { (if FurnaceStatus }=\text { Stage } 1) \\ \text { FurnaceCap }_{2} & \text { (if FurnaceStatus }=\text { Stage2) } \\ 0 & \text { (if FurnaceStatus }=\text { off })\end{cases}
$$

where FurnaceCap ${ }_{1}$ and FurnaceCap 2 are the furnace capacity at the $1^{\text {st }}$ stage and the full capacity with both stages on, respectively; FurnaceStatus indicates the furnace status, which can be off, $1^{\text {st }}$ stage running (Stage1), or both stages running (Stage2). The furnace capacities, both FurnaceCap ${ }_{1}$ andFurnaceCap ${ }_{2}$, are the nameplate capacities recorded at startup, and they are listed in Table A-1 in Appendix A. The furnace status was derived from the measured heating control command signals (HeatCmd1and HeatCmd2 in Table 1). For example, the furnace ran at its $1^{\text {st }}$ stage if the heating commands had HeatCmd $1=1$ and HeatCmd $2=0$.

\subsubsection{Determination of RTU Actual Heating and Cooling Status}

As mentioned in Section 5.1.2, ActualHeat and ActualCool were the two variables used to indicate whether an RTU had its gas furnace on or compressor on during a time step. The values of these two variables are derived from meter measurements and logged control variables according to the sequence shown in Figure 6. Although the logged points contained control variables to indicate the heating and cooling commands (e.g., CoolCmd1, CoolCmd2, HeatCmd1, and HeatCmd2 in Table 1), they were not used directly to determine the actual RTU heating and cooling status for the following reasons: 
- The control sequence had a 4-minute minimum runtime for compressors and gas furnaces to avoid short cycling. If the space temperature met the cut-off set point in less than 4 minutes after the RTU initiated its mechanical cooling (or heating), the cooling (or heating) command was off but the compressor (or gas furnace) continued running for the remaining time in that 4minute window.

- The RTUs at one site had dehumidification control. Initially, the dehumidification signal was not monitored. There were many time steps with the cooling command off but the compressor still on for the purpose of dehumidification.

- The cooling commands may get stuck for some time. In this situation, the cooling commands were true (i.e., CoolCmd $1=1$ or $\operatorname{CoolCmd2}=1$ ) when the compressor was actually off.

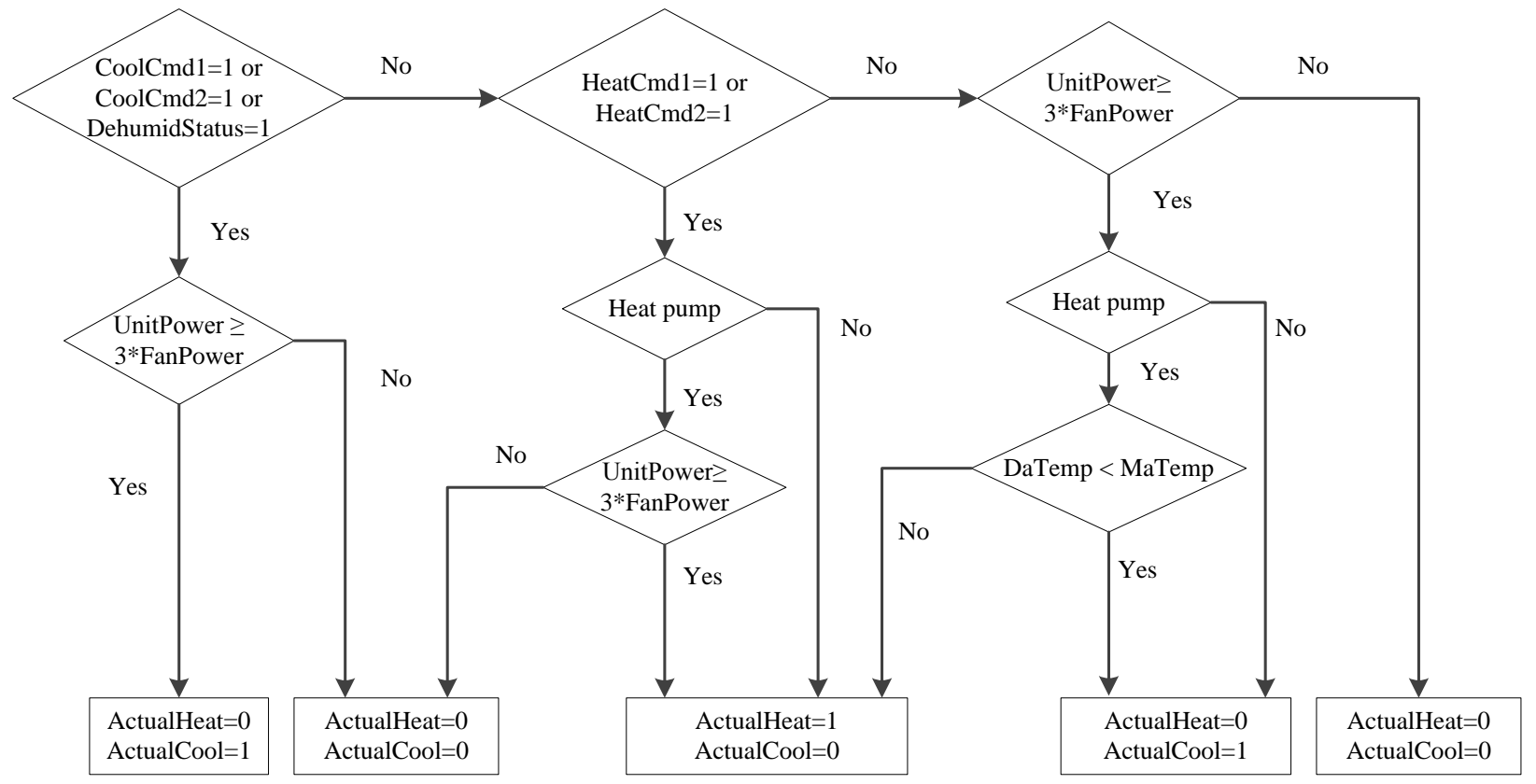

Figure 6: Flow chart for determining the RTU actual heating and cooling status based on the measured control variables

As shown in Figure 6, the RTU total power was also used to determine ActualHeat and ActualCool by comparing the RTU total power (UnitPower) and the supply-fan power (FanPower). If the RTU total power was several times greater than the supply fan power (e.g., a factor of 3 was used in this work), the compressor must be on no matter what the heating or cooling commands are. The discharge-air temperature (DaTemp) and the mixed-air temperature (MaTemp) were used to determine the heat pump heating/cooling status if both heating and cooling commands were zero. Note that comparing the RTU total power and the supply-fan power works for cooling and when a heat pump was used for heating. For RTUs with gas heat, the heating status was determined from the heating commands (i.e., HeatCmd1 and HeatCmd2).

\subsubsection{Data Aggregation and Normalization in Daily Format}

As stated previously, the data was monitored at 1-minute intervals. However, the 1-minute interval data were not suitable for regression model development. This is because the compressor (or gas 
furnace) cycles to meet the space thermal loads. Under the same weather conditions, the RTU may have a very different energy use signature depending on the compressor (or gas furnace) running status. The highly diversified signature of RTU energy use will lead to unreliable regression models. Therefore, the 1-minute monitored data were aggregated daily for use in the regression models.

Because the RTU only operated when the space it is serving was occupied, the daily data were aggregated from only those occupied periods. For both the pre-retrofit period and the post-retrofit period, the daily data aggregation resulted in the following data list:

- Day type (DayType). The day type was an enumerated variable used to indicate the day of the week.

- RTU runtime (RunTime, in hours). This was the total RTU running time counted from the monitored data records that were not marked as an error. Because of the existence of error data records, the RTU runtime was not necessarily equal to the scheduled RTU operation hours.

- Average outdoor-air temperature $\left(A v g O A T\right.$, in $\left.{ }^{\circ} \mathrm{F}\right)$ when the RTU was operating. The average outdoor-air temperature was computed from those records counted by the RTU runtime. Hence, $A v g O A T$ differed from the daily average outdoor-air temperature conventionally used in literature, which covers the entire 24 hours.

- Daily supply-fan energy (DailyFanEnergy, in kWh). The daily supply-fan energy was calculated as:

$$
\text { DailyFanEnergy }=\left(\sum_{i} \text { FanPower }_{i}\right) / 60 \text {, }
$$

where the subscript $i$ indicates the monitored record not marked as an error.

- Daily cooling energy (DailyCoolEnergy, in kWh). The daily cooling energy was calculated as:

$$
\text { DailyCoolEnergy }=\left(\sum_{i} \text { CoolPower }_{i}\right) / 60 \text {, }
$$

- Daily heating energy (DailyHeatEnergy, in kWh for heat pumps and in kBtu for gas furnaces). The daily heating energy was calculated as:

$$
\text { DailyHeatEnergy }=\left(\sum_{i} \text { HeatPower }_{i}\right) / 60 \text {, }
$$

- Daily total RTU electricity consumption (DailyRTUElec, in $\mathrm{kWh}$ ). For heat pumps, the daily total RTU electricity consumption included all of the energy used for heating, cooling, the supply fan, and the RTU control system. For RTUs with gas heat, however, the heating energy was not included. The daily RTU electricity consumption was calculated as:

$$
\text { DailyRTUElec }=\left(\sum_{i} U_{n i t P} w r_{i}\right) / 60
$$

where UnitPwr is the measured total RTU power in kW.

It was found that the daily runtime may vary for a given RTU. The varying runtime was caused by any of the four reasons: 1) the scheduled RTU operation hours differ between weekdays and weekends; 2 ) if optimal start was used, the RTU starting time may have varied depending on the control parameter values used by optimal start; 3 ) the number of "error" data records were different and 4) units running to meet the unoccupied set points. Because the daily RTU runtime varied, the daily energy consumption for fan, heating, and cooling needed to be normalized by dividing it by the RTU runtime (fan runtime) for 
that day. The normalized daily energy consumption data were then used for regression model development.

\subsection{Regression MOdel DeVELOPMENT}

Regression models were used to correlate the daily average heating, cooling and total energy consumption (previously described) with the average outdoor-air temperature. Theoretically, these regression models can have one to five parameters depending on building type and the energy-use pattern (ASHRAE 2002). After a quick look at several RTUs' scatter charts showing the relationship between RTU's energy use and outdoor-air temperature, it was found that the three-parameter (3-P) and the five-parameter (5-P) change-point models were appropriate. The change point is a threshold below (above) which mechanical cooling (heating) is not needed to maintain the space temperature in its deadband. The 5-P change-point model was applied to the total electricity for heat pumps. The 3-P change-point model was applied to all other cases including cooling only, heating only, and the total electricity consumption when the RTU used natural gas for heating. After developing the regression models for each RTU, if the 3-P or the 5-P models were not appropriate, alternate models will be considered.

The 3-P change-point model for RTU cooling is conceptually illustrated in Figure 7, which has the following functional form:

$E_{\text {cool }}=C_{C}+B_{C} *\left(A v g O A T-T_{C C P}\right)_{+}$,

where, $E_{\text {cool }}$ is the daily average RTU cooling energy in $\mathrm{kWh} / \mathrm{h} ; C_{C}, B_{C}$, and $T_{C C P}$ are regression coefficients as shown in Figure 7; the subscript " + " means that only positive values of the parenthetical expression are considered; and the variable $A v g O A T$ refers to the average outdoor-air temperature in ${ }^{\circ} \mathrm{F}$.

The 3-P change-point model for RTU heating is conceptually illustrated in Figure 8, which has the following functional form:

$E_{\text {heat }}=C_{H}-B_{H} *\left(T_{H C P}-A v g O A T\right)_{+}$,

where $E_{\text {heat }}$ is the daily average RTU heating energy (in $\mathrm{kWh} / \mathrm{h}$ for heat pumps and $\mathrm{kBtu} / \mathrm{h}$ for gas furnaces); $C_{H}, B_{H}$ (negative), and $T_{H C P}$ are regression coefficients for heating, as shown in Figure 8. 


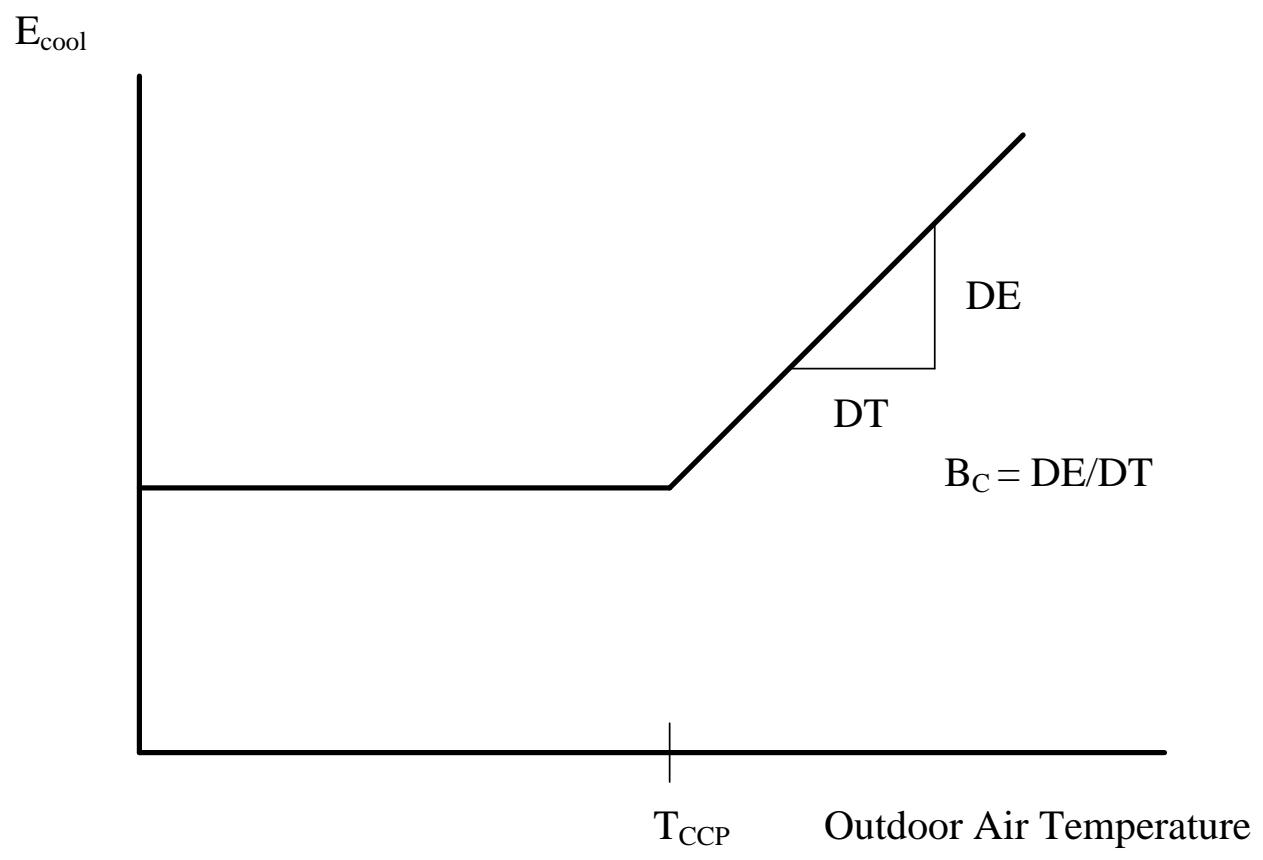

Figure 7: A representation of a 3-parameter regression model for cooling only or the total electricity of an RTU with gas heat

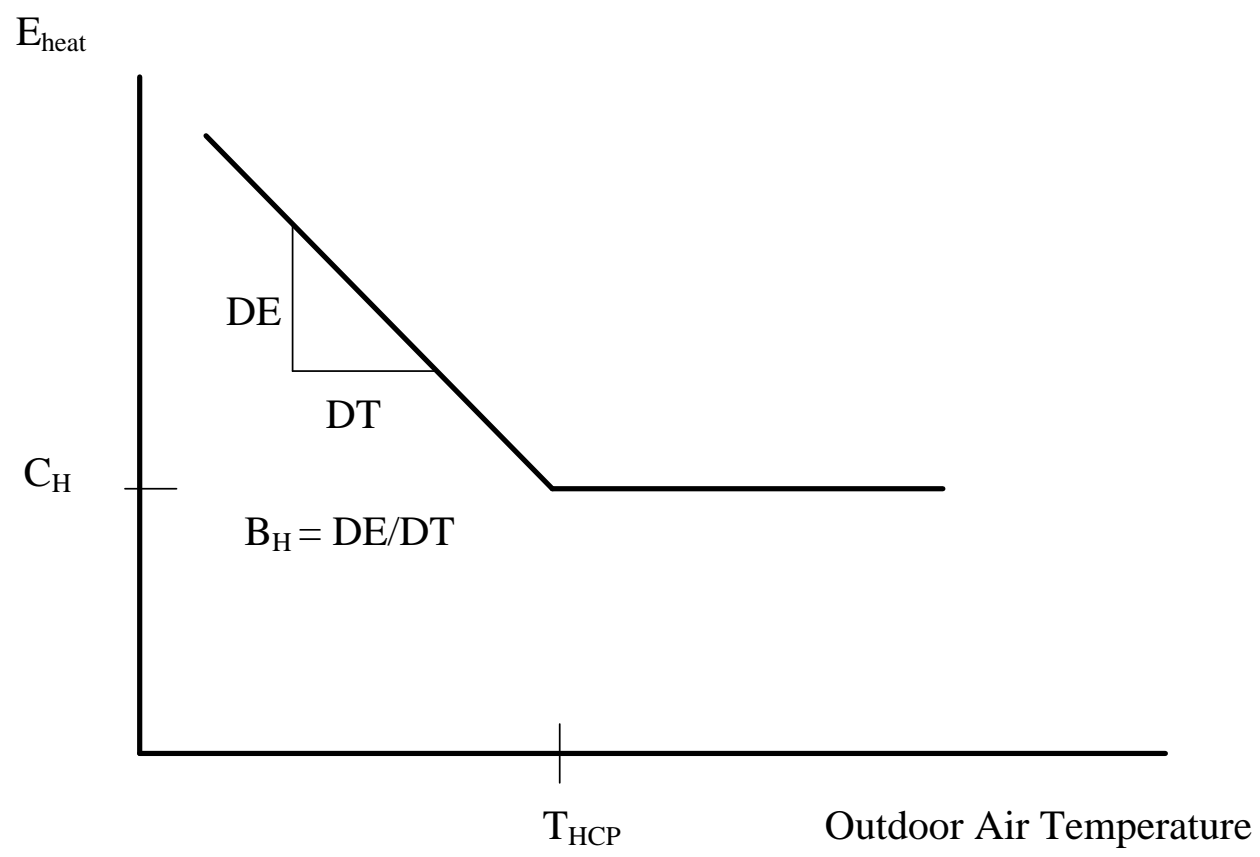

Figure 8: A representation of a 3-parameter regression model for RTU heating only

For RTUs with gas heat, the 3-P change-point model for the total electricity consumption (including cooling, fan, and the parasitic energy for equipment control) had the same look as illustrated in Figure 7. The model can be expressed with the following equation:

$E_{\text {totalelec }}=C_{C F}+B_{C} *\left(\text { AvgOAT }-T_{C C P}\right)_{+}$, 
where $E_{\text {totalElec }}$ is the daily average RTU total electricity use in $\mathrm{kWh} / \mathrm{h}$; and $C_{C F}, B_{C}$, and $T_{C C P}$ are regression coefficients.

For heat pumps, the most likely model for the total electricity consumption (including heating, cooling, fan, and the parasitic energy for equipment control) is a 5-P model, which is conceptually illustrated in Figure 9 and has the following functional form:

$E_{\text {totalelec }}=C_{H C}-B_{H} *\left(T_{H C P}-A v g O A T\right)_{+}+B_{C} *\left(A v g O A T-T_{C C P}\right)_{+}$,

where $C_{H C}, B_{\mathrm{H}}$ (negative), $B_{C}, T_{H C P}$ and $T_{C C P}$ are regression coefficients.

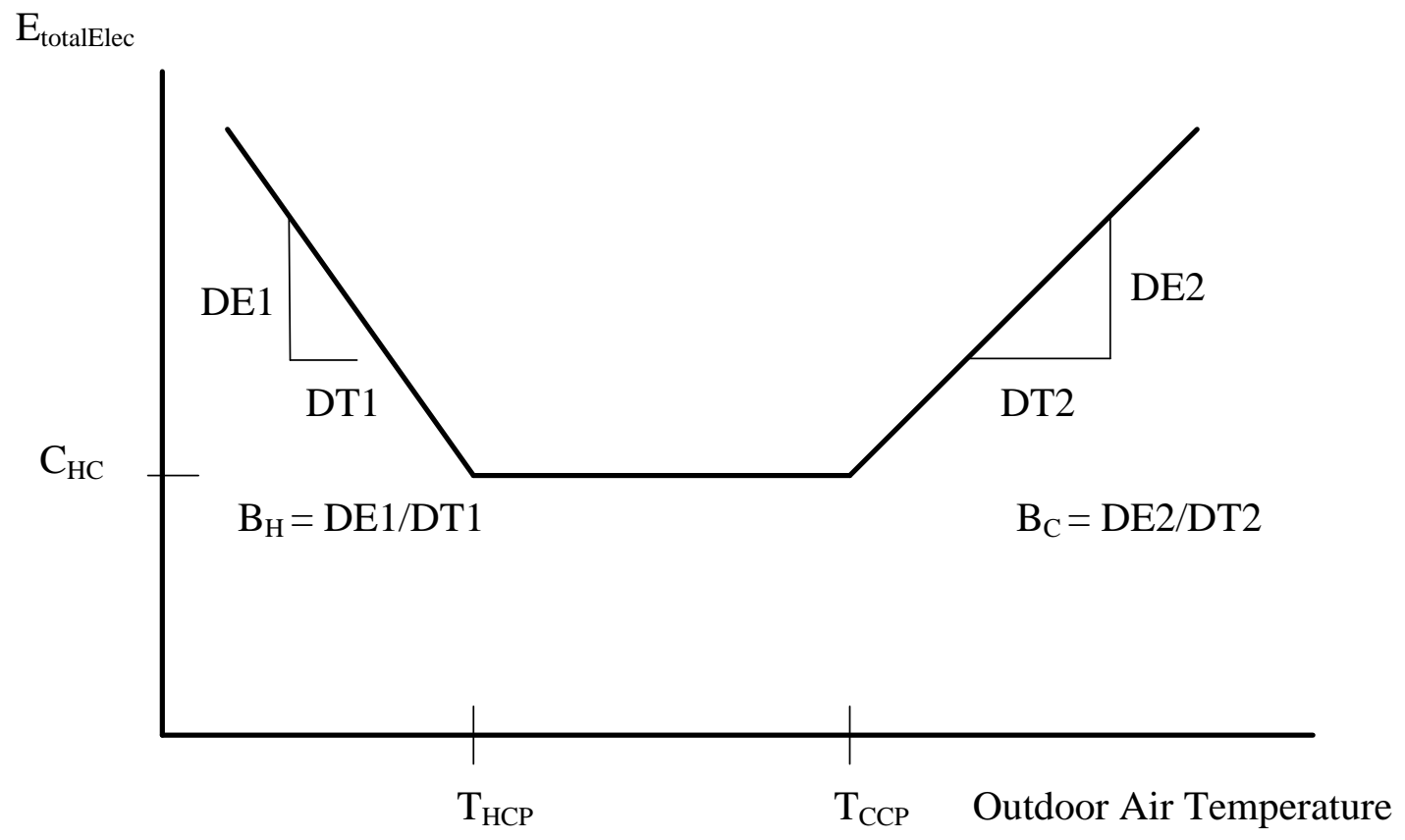

Figure 9: A representation of a 5-P regression model total electricity of a heat pump

\subsection{Energy Charting And Metrics Tool}

The Energy Charting and Metrics (ECAM) Tool was used to develop the regression models and the coefficients based on the normalized daily energy consumption data and the average outdoor-air temperature. ECAM is available as a free add-on for Microsoft Excel; the tool makes extensive use of Excel pivot tables. Development of regression models is one of ECAM's many key features, which also includes creation of charts to help building re-tuning and comparing energy consumption from retrofits or retro-commissioning. More details on ECAM's functionalities and its use can be found in Taasevigen et al. (2011).

\subsection{Energy Savings Calculation}

The regression models were used to determine energy savings from the advanced RTU controller in two ways: actual savings and normalized savings (ASHRAE 2002). To obtain the actual savings, the preretrofit regression model was used with actual monitored data (i.e., average daily outdoor-air 
temperature) from the post-retrofit period to estimate the expected energy consumption with standard controls. The differences between the expected energy use and the measured actual energy use during the post-retrofit period were summed together to obtain the actual savings. To obtain the normalized savings, both pre- and post- retrofit models were used with the TMY weather data over 1 year to estimate both the consumption with standard controls and advanced controls. The differences between the estimated pre- and post-retrofit energy use from the two regression models were summed to obtain the normalized annual savings. The equations used to calculate energy savings were presented below.

The actual savings for different energy end uses are calculated as:

$$
\begin{aligned}
& \text { FanE }_{\text {actSave }}=\text { Fan } E_{\text {pre }, m}-\text { FanE }_{\text {meas }, m}, \\
& \text { Cool }_{\text {actSave }}=\text { CoolE }_{\text {pre }, m}-\text { CoolE }_{\text {meas }, m}, \\
& \text { Heat } E_{\text {actSave }}=\text { Heat } E_{\text {pre }, m}-\text { Heat } E_{\text {meas }, m}, \\
& R T U E_{\text {actSave }}=\text { RTUE } E_{\text {pre }, m}-\text { RTUE }_{\text {meas }, m} ;
\end{aligned}
$$

where FanE, CoolE, HeatE, and RTUE are the fan energy (kWh), the cooling energy (kWh), the heating energy ( $\mathrm{kWh}$ for heat pumps and kBtu for gas furnaces), and the total RTU electricity consumption ( $\mathrm{kWh}$ ), respectively; the subscript actSave represents the actual savings; $m$ stands for the total number of days in the post-retrofit period; pre and meas respectively represent the pre-retrofit energy estimated for the post-retrofit period and the measured energy use over the post-retrofit period.

The expected fan energy use is calculated as:

FanE $_{\text {pre }, m}=\sum_{j=1}^{m}\left(\right.$ FanPwr $_{\text {base }} *$ RunTime $\left._{j}\right)$,

where the subscript $j$ represents the day index in the post-retrofit period; FanPwr base denotes the supply-fan power (kW) at $100 \%$ speed (see Section 5.1.2); RunTime is the RTU running time (hours) calculated from the data records (see Section 5.1.4).

The expected cooling energy, heating energy and total RTU electricity consumption were calculated from the corresponding pre-retrofit regression model along with the daily average outdoor-air temperature during the post-retrofit period. For example, for an RTU with gas heat, the expected total electricity use is calculated as:

$R T U E_{\text {pre }, m}=\sum_{j=1}^{m}\left\{\left[C_{C F}+B_{C} *\left(A v g O A T_{j}-T_{C C P}\right)_{+}\right]_{\text {pre }} *\right.$ RunTime $\left._{j}\right\}$,

where $C_{C F}, B_{C}$, and $T_{C C P}$ are regression coefficients for the pre-retrofit RTU total electricity model (see Section 5.2); and AvgOAT is the average outdoor-air temperature $\left({ }^{\circ} \mathrm{F}\right)$ calculated from the monitored data (see Section 5.1.4). The expected heating energy and cooling energy under standard controls during post-retrofit period can be calculated in a similar manner.

The actual energy savings were for a specific period, which may be less than 1 year and vary with different units. In addition, the weather experienced during that period may not represent the typical weather conditions in a particular location. Therefore, normalized annual energy savings based on the typical meteorological year (TMY) weather data were helpful to understand the impact of the RTU 
retrofit controller and compare the savings for different units. The normalized annual savings for different energy end uses are calculated as:

$$
\begin{aligned}
& \operatorname{CoolE}_{\text {normsave }}=\operatorname{CoolE}_{\text {pre }, T M Y}-\operatorname{CoolE}_{\text {post }, T M Y}, \\
& \text { Heat } E_{\text {normsave }}=\text { Heat } E_{\text {pre }, T M Y}-\text { Heat } E_{\text {post }, T M Y} \text {, } \\
& R T U E_{\text {normsave }}=R T U E_{\text {pre }, T M Y}-R T U E_{\text {post } T M Y} \text {, }
\end{aligned}
$$

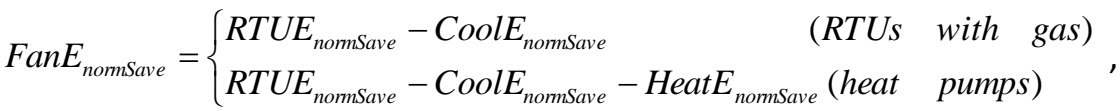

where the subscripts normSave,pre, post, and TMY represent the normalized savings, the pre-retrofit energy use projected to the whole TMY, the post-retrofit energy use projected to the whole TMY, and the number of days (i.e., 365) in the TMY, respectively.

The projected cooling energy, heating energy and total RTU electricity were calculated from the corresponding regression models (both pre-retrofit and post-retrofit) driven by the daily average outdoor-air temperature from TMY. For example, for an AC unit, the projected total electricity uses in the pre- and post-retrofit periods are calculated as:

$$
\begin{aligned}
& R T U E_{\text {pre }, T M Y}=\sum_{j=1}^{365}\left\{\left[C_{C F}+B_{C} *\left(A v g O A T_{j}-T_{C C P}\right)_{+}\right]_{\text {pre }} * \text { OccTime }_{j}\right\} \\
& R T U E_{\text {post }, T M Y}=\sum_{j=1}^{365}\left\{\left[C_{C F}+B_{C} *\left(\text { AvgOAT }_{j}-T_{C C P}\right)_{+}\right]_{\text {post }} * \text { OccTime }_{j}\right\}
\end{aligned}
$$

where, OccTime indicates the total occupancy time (hours) for each day, which is derived from the occupancy schedule; $A v g O A T$ is the outdoor-air temperature $\left({ }^{\circ} \mathrm{F}\right)$ averaged over the occupied period based on the TMY data; $C_{C F}, B_{C}$, and $T_{C C P}$ are regression coefficients for the RTU total electricity model (see Section 5.2). The coefficients for the pre-retrofit (or post-retrofit) regression model were used to calculate the projected pre-retrofit (or post-retrofit) electricity uses.

After the absolute energy savings were calculated, percentage savings can be also calculated. For example, the actual percent savings for RTU total electricity $\left(F_{\text {actsave }}\right)$ is calculated as:

$F_{\text {actSave }}=\frac{R T U E_{\text {actSave }}}{R T U E_{\text {pre }, m}} * 100 \%$

The percentage savings for RTU supply-fan energy, heating energy and cooling energy were calculated in a similar manner.

\subsection{SAVINGS UnCERTAINTY ESTIMATION}

Because there can be errors in measurements and also errors associated with models, the saving estimates will have some uncertainty. According to ASHRAE Guideline 14 (ASHRAE 2002), the following three primary sources of quantifiable uncertainty shall be considered in savings determination: 
- Sampling uncertainty generated from not measuring the entire set. The current study was intended to measure the savings potential of each RTU. Therefore, the sampling uncertainty was not considered. Although the savings results will be studied in different RTU groups such as those at the same building site and those within the same capacity range, the RTUs selected for retrofits were by no means the random sample of the entire set.

- Measurement equipment error generated from the calibration, range, and repeatability of the equipment and installation effects. Measurement errors were estimated for non-billing energy use meters and the measurements of post-retrofit independent variables. Thus, in this work, the sources of measurement equipment errors came from the electric power meter and the outdoor-air temperature sensor.

- Modeling uncertainty generated from the prediction error of the regression models. Because gas consumption was not measured, uncertainty associated with heating models was not calculated.

The fractional savings uncertainty, expressed as the ratio of the expected savings uncertainty to the total savings, is estimated for both the actual savings and the normalized savings.

\subsubsection{Actual Savings Uncertainty}

For actual savings, the fractional savings uncertainty is calculated as:

$U=\left(U_{\text {model }}^{2}+U^{2}{ }_{i v}+U^{2}{ }_{\text {meter }}\right)^{0.5}$,

where $U$ indicates the savings uncertainty; the subscripts model, iv, and meter refer to the uncertainty from the regression model, the independent variable (i.e., outdoor-air temperature sensor) measurement error, and the power meter measurement error, respectively.

Based on ASHRAE (2002), the modeling uncertainty $\left(U_{\text {model }}\right)$ is calculated as:

$U_{\text {model }}=\frac{t * 1.26 * C V_{\text {pre }}}{F_{\text {actsave }}} *\left(\frac{n+2}{n * m}\right)^{0.5}$,

where $t$ is the t-statistic determined from the confidence level and the number of data points in the preretrofit period; $n$ is the number of data points (i.e., days) used to develop the pre-retrofit regression model; $m$ is the number of data points (i.e., days) in the post-retrofit period; $C V_{\text {pre }}$ is the coefficient of variation of the root mean square error for the pre-retrofit regression model; and $F_{\text {actsave }}$ is the actual savings percentage as calculated by Equation 5-25.

More information about how to obtain the t-statistic and the coefficient of variation can be found in ASHRAE (2002).

The fractional savings uncertainty created by the error in measurement of outdoor-air temperature $\left(U_{\text {iv }}\right)$ during the post-retrofit period is calculated as:

$U_{i v}=\frac{t}{F_{\text {actsave }}}\left|F_{\text {max }}-F_{\text {min }}\right|$,

where $F_{\text {max }}$ and $F_{\text {min }}$ indicate the savings percentage re-calculated by replacing the original daily average outdoor-air temperature $A v g O A T$ with $A v g O A T+\triangle T$ and $A v g O A T-\triangle T$, respectively. Note 
that $\Delta T$ is the maximum deviation of the outdoor-air temperature sensor measurement, which is equal to $0.36^{\circ} \mathrm{F}$ based on the sensor accuracy. As outlined in Section 5.3, the approach of using the pre-retrofit regression model with $A v g O A T+\triangle T$ and $A v g O A T-\triangle T$ is used to calculate $F_{\text {max }}$ and $F_{\text {min }}$.

The fractional savings uncertainty caused by the power meter measurement error $\left(U_{\text {meter }}\right)$ was estimated at a constant of $0.5 \%$, which is the relative error of the power meter reading. That is,

$U_{\text {meter }}=0.5 \%$,

\subsubsection{Normalized Savings Uncertainty}

For normalized savings, the fractional savings uncertainty is calculated as:

$U=\frac{\Delta E}{\mid R T U E_{\text {normsave }}}$,

where $\Delta E$ is the absolute uncertainty in electricity savings ( $\mathrm{kWh})$; and $R T U E_{\text {normsave }}$ is the normalized annual electricity savings calculated from Equation 5-21.

The normalized savings were calculated by running the pre- and post-retrofit regression models using the TMY outdoor-air temperature data. No physical measurements were involved. The absolute savings uncertainty $\Delta E$ is calculated as described by Effinger et al. (2009):

$\Delta E=\left(\Delta E_{\text {pre }}^{2}+\Delta E_{\text {post }}^{2}\right)^{0.5}$,

where $\Delta E_{\text {pre }}$ and $\Delta E_{\text {post }}$ are the absolute savings uncertainty for the pre-retrofit and post-retrofit regression models. They were calculated using the following equations:

$\Delta E_{\text {pre }}=t * 1.26 * C V_{\text {pre }} *\left(\frac{n_{\text {pre }}+2}{n_{\text {pre }} * m_{T M Y}}\right)^{0.5} * R T U E_{\text {pre }, T M Y}$

$\Delta E_{\text {post }}=t * 1.26 * C V_{\text {post }} *\left(\frac{n_{\text {post }}+2}{n_{\text {post }} * m_{T M Y}}\right)^{0.5} * R T U E_{\text {post }, T M Y}$

where $C V_{\text {pre }}$ is the coefficient of variation of the root mean square error for the pre-retrofit regression model; $C V_{\text {post }}$ is the coefficient of variation of the root mean square error for the post-retrofit regression model; $n_{\text {pre }}$ is the number of data points (i.e., days) used to develop the pre-retrofit regression model; $n_{\text {post }}$ is the number of data points (i.e., days) used to develop the post-retrofit regression model; $m_{T M Y}$ is the number of days in the TMY data set when the RTU is scheduled to operate; $R T U E_{\text {pre,TMY }}$ is the expected RTU total electricity consumption (kWh) for the whole TMY based on the pre-retrofit regression model; and $R T U E_{\text {post,TMY }}$ is the expected RTU total electricity consumption ( $\mathrm{kWh}$ ) for the whole TMY based on the post-retrofit regression model. 


\section{Advanced Controls And Economizer Controls VALIDATION}

One of the major objectives of this study was to validate that the advanced controller functions in the field. In comparison with the pre-retrofit RTU operation, the advanced controller used in this field test study had three major energy-efficiency features: the supply-fan speed control, DCV, and integrated airside economizer control. Therefore, the validation process concentrated on the supply-fan, the DCV, and the air-side economizer operations. This section presents the validation approach and the findings from this validation process.

\subsection{VALIDATION OF THE SUPPLY FAN OPERATION}

When the advanced RTU control is activated, the supply fan runs at different speeds depending on the RTU's operation modes. Based on the control sequence described in Section 2, the supply-fan speed normally varied according to the following rules:

Rule 1: If an RTU ran in the ventilation mode, supply-fan speed was $40 \%$.

Rule 2: If an RTU ran in the economizing only mode and the outdoor-air temperature was less than $58^{\circ} \mathrm{F}$, supply-fan speed was $75 \%$ for the $1^{\text {st }}$ stage cooling and supply-fan speed was $90 \%$ for the $2^{\text {nd }}$ stage cooling.

Rule 3: If an RTU ran in the economizing only mode and the outdoor-air temperature was greater than $58^{\circ} \mathrm{F}$, supply-fan speed is $90 \%$.

Rule 4: If an RTU ran in the $1^{\text {st }}$ stage DX cooling and the outdoor-air temperature was between 58 and $70^{\circ} \mathrm{F}$, supply-fan speed was $90 \%$.

Rule 5: If an RTU ran in the $1^{\text {st }}$ stage DX cooling and the outdoor-air temperature was greater than $70^{\circ} \mathrm{F}$, supply-fan speed was $75 \%$.

Rule 6: If an RTU ran in the $2^{\text {nd }}$ stage DX cooling and the outdoor-air temperature was greater than $70^{\circ} \mathrm{F}$, supply-fan speed was $90 \%$.

Rule 7: If an RTU ran in the $1^{\text {st }}$ stage heating, supply-fan speed was $75 \%$.

Rule 8: If an RTU ran in the $2^{\text {nd }}$ stage heating, supply-fan speed was $90 \%$.

Because of the large amount of 1-minute data collected during the monitoring period, it was not feasible to validate the fan speed at every time step. To prioritize problems, database queries representing each of the eight rules described above were used on all RTUs to provide statistics on the number of records violating the supply-fan speed rule corresponding to that RTU operational condition. Using this information, the percentage of records violating the supply-fan speed rules can be calculated. An arbitrary $10 \%$ threshold was used to decide whether further investigations were needed to analyze the causes of the rule violation. For each RTU, if the percentage of records violating a supply-fan speed rule was more than $10 \%$, efforts were taken to look into the 1-minute raw data for possible causes of the rule violation; otherwise, the supply-fan speed control was considered to be working properly. An 
example illustrates the validation process clearly. For unit 223, the statistical results for all eight rules are shown in Table 4.

Table 4: Example results from the fan-speed control validation process using database query

\begin{tabular}{|r|r|r|r|}
\hline Rule & $\begin{array}{r}\text { Total number of data records for } \\
\text { the base operational condition }\end{array}$ & $\begin{array}{r}\text { Total number of rule- } \\
\text { violating data records }\end{array}$ & $\begin{array}{r}\text { Percentage of data records } \\
\text { violating the rule (\%) }\end{array}$ \\
\hline Rule 1 & 148392 & 2203 & 1.5 \\
\hline Rule 2* & $\mathrm{NA}$ & $\mathrm{NA}$ & $\mathrm{NA}$ \\
\hline Rule 3 & 2295 & 103 & 4.5 \\
\hline Rule 4 & 777 & 4 & 0.5 \\
\hline Rule 5 & 4777 & 156 & 3.3 \\
\hline Rule 6 & 17870 & 276 & 1.5 \\
\hline Rule 7 & 2463 & 691 & 28.1 \\
\hline Rule 8 & 3524 & 162 & 4.6 \\
\hline
\end{tabular}

* NA means no data returned from the database query.

The following needs to be noted for Table 4:

- The monitored control signals were used to establish the database queries for counting the number of data records. For example, for Rule 3, the base operational condition was RTU running in the economizing only mode with the outdoor-air temperature greater than $58^{\circ} \mathrm{F}$. The data records satisfying the base operational condition included the following requirements: 1 ) the data record was not marked as error; 2) RTU ran under the advanced control logic (ESMMode is True); 3) space was occupied (Occupied = True); 4) RTU operated in the economizing only mode (CoolCmd1 = False, CoolCmd2 = False, and EconMode = True); and 5) the outdoor-air temperature was greater than $58^{\circ} \mathrm{F}\left(\right.$ OaTemp $\left.>58^{\circ} \mathrm{F}\right)$. Table 1 can be referred to for the definition of variables used in the parentheses. Similarly, the data records violating Rule 3 were counted based on the following requirements: 1 ) the above five requirements satisfying the base operational condition for Rule 3 were met; and 2) supply-fan speed was not equal to $90 \%$.

- Unit 223 had more than $10 \%$ of the data records violating Rule 7 (i.e., supply-fan speed was not at $75 \%$ ) when it ran in the $1^{\text {st }}$ stage heating mode. Efforts were made to detect the causes of Rule 7 violation. It was found that during many furnace cycles, the controller received the heating call from the thermostat for only 1 minute. Based on the control sequence, the supplyfan speed continued to run at the heating speed (i.e., 75\%) for another 2 minutes after the heating call terminates. Then, the supply-fan speed went to $40 \%$ at the $4^{\text {th }}$ minute, starting from the heating call. Meanwhile, the control sequence had a 4-minute minimum runtime for the heating command. Thus, the $4^{\text {th }}$ minute data record of the furnace on cycle was found to violate Rule 7. This detailed investigation ensured that the rule-violating data records were explained and the advanced controller worked properly for the supply-fan speed control.

Similar statistics and investigation of rule-violating records were made for all other tested RTUs. Overall, based on the analysis of the monitored data, the supply-fan speed control worked correctly according to the control sequence. Although for some units, many data records were reported to "violate" the rules for supply-fan speed control, yet they actually followed the control sequence. This phenomenon 
happened because the control sequences were not completely covered by the database queries in two situations: RTU mode transition periods and RTU limit controls. For example, the control sequence indicated that the supply fan continued to run at the cooling speed for 2 minutes after the cooling command had terminated to dissipate any residual cold from the cooling coil. In this case, the supply fan ran at $75 \%$ or $90 \%$, although the control signal indicated RTU running in the ventilation mode. An example for the RTU limit controls was that the supply-fan speed increased if the discharge-air temperature fell below $48^{\circ} \mathrm{F}$. In this case, the supply fan ran at $100 \%$ in the mechanical cooling modes.

A couple of other findings from the process of supply-fan speed control validation are also provided below, although they do not relate to supply-fan speed control.

- The data points got stuck for a period of time. For example, Figure 10 shows the electric power (UnitPwr) and the control signal for the $1^{\text {st }}$ stage cooling command (CoolCmd1) for unit 223 on October 4, 2012. CoolCmd1 was "true" from 7:34 to 13:48, but the unit power was very small, which indicates that CoolCmd1 is "stuck." Based on the feedback from the controller manufacturer, the stuck points primarily occurred in the transfer from the input/output device of the controller to the monitoring platform. The stuck point issue was related to data collection but not equipment operation. As can be seen from Figure 10, although the cool command point is "stuck," the small unit power indicated that the unit was not actually cooling. When a point was "stuck," it was generally released after a new cooling command was initiated. For example, after the new cooling command at about 13:50, CoolCmd1 came back to normal. The existence of stuck points is one of the reasons that actual cooling and heating status needed to be determined from the control signals (see Section 5.1.3).

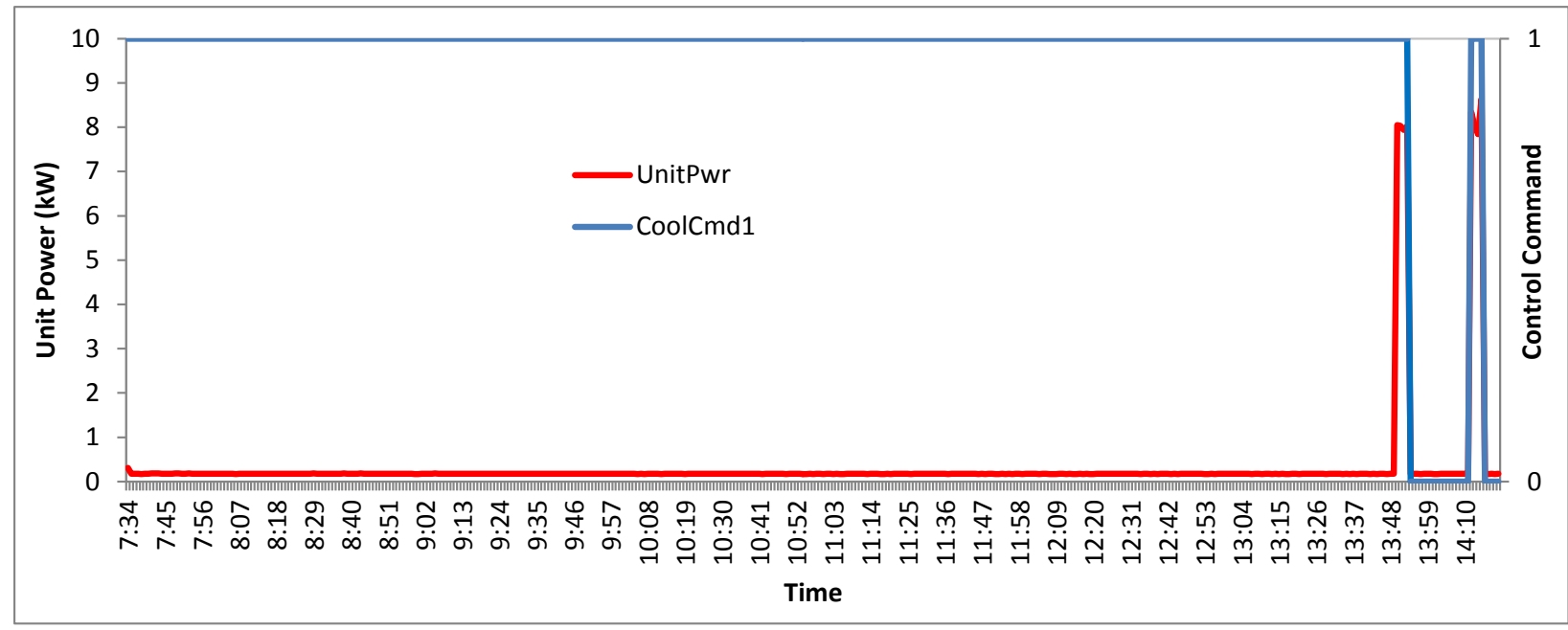

Figure 10: An example of a stuck cooling command for unit 223

- Heat pump units had heat spikes in cooling. For example, Figure 11 shows the mixed-air temperature (MaTemp), the discharge-air temperature (DaTemp), and the control signal for the $1^{\text {st }}$ stage cooling command (CoolCmd1) for unit 378 on August 31, 2012. There are a total of nine cooling cycles during the period from 8:00 to 13:30. Five cooling cycles had the heat spike problem, as indicated by the high discharge-air temperature. This issue was discussed with the controller manufacturer. It seems that the problem was at the start of cooling call, the compressor is turned on before the heat pump's reversing valve had opened. However, it was not clear why the problem happened for some cooling cycles but not others. 


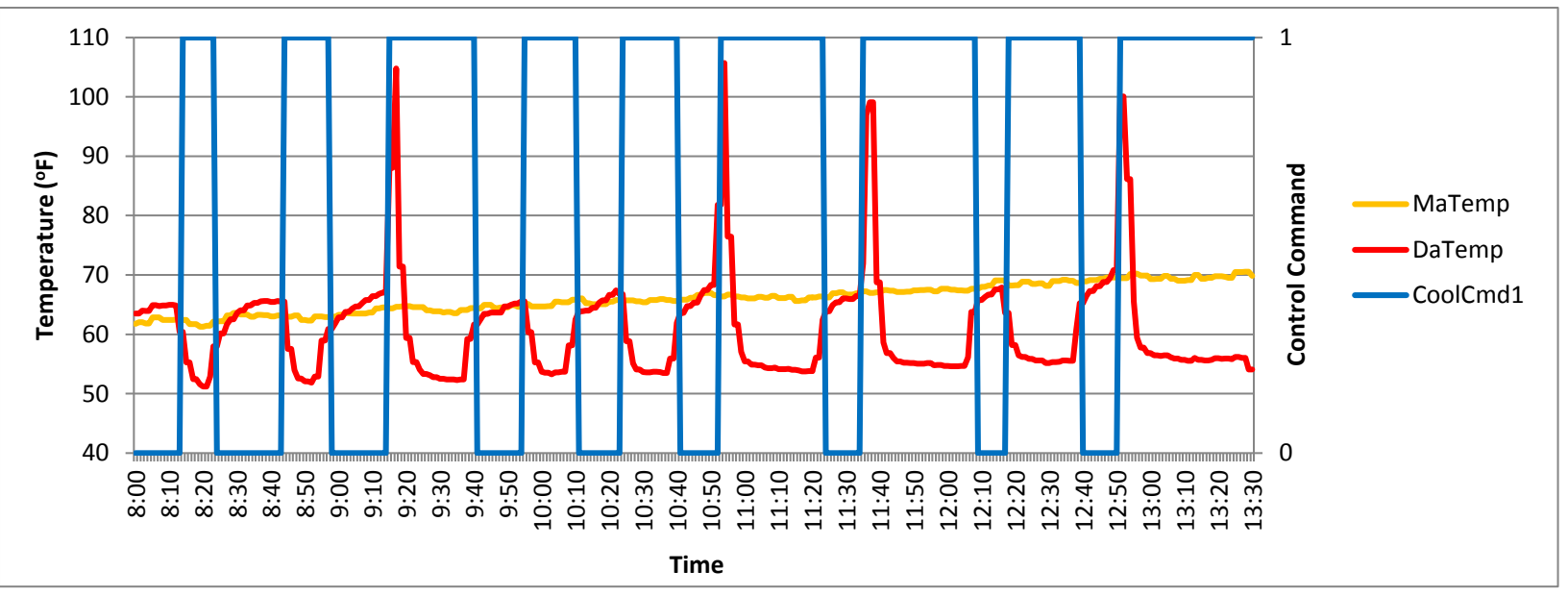

Figure 11: An example of heat spikes during cooling mode for heat pumps

\subsection{VALIDATION OF THE DEMAND-CONTROLLED VENTILATION (DCV) OPERATION}

With demand-controlled ventilation, the outdoor-air damper was modulated based on the measured $\mathrm{CO}_{2}$ concentration in the return-air stream. The advanced controller calculated the percentage of outdoor air (PercentOA) in the design supply-air stream as the product of supply-fan speed and outdoorair damper position. There is a setting for the minimum outdoor-air percentage (MinOA) and another setting for the maximum outdoor-air percentage (MaxOA) in response to $\mathrm{DCV}$. If the measured $\mathrm{CO}_{2}$ concentration in the return-air stream was less than the $\mathrm{CO}_{2}$ concentration set point ( $\left.<1000 \mathrm{ppm}\right)$, the outdoor-air damper was set to the MinOA position, unless air-side economizer was active. If the measured $\mathrm{CO}_{2}$ concentration is greater than the $\mathrm{CO}_{2}$ concentration set point (>1000 ppm), the advanced controller used a PID loop to control the damper opening in response to the measured $\mathrm{CO}_{2}$ concentration in the return-air stream. The product of the damper position and fan speed will never exceed MaxOA position.

DCV operation was validated using the same approach as that for the supply fan control. Database queries are used to generate statistics on the number of records for two situations: $\mathrm{CO}_{2}$ concentration was less than 1,000 ppm; and $\mathrm{CO}_{2}$ concentration was greater than $1,000 \mathrm{ppm}$. The rules for the above two situations are as follows:

Rule 9: If the measured $\mathrm{CO}_{2}$ concentration was less than $1,000 \mathrm{ppm}$ and the unit was not running in the economizer mode, PercentOA was MinOA ( $5 \%$ for all RTUs).

Rule 10: If the sensed $\mathrm{CO}_{2}$ concentration was greater than $1,000 \mathrm{ppm}$ and the unit was not running in the economizer mode, PercentOA lies in between MinOA (5\% for all RTUs) and MaxOA.

The statistics and investigation of rule-violating records were made for all RTUs. This process lead to the conclusion that the DCV control in the advanced controller worked correctly according to the control sequence. Figure 12 is an example showing the related control variables for DCV on November 23, 2012 for unit 203. Because this unit serves a shopping mall and that day was Thanksgiving holiday, the measured $\mathrm{CO}_{2}$ concentration was greater than $1,000 \mathrm{ppm}$ for most times. Unit 203 had MaxOA set at $30 \%$. Thus, when the measured $\mathrm{CO}_{2}$ concentration is continuously above $1000 \mathrm{ppm}$ from 8:00 to 18:30, PercentOA was at $30 \%$ (i.e., $\mathrm{MaxOA}$ ). When the measured $\mathrm{CO}_{2}$ concentration was continuously below 1,000 ppm from 20:30 to 21:50, PercentOA is at 5\% (i.e., MinOA). When the measured $\mathrm{CO}_{2}$ 
concentration fluctuated around 1,000 ppm (e.g., from 19:10 to 20:30), the damper opening and thereby PercentOA dynamically changed based on the response from the PID control loop.

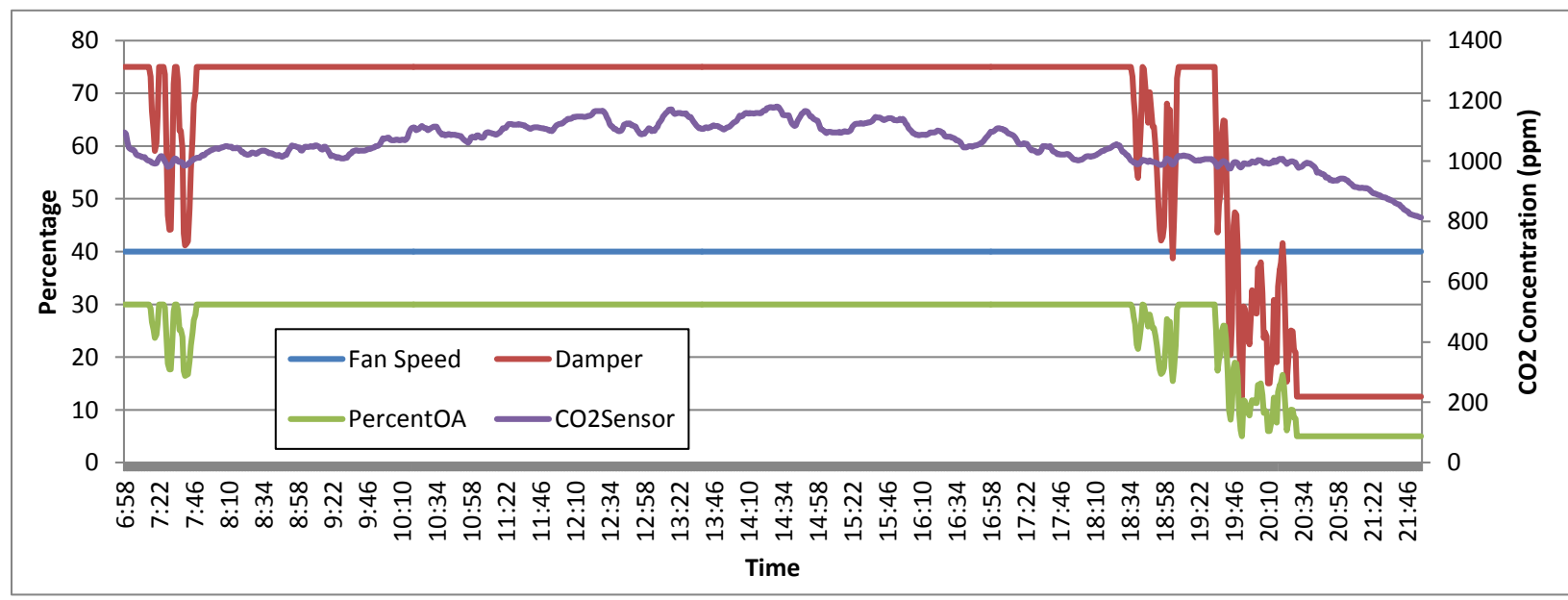

Figure 12: An example of DCV operation

\subsection{VALIDATION OF THE ECONOMIZER OPERATION}

When the space temperature was above the cooling set point, cooling is needed. The cooling needs could be met by outdoor air alone (economizing), combination of outdoor air and mechanical cooling (integrated economizing) or mechanical cooling. There were number of rules that governed the economizer controls. For example, if the RTU controls supported differential dry-bulb economizer control and if the return-air temperature was higher than the outdoor-air temperature and if there was a call for cooling, the outdoor-air damper must be open $100 \%$. The measured outdoor-, return-, mixedand discharge-air temperatures, and the outdoor-air damper and cooling signals were used together to validate the economizer operation. In addition to the outdoor-air damper signal, the outdoor-air fraction (OAF) was computed from the measured temperatures and compared to its expected OAF value.

\subsubsection{Validation of the Economizer Controls}

Economizer control was validated using the same approach as the supply-fan control and DCV. Database queries were used to generate statistics on the number of records for three situations: the outdoor-air damper does not fully open when it should; the outdoor-air damper was opening more than the minimum position; and economizing when there was no call for cooling. The rules for the above three situations were formulated as shown below:

Rule 11: If the advanced controller received a cooling call and the outdoor-air condition was favorable for economizing, the damper must be in a fully open position (or to maintain a fixed-air discharge-air temperature, typically $50^{\circ} \mathrm{F}$ ).

Rule 12: If the advanced controller received a cooling call and the outdoor condition was not favorable for economizing, the damper must be at the minimum position satisfying MinOA (see Section 6.2). 
Rule 13: If the advanced controller did not receive a cooling call, the damper must be at the minimum position satisfying MinOA (see Section 6.2).

The query results showed that a majority of RTUs had very low percentages of data records violating the above three rules on economizer control. If for any unit the rule was violated more than $10 \%$ of the time, efforts were made to investigate the causes. The investigation led to the following findings:

- The low-limit control of discharge-air temperature caused some units to have a large percentage of data records violating Rule 11. As explained in Section 2, when the discharge-air temperature dropped below the low limit of $48^{\circ} \mathrm{F}$, the damper was modulated to maintain a $50^{\circ} \mathrm{F}$ dischargeair temperature even if there was an economizing call.

- RTU 383 has $27 \%$ of the data records violating Rule 12 . Efforts were made to detect the cause of this large number of violations but were unsuccessful. All rule-violating records occurred between June 2012 and September 2012.

In addition to the three economizer rules, the units may had other economizer faults that could not be detected by simple rules. To identify those faults, a diagnostics tool (AirDx) was used. The findings from use of the tool are summarized in the next subsection.

\subsubsection{Validation of the Economizer Operations}

In addition to the correct execution of the sequence of operations, the physical components of economizers must function properly to achieve the maximum energy savings from the advanced controls. For this purpose, an air-side diagnostic software tool (Katipamula et al. 1999 and 2003) was used to validate the economizer's operation. Using measured temperatures and RTU operation schedules, AirDx identified certain faults that potentially reduce energy savings or cause ventilation problems. OAF is the fraction of actual outdoor-air volume relative to the RTU's total supply air volume. For all RTUs, the desired OAF was between $5 \%$ and $100 \%$, corresponding to the minimum and the maximum damper position, respectively. Thus, with the aid of AirDx, the relative effectiveness of the economizer was determined by comparing the desired OAF and the OAF calculated from the temperature measurements. Table 5 shows the percentage of data records with the calculated OAF in the ranges of 0 to $10 \%, 10 \%$ to $20 \%$, and greater than $20 \%$ by site (average across the site) when the advanced controller commanded the damper to the minimum position. This table indicates whether over-ventilation was a potential problem at a site. Some sites $(28,40$ and 41$)$ consistently had higher $\mathrm{OAF}$ than expected. This is not a control problem, but was most likely caused by damper leakage and non-linear relationship of damper position to the OAF.

Over-ventilation occurred when the outdoor-air damper opened wider when it was commanded to be at the minimum position or when OAF exceeded the expected minimum OAF even when the outdoor-air damper was at the minimum position. Table 5 shows that site 40 has more than $50 \%$ of data records with the calculated OAF greater than $20 \%$ while the actual expected OAF was $5 \%$. AirDx consistently reported the same economizer fault for all RTUs at this site. For example, Figure 13 shows the AirDx output for RTU 370 at Site 40 during July. The AirDx output is displayed by month with each column representing 1 day ascending from left to right within 1 month and each square representing 1 hour ascending from top to bottom within 1 day. The bar within a square indicates that the RTU compressor state changes, such as from off to on. In this figure, the red squares indicate the problem of over ventilation (or energy waste). 
Table 5: Distribution of calculated OAF by site when the damper was commanded to the minimum position

\begin{tabular}{|r|r|r|r|r|}
\hline \multirow{2}{*}{$\begin{array}{c}\text { Site } \\
\text { ID }\end{array}$} & \multirow{2}{*}{$\begin{array}{c}\text { Number } \\
\text { of RTUs }\end{array}$} & \multicolumn{3}{|c|}{ OAF Range } \\
\cline { 3 - 5 } & & $\mathbf{5 1 0 \%}$ & $\mathbf{1 0 \% - 2 0 \%}$ & $\mathbf{2 2 0} \%$ \\
\hline 28 & 27 & $37 \%$ & $37 \%$ & $\mathbf{2 6 \%}$ \\
\hline 39 & 2 & $96 \%$ & $\mathbf{2} \%$ & $\mathbf{2} \%$ \\
\hline 40 & 8 & $17 \%$ & $32 \%$ & $51 \%$ \\
\hline 41 & 1 & $68 \%$ & $12 \%$ & $21 \%$ \\
\hline 43 & 6 & $84 \%$ & $13 \%$ & $3 \%$ \\
\hline 44 & 11 & $95 \%$ & $2 \%$ & $3 \%$ \\
\hline 46 & 2 & $84 \%$ & $12 \%$ & $4 \%$ \\
\hline 51 & 5 & $100 \%$ & $0 \%$ & $0 \%$ \\
\hline
\end{tabular}

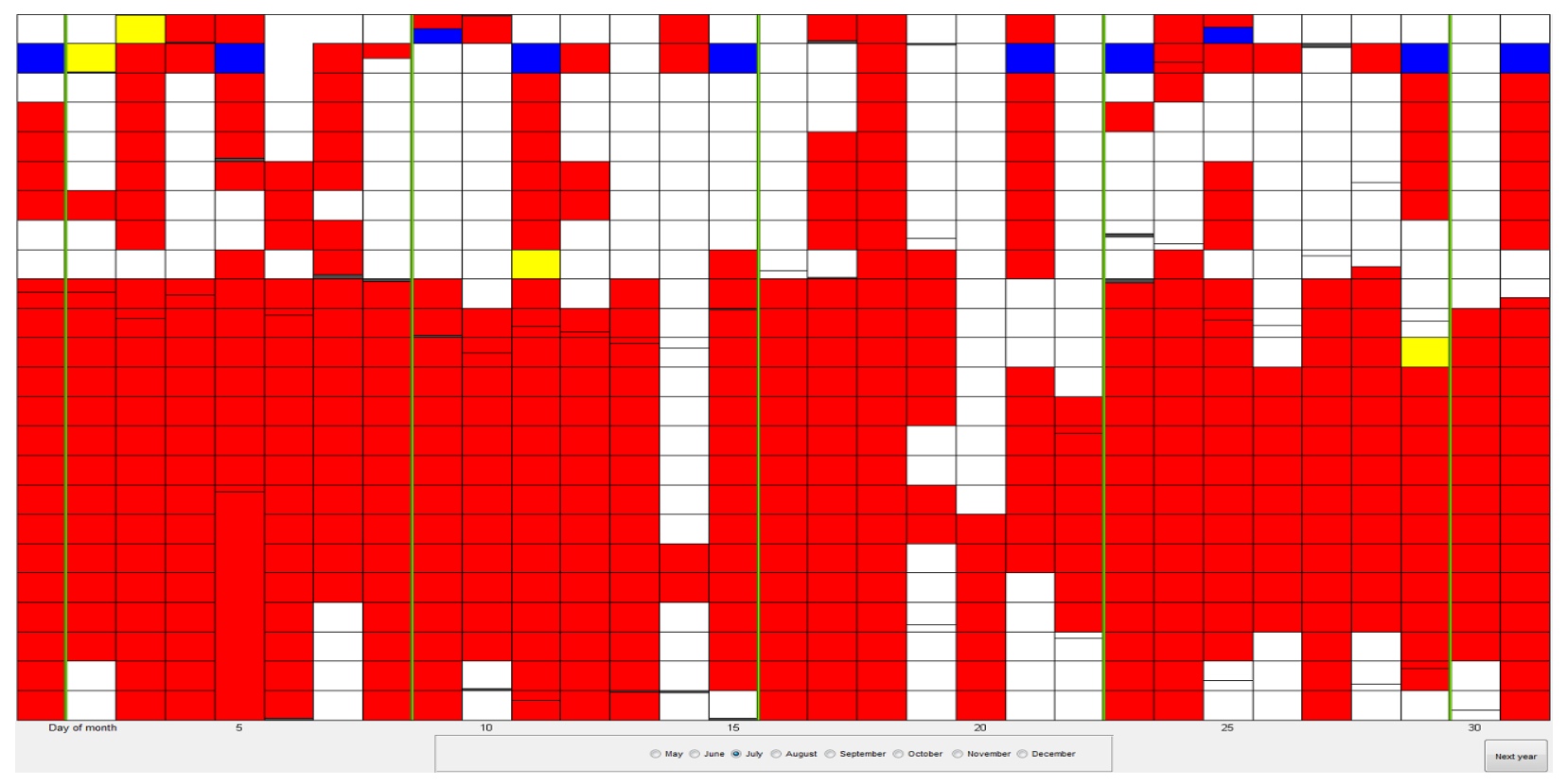

Figure 13: AirDx output for RTU 370 in July, 2012

Several RTUs at site 28 exhibited the same over-ventilation problems as RTU 370 . Because the OAF is calculated from the measured return-, outdoor-, and mixed-air temperatures, any inaccuracies or biases in temperature sensors made the calculated OAF unreliable. Small biases (less than $2^{\circ} \mathrm{F}$ ) are difficult to detect. Therefore, the reported over-ventilation may have been caused by either real damper problems (leakage) or temperature sensor faults. The AirDx tool identified that five RTUs at site 28 have faults associated with the mixed-air temperature sensor. However, the temperature sensors were checked before installation, so the problem may not be associated with sensing element but the location of the sensors. Accurate measurement of mixed-air temperature is difficult in RTUs because of stratification of air. Some units have more stratification than others, either because of the design or site construction (position of return-air ducts) or proximity of the sensor to cooling/heating coils. 
As Table 5 shows, RTUs at sites 39, 43, 44, 46, and 51 had the calculated OAFs less than $10 \%$ for a large portion of the operations when the damper was commanded to the minimum position. This indicated that the RTUs at these sites basically did not have the over-ventilation problem.

Table 6 shows the percentage of data records with the calculated OAF in the ranges of $85 \%$ to $100 \%$, $70 \%$ to $85 \%, 50 \%$ to $70 \%$, and less than $50 \%$ by site (average across site) when the advanced controller commanded the damper to the fully open position. This table indicates conditions when OAF was not $100 \%$ when the damper was fully open. Most sites with exception of 40 and 46, had issues bringing in $100 \%$ outdoor air even when the damper was fully open. Again, this was not a control problem, but was most likely caused by damper leakage, non-linear relationship of damper position to the OAF and inaccuracies or biases in temperature sensors.

Table 6: Distribution of calculated OAF by site when the damper was commanded to the fully open position

\begin{tabular}{|r|r|r|r|r|r|}
\hline \multirow{2}{*}{$\begin{array}{r}\text { Site } \\
\text { ID }\end{array}$} & \multirow{2}{*}{$\begin{array}{r}\text { Number } \\
\text { of RTUs }\end{array}$} & \multicolumn{4}{|c|}{ OAF Range } \\
\cline { 3 - 6 } & 27 & $\leq \mathbf{5 0 \%}$ & $\mathbf{5 0 \% - 7 0 \%}$ & $\mathbf{7 0 \% - 8 5 \%}$ & $\mathbf{2 8 5 \%}$ \\
\hline 28 & $10 \%$ & $29 \%$ & $21 \%$ & $40 \%$ \\
\hline 39 & 2 & $93 \%$ & $7 \%$ & $0 \%$ & $0 \%$ \\
\hline 40 & 8 & $0 \%$ & $0 \%$ & $2 \%$ & $98 \%$ \\
\hline 41 & 1 & $22 \%$ & $41 \%$ & $23 \%$ & $14 \%$ \\
\hline 43 & 6 & $6 \%$ & $7 \%$ & $66 \%$ & $22 \%$ \\
\hline 44 & 11 & $38 \%$ & $23 \%$ & $4 \%$ & $35 \%$ \\
\hline 46 & 2 & $5 \%$ & $3 \%$ & $8 \%$ & $84 \%$ \\
\hline 51 & 5 & $18 \%$ & $25 \%$ & $31 \%$ & $26 \%$ \\
\hline
\end{tabular}

Table 6 shows that the two RTUs at site 39 had the calculated OAF less than 50\% while the desired OAF was $100 \%$. This indicates that outdoor-air dampers on RTUs at this site were not functioning properly. For example, the fault is clearly illustrated in Figure 14 for RTU 363, where the mixed-and return-air temperatures (MAT and RAT in the figure) are plotted against the outdoor-air temperature for times when this condition occurs. This figure shows that the mixed-air temperature was very close to the return-air temperature, demonstrating that little outdoor air was being brought into the mixed-air chamber when economizing. 


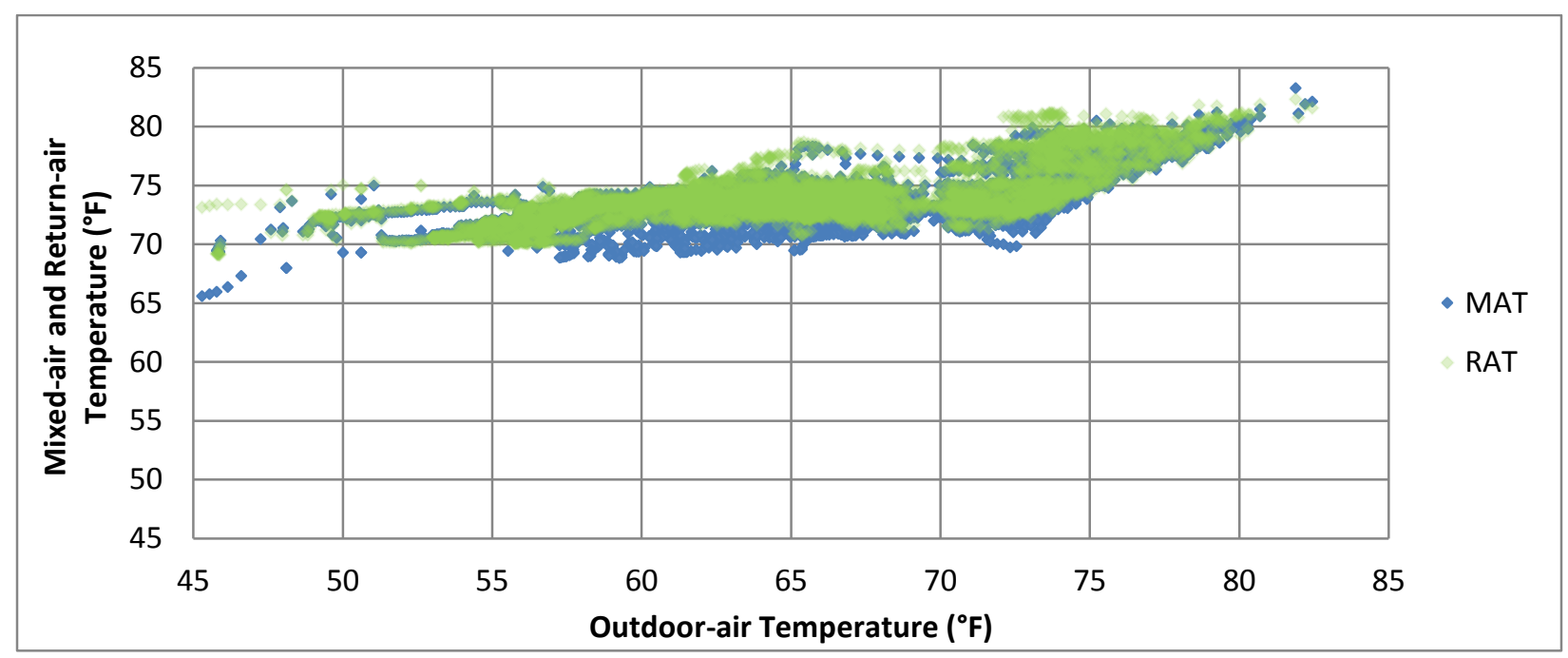

Figure 14: Mixed-and return-air temperatures versus outdoor-air temperature for RTU 363 when the damper was commanded to a fully open position

As Table 6 also shows, RTUs at site 41 and site 44 also had the problem of OAF being low when the damper was fully open for economizing. In contrast, RTUs at sites 40, 43 and 46 show OAF that was consistent with a fully open the outdoor-air damper.

The condition of OAF at less than $100 \%$ when the outdoor-air damper was fully open can be caused by several reasons including damper actuator faults, damper leakage, and sensor faults. For example, maintenance work was performed in September 2012 on RTU 381 (at site 44) to seal return-air leakage. Figure 15 plots the mixed-and return-air temperatures against the outdoor-air temperature for RTU 381. Only data records having damper commanded at $100 \%$ for economizing are plotted. The mixed-air temperatures are marked differently for those data records before and after sealing the damper. The figure shows that before sealing the damper, the mixed-air temperature was very close to the return-air temperature, leading to the calculated OAF that was much less than $100 \%$. However, after sealing the damper, the mixed-air temperature was very close to the outdoor-air temperature, leading to the calculated OAF approximating $100 \%$. 


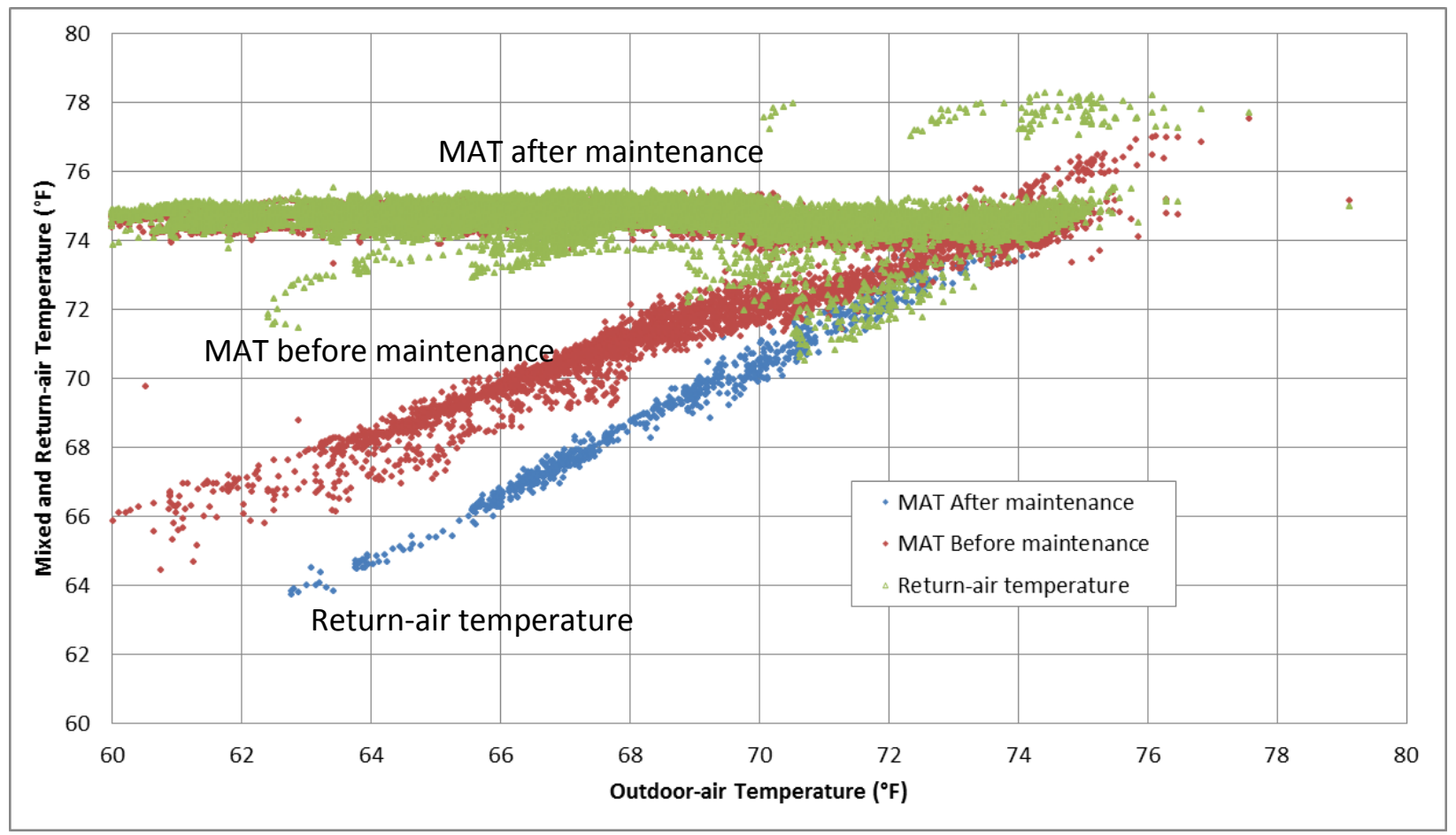

Figure 15: Mixed-and return-air temperatures versus outdoor-air temperature for RTU 381 when the damper was commanded to a fully open position 


\section{ENERgy SAVIngs RESUltS}

Based on the methodology presented in Section 5, actual energy savings and normalized energy savings were calculated for each RTU. The uncertainties associated with the energy savings were also estimated for each linear piece of the change-point regression model and the entire model. This section provides the results for each individual unit and the aggregated results for sites, RTU size ranges, and RTU types.

\subsection{SUMMARY OF REgRESSION MODEL DEVELOPMENT}

The regression models were developed for all RTUs using the methodology described in Section 5 . Using the regression models, the energy savings from the advanced RTU controller is estimated in two ways: actual savings and normalized savings (ASHRAE 2002). To obtain the actual savings, the preretrofit regression model was used with actual post-retrofit monitored data (i.e., average daily outdoorair temperature) to estimate the expected energy consumption during pre-retrofit period (standard controls). The number of days in each mode (pre- and post-retrofit) for each unit are listed in Table A-3 in Appendix A. The differences between the expected energy use and the measured actual energy use during the post-retrofit period represented the actual savings. To obtain the normalized savings, both pre- and post- retrofit models were used with the TMY weather data over a whole year to estimate both the consumption with standard controls and advanced controls. The differences between the estimated pre- and post-retrofit energy use from the two regression models represented the normalized annual savings. Refer to Section 5 for more details on the modeling details.

\subsection{RESUlTS BY UnIT}

Table 7 lists the percentage of actual energy savings and the actual savings uncertainty for all RTUs, which can be either heat pumps (HPs) or conventional air conditioners (ACs) with natural gas heat. The percentage of energy savings was calculated with the estimated pre-retrofit energy consumption as the base (see Equation 5-25). Reported energy savings included supply-fan energy (electricity), heating energy (electricity for HP units and gas for AC units), cooling energy (electricity) and total RTU electricity. Reported uncertainties were the overall fractional uncertainty for RTU electricity savings from both measurement error and modeling inaccuracy.

The following needs to be noted when looking at Table 7:

- Results for four units (RTU 216, 230, 390 and 391) are not reported in this section. RTUs 216 and 230 are not reported because they were usually offline throughout the test period. RTUs 390 and 391 are not reported because their uncertainty was higher than $100 \%$, which did not meet the performance requirement by ASHRAE (2002).

- Several units (e.g., RTU 215, 225) did not have cooling savings reported (listed as "NA", not available) because they rarely ran in the mechanical cooling mode and as a result, the cooling regression model was not generated by the ECAM tool.

- The percentage of actual RTU electricity savings was in the range between $22 \%$ and $91 \%$, with an average of $56 \%$. The fractional uncertainty for actual RTU electricity savings ranged between $2 \%$ and $77 \%$, with an average of $22 \%$. To meet the performance path in compliance with ASHRAE Guideline 14 (2002), the maximum acceptable level of uncertainty was $50 \%$ of annual 
savings at $68 \%$ confidence. Because the savings uncertainty presented in this work used $95 \%$ confidence, that maximum acceptable uncertainty was adjusted to $100 \%$ after considering the difference of $t$-statics corresponding to the two confidence levels. It can be seen from Table 7 that all units had their savings uncertainty much less than the maximum level of uncertainty to meet ASHRAE Guideline 14 requirement.

- The percentage of actual fan energy savings was in the range between $26 \%$ and $94 \%$, with an average of $75 \%$.

- Many RTUs had negative heating and cooling energy savings, although the advanced controller was not expected to increase heating energy and cooling energy. The problem of negative heating and cooling energy savings was most likely caused by any of the following three reasons. First, the magnitude of heating and cooling savings was small. In extremely hot or cold climates, use of DCV will produce heating and cooling savings and integrated economizer also produced additional cooling savings, albeit small. Since most of the demonstration sites were not in extreme climates, the heating and cooling savings were modest. Second, heating energy was not measured for AC units with natural gas heating. Instead, the nominal furnace capacity was used together with the control signals to calculate heating energy consumption. Thus, any misinterpretations of the control signals (i.e., static data and mode transition period) decreased the reliability of the source data for regression model development. Third, for some units, the number of data points for RTU heating or cooling was not sufficient to develop robust regression models, causing high uncertainty associated with the heating or cooling energy savings.

Table 7: Percentage of actual savings and uncertainty by units

\begin{tabular}{|c|c|c|c|c|c|c|}
\hline \multirow[b]{2}{*}{$\begin{array}{l}\text { RTU } \\
\text { ID }\end{array}$} & \multirow{2}{*}{$\begin{array}{l}\text { RTU } \\
\text { Type }\end{array}$} & \multicolumn{4}{|c|}{ Energy Savings (\%) } & \multirow{2}{*}{$\begin{array}{c}\text { Overall Total } \\
\text { Uncertainty (\%) }\end{array}$} \\
\hline & & Fan & Heating & Cooling & $\begin{array}{l}\text { Total RTU } \\
\text { Electricity }\end{array}$ & \\
\hline 202 & $A C$ & 92 & 31 & NA & 90 & 2 \\
\hline 203 & $A C$ & 89 & -37 & -11 & 76 & 10 \\
\hline 204 & $A C$ & 92 & -5 & -132 & 89 & 3 \\
\hline 205 & $A C$ & 90 & 56 & 4 & 76 & 3 \\
\hline 206 & $A C$ & 94 & -47 & NA & 91 & 4 \\
\hline 207 & $A C$ & 78 & -167 & 36 & 65 & 14 \\
\hline 209 & $A C$ & 45 & 1 & 46 & 45 & 36 \\
\hline 210 & $A C$ & 79 & 86 & -7 & 45 & 27 \\
\hline 212 & $A C$ & 60 & -7 & 74 & 67 & 12 \\
\hline 213 & $A C$ & 91 & -29 & 40 & 84 & 3 \\
\hline 214 & $A C$ & 79 & 31 & 45 & 57 & 23 \\
\hline 215 & $A C$ & 89 & 50 & NA & 87 & 2 \\
\hline 217 & $A C$ & 82 & -3 & 69 & 78 & 4 \\
\hline 218 & $A C$ & 68 & 59 & 16 & 39 & 38 \\
\hline 219 & $A C$ & 61 & -4 & -240 & 22 & 72 \\
\hline 220 & $A C$ & 73 & -1 & 59 & 66 & 20 \\
\hline 221 & $A C$ & 90 & -43 & -90 & 83 & 3 \\
\hline 222 & $A C$ & 91 & -50 & 69 & 80 & 7 \\
\hline 223 & $A C$ & 80 & -9 & 28 & 49 & 28 \\
\hline 224 & $A C$ & 80 & -63 & 57 & 65 & 19 \\
\hline 225 & $A C$ & 90 & 8 & NA & 89 & 3 \\
\hline
\end{tabular}




\begin{tabular}{|c|c|c|c|c|c|c|}
\hline \multirow{2}{*}{$\begin{array}{l}\text { RTU } \\
\text { ID }\end{array}$} & \multirow{2}{*}{$\begin{array}{l}\text { RTU } \\
\text { Type }\end{array}$} & \multicolumn{4}{|c|}{ Energy Savings (\%) } & \multirow{2}{*}{$\begin{array}{l}\text { Overall Total } \\
\text { Uncertainty (\%) }\end{array}$} \\
\hline & & Fan & Heating & Cooling & $\begin{array}{l}\text { Total RTU } \\
\text { Electricity }\end{array}$ & \\
\hline 226 & $A C$ & 70 & 58 & 34 & 54 & 20 \\
\hline 227 & $A C$ & 87 & 22 & NA & 87 & 5 \\
\hline 228 & $A C$ & 57 & 5 & 23 & 38 & 37 \\
\hline 229 & AC & 91 & 25 & NA & 88 & 2 \\
\hline 231 & $A C$ & 72 & 53 & 27 & 58 & 16 \\
\hline 362 & $A C$ & 40 & 55 & 19 & 26 & 51 \\
\hline 363 & $\mathrm{AC}$ & 84 & 2 & 29 & 71 & 6 \\
\hline 364 & $A C$ & 66 & -41 & 6 & 42 & 16 \\
\hline 365 & $A C$ & 73 & -20 & 0 & 50 & 18 \\
\hline 366 & $A C$ & 73 & -32 & -146 & 35 & 34 \\
\hline 367 & $A C$ & 26 & -2 & -1935 & 34 & 24 \\
\hline 368 & $A C$ & 55 & -5 & -18 & 36 & 28 \\
\hline 369 & $A C$ & 76 & -14 & -47 & 60 & 10 \\
\hline 370 & $\mathrm{AC}$ & 79 & -2 & -16 & 61 & 10 \\
\hline 371 & $A C$ & 71 & -51 & 9 & 50 & 13 \\
\hline 372 & $\mathrm{HP}$ & 77 & 36 & 50 & 64 & 14 \\
\hline 375 & $\mathrm{HP}$ & 77 & 28 & 25 & 48 & 20 \\
\hline 376 & $\mathrm{HP}$ & 78 & -18 & 36 & 26 & 77 \\
\hline 377 & $\mathrm{HP}$ & 75 & 15 & 49 & 49 & 17 \\
\hline 378 & $\mathrm{HP}$ & 57 & -7 & -163 & 50 & 14 \\
\hline 379 & $\mathrm{HP}$ & 73 & 17 & 30 & 44 & 23 \\
\hline 380 & $\mathrm{HP}$ & 76 & 3 & 37 & 32 & 54 \\
\hline 381 & $\mathrm{HP}$ & 69 & 10 & 24 & 29 & 75 \\
\hline 382 & $\mathrm{HP}$ & 80 & 32 & -8 & 47 & 28 \\
\hline 383 & $\mathrm{HP}$ & 74 & -3 & 35 & 32 & 52 \\
\hline 384 & $\mathrm{HP}$ & 80 & 19 & 15 & 55 & 24 \\
\hline 385 & $\mathrm{HP}$ & 76 & 25 & -28 & 42 & 36 \\
\hline 386 & $\mathrm{HP}$ & 82 & 15 & -6 & 44 & 22 \\
\hline 387 & $\mathrm{HP}$ & 74 & 5 & 25 & 37 & 32 \\
\hline 388 & $\mathrm{HP}$ & 86 & 2 & -28 & 34 & 64 \\
\hline 389 & $\mathrm{HP}$ & 65 & 28 & 16 & 36 & 28 \\
\hline 407 & $A C$ & 42 & 47 & 27 & 30 & 30 \\
\hline 408 & $A C$ & 66 & 3 & 5 & 28 & 55 \\
\hline 409 & $A C$ & 83 & 20 & -20 & 40 & 31 \\
\hline 410 & $A C$ & 55 & 23 & -10 & 46 & 16 \\
\hline 411 & $A C$ & 44 & 1 & 23 & 35 & 34 \\
\hline 423 & $A C$ & 90 & 44 & 87 & 84 & 2 \\
\hline 424 & $A C$ & 75 & -101 & 41 & 59 & 11 \\
\hline 425 & $A C$ & 83 & -61 & -20 & 71 & 5 \\
\hline 426 & $A C$ & 84 & 69 & 12 & 66 & 7 \\
\hline 427 & $A C$ & 87 & 68 & 61 & 82 & 3 \\
\hline
\end{tabular}

With the measured energy savings and the estimate of the total savings uncertainty, the expected range for percent energy savings at a certain confidence level (i.e., $95 \%$ used in this work) was estimated for 
each RTU. RTU 212 is used as an example to illustrate the approach of deriving the savings range from uncertainty. From Table 7, RTU 212 had $67 \%$ of measured electricity savings with $12 \%$ uncertainty at $95 \%$ confidence. The expected range of electricity savings for this RTU was calculated as $67 \% \pm$ $(67 \% * 12 \%)=67 \% \pm 8 \%$. This means that RTU 212 has no less than $59 \%$ electricity savings at $95 \%$ confidence level. The expected savings ranges were calculated for all RTUs and they are shown in Figure 16. This figure shows the following general trend: the higher the percentage of electricity savings, the smaller the uncertainty and thereby the shorter the error bar. Units with a higher percentage of savings usually have most of their time running only the fan (either ventilation mode or economizing mode) when they were on. Because there was little variation in fan energy versus outdoor-air temperature, the modeling uncertainty was low for those units.



Figure 16: Percentage of actual energy savings and uncertainty range at 95\% confidence for each RTU

Table 8 shows the percentage of normalized annual energy savings and the normalized savings uncertainty for all RTUs. Some findings specific to normalized savings are listed as follows:

- RTU 227 was not reported in Table 8 because it had savings uncertainty more than $100 \%$. Its high normalized savings uncertainty came from the post-retrofit regression model because RTU 227 had much lower actual savings uncertainty (i.e., 5\%). 
- Most units had the normalized savings uncertainty lower than the actual savings uncertainty. This is because the post-retrofit period had more data points (i.e., $m$ in Equation 5-27) when calculating the normalized savings uncertainty.

- The percentage of normalized annual RTU electricity savings was in the range between $22 \%$ and $90 \%$, with an average of $57 \%$. The fractional uncertainty for normalized RTU electricity savings ranges between $1 \%$ and $51 \%$, with an average of $12 \%$.

- A few units (e.g., RTU 367 and 372) had unreasonable results for either fan or cooling energy savings. Possible causes include the following. First, the baseline cooling energy was small so dividing a small number may cause high percentage values. Second, as Equation 5-22 shows, the normalized fan energy was calculated from the regression models for total RTU electricity, heating and cooling. Thus, if the change points for the total RTU electricity model and the heating or cooling model were different, the predicted fan energy may not be reliable. Because the focus of this work was on total RTU electricity savings, these RTUs were not excluded from our analysis even though they have unreasonable percentage of fan or cooling savings.

Table 8: Percentage of normalized savings and uncertainty by units

\begin{tabular}{|c|c|c|c|c|c|c|}
\hline \multirow{2}{*}{$\begin{array}{l}\text { RTU } \\
\text { ID }\end{array}$} & \multirow{2}{*}{$\begin{array}{l}\text { RTU } \\
\text { Type }\end{array}$} & \multicolumn{4}{|c|}{ Energy Savings (\%) } & \multirow{2}{*}{$\begin{array}{c}\text { Overall Total } \\
\text { Uncertainty } \\
(\%)\end{array}$} \\
\hline & & Fan & Heating & Cooling & $\begin{array}{l}\text { Total RTU } \\
\text { Electricity }\end{array}$ & \\
\hline 202 & $A C$ & 86 & 19 & NA & 86 & 1 \\
\hline 203 & $A C$ & 87 & -56 & -19 & 81 & 8 \\
\hline 204 & $A C$ & 90 & 20 & -239 & 90 & 2 \\
\hline 205 & $A C$ & 83 & 49 & -55 & 79 & 2 \\
\hline 206 & $A C$ & 90 & -43 & NA & 90 & 3 \\
\hline 207 & $A C$ & 80 & -304 & 33 & 65 & 4 \\
\hline 209 & $A C$ & 43 & 1 & 46 & 45 & 15 \\
\hline 210 & $A C$ & 87 & 84 & -26 & 69 & 6 \\
\hline 212 & $A C$ & 68 & -17 & 74 & 70 & 9 \\
\hline 213 & $A C$ & 90 & 22 & 37 & 88 & 2 \\
\hline 214 & $A C$ & 78 & 38 & 50 & 63 & 5 \\
\hline 215 & $A C$ & 67 & 28 & NA & 67 & 11 \\
\hline 217 & $A C$ & 61 & -1 & 55 & 61 & 9 \\
\hline 218 & $A C$ & 72 & 43 & 15 & 46 & 8 \\
\hline 219 & $A C$ & 69 & -50 & -247 & 30 & 42 \\
\hline 220 & $A C$ & 73 & -8 & 62 & 68 & 11 \\
\hline 221 & $A C$ & 87 & -44 & -290 & 85 & 2 \\
\hline 222 & $A C$ & 83 & -94 & 74 & 83 & 4 \\
\hline 223 & $A C$ & 80 & 9 & 44 & 68 & 6 \\
\hline 224 & $A C$ & 80 & -201 & 59 & 71 & 7 \\
\hline 225 & $A C$ & 90 & 7 & NA & 90 & 1 \\
\hline 226 & $A C$ & 74 & 38 & 35 & 59 & 4 \\
\hline 228 & $A C$ & 56 & 3 & 23 & 38 & 12 \\
\hline 229 & $A C$ & 81 & 30 & NA & 81 & 2 \\
\hline 231 & $A C$ & 70 & 49 & 27 & 61 & 6 \\
\hline 362 & $A C$ & 41 & 55 & 23 & 31 & 25 \\
\hline 363 & $A C$ & 85 & 4 & 35 & 79 & 4 \\
\hline
\end{tabular}




\begin{tabular}{|c|c|c|c|c|c|c|}
\hline \multirow{2}{*}{$\begin{array}{l}\text { RTU } \\
\text { ID }\end{array}$} & \multirow{2}{*}{$\begin{array}{l}\text { RTU } \\
\text { Type }\end{array}$} & \multicolumn{4}{|c|}{ Energy Savings (\%) } & \multirow{2}{*}{$\begin{array}{l}\text { Overall Total } \\
\text { Uncertainty } \\
\text { (\%) }\end{array}$} \\
\hline & & Fan & Heating & Cooling & $\begin{array}{l}\text { Total RTU } \\
\text { Electricity }\end{array}$ & \\
\hline 364 & $A C$ & 72 & -54 & 7 & 50 & 6 \\
\hline 365 & $A C$ & 76 & -11 & -2 & 59 & 7 \\
\hline 366 & $A C$ & 76 & -4 & -434 & 57 & 10 \\
\hline 367 & $A C$ & 52 & -1 & -1971 & 34 & 22 \\
\hline 368 & $A C$ & 61 & -3 & -23 & 41 & 13 \\
\hline 369 & $A C$ & 80 & -5 & -65 & 65 & 4 \\
\hline 370 & $A C$ & 82 & -10 & -22 & 66 & 4 \\
\hline 371 & $A C$ & 76 & -51 & 8 & 54 & 6 \\
\hline 372 & $\mathrm{HP}$ & 888 & 72 & 30 & 43 & 18 \\
\hline 375 & $\mathrm{HP}$ & 70 & 27 & 31 & 45 & 13 \\
\hline 376 & HP & 69 & -11 & 33 & 22 & 46 \\
\hline 377 & $\mathrm{HP}$ & 68 & 18 & 36 & 43 & 15 \\
\hline 378 & HP & 66 & -20 & -188 & 43 & 12 \\
\hline 379 & $\mathrm{HP}$ & 64 & 18 & 27 & 41 & 20 \\
\hline 380 & $\mathrm{HP}$ & 72 & 4 & 32 & 30 & 33 \\
\hline 381 & HP & 68 & 10 & 23 & 27 & 43 \\
\hline 382 & $\mathrm{HP}$ & 74 & 32 & -8 & 44 & 13 \\
\hline 383 & HP & 64 & 4 & 32 & 28 & 26 \\
\hline 384 & HP & 79 & 14 & 13 & 49 & 23 \\
\hline 385 & $\mathrm{HP}$ & 70 & 28 & -33 & 41 & 25 \\
\hline 386 & HP & 76 & 16 & -5 & 43 & 22 \\
\hline 387 & $\mathrm{HP}$ & 67 & 5 & 25 & 38 & 19 \\
\hline 388 & $\mathrm{HP}$ & 78 & 2 & -27 & 32 & 51 \\
\hline 389 & $\mathrm{HP}$ & 64 & 30 & 20 & 37 & 18 \\
\hline 407 & $A C$ & 41 & 39 & 48 & 45 & 6 \\
\hline 408 & $A C$ & 74 & 5 & -2 & 50 & 10 \\
\hline 409 & $A C$ & 69 & 17 & 30 & 62 & 10 \\
\hline 410 & $A C$ & 70 & 21 & -171 & 64 & 6 \\
\hline 411 & $A C$ & 42 & 1 & 18 & 33 & 28 \\
\hline 423 & $A C$ & 80 & 48 & 70 & 80 & 1 \\
\hline 424 & $A C$ & 69 & -165 & 44 & 61 & 4 \\
\hline 425 & $A C$ & 81 & -66 & -28 & 74 & 3 \\
\hline 426 & $A C$ & 79 & 71 & 15 & 70 & 3 \\
\hline 427 & $A C$ & 84 & 56 & 60 & 83 & 2 \\
\hline
\end{tabular}

Figure 17 shows the expected savings range for normalized annual savings. Across all RTUs, the minimum normalized electricity savings at $95 \%$ confidence was between $12 \%$ and $89 \%$. In comparison with actual savings (Figure 16), the error bars were much shorter for most units because of the smaller normalized savings uncertainty. 


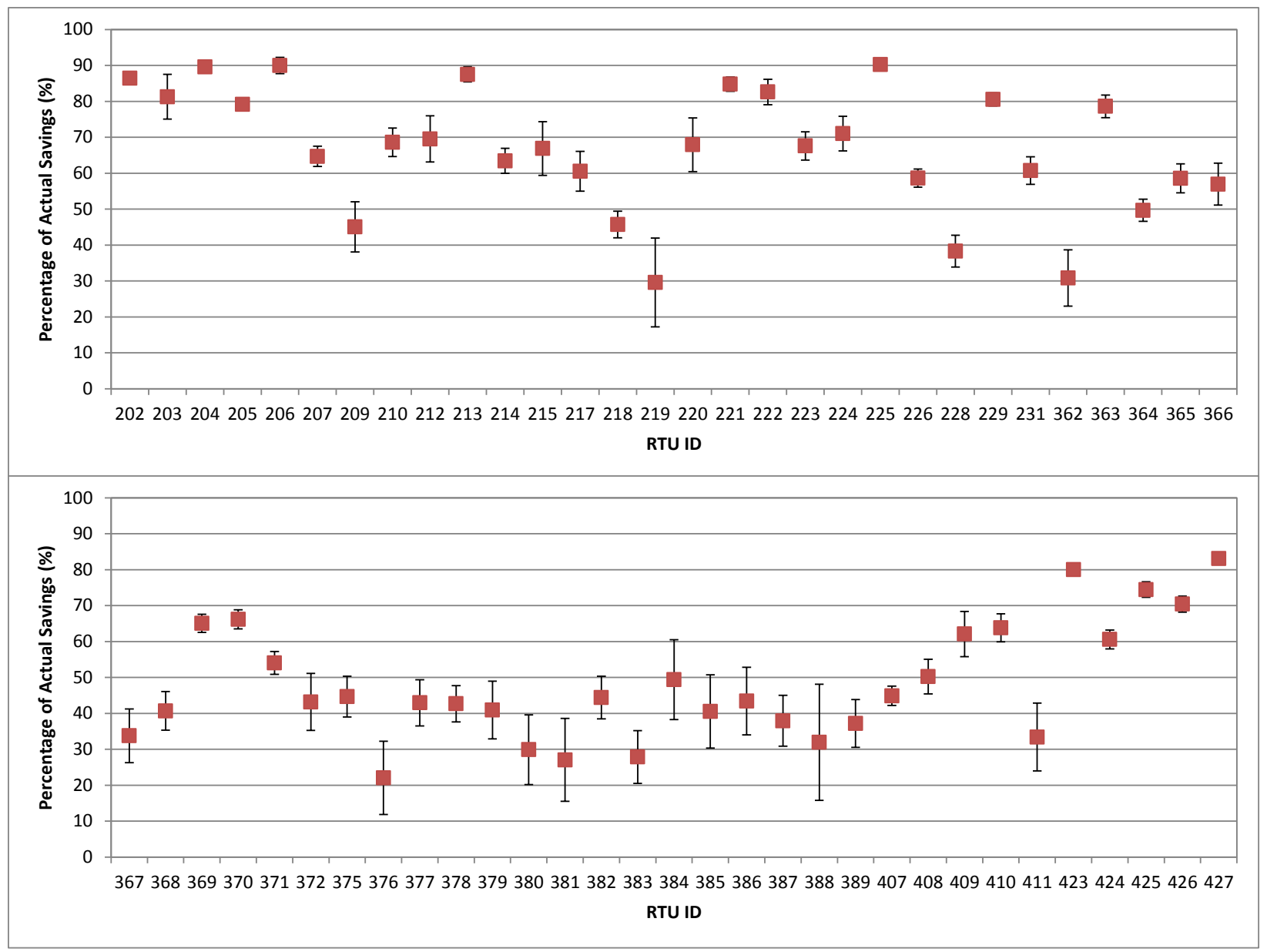

Figure 17: Percent of normalized annual energy savings and uncertainty range at 95\% confidence for each RTU

Figure 18 shows the frequency distribution of actual and normalized RTU electricity savings. The majority were in the range between $25 \%$ and $90 \%$. Because the electricity savings mostly came from fan energy reduction, the units with lower savings usually had longer compressor runtimes while the units with higher savings had shorter compressor runtimes.

Based on the previous discussion on savings uncertainty, three units (RTUs 227, 390, and 391) had either actual savings uncertainty or normalized savings uncertainty larger than $100 \%$. These three units were excluded in the following discussions. 


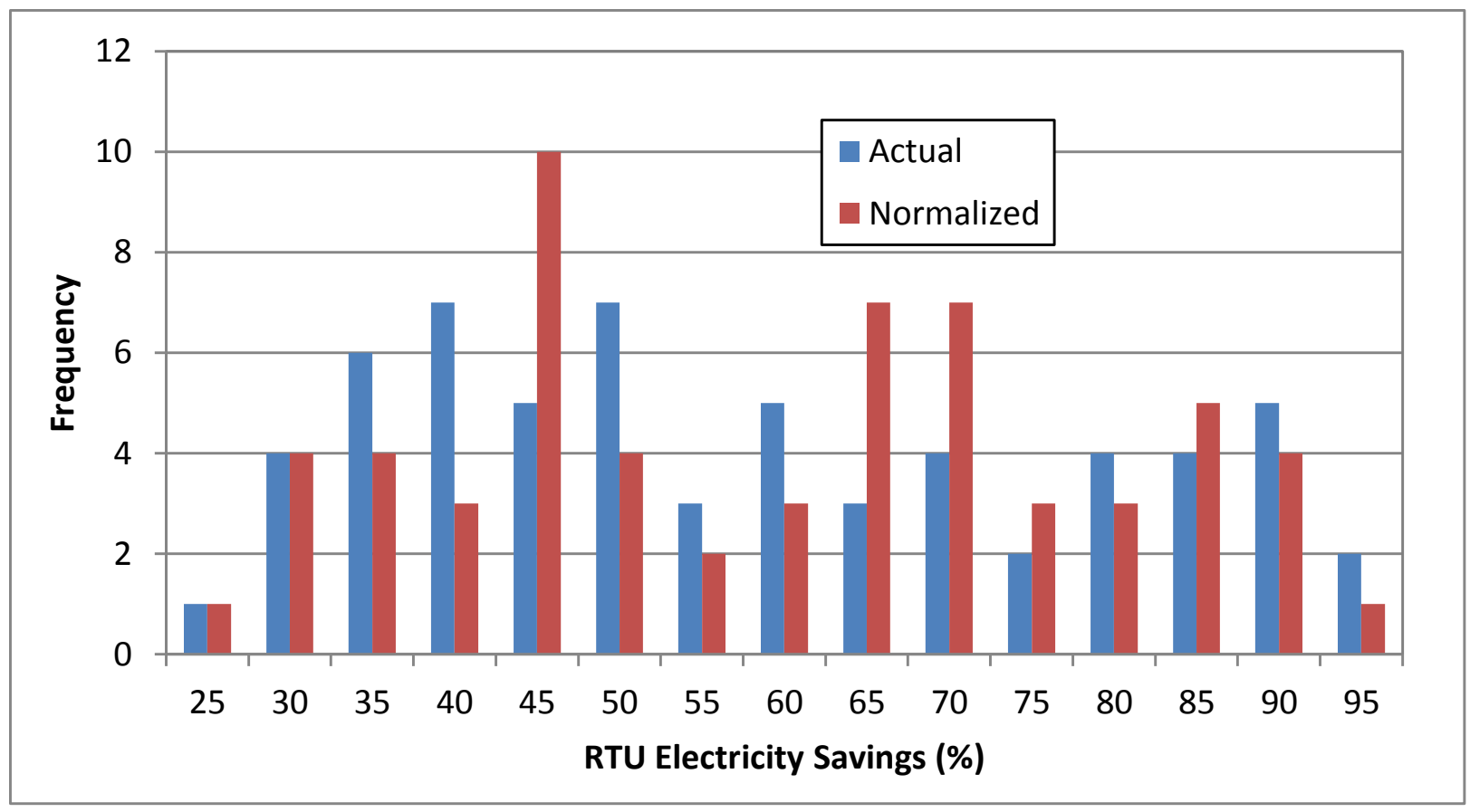

Figure 18: Frequency distribution of actual and normalized RTU electricity savings

In addition to the percentage of RTU electricity savings, review of the absolute savings would be also useful to understand the impact of the advanced controller. The variables that had significant effect on the savings included: building type (static pressure and occupancy variations), climate location, unit runtime (total runtime and compressor runtime versus supply fan runtime) and the unit size (supply-fan motor).

Table 9 provides actual supply-fan energy savings, actual RTU electricity savings, and actual electricity savings per hour for all units. The following needs to be noted for this table:

- The post-retrofit runtime was the total hours for those days used for regression model development. As a result of data filtering (as discussed in Section 5.1), the RTU runtime was not simply calculated by multiplying the number of post-retrofit days and the scheduled RTU operation hours per day.

- Units at the same site had different post-retrofit run hours because of 1) different operating schedules; 2) equipment failure occurring for some units but not others; and 3) exclusion of different number of data records during filtering process.

- As expected, fan energy savings made a dominant contribution to the total RTU electricity savings. Many units even had fan energy savings larger than the total electricity savings. This happened because fan energy savings and RTU electricity savings were calculated independently and as reported earlier, there were negative cooling energy savings for some units. Fan energy savings were estimated based on the fan power law and the logged supply-fan speeds. RTU electricity savings were estimated from the regression models. The uncertainties associated with the fan power law exponent and the regression models may cause the problem of supplyfan energy savings being larger than total RTU electricity savings. However, this was not regarded as a serious problem because total RTU electricity savings are our major interest. 
- Actual RTU electricity savings ranged between 0.35 and $7.68 \mathrm{kWh} / \mathrm{h}$ ( $\mathrm{kWh}$ per unit/fan run hour), with an average of $2.41 \mathrm{kWh} / \mathrm{h}$, while the fan only electricity savings ranged between $0.32 \mathrm{kWh} / \mathrm{h}$ to $6.64 \mathrm{kWh} / \mathrm{h}$ with an average of $1.95 \mathrm{kWh} / \mathrm{h}$.

- Actual RTU electricity savings ranged between 197 and 1,300 kWh/h/hp (kWh per unit run hour and per unit fan hp) with an average of $709 \mathrm{Wh} / \mathrm{h} / \mathrm{hp}$, while the fan only electricity savings ranged between $194 \mathrm{Wh} / \mathrm{h} / \mathrm{hp}$ and $702 \mathrm{Wh} / \mathrm{h} / \mathrm{hp}$ with an average of $556 \mathrm{Wh} / \mathrm{h} / \mathrm{hp}$.

- Actual RTU electricity savings was in the ranged between 23 and $339 \mathrm{kWh} / \mathrm{h} /$ ton ( $\mathrm{kWh}$ per unit run hour and per ton) with an average of $163 \mathrm{Wh} / \mathrm{h} / \mathrm{ton}$.

- Although there was significant variation of the electricity savings per hour, it generally increases with the size of the unit (Figure 19). Figure 19 also shows the runtime normalized electricity savings by RTU type (AC versus HP). The variations at any given size were likely caused by particular building and unit characteristics such as building type, climate conditions, and the supply-fan static pressure. The trend was consistent with both ACs and HPs.

- Figure 20 shows the variation of actual RTU electricity savings per unit run hour as a function of RTU size. In this figure, the units with similar size at each site are averaged. The number next to the marker shows the site ID and the character shows the RTU manufacturer ( $C=C$ arrier, $\mathrm{L}=\mathrm{Lennox}$ and $\mathrm{T}=\mathrm{Trane}$ ). Although there does not appear to be any strong relationship with make of the unit, most of the Trane units were below the linear trend line, most of the Carrier units were above the line and the Lennox units were closer to the line. 
Table 9: Absolute actual savings for all units

\begin{tabular}{|c|c|c|c|c|c|c|c|c|c|c|c|}
\hline $\begin{array}{l}\text { RTU } \\
\text { ID }\end{array}$ & $\begin{array}{l}\text { RTU } \\
\text { Type }\end{array}$ & $\begin{array}{l}\text { RTU } \\
\text { Size } \\
\text { (ton) }\end{array}$ & $\begin{array}{l}\text { RTU } \\
\text { Fan } \\
\text { Power } \\
\text { (hp) }\end{array}$ & $\begin{array}{l}\text { Post- } \\
\text { Retrofit } \\
\text { Runtime } \\
\text { (hr) }\end{array}$ & $\begin{array}{l}\text { Fan } \\
\text { Energy } \\
\text { Savings } \\
\text { (kWh) }\end{array}$ & $\begin{array}{l}\text { Fan } \\
\text { Energy } \\
\text { Savings } \\
\text { per } \\
\text { Hour } \\
\text { (kWh/h) }\end{array}$ & $\begin{array}{l}\text { Fan Energy } \\
\text { Savings per } \\
\text { Hour and } \\
\text { per hp } \\
(\mathrm{Wh} / \mathrm{h} / \mathrm{hp})\end{array}$ & $\begin{array}{l}\text { Total } \\
\text { RTU } \\
\text { Electrici } \\
\text { ty } \\
\text { Savings } \\
\text { (kWh) }\end{array}$ & $\begin{array}{l}\text { RTU } \\
\text { Electricity } \\
\text { Savings } \\
\text { per Hour } \\
\text { (kWh/h) }\end{array}$ & 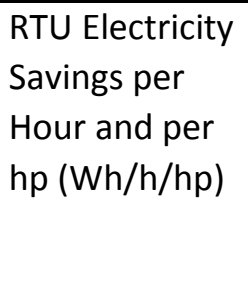 & $\begin{array}{l}\text { RTU } \\
\text { Electricity } \\
\text { Savings per } \\
\text { Hour and per } \\
\text { ton } \\
\text { (Wh/h/ton) }\end{array}$ \\
\hline 202 & $A C$ & 10 & 3.7 & 3204 & 8192 & 2.56 & 693 & 8259 & 2.58 & 699 & 258 \\
\hline 203 & $A C$ & 10 & 2.3 & 2777 & 4214 & 1.52 & 665 & 3562 & 1.28 & 562 & 128 \\
\hline 204 & $A C$ & 10 & 3.1 & 4075 & 8573 & 2.10 & 689 & 7782 & 1.91 & 625 & 191 \\
\hline 205 & $A C$ & 15 & 2.4 & 3631 & 5805 & 1.60 & 679 & 5777 & 1.59 & 675 & 106 \\
\hline 206 & $A C$ & 10 & 2.8 & 2588 & 5139 & 1.99 & 702 & 4951 & 1.91 & 676 & 191 \\
\hline 207 & $A C$ & 25 & 8.9 & 1170 & 6099 & 5.21 & 588 & 8059 & 6.89 & 777 & 276 \\
\hline 209 & $A C$ & 5 & 0.9 & 3377 & 1067 & 0.32 & 338 & 3443 & 1.02 & 1092 & 204 \\
\hline 210 & $A C$ & 25 & 11.3 & 2109 & 14005 & 6.64 & 589 & 13201 & 6.26 & 555 & 250 \\
\hline 212 & $A C$ & 25 & 9.4 & 3605 & 15242 & 4.23 & 448 & 27690 & 7.68 & 814 & 307 \\
\hline 213 & $A C$ & 15 & 3.8 & 3522 & 9191 & 2.61 & 686 & 9726 & 2.76 & 726 & 184 \\
\hline 214 & $A C$ & 10 & 1.6 & 2827 & 2627 & 0.93 & 592 & 5079 & 1.80 & 1145 & 180 \\
\hline 215 & $A C$ & 10 & 2.5 & 3406 & 5578 & 1.64 & 665 & 5526 & 1.62 & 658 & 162 \\
\hline 217 & $A C$ & 10 & 2.6 & 3714 & 5835 & 1.57 & 613 & 5916 & 1.59 & 622 & 159 \\
\hline 218 & $A C$ & 10 & 2.9 & 3601 & 5333 & 1.48 & 508 & 6826 & 1.90 & 650 & 190 \\
\hline
\end{tabular}




\begin{tabular}{|c|c|c|c|c|c|c|c|c|c|c|c|}
\hline $\begin{array}{l}\text { RTU } \\
\text { ID }\end{array}$ & $\begin{array}{l}\text { RTU } \\
\text { Type }\end{array}$ & $\begin{array}{l}\text { RTU } \\
\text { Size } \\
\text { (ton) }\end{array}$ & $\begin{array}{l}\text { RTU } \\
\text { Fan } \\
\text { Power } \\
\text { (hp) }\end{array}$ & $\begin{array}{l}\text { Post- } \\
\text { Retrofit } \\
\text { Runtime } \\
\text { (hr) }\end{array}$ & $\begin{array}{l}\text { Fan } \\
\text { Energy } \\
\text { Savings } \\
\text { (kWh) }\end{array}$ & $\begin{array}{l}\text { Fan } \\
\text { Energy } \\
\text { Savings } \\
\text { per } \\
\text { Hour } \\
(\mathrm{kWh} / \mathrm{h})\end{array}$ & $\begin{array}{l}\text { Fan Energy } \\
\text { Savings per } \\
\text { Hour and } \\
\text { per hp } \\
\text { (Wh/h/hp) }\end{array}$ & $\begin{array}{l}\text { Total } \\
\text { RTU } \\
\text { Electrici } \\
\text { ty } \\
\text { Savings } \\
\text { (kWh) }\end{array}$ & $\begin{array}{l}\text { RTU } \\
\text { Electricity } \\
\text { Savings } \\
\text { per Hour } \\
\text { (kWh/h) }\end{array}$ & $\begin{array}{l}\text { RTU Electricity } \\
\text { Savings per } \\
\text { Hour and per } \\
h p(W h / h / h p)\end{array}$ & $\begin{array}{l}\text { RTU } \\
\text { Electricity } \\
\text { Savings per } \\
\text { Hour and per } \\
\text { ton } \\
\text { (Wh/h/ton) }\end{array}$ \\
\hline 219 & $A C$ & 15 & 1.7 & 871 & 686 & 0.79 & 458 & 306 & 0.35 & 205 & 23 \\
\hline 220 & $A C$ & 15 & 1.4 & 3474 & 2597 & 0.75 & 545 & 5150 & 1.48 & 1081 & 99 \\
\hline 221 & $A C$ & 10 & 2.0 & 3195 & 4280 & 1.34 & 677 & 4151 & 1.30 & 656 & 130 \\
\hline 222 & $A C$ & 15 & 1.9 & 3760 & 4730 & 1.26 & 680 & 5775 & 1.54 & 830 & 102 \\
\hline 223 & $A C$ & 15 & 2.4 & 3019 & 4393 & 1.46 & 597 & 6620 & 2.19 & 899 & 146 \\
\hline 224 & $A C$ & 10 & 1.7 & 3276 & 3345 & 1.02 & 601 & 7241 & 2.21 & 1300 & 221 \\
\hline 225 & $A C$ & 10 & 2.0 & 2429 & 3195 & 1.32 & 673 & 3233 & 1.33 & 681 & 133 \\
\hline 226 & $A C$ & 12.5 & 3.4 & 3329 & 5933 & 1.78 & 526 & 9218 & 2.77 & 818 & 222 \\
\hline 228 & $A C$ & 10 & 3.1 & 3592 & 4717 & 1.31 & 430 & 7130 & 1.98 & 649 & 198 \\
\hline 229 & $A C$ & 10 & 5.0 & 3201 & 10916 & 3.41 & 679 & 10866 & 3.39 & 676 & 339 \\
\hline 231 & $A C$ & 7.5 & 2.2 & 3521 & 4217 & 1.20 & 544 & 3996 & 1.13 & 515 & 151 \\
\hline 362 & $A C$ & 18 & 3.3 & 2949 & 2957 & 1.00 & 300 & 6242 & 2.12 & 632 & 118 \\
\hline 363 & $A C$ & 20 & 7.7 & 3551 & 17324 & 4.88 & 634 & 19162 & 5.40 & 701 & 270 \\
\hline 364 & $A C$ & 25 & 6.4 & 2519 & 7967 & 3.16 & 498 & 11192 & 4.44 & 699 & 178 \\
\hline 365 & $A C$ & 25 & 6.8 & 2653 & 9885 & 3.73 & 551 & 11426 & 4.31 & 636 & 172 \\
\hline
\end{tabular}




\begin{tabular}{|c|c|c|c|c|c|c|c|c|c|c|c|}
\hline $\begin{array}{l}\text { RTU } \\
\text { ID }\end{array}$ & $\begin{array}{l}\text { RTU } \\
\text { Type }\end{array}$ & $\begin{array}{l}\text { RTU } \\
\text { Size } \\
\text { (ton) }\end{array}$ & $\begin{array}{l}\text { RTU } \\
\text { Fan } \\
\text { Power } \\
\text { (hp) }\end{array}$ & $\begin{array}{l}\text { Post- } \\
\text { Retrofit } \\
\text { Runtime } \\
\text { (hr) }\end{array}$ & $\begin{array}{l}\text { Fan } \\
\text { Energy } \\
\text { Savings } \\
\text { (kWh) }\end{array}$ & $\begin{array}{l}\text { Fan } \\
\text { Energy } \\
\text { Savings } \\
\text { per } \\
\text { Hour } \\
\text { (kWh/h) }\end{array}$ & $\begin{array}{l}\text { Fan Energy } \\
\text { Savings per } \\
\text { Hour and } \\
\text { per hp } \\
\text { (Wh/h/hp) }\end{array}$ & $\begin{array}{l}\text { Total } \\
\text { RTU } \\
\text { Electrici } \\
\text { ty } \\
\text { Savings } \\
\text { (kWh) }\end{array}$ & $\begin{array}{l}\text { RTU } \\
\text { Electricity } \\
\text { Savings } \\
\text { per Hour } \\
\text { (kWh/h) }\end{array}$ & 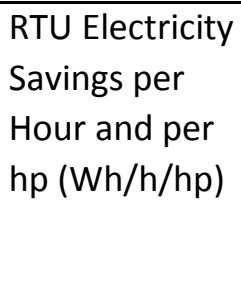 & $\begin{array}{l}\text { RTU } \\
\text { Electricity } \\
\text { Savings per } \\
\text { Hour and per } \\
\text { ton } \\
\text { (Wh/h/ton) }\end{array}$ \\
\hline 366 & $A C$ & 25 & 6.7 & 2465 & 8993 & 3.65 & 544 & 5748 & 2.33 & 348 & 93 \\
\hline 367 & $A C$ & 25 & 8.1 & 4211 & 6606 & 1.57 & 194 & 13694 & 3.25 & 402 & 130 \\
\hline 368 & $A C$ & 25 & 6.4 & 3296 & 8716 & 2.64 & 412 & 11203 & 3.40 & 529 & 136 \\
\hline 369 & $A C$ & 25 & 7.0 & 4093 & 16352 & 3.99 & 572 & 17755 & 4.34 & 621 & 174 \\
\hline 370 & $A C$ & 25 & 6.9 & 4103 & 16699 & 4.07 & 593 & 18029 & 4.39 & 641 & 176 \\
\hline 371 & $\overline{A C}$ & 25 & 6.4 & 4174 & 14282 & 3.42 & 535 & 18399 & 4.41 & 690 & 176 \\
\hline 372 & HP & 12.5 & 3.1 & 1040 & 1886 & 1.81 & 576 & 2986 & 2.87 & 912 & 230 \\
\hline 375 & $\mathrm{HP}$ & 15 & 3.4 & 1384 & 2734 & 1.98 & 574 & 4083 & 2.95 & 857 & 197 \\
\hline 376 & $\mathrm{HP}$ & 15 & 1.4 & 1438 & 1169 & 0.81 & 586 & 1003 & 0.70 & 503 & 46 \\
\hline 377 & $\mathrm{HP}$ & 7.5 & 1.4 & 1427 & 1149 & 0.80 & 560 & 1615 & 1.13 & 787 & 151 \\
\hline 378 & $\mathrm{HP}$ & 10 & 3.3 & 1374 & 1963 & 1.43 & 427 & 2907 & 2.12 & 632 & 212 \\
\hline 379 & $\mathrm{HP}$ & 5 & 0.6 & 1428 & 451 & 0.32 & 545 & 707 & 0.49 & 853 & 99 \\
\hline 380 & HP & 7.5 & 1.4 & 1417 & 1132 & 0.80 & 570 & 1516 & 1.07 & 763 & 143 \\
\hline 381 & HP & 15 & 2.6 & 3045 & 4137 & 1.36 & 517 & 5891 & 1.93 & 736 & 129 \\
\hline 382 & HP & 15 & 2.7 & 3048 & 4923 & 1.62 & 600 & 7816 & 2.56 & 953 & 171 \\
\hline
\end{tabular}




\begin{tabular}{|c|c|c|c|c|c|c|c|c|c|c|c|}
\hline $\begin{array}{l}\text { RTU } \\
\text { ID }\end{array}$ & $\begin{array}{l}\text { RTU } \\
\text { Type }\end{array}$ & $\begin{array}{l}\text { RTU } \\
\text { Size } \\
\text { (ton) }\end{array}$ & $\begin{array}{l}\text { RTU } \\
\text { Fan } \\
\text { Power } \\
\text { (hp) }\end{array}$ & $\begin{array}{l}\text { Post- } \\
\text { Retrofit } \\
\text { Runtime } \\
\text { (hr) }\end{array}$ & $\begin{array}{l}\text { Fan } \\
\text { Energy } \\
\text { Savings } \\
\text { (kWh) }\end{array}$ & $\begin{array}{l}\text { Fan } \\
\text { Energy } \\
\text { Savings } \\
\text { per } \\
\text { Hour } \\
\text { (kWh/h) }\end{array}$ & $\begin{array}{l}\text { Fan Energy } \\
\text { Savings per } \\
\text { Hour and } \\
\text { per hp } \\
\text { (Wh/h/hp) }\end{array}$ & $\begin{array}{l}\text { Total } \\
\text { RTU } \\
\text { Electrici } \\
\text { ty } \\
\text { Savings } \\
\text { (kWh) }\end{array}$ & $\begin{array}{l}\text { RTU } \\
\text { Electricity } \\
\text { Savings } \\
\text { per Hour } \\
\text { (kWh/h) }\end{array}$ & $\begin{array}{l}\text { RTU Electricity } \\
\text { Savings per } \\
\text { Hour and per } \\
\mathrm{hp}(\mathrm{Wh} / \mathrm{h} / \mathrm{hp})\end{array}$ & $\begin{array}{l}\text { RTU } \\
\text { Electricity } \\
\text { Savings per } \\
\text { Hour and per } \\
\text { ton } \\
\text { (Wh/h/ton) }\end{array}$ \\
\hline 383 & $\mathrm{HP}$ & 15 & 2.7 & 2923 & 4347 & 1.49 & 555 & 4910 & 1.68 & 626 & 112 \\
\hline 384 & HP & 20 & 2.9 & 2876 & 5003 & 1.74 & 603 & 6084 & 2.12 & 734 & 106 \\
\hline 385 & $\mathrm{HP}$ & 15 & 2.7 & 3013 & 4691 & 1.56 & 572 & 6379 & 2.12 & 778 & 141 \\
\hline 386 & $\mathrm{HP}$ & 15 & 2.2 & 3051 & 4190 & 1.37 & 615 & 4650 & 1.52 & 682 & 102 \\
\hline 387 & $\mathrm{HP}$ & 15 & 2.4 & 2990 & 3955 & 1.32 & 558 & 5544 & 1.85 & 783 & 124 \\
\hline 388 & $\mathrm{HP}$ & 15 & 2.4 & 2837 & 4444 & 1.57 & 644 & 4621 & 1.63 & 669 & 109 \\
\hline 389 & $\mathrm{HP}$ & 15 & 2.5 & 2844 & 3482 & 1.22 & 491 & 6809 & 2.39 & 960 & 160 \\
\hline 407 & $A C$ & 7.5 & 1.4 & 1523 & 660 & 0.43 & 313 & 1991 & 1.31 & 945 & 174 \\
\hline 408 & $A C$ & 10 & 1.9 & 3604 & 3355 & 0.93 & 492 & 3838 & 1.06 & 563 & 106 \\
\hline 409 & $A C$ & 15 & 3.4 & 3308 & 7000 & 2.12 & 624 & 2215 & 0.67 & 197 & 45 \\
\hline 410 & $A C$ & 25 & 4.0 & 3624 & 5937 & 1.64 & 410 & 11822 & 3.26 & 816 & 130 \\
\hline 411 & $A C$ & 25 & 5.9 & 3309 & 6522 & 1.97 & 333 & 10129 & 3.06 & 517 & 122 \\
\hline 423 & $A C$ & 10 & 2.6 & 1725 & 3083 & 1.79 & 676 & 3094 & 1.79 & 679 & 179 \\
\hline 424 & $A C$ & 10 & 2.4 & 1669 & 2218 & 1.33 & 563 & 2899 & 1.74 & 737 & 174 \\
\hline 425 & $A C$ & 10 & 3.0 & 1701 & 3212 & 1.89 & 625 & 3551 & 2.09 & 691 & 209 \\
\hline
\end{tabular}




\begin{tabular}{|l|l|l|l|l|l|l|l|l|l|l|l|}
\hline $\begin{array}{l}\text { RTU } \\
\text { ID }\end{array}$ & $\begin{array}{l}\text { RTU } \\
\text { Type }\end{array}$ & $\begin{array}{l}\text { RTU } \\
\text { Size } \\
\text { (ton) }\end{array}$ & $\begin{array}{l}\text { RTU } \\
\text { Fan } \\
\text { Power } \\
(\mathrm{hp})\end{array}$ & $\begin{array}{l}\text { Post- } \\
\text { Retrofit } \\
\text { Runtime } \\
(\mathrm{hr})\end{array}$ & $\begin{array}{l}\text { Fan } \\
\text { Energy } \\
\text { Savings } \\
(\mathrm{kWh})\end{array}$ & $\begin{array}{l}\text { Fan } \\
\text { Energy } \\
\text { Savings } \\
\text { per } \\
\text { Hour } \\
(\mathrm{kWh} / \mathrm{h})\end{array}$ & $\begin{array}{l}\text { Fan Energy } \\
\text { Savings per } \\
\text { Hour and } \\
\text { per hp } \\
(\mathrm{Wh} / \mathrm{h} / \mathrm{hp})\end{array}$ & $\begin{array}{l}\text { Total } \\
\text { RTU } \\
\text { Electrici } \\
\text { ty } \\
\text { Savings } \\
(\mathrm{kWh})\end{array}$ & $\begin{array}{l}\text { RTU } \\
\text { Electricity } \\
\text { Savings } \\
\text { per Hour } \\
(\mathrm{kWh} / \mathrm{h})\end{array}$ & $\begin{array}{l}\text { RTU Electricity } \\
\text { Savings per } \\
\text { Hour and per } \\
\mathrm{hp}(\mathrm{Wh} / \mathrm{h} / \mathrm{hp})\end{array}$ & $\begin{array}{l}\text { RTU } \\
\text { Electricity } \\
\text { Savings per } \\
\text { Hour and per } \\
\text { ton } \\
(\mathrm{Wh} / \mathrm{h} / \mathrm{ton})\end{array}$ \\
\hline 426 & AC & 10 & 2.7 & 1708 & 2936 & 1.72 & 629 & 3052 & 1.79 & 654 & 179 \\
\hline 427 & AC & 10 & 3.0 & 1708 & 3405 & 1.99 & 656 & 3925 & 2.30 & \\
\hline
\end{tabular}




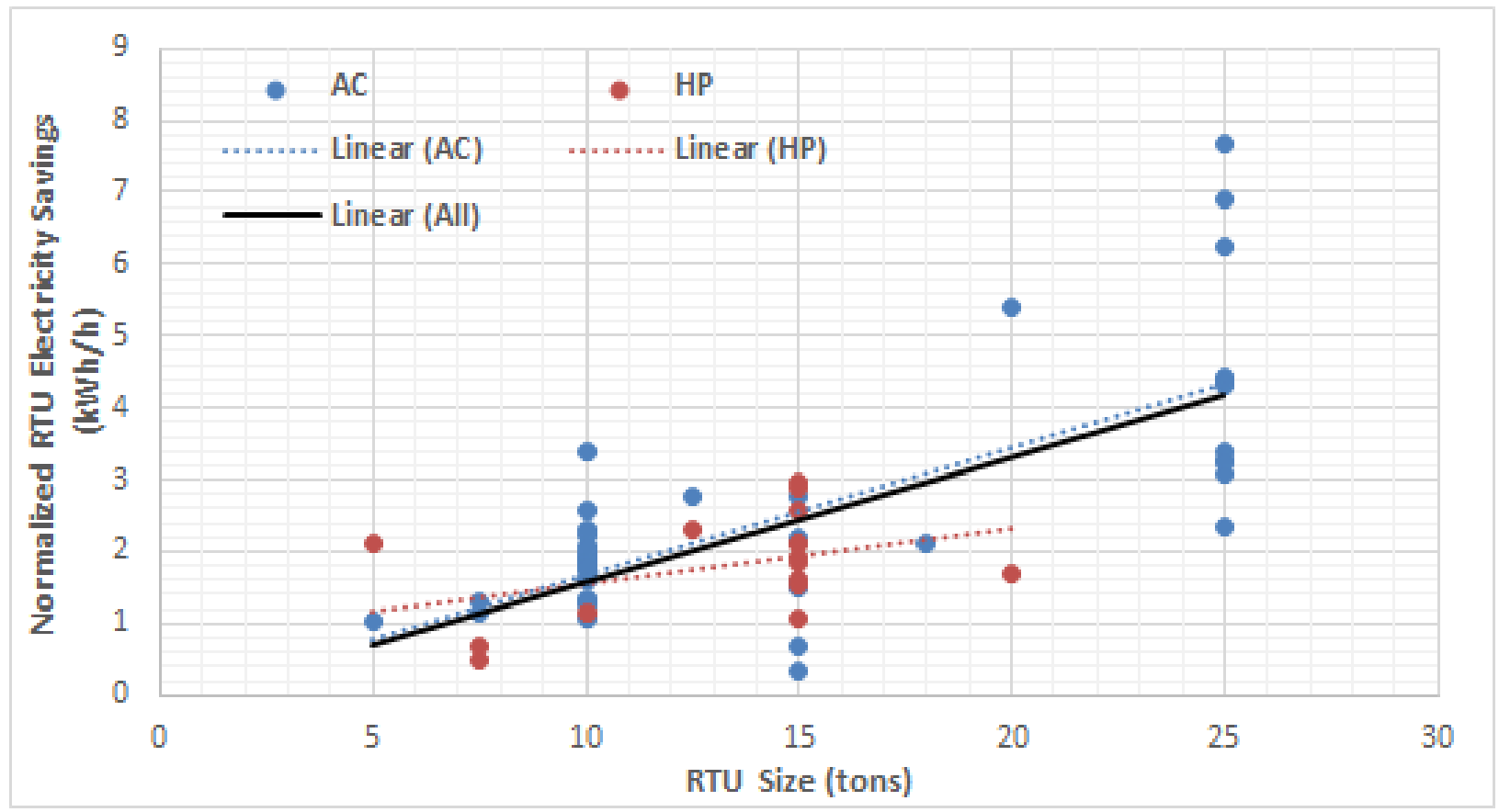

Figure 19: Variation of actual RTU electricity savings per unit run hour with RTU size

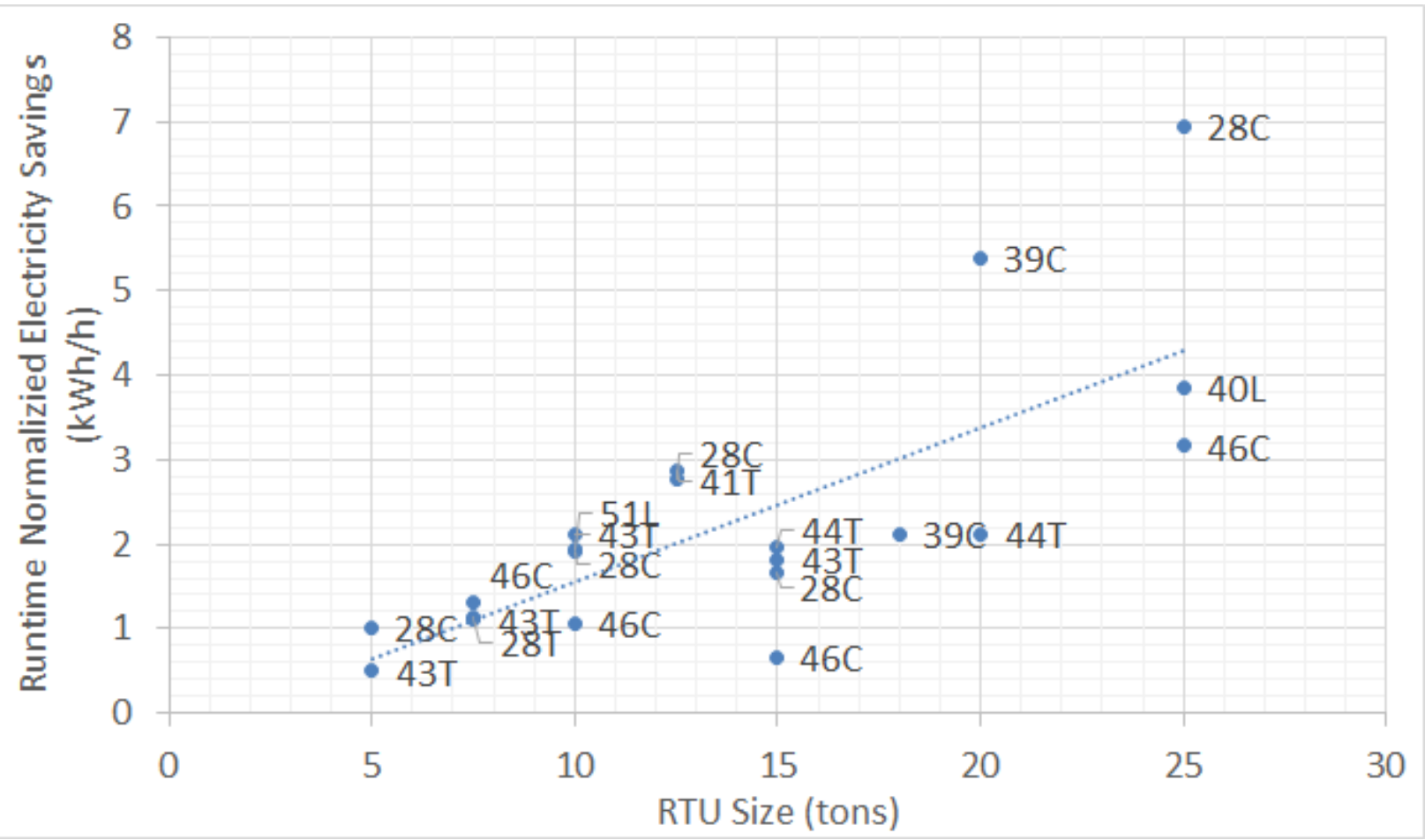

Figure 20: Variation of average actual RTU electricity savings per unit run hour with RTU size

Figure 21 shows the variation of actual RTU electricity savings per unit run hour and per ton as a function of RTU size. Again, in this figure, the units with similar size at each site are averaged. The number next to the marker shows the site ID and the character shows the RTU manufacturer. Although there is not a strong trend with RTU size, there is still some trend. 
Figure 22 shows the variation of actual RTU electricity savings per unit run hour and per supply fan motor hp as a function of RTU size. Although there is some scatter, there is no obvious trend with the size of the unit. It appears that normalizing savings with the unit run hours and fan motor size, the savings do not show a strong trend with size across the eight sites. Most units have savings between 400 and $900 \mathrm{Wh} / \mathrm{h} / \mathrm{hp}$, with an average savings across all sites being $712 \mathrm{Wh} / \mathrm{h} / \mathrm{hp}$. Therefore, it appears that normalizing the actual electricity savings with unit runtime and fan motor size is a better indicator of a potential RTU electricity savings.

Table 10 shows the TMY weather normalized annual savings for all units. This table is similar to Table 9 and leads to similar findings as those previously discussed. Several specific notes for Table 10 include the following:

- The RTU runtime was based on the operation schedule (see Table 11) derived from the test data. These schedules are obtained by observing the change of fan running status over 1 week. The schedules were rounded to the nearest whole hour for the ease of average temperature calculation.

- Annual TMY weather normalized savings was in the range between $0.47 \mathrm{kWh} / \mathrm{h}$ (kWh per RTU runtime) and $7.21 \mathrm{kWh} / \mathrm{h}$, with an average of $2.39 \mathrm{kWh} / \mathrm{h}$, while the fan only electricity savings range between $0.36 \mathrm{kWh} / \mathrm{h}$ to $7.37 \mathrm{kWh} / \mathrm{h}$ with an average of $2.18 \mathrm{kWh} / \mathrm{h}$.

- Annual TMY weather normalized RTU electricity savings was in the range between $218 \mathrm{Wh} / \mathrm{h} / \mathrm{hp}$ and $1,086 \mathrm{Wh} / \mathrm{h} / \mathrm{hp}$ with an average of $695 \mathrm{Wh} / \mathrm{h} / \mathrm{hp}$, while the fan only electricity savings ranged between $201 \mathrm{Wh} / \mathrm{h} / \mathrm{hp}$ to $929 \mathrm{Wh} / \mathrm{h} / \mathrm{hp}$ with an average of $595 \mathrm{Wh} / \mathrm{h} / \mathrm{hp}$.

- In addition to electricity savings per hour, annual electricity savings per hour and per ton was also provided and it ranged between 32 and 312 Wh per unit run hour and per ton, with an average of $160 \mathrm{Wh} / \mathrm{h} / \mathrm{ton}$.

Figure 23 shows the variation of normalized RTU electricity savings per unit run hour and per ton of cooling capacity of the unit as a function of RTU size. Figure 24 shows the variation of normalized RTU electricity savings per unit run hour and per supply fan motor hp as a function of RTU size. Although there is some scatter just like the similar actual savings plot, there is no obvious trend with the size of the unit. It appears that normalizing savings with the unit run hours and the fan motor size, correlates well with the annual savings across the eight sites. Most units had savings between $500 \mathrm{Wh} / \mathrm{h} / \mathrm{hp}$ and $800 \mathrm{Wh} / \mathrm{h} / \mathrm{hp}$, with an average savings across all sites being $703 \mathrm{Wh} / \mathrm{h} / \mathrm{hp}$.

Figure 25 shows the variation of normalized fan electricity savings per unit run hour and per supply fan motor hp as a function of RTU size. The trend is similar to the RTU savings (Figure 24) but most of the normalized savings are between $550 \mathrm{Wh} / \mathrm{h} / \mathrm{hp}$ and $650 \mathrm{Wh} / \mathrm{h} / \mathrm{hp}$ with average of about $554 \mathrm{Wh} / \mathrm{h} / \mathrm{hp}$. 


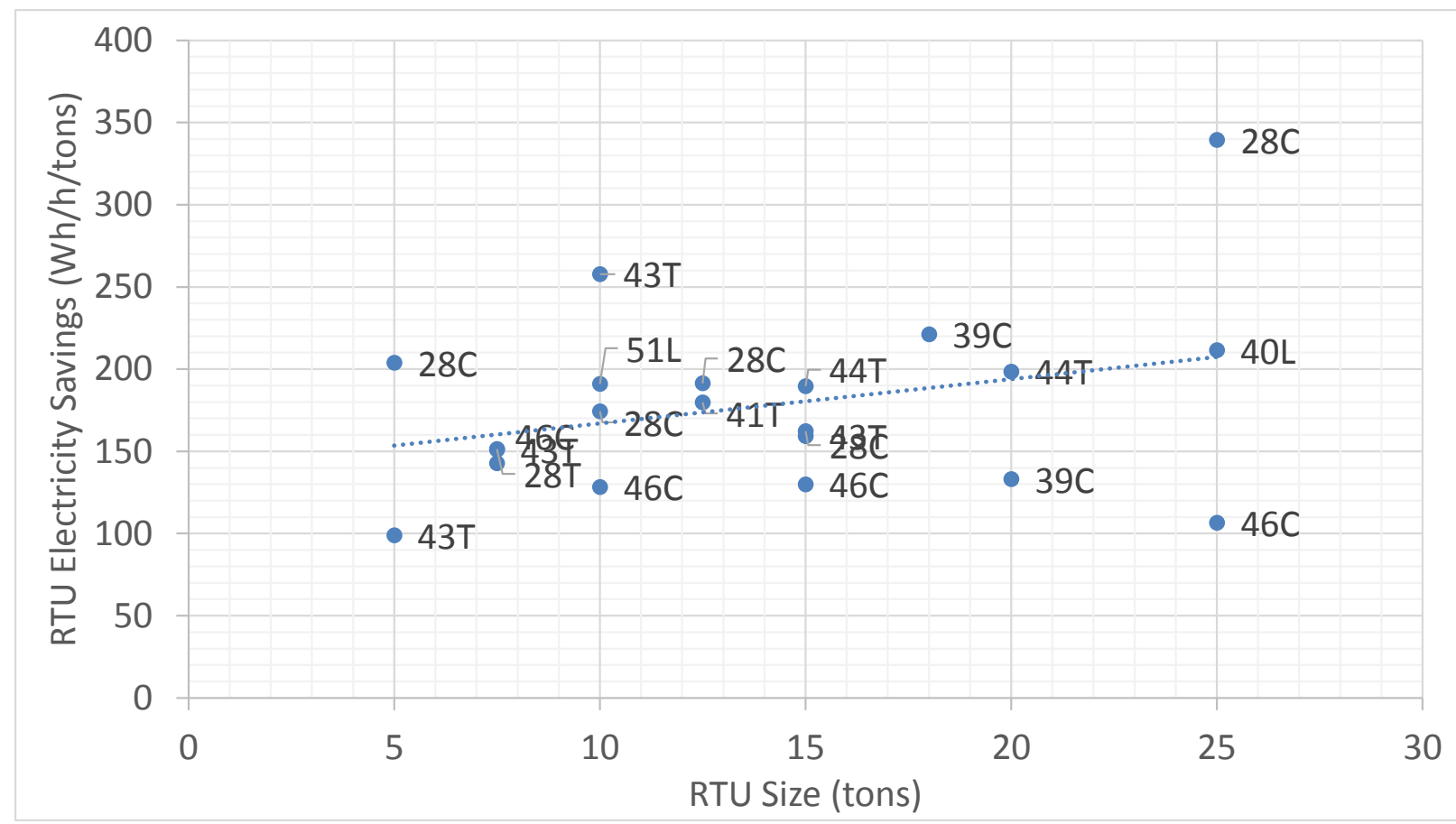

Figure 21: Variation of average actual RTU electricity savings per unit run hour and per ton with RTU size

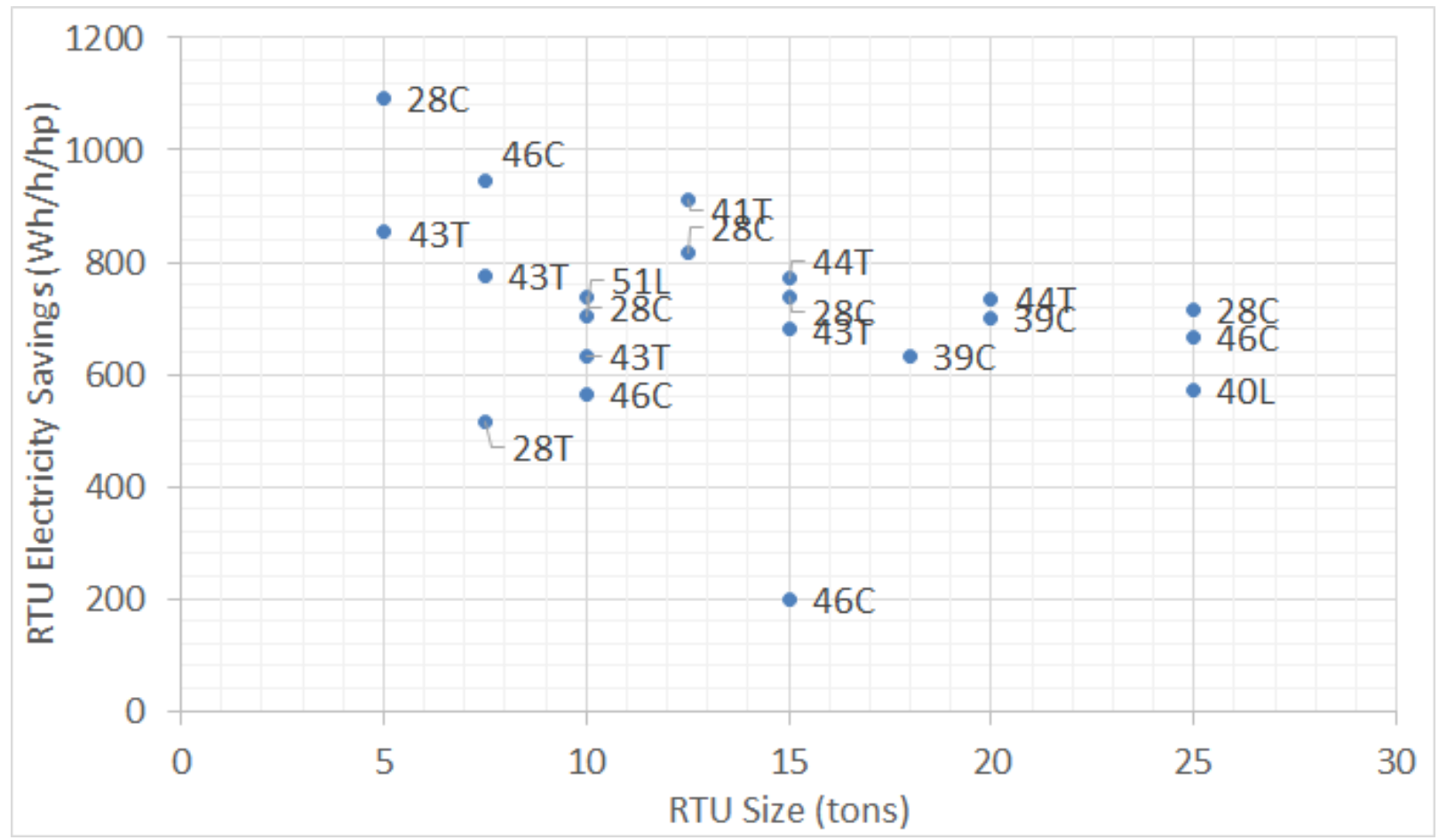

Figure 22: Variation of average actual RTU electricity savings per unit run hour and per fan motor hp with RTU size 
Table 10: TMY weather normalized annual savings for all units

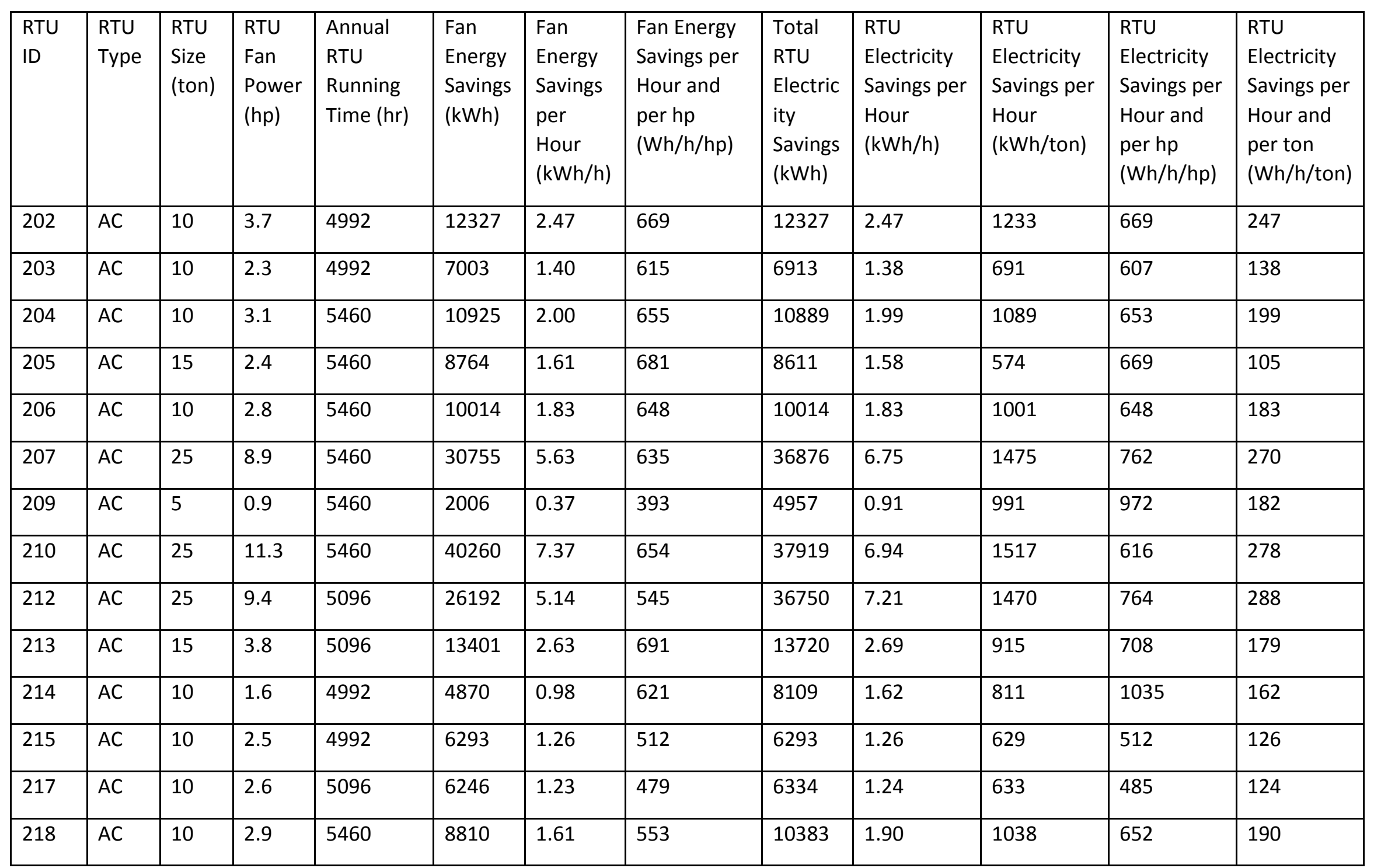




\begin{tabular}{|c|c|c|c|c|c|c|c|c|c|c|c|c|}
\hline $\begin{array}{l}\text { RTU } \\
\text { ID }\end{array}$ & $\begin{array}{l}\text { RTU } \\
\text { Type }\end{array}$ & $\begin{array}{l}\text { RTU } \\
\text { Size } \\
\text { (ton) }\end{array}$ & $\begin{array}{l}\text { RTU } \\
\text { Fan } \\
\text { Power } \\
\text { (hp) }\end{array}$ & $\begin{array}{l}\text { Annual } \\
\text { RTU } \\
\text { Running } \\
\text { Time (hr) }\end{array}$ & $\begin{array}{l}\text { Fan } \\
\text { Energy } \\
\text { Savings } \\
\text { (kWh) }\end{array}$ & $\begin{array}{l}\text { Fan } \\
\text { Energy } \\
\text { Savings } \\
\text { per } \\
\text { Hour } \\
\text { (kWh/h) }\end{array}$ & $\begin{array}{l}\text { Fan Energy } \\
\text { Savings per } \\
\text { Hour and } \\
\text { per hp } \\
\text { (Wh/h/hp) }\end{array}$ & $\begin{array}{l}\text { Total } \\
\text { RTU } \\
\text { Electric } \\
\text { ity } \\
\text { Savings } \\
\text { (kWh) }\end{array}$ & $\begin{array}{l}\text { RTU } \\
\text { Electricity } \\
\text { Savings per } \\
\text { Hour } \\
\text { (kWh/h) }\end{array}$ & $\begin{array}{l}\text { RTU } \\
\text { Electricity } \\
\text { Savings per } \\
\text { Hour } \\
\text { (kWh/ton) }\end{array}$ & $\begin{array}{l}\text { RTU } \\
\text { Electricity } \\
\text { Savings per } \\
\text { Hour and } \\
\text { per hp } \\
\text { (Wh/h/hp) }\end{array}$ & $\begin{array}{l}\text { RTU } \\
\text { Electricity } \\
\text { Savings per } \\
\text { Hour and } \\
\text { per ton } \\
\text { (Wh/h/ton) }\end{array}$ \\
\hline 219 & $A C$ & 15 & 1.7 & 4992 & 4854 & 0.97 & 566 & 2369 & 0.47 & 158 & 276 & 32 \\
\hline 221 & $A C$ & 10 & 2.0 & 4992 & 6687 & 1.34 & 676 & 6531 & 1.31 & 653 & 661 & 131 \\
\hline 222 & $A C$ & 15 & 1.9 & 4992 & 6279 & 1.26 & 680 & 6736 & 1.35 & 449 & 729 & 90 \\
\hline 223 & $A C$ & 15 & 2.4 & 4992 & 7892 & 1.58 & 648 & 10219 & 2.05 & 681 & 839 & 136 \\
\hline 228 & $A C$ & 10 & 3.1 & 5200 & 7077 & 1.36 & 445 & 10340 & 1.99 & 1034 & 650 & 199 \\
\hline 229 & $A C$ & 10 & 5.0 & 4888 & 15232 & 3.12 & 621 & 15232 & 3.12 & 1523 & 621 & 312 \\
\hline 231 & $A C$ & 7.5 & 2.2 & 5460 & 5500 & 1.01 & 4457 & 6082 & 1.11 & 811 & 506 & 149 \\
\hline 362 & $A C$ & 18 & 3.3 & 7904 & 9045 & 1.14 & 342 & 15457 & 1.96 & 859 & 584 & 109 \\
\hline 363 & $A C$ & 20 & 7.7 & 7904 & 38920 & 4.92 & 640 & 41229 & 5.22 & 2061 & 678 & 261 \\
\hline 364 & $A C$ & 25 & 6.4 & 5460 & 23898 & 4.38 & 689 & 25034 & 4.58 & 1001 & 721 & 183 \\
\hline 365 & $A C$ & 25 & 6.8 & 5460 & 24570 & 4.50 & 665 & 24357 & 4.46 & 974 & 659 & 178 \\
\hline
\end{tabular}




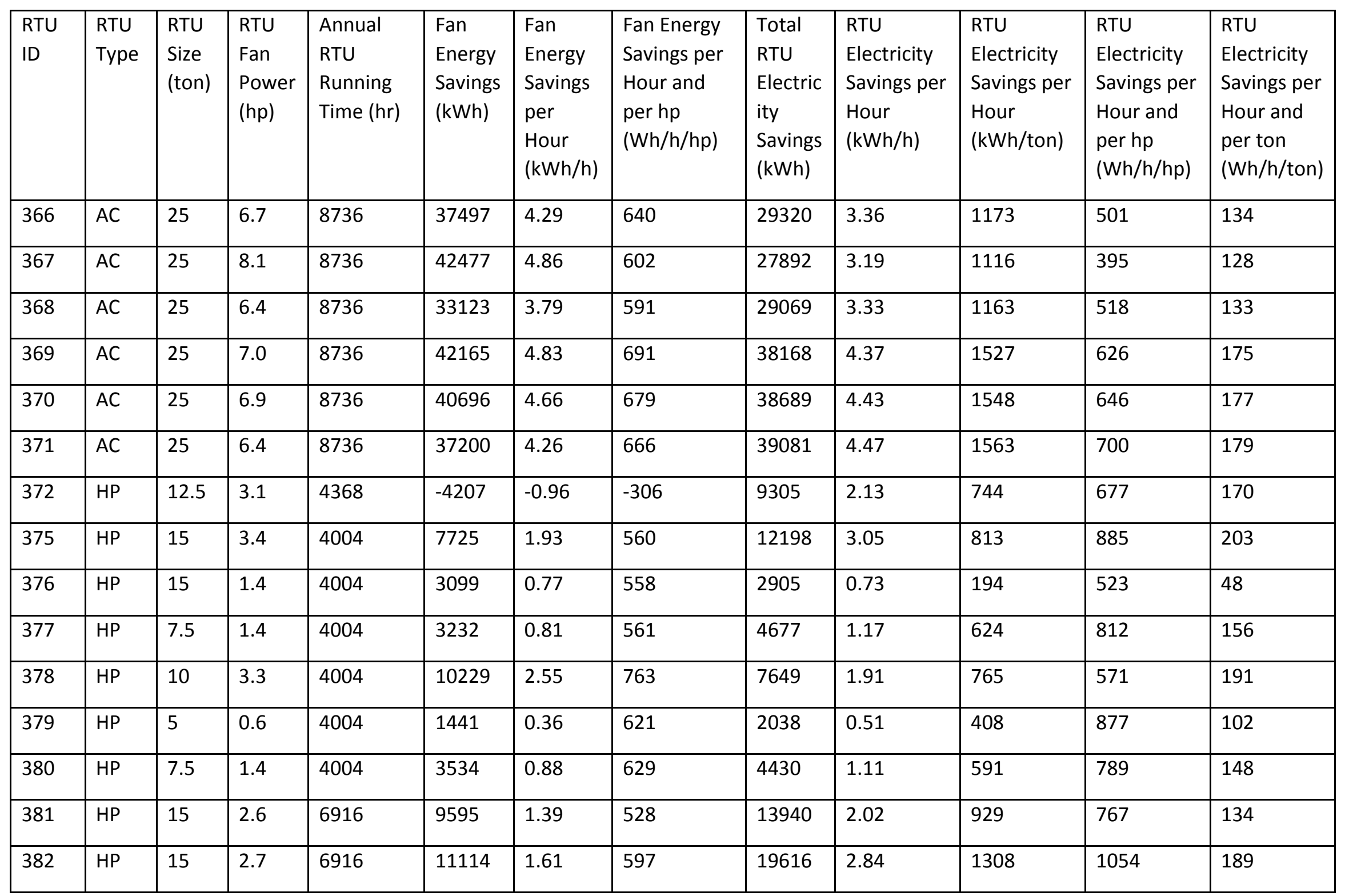




\begin{tabular}{|c|c|c|c|c|c|c|c|c|c|c|c|c|}
\hline $\begin{array}{l}\text { RTU } \\
\text { ID }\end{array}$ & $\begin{array}{l}\text { RTU } \\
\text { Type }\end{array}$ & $\begin{array}{l}\text { RTU } \\
\text { Size } \\
\text { (ton) }\end{array}$ & $\begin{array}{l}\text { RTU } \\
\text { Fan } \\
\text { Power } \\
\text { (hp) }\end{array}$ & $\begin{array}{l}\text { Annual } \\
\text { RTU } \\
\text { Running } \\
\text { Time (hr) }\end{array}$ & $\begin{array}{l}\text { Fan } \\
\text { Energy } \\
\text { Savings } \\
\text { (kWh) }\end{array}$ & $\begin{array}{l}\text { Fan } \\
\text { Energy } \\
\text { Savings } \\
\text { per } \\
\text { Hour } \\
(\mathrm{kWh} / \mathrm{h})\end{array}$ & $\begin{array}{l}\text { Fan Energy } \\
\text { Savings per } \\
\text { Hour and } \\
\text { per hp } \\
\text { (Wh/h/hp) }\end{array}$ & $\begin{array}{l}\text { Total } \\
\text { RTU } \\
\text { Electric } \\
\text { ity } \\
\text { Savings } \\
\text { (kWh) }\end{array}$ & $\begin{array}{l}\text { RTU } \\
\text { Electricity } \\
\text { Savings per } \\
\text { Hour } \\
\text { (kWh/h) }\end{array}$ & $\begin{array}{l}\text { RTU } \\
\text { Electricity } \\
\text { Savings per } \\
\text { Hour } \\
\text { (kWh/ton) }\end{array}$ & $\begin{array}{l}\text { RTU } \\
\text { Electricity } \\
\text { Savings per } \\
\text { Hour and } \\
\text { per hp } \\
\text { (Wh/h/hp) }\end{array}$ & $\begin{array}{l}\text { RTU } \\
\text { Electricity } \\
\text { Savings per } \\
\text { Hour and } \\
\text { per ton } \\
\text { (Wh/h/ton) }\end{array}$ \\
\hline 383 & $\mathrm{HP}$ & 15 & 2.7 & 6916 & 9941 & 1.44 & 536 & 12181 & 1.76 & 812 & 657 & 117 \\
\hline 384 & $\mathrm{HP}$ & 20 & 2.9 & 6916 & 12787 & 1.85 & 641 & 14705 & 2.13 & 735 & 738 & 106 \\
\hline 385 & $\mathrm{HP}$ & 15 & 2.7 & 6916 & 10793 & 1.56 & 573 & 16511 & 2.39 & 1101 & 877 & 159 \\
\hline 386 & $\mathrm{HP}$ & 15 & 2.2 & 6916 & 9573 & 1.38 & 620 & 10910 & 1.58 & 727 & 706 & 105 \\
\hline 387 & $\mathrm{HP}$ & 15 & 2.4 & 6916 & 9310 & 1.35 & 568 & 12671 & 1.83 & 845 & 774 & 122 \\
\hline 388 & $\mathrm{HP}$ & 15 & 2.4 & 6916 & 10948 & 1.58 & 651 & 11279 & 1.63 & 752 & 670 & 109 \\
\hline 389 & $\mathrm{HP}$ & 15 & 2.5 & 6916 & 8645 & 1.25 & 501 & 18732 & 2.71 & 1249 & 1086 & 181 \\
\hline 407 & $A C$ & 7.5 & 1.4 & 8736 & 3918 & 0.45 & 324 & 9853 & 1.13 & 1314 & 815 & 150 \\
\hline 408 & $A C$ & 10 & 1.9 & 8736 & 9575 & 1.10 & 580 & 9441 & 1.08 & 944 & 572 & 108 \\
\hline 409 & $A C$ & 15 & 3.4 & 8736 & 5949 & 0.68 & 201 & 6465 & 0.74 & 431 & 218 & 49 \\
\hline 410 & $A C$ & 25 & 4.0 & 8736 & 32432 & 3.71 & 929 & 30264 & 3.46 & 1211 & 867 & 139 \\
\hline 411 & $A C$ & 25 & 5.9 & 8736 & 17633 & 2.02 & 341 & 21681 & 2.48 & 867 & 419 & 99 \\
\hline 423 & $A C$ & 10 & 2.6 & 4420 & 7590 & 1.72 & 650 & 7592 & 1.72 & 759 & 650 & 172 \\
\hline 424 & $A C$ & 10 & 2.4 & 4420 & 5848 & 1.32 & 561 & 7768 & 1.76 & 777 & 745 & 176 \\
\hline 425 & $A C$ & 10 & 3.0 & 4420 & 9403 & 2.13 & 704 & 9205 & 2.08 & 920 & 689 & 208 \\
\hline
\end{tabular}




\begin{tabular}{|l|l|l|l|l|l|l|l|l|l|l|l|l|}
\hline $\begin{array}{l}\text { RTU } \\
\text { ID }\end{array}$ & $\begin{array}{l}\text { RTU } \\
\text { Type }\end{array}$ & $\begin{array}{l}\text { RTU } \\
\text { Size } \\
\text { (ton) }\end{array}$ & $\begin{array}{l}\text { RTU } \\
\text { Fan } \\
\text { Power } \\
\text { (hp) }\end{array}$ & $\begin{array}{l}\text { Annual } \\
\text { RTU } \\
\text { Running } \\
\text { Time }(\mathrm{hr})\end{array}$ & $\begin{array}{l}\text { Fan } \\
\text { Energy } \\
\text { Savings } \\
(\mathrm{kWh})\end{array}$ & $\begin{array}{l}\text { Fan } \\
\text { Energy } \\
\text { Savings } \\
\text { per } \\
\text { Hour } \\
(\mathrm{kWh} / \mathrm{h})\end{array}$ & $\begin{array}{l}\text { Fan Energy } \\
\text { Savings per } \\
\text { Hour and } \\
\text { per hp } \\
(\mathrm{Wh} / \mathrm{h} / \mathrm{hp})\end{array}$ & $\begin{array}{l}\text { Total } \\
\text { RTU } \\
\text { Electric } \\
\text { ity } \\
\text { Savings } \\
(\mathrm{kWh})\end{array}$ & $\begin{array}{l}\text { RTU } \\
\text { Electricity } \\
\text { Savings per } \\
\text { Hour } \\
(\mathrm{kWh} / \mathrm{h})\end{array}$ & $\begin{array}{l}\text { RTU } \\
\text { Electricity } \\
\text { Savings per } \\
\text { Hour } \\
(\mathrm{kWh} / \text { ton })\end{array}$ & $\begin{array}{l}\text { RTU } \\
\text { Electricity } \\
\text { Savings per } \\
\text { Hour and } \\
\text { per hp } \\
(\mathrm{Wh} / \mathrm{h} / \mathrm{hp})\end{array}$ & $\begin{array}{l}\text { RTU } \\
\text { Electricity } \\
\text { Savings per } \\
\text { Hour and } \\
\text { per ton } \\
(\mathrm{Wh} / \mathrm{h} / \text { ton) }\end{array}$ \\
\hline 426 & AC & 10 & 2.7 & 4420 & 7728 & 1.75 & 640 & 7960 & 1.80 & 796 & 659 \\
\hline 427 & AC & 10 & 3.0 & 4420 & 9515 & 2.15 & 708 & 9867 & 2.23 & 987 & 735 \\
\hline
\end{tabular}




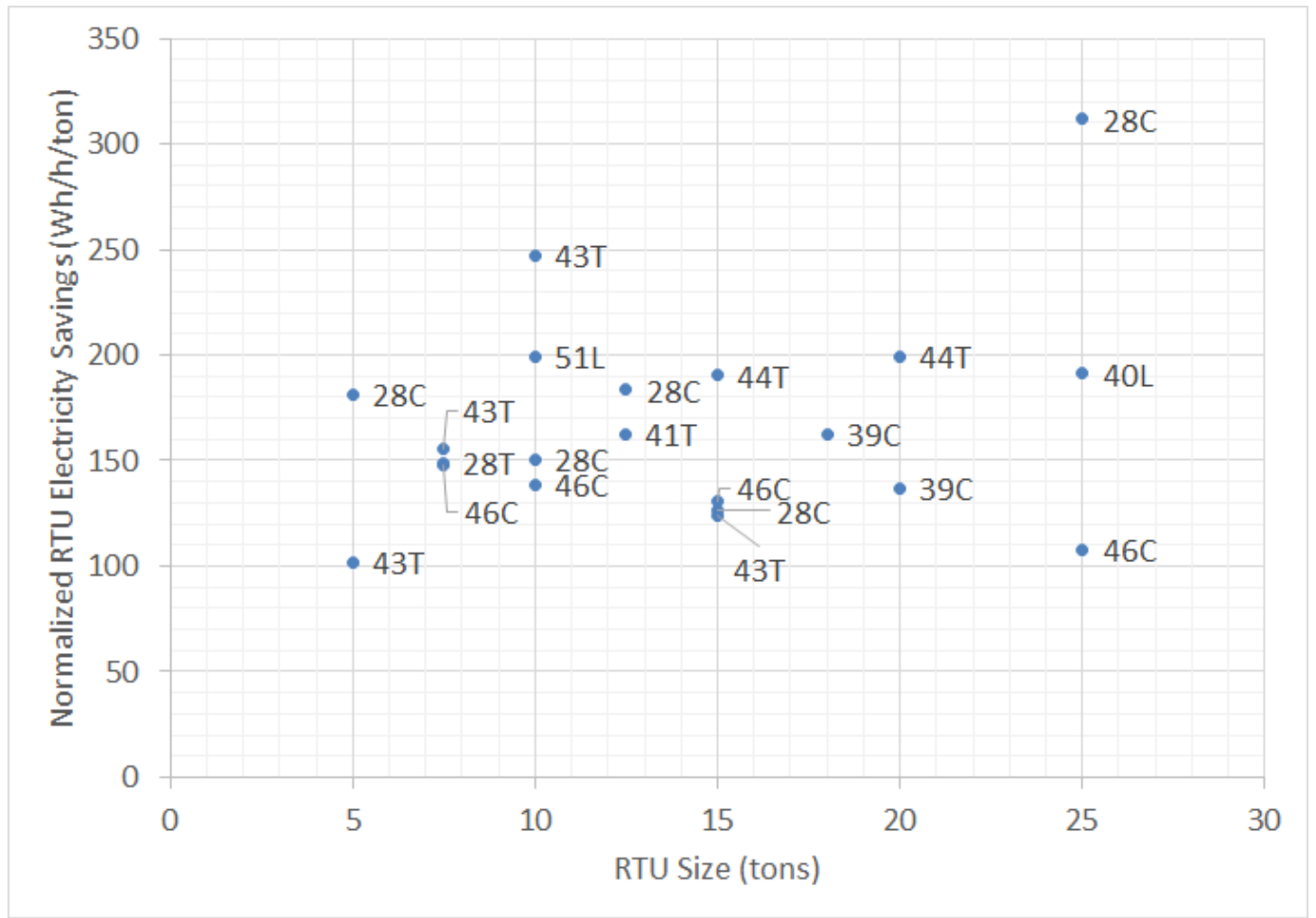

Figure 23: Variation of average normalized RTU electricity savings per unit run hour and per ton with RTU size

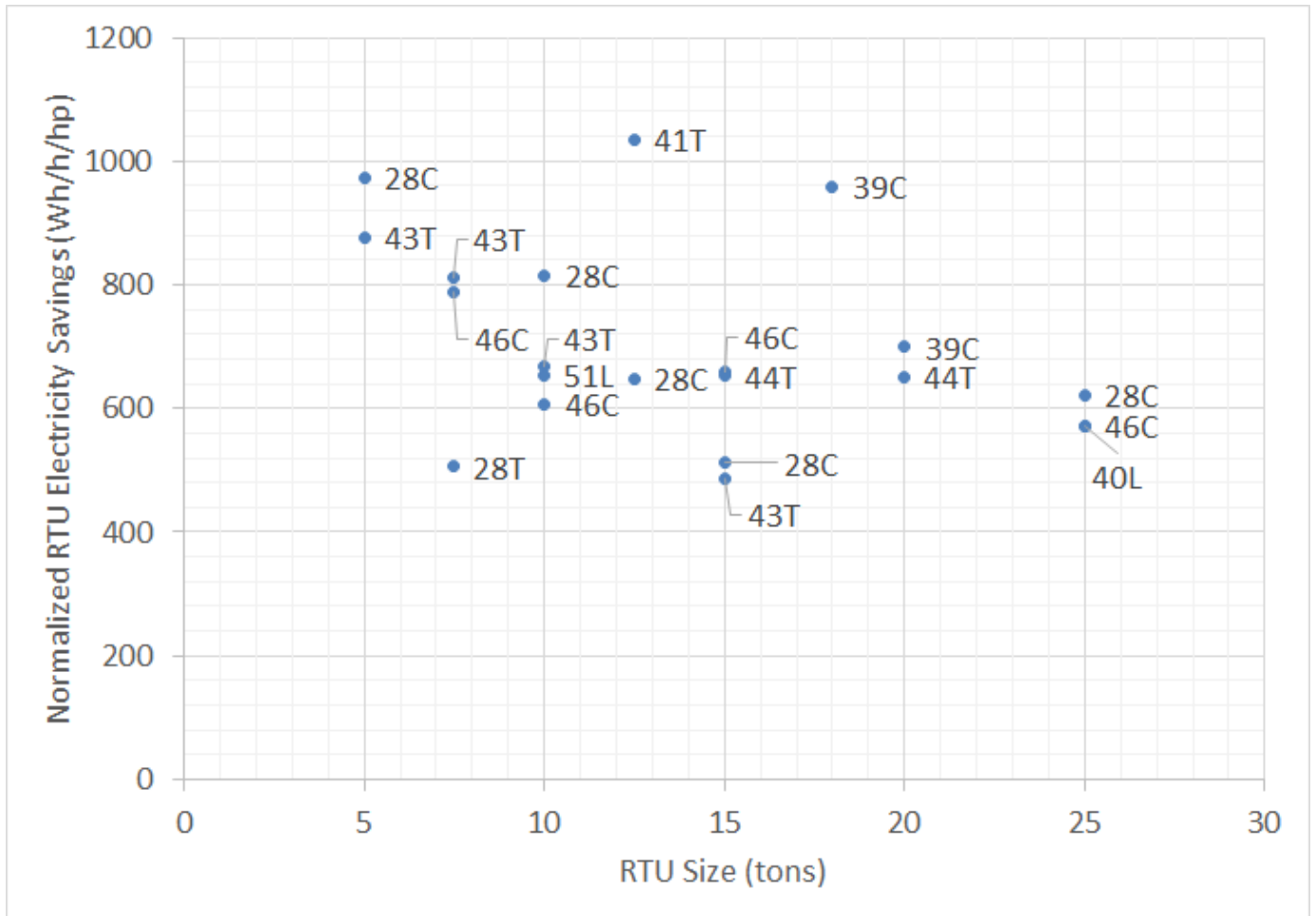

Figure 24: Variation of average normalized RTU electricity savings per unit run hour and per fan motor hp with RTU size 


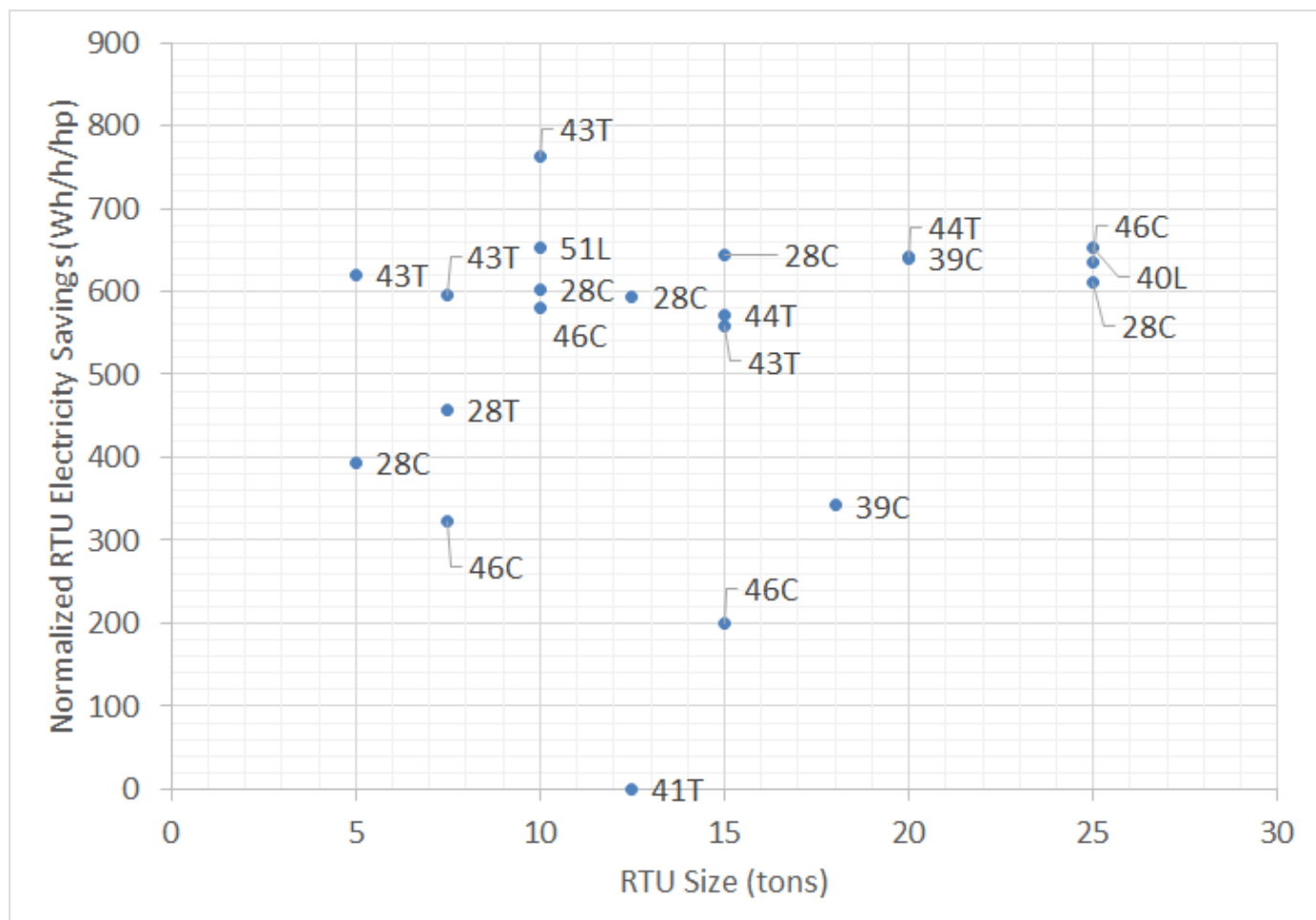

Figure 25: Variation of average normalized fan electricity savings per unit run hour and per fan motor hp with RTU size

Table 11: RTU operation schedules used for normalized annual RTU savings calculation

\begin{tabular}{|c|c|c|}
\hline Site ID & RTUs & RTU Operation Schedule \\
\hline \multirow{4}{*}{28} & 229 & $\begin{array}{l}\text { Mon.-Thu.: } 8: 00 \text { to } 21: 00 \\
\text { Fri. and Sat.: } 8: 00 \text { to } 23: 00 \\
\text { Sun.: } 8: 00 \text { to } 20: 00\end{array}$ \\
\hline & $\begin{array}{l}203,214,215,219-226 \text { and } \\
228\end{array}$ & $\begin{array}{l}\text { Mon.-Sat.: } 8: 00 \text { to } 22: 00 \\
\text { Sun.: } 8: 00 \text { to } 20: 00\end{array}$ \\
\hline & 204-210, 218 and 231 & Mon.-Fri.: $8: 00$ to $23: 00$ \\
\hline & $202,212,213$ and 217 & Mon.-Fri.: 8:00 to $22: 00$ \\
\hline 39 & All & $\begin{array}{l}\text { Mon.-Fri.: } 0: 00 \text { to } 24: 00 \\
\text { Sat.: 0:00 to } 14: 00 \\
\text { Sun.: 0:00 to } 18: 00\end{array}$ \\
\hline \multirow{2}{*}{40} & 364 and 365 & Mon.-Sun.: 9:00 to $24: 00$ \\
\hline & $366-371$ & Mon.-Sun.: 0:00 to $24: 00$ \\
\hline 41 & All & Mon.-Fri.: $6: 00$ to $18: 00$ \\
\hline 43 & All & Mon.-Fri.: $6: 00$ to $17: 00$ \\
\hline 44 & All & Mon.-Fri.: $6: 00$ to $1: 00$ \\
\hline 46 & All & Mon.-Sun.: 0:00 to $24: 00$ \\
\hline 51 & All & $\begin{array}{l}\text { Mon.-Thu.: } 8: 00 \text { to } 21: 00 \\
\text { Fri.: } 8: 00 \text { to } 22: 00 \\
\text { Sat.: } 9: 00 \text { to } 19: 00 \\
\text { Sun.: } 10: 00 \text { to } 18: 00\end{array}$ \\
\hline
\end{tabular}


Figure 26 and Figure 27 show the predicted versus actual annual normalized electricity savings for the RTU and the fan, respectively. The predicted savings were computed using a multiple linear regression with RTU runtime and fan horse power as independent variables (Table 12). Based on the regression statistics it appears the unit runtime (fan runtime) and fan horse power were good predictors of the potential energy savings from the advanced RTU controller retrofit. Note that for this analysis, the fan horsepower was actually measured and not the name plate reading. Using the nameplate reading will introduce some uncertainty but could still be valid.

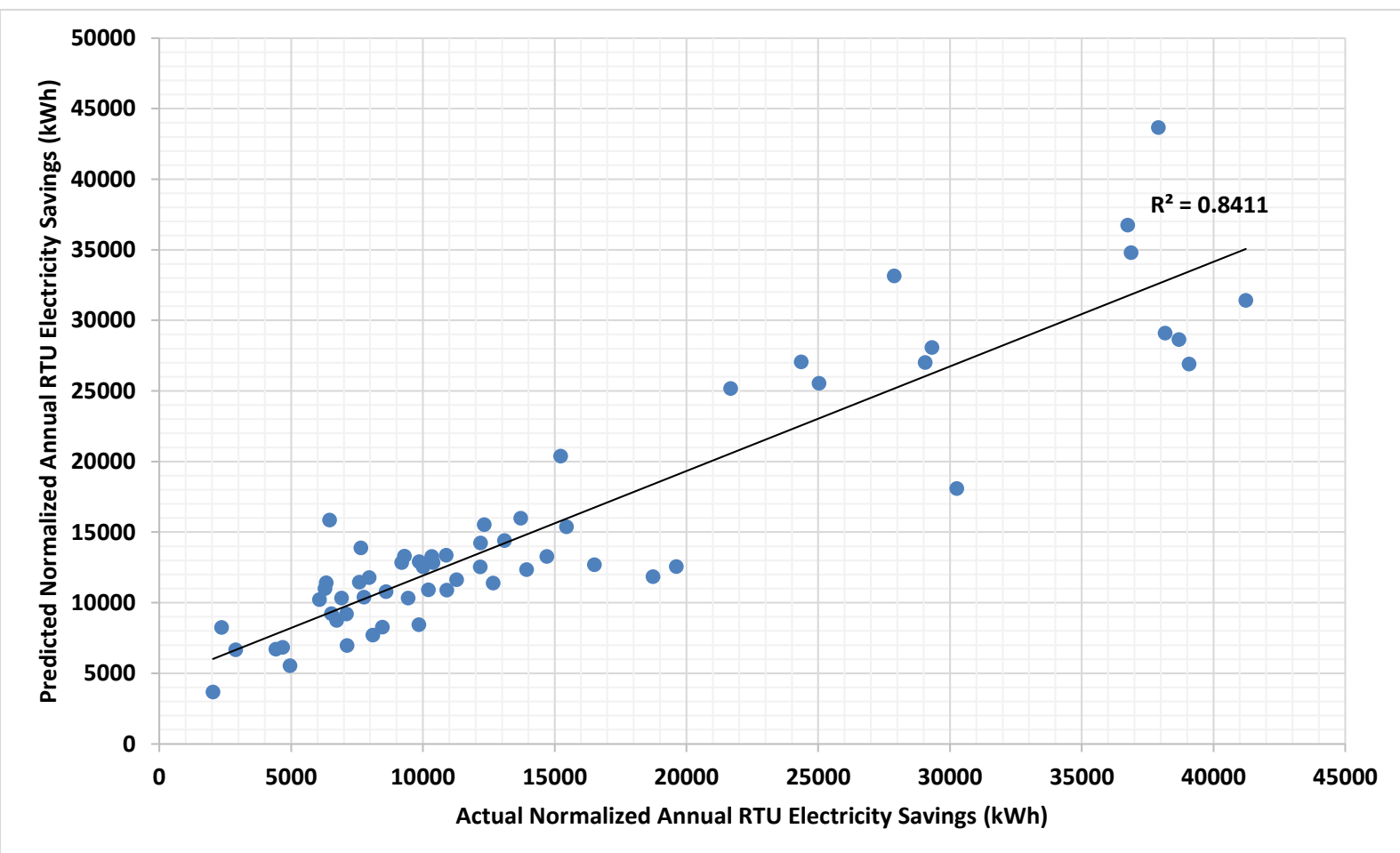

Figure 26: Predicted versus actual normalized annual RTU electricity savings

Table 12: Summary of the regression analysis

\begin{tabular}{|l|r|l|r|}
\hline \multicolumn{2}{|l|}{ RTU Electricity } & Fan Electricity \\
\hline Intercept & 0 & Intercept & 0 \\
\hline Runtime & 0.382 & Runtime & 0.069 \\
\hline Fan Horse Power & 3687.7 & Fan Horse Power & 3975.2 \\
\hline Adjusted R-Squared & 0.922 & Adjusted R-Squared & 0.896 \\
\hline
\end{tabular}

Figure 28 compares the frequency distributions of RTU electricity savings per unit run hour for actual and normalized savings. A majority of actual and normalized savings was in the range between 1.0 and $3.5 \mathrm{kWh} / \mathrm{h}$. Figure 29 compares the frequency distributions of RTU electricity savings per unit run hour and per supply fan motor hp for actual and normalized savings. A majority of actual and normalized savings were in the range between 600 and $900 \mathrm{Wh} / \mathrm{h} / \mathrm{hp}$. 


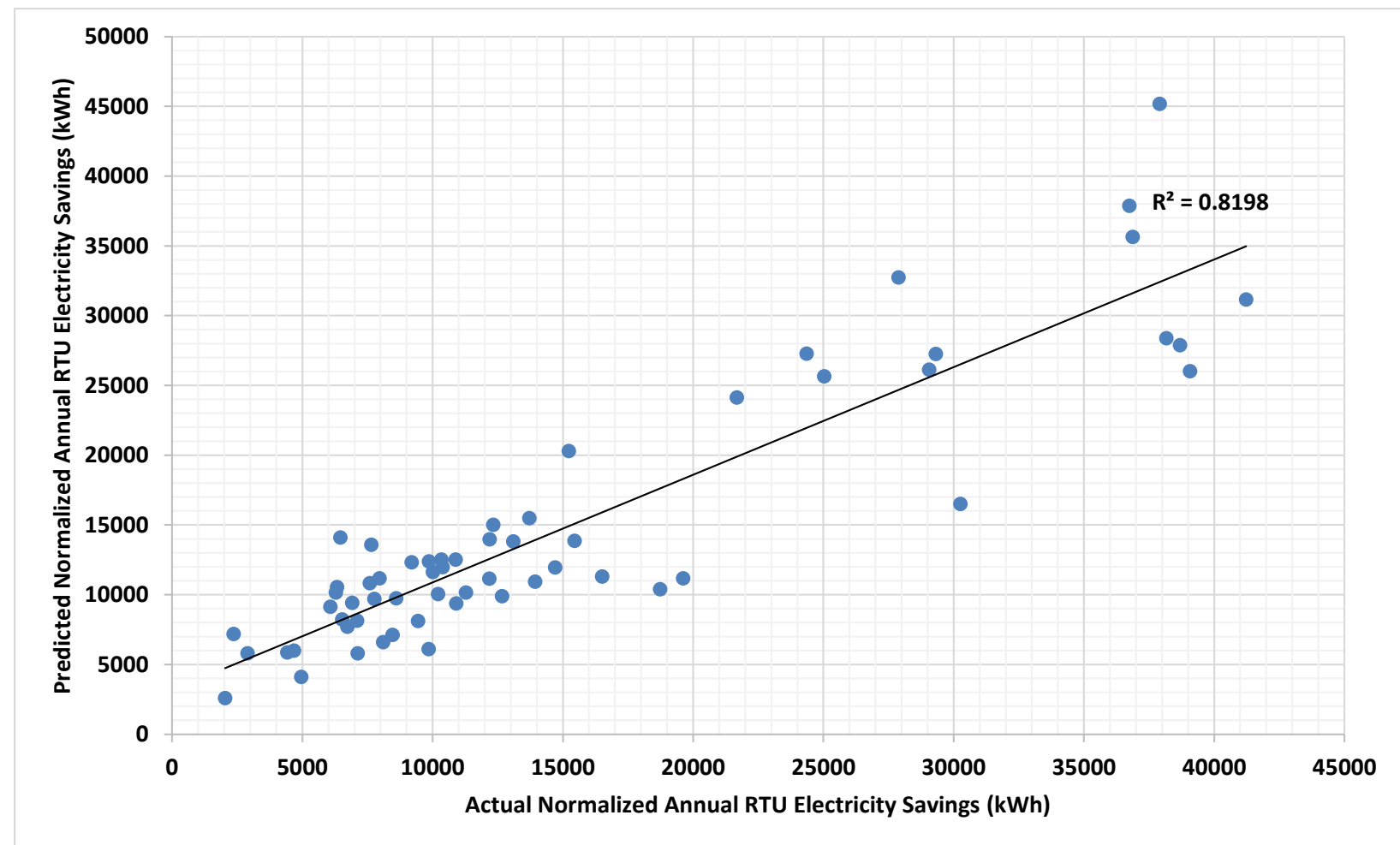

Figure 27: Predicted versus actual normalized annual fan electricity savings

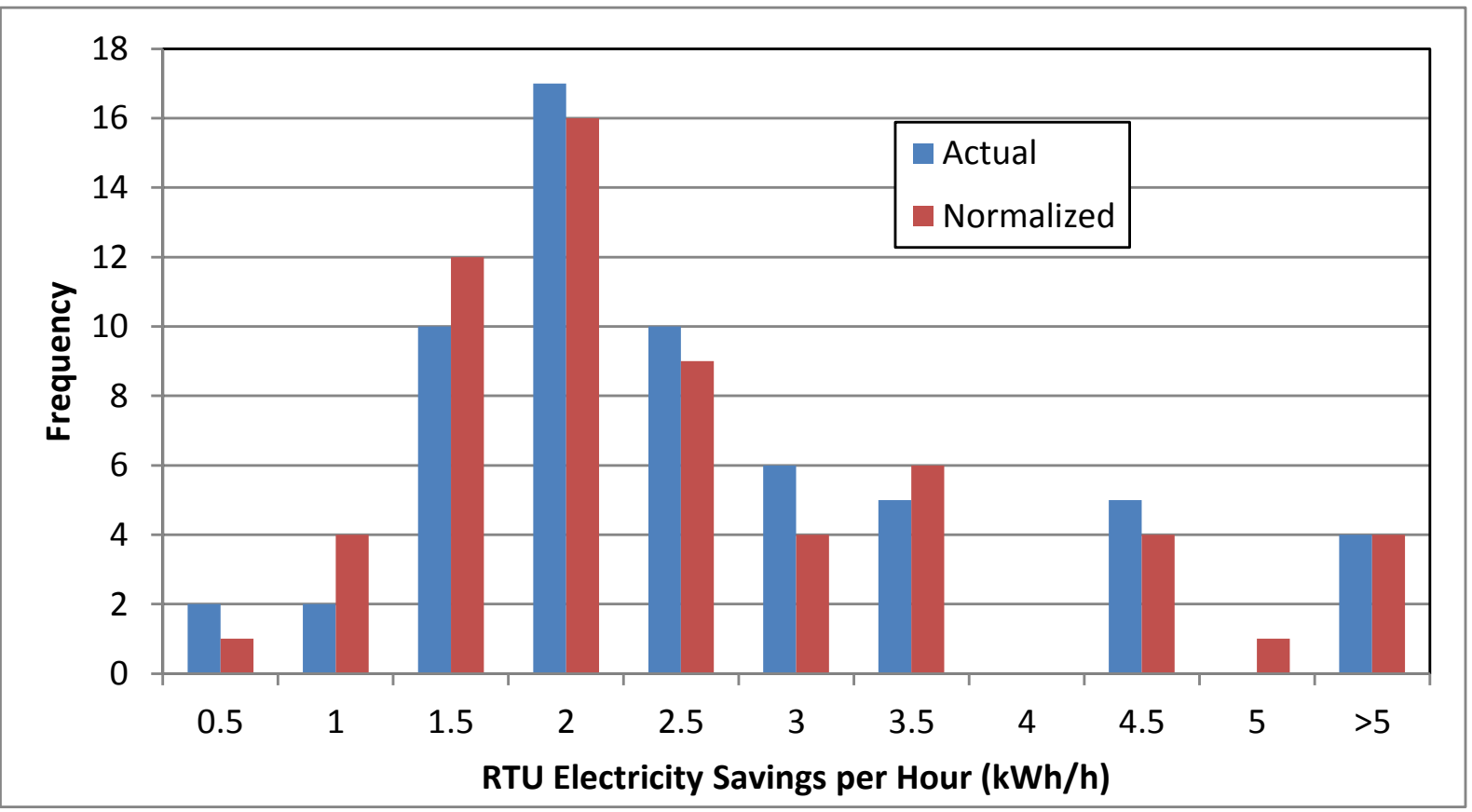

Figure 28: Frequency distribution of RTU electricity savings per unit run hour 


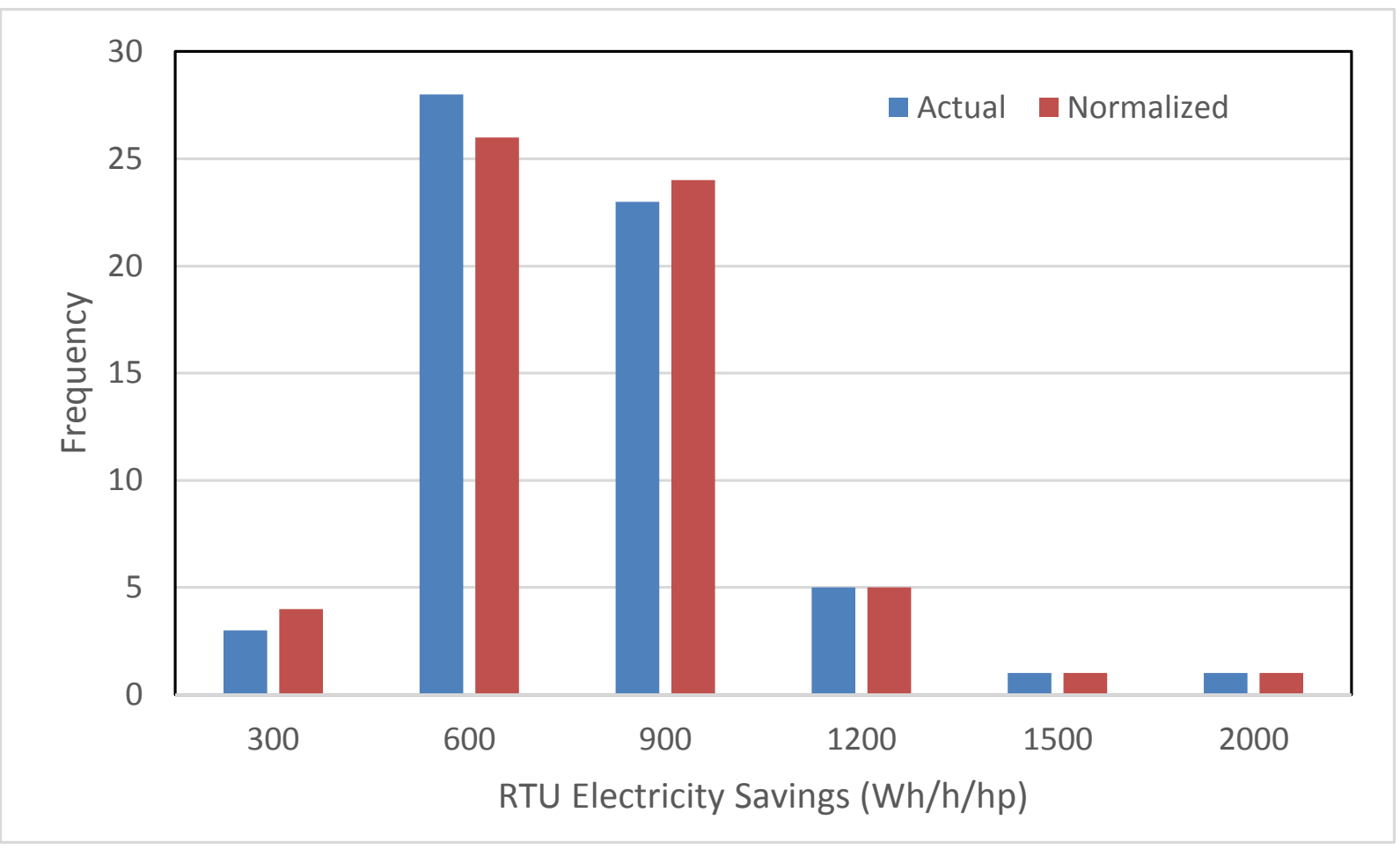

Figure 29: Frequency distribution of RTU electricity savings per unit run hour and supply fan motor hp Table 13 provides the quartiles of electricity savings.

Table 13: Quartiles of electricity savings for all RTUs

\begin{tabular}{|l|c|c|c|c|}
\hline \multirow{2}{*}{ Quartile } & \multicolumn{2}{|c|}{ Percentage of RTU Electricity Savings (\%) } & \multicolumn{2}{c|}{ RTU Electricity Savings per Hour (kWh/h) } \\
\cline { 2 - 5 } & Actual Savings & Normalized Savings & Actual Savings & Normalized Savings \\
\hline $25^{\text {th }}$ percentile & 38 & 43 & 1.54 & 1.38 \\
\hline $\begin{array}{l}50^{\text {th }} \text { percentile } \\
\text { (median) }\end{array}$ & 50 & 59 & 1.98 & 1.96 \\
\hline $75^{\text {th }}$ percentile & 71 & 70 & 2.87 & 2.84 \\
\hline
\end{tabular}

The results presented in this section demonstrate retrofitting an RTU with an advanced controller can lead to significant RTU energy savings. The impact of the advanced controller on RTU operation was also investigated through the changes of runtime in different operational modes before and after the controller retrofit.

- Table 14 provides the percentage of runtime in different modes throughout the entire measurement period. Five RTU operational modes considered included heating, ventilation, economizing mode only, mechanical cooling with integrated economizer, and mechanical cooling only. It must be noted that comparing runtime percentages, as shown in Table 14 is a valid approach only if 1 ) the pre- and post-retrofit periods have an approximately equal number of days; and 2) the pre- and post-retrofit periods cover identical or very similar weather 
conditions. Because the standard and the advanced control logic was alternated daily, the above two conditions were basically met for all sites except site 28 . Units on site 28 had more postretrofit days than pre-retrofit days because the daily alternation of control logic was started a few months after the retrofits were completed. The following needs to be noted when looking at the data in Table 14:

- All runtime percentages in different modes add to $100 \%$ for both pre- and post- retrofit periods.

- If an economizer was included, it was not integrated with mechanical cooling under the preretrofit control logic. Therefore, the percentage of runtime in integrated economizer mode was always zero for pre-retrofit period. RTU 407 is an exception probably caused by the control signal noises.

- Most units operated over $70 \%$ of the time in the ventilation mode.

- For almost all units, the percentage of runtime in heating decreased after the controller retrofit because of reduced outdoor-air supply from DCV. Because of the enhanced economizer from the controller retrofit, the runtime in economizing modes (both economizing only mode and integrated economizing mode) increased while the runtime in mechanical cooling only mode decreased. The change of runtime in ventilation mode varied depending on the magnitudes of runtime changes in other modes.

Table 14: Comparison of percentage of runtime in different modes between pre-and post-retrofit

\begin{tabular}{|c|c|c|c|c|c|c|c|c|c|c|}
\hline \multirow{2}{*}{$\begin{array}{l}\text { RTU } \\
\text { ID }\end{array}$} & \multicolumn{2}{|c|}{ Heating (\%) } & \multicolumn{2}{|c|}{ Ventilation (\%) } & \multicolumn{2}{|c|}{$\begin{array}{c}\text { Economizing Only } \\
\text { (\%) }\end{array}$} & \multicolumn{2}{|c|}{$\begin{array}{c}\text { Integrated } \\
\text { Economizer (\%) }\end{array}$} & \multicolumn{2}{|c|}{$\begin{array}{l}\text { DX Cooling Only } \\
\text { (\%) }\end{array}$} \\
\hline & Pre- & Post- & Pre- & Post- & Pre- & Post- & Pre- & Post- & Pre- & Post- \\
\hline 202 & 5 & 2 & 95 & 98 & 0 & 0 & 0 & 0 & 0 & 0 \\
\hline 203 & 0 & 0 & 98 & 97 & 0 & 0 & 0 & 0 & 2 & 2 \\
\hline 204 & 2 & 1 & 98 & 98 & 0 & 1 & 0 & 0 & 0 & 0 \\
\hline 205 & 1 & 0 & 98 & 98 & 0 & 0 & 0 & 0 & 0 & 1 \\
\hline 206 & 1 & 1 & 99 & 99 & 0 & 0 & 0 & 0 & 0 & 1 \\
\hline 207 & 0 & 1 & 83 & 82 & 0 & 7 & 0 & 6 & 17 & 5 \\
\hline 209 & 65 & 48 & 14 & 35 & 0 & 1 & 0 & 13 & 21 & 4 \\
\hline 210 & 1 & 0 & 79 & 75 & 0 & 2 & 0 & 12 & 19 & 11 \\
\hline 212 & 3 & 2 & 81 & 57 & 4 & 36 & 0 & 3 & 12 & 2 \\
\hline 213 & 0 & 0 & 98 & 98 & 0 & 0 & 0 & 0 & 2 & 2 \\
\hline 214 & 7 & 2 & 78 & 82 & 0 & 3 & 0 & 7 & 15 & 6 \\
\hline 215 & 10 & 5 & 90 & 95 & 0 & 0 & 0 & 0 & 0 & 0 \\
\hline 217 & 25 & 16 & 75 & 84 & 0 & 0 & 0 & 0 & 0 & 0 \\
\hline 218 & 3 & 0 & 76 & 65 & 0 & 7 & 0 & 19 & 21 & 8 \\
\hline 219 & 11 & 8 & 85 & 64 & 1 & 20 & 0 & 8 & 3 & 0 \\
\hline 220 & 15 & 7 & 77 & 84 & 0 & 4 & 0 & 4 & 9 & 2 \\
\hline 221 & 3 & 2 & 96 & 97 & 0 & 0 & 0 & 1 & 0 & 0 \\
\hline 222 & 3 & 1 & 96 & 98 & 0 & 0 & 0 & 0 & 2 & 1 \\
\hline 223 & 7 & 3 & 81 & 83 & 0 & 1 & 0 & 5 & 12 & 9 \\
\hline 224 & 6 & 3 & 89 & 84 & 0 & 2 & 0 & 7 & 5 & 5 \\
\hline 225 & 8 & 3 & 93 & 97 & 0 & 0 & 0 & 0 & 0 & 0 \\
\hline 226 & 15 & 4 & 69 & 70 & 0 & 9 & 0 & 12 & 16 & 5 \\
\hline 228 & 54 & 21 & 32 & 56 & 0 & 3 & 0 & 17 & 14 & 3 \\
\hline
\end{tabular}




\begin{tabular}{|c|c|c|c|c|c|c|c|c|c|c|}
\hline \multirow{2}{*}{$\begin{array}{l}\text { RTU } \\
\text { ID }\end{array}$} & \multicolumn{2}{|c|}{ Heating (\%) } & \multicolumn{2}{|c|}{ Ventilation (\%) } & \multicolumn{2}{|c|}{$\begin{array}{l}\text { Economizing Only } \\
(\%)\end{array}$} & \multicolumn{2}{|c|}{$\begin{array}{c}\text { Integrated } \\
\text { Economizer (\%) }\end{array}$} & \multicolumn{2}{|c|}{$\begin{array}{l}\text { DX Cooling Only } \\
\text { (\%) }\end{array}$} \\
\hline & Pre- & Post- & Pre- & Post- & Pre- & Post- & Pre- & Post- & Pre- & Post- \\
\hline 229 & 5 & 1 & 95 & 99 & 0 & 0 & 0 & 0 & 0 & 0 \\
\hline 231 & 11 & 2 & 84 & 81 & 0 & 11 & 0 & 2 & 6 & 4 \\
\hline 362 & 16 & 7 & 47 & 37 & 3 & 27 & 0 & 8 & 34 & 22 \\
\hline 363 & 4 & 3 & 84 & 85 & 0 & 3 & 0 & 1 & 12 & 8 \\
\hline 364 & 2 & 2 & 59 & 48 & 2 & 13 & 0 & 6 & 37 & 31 \\
\hline 365 & 21 & 20 & 62 & 58 & 0 & 1 & 0 & 1 & 16 & 21 \\
\hline 366 & 16 & 15 & 75 & 61 & 0 & 1 & 0 & 1 & 9 & 23 \\
\hline 367 & 45 & 44 & 54 & 38 & 0 & 0 & 0 & 0 & 1 & 18 \\
\hline 368 & 40 & 38 & 36 & 28 & 0 & 0 & 0 & 2 & 24 & 33 \\
\hline 369 & 15 & 14 & 78 & 72 & 0 & 1 & 0 & 1 & 7 & 13 \\
\hline 370 & 6 & 5 & 85 & 80 & 0 & 1 & 0 & 1 & 9 & 14 \\
\hline 371 & 1 & 1 & 77 & 69 & 1 & 8 & 0 & 3 & 21 & 18 \\
\hline 372 & 3 & 2 & 81 & 82 & 0 & 3 & 0 & 3 & 16 & 10 \\
\hline 375 & 18 & 10 & 74 & 81 & 0 & 5 & 0 & 1 & 8 & 3 \\
\hline 376 & 12 & 9 & 81 & 82 & 0 & 6 & 0 & 2 & 7 & 2 \\
\hline 377 & 13 & 7 & 80 & 78 & 1 & 12 & 0 & 2 & 6 & 1 \\
\hline 378 & 1 & 1 & 82 & 60 & 13 & 24 & 0 & 9 & 4 & 5 \\
\hline 379 & 4 & 2 & 85 & 78 & 2 & 15 & 0 & 3 & 9 & 3 \\
\hline 380 & 12 & 9 & 82 & 84 & 0 & 4 & 0 & 2 & 6 & 1 \\
\hline 381 & 27 & 23 & 65 & 67 & 0 & 5 & 0 & 2 & 8 & 4 \\
\hline 382 & 20 & 13 & 76 & 81 & 0 & 3 & 0 & 1 & 4 & 2 \\
\hline 383 & 18 & 14 & 74 & 78 & 0 & 4 & 0 & 1 & 9 & 3 \\
\hline 384 & 5 & 4 & 92 & 91 & 0 & 3 & 0 & 1 & 3 & 1 \\
\hline 385 & 23 & 13 & 73 & 76 & 0 & 7 & 0 & 3 & 4 & 1 \\
\hline 386 & 9 & 6 & 84 & 84 & 0 & 5 & 0 & 3 & 7 & 2 \\
\hline 387 & 7 & 5 & 75 & 74 & 0 & 6 & 0 & 12 & 18 & 3 \\
\hline 388 & 10 & 9 & 89 & 90 & 0 & 0 & 0 & 0 & 0 & 0 \\
\hline 389 & 22 & 13 & 61 & 65 & 0 & 9 & 0 & 8 & 17 & 4 \\
\hline 407 & 2 & 1 & 22 & 13 & 8 & 28 & 0 & 14 & 68 & 45 \\
\hline 408 & 10 & 9 & 60 & 59 & 0 & 0 & 0 & 0 & 30 & 32 \\
\hline 409 & 17 & 8 & 77 & 83 & 0 & 0 & 0 & 1 & 6 & 8 \\
\hline 410 & 15 & 15 & 77 & 75 & 0 & 0 & 0 & 0 & 8 & 11 \\
\hline 411 & 45 & 46 & 29 & 31 & 0 & 0 & 0 & 0 & 26 & 23 \\
\hline 423 & 9 & 3 & 91 & 97 & 0 & 0 & 0 & 0 & 0 & 0 \\
\hline 424 & 0 & 0 & 77 & 69 & 3 & 18 & 0 & 4 & 20 & 9 \\
\hline 425 & 0 & 0 & 94 & 83 & 0 & 10 & 0 & 3 & 5 & 4 \\
\hline 426 & 2 & 0 & 89 & 83 & 0 & 7 & 0 & 2 & 9 & 8 \\
\hline 427 & 13 & 2 & 84 & 90 & 0 & 6 & 0 & 1 & 4 & 2 \\
\hline
\end{tabular}

Because total RTU electricity savings were the major focus of this work, subsequent discussions on aggregated results no longer cover heating, cooling and fan energy consumption individually. 


\subsection{ReSUlts by BuILDing Site}

Table 15 shows the percentage of total RTU electricity savings and the overall uncertainty of total electricity savings for all eight building sites. The percentage of electricity savings was calculated by dividing the sum of electricity savings by the sum of projected baseline electricity consumption. The savings uncertainty at a building site was calculated from each unit's fractional uncertainty and electricity savings, according to the equation below.

$U_{\text {site }}=\frac{\sqrt{\sum\left(U_{i} * R T U E_{\text {save }, i}\right)^{2}}}{\sum R T U E_{\text {save }, i}}$

where $U$ is the savings uncertainty, $R T U E_{\text {save }}$ is the saved RTU electricity in kWh, the subscripts site and $i$ represent a building site and each individual unit at that site.

Major conclusions from Table 15 are as follows:

- For both actual and normalized savings, the percentage of RTU electricity savings was in the range between 37\% (Site ID=44) and 73\% (Site ID=51). Five building sites (Site ID= 28, 39, 43, 44, 51 ) had no more than $5 \%$ difference between the actual savings and the normalized annual savings. Their closeness likely resulted from the representative weather coverage through the post-retrofit period. In some sense, if the field measurement period covered the heating season, the cooling season and the shoulder season, it can be reasonably regarded as a down-scaled annual measurement.

- Actual savings uncertainty ranged between $3 \%$ (Site ID=51) and $15 \%$ (Site ID=46), while normalized savings uncertainty ranged between $1 \%$ (Site ID=51) and $18 \%$ (Site ID=41). For building sites with multiple units, the aggregated savings uncertainty was much smaller than those for individual units, which was expected (see Equation 7-1).

Table 15: Percentage of RTU electricity savings and uncertainty by building site

\begin{tabular}{|c|c|c|c|c|c|c|c|}
\hline \multirow{2}{*}{$\begin{array}{l}\text { Site } \\
\text { ID }\end{array}$} & \multirow{2}{*}{$\begin{array}{l}\text { Climate } \\
\text { Zone }\end{array}$} & \multirow{2}{*}{$\begin{array}{l}\text { Number } \\
\text { of RTUs }\end{array}$} & \multirow{2}{*}{$\begin{array}{l}\text { RTU } \\
\text { Type }\end{array}$} & \multicolumn{2}{|c|}{ Actual Savings } & \multicolumn{2}{|c|}{ Normalized Savings } \\
\hline & & & & $\begin{array}{l}\text { RTU Electricity } \\
\text { (\%) }\end{array}$ & $\begin{array}{l}\text { Uncertainty } \\
\text { (\%) }\end{array}$ & $\begin{array}{l}\text { RTU Electricity } \\
\text { (\%) }\end{array}$ & $\begin{array}{c}\text { Uncertainty } \\
\text { (\%) }\end{array}$ \\
\hline 28 & $4 C$ & 25 & $A C$ & 63 & 4 & 67 & 2 \\
\hline 39 & $5 A$ & 2 & $A C$ & 50 & 13 & 55 & 8 \\
\hline 40 & $4 \mathrm{~A}$ & 8 & $A C$ & 46 & 6 & 52 & 4 \\
\hline 41 & $4 C$ & 1 & HP & 64 & 14 & 43 & 18 \\
\hline 43 & $4 C$ & 6 & HP & 43 & 13 & 38 & 8 \\
\hline 44 & $4 C$ & 9 & HP & 39 & 14 & 37 & 9 \\
\hline 46 & $3 B$ & 5 & $A C$ & 37 & 15 & 48 & 8 \\
\hline 51 & $4 C$ & 5 & $A C$ & 72 & 3 & 73 & 1 \\
\hline
\end{tabular}


Table 16 provides the absolute electricity savings for all sites. In this table, the cooling tons are the sum of the nominal cooling capacities of the tested RTU on each site. Total RTU electricity savings are summed from the results for individual RTUs. The average RTU electricity savings per hour is calculated by dividing the sum of total savings by the sum of RTU run hours from Table 7 and Table 8 . For normalized savings, the average savings per cooling tonnage was also calculated by dividing the sum of total savings by the cooling tons on each site. Actual savings per ton were not calculated to avoid misleading comparisons because different building sites had measurement periods with different seasons and length of time covered. Major conclusions from results presented in Table 16 include:

- Actual electricity savings ranged between 1.40 (Site ID=43) and 3.91 (Site ID=39, 40) kWh/ $\mathrm{h}$. The weather normalized electricity savings ranges between 1.41 (Site ID=43) and 3.97 (Site ID=40) $\mathrm{kWh} / \mathrm{h}$. Most sites had very close hourly electricity savings results between actual savings and normalized savings.

- The weather normalized RTU electricity savings per ton was in the range between 565 and 1,492 $\mathrm{kWh}$ /ton. This large range of savings was related to equipment sizing, the length of RTU runtime, and building load characteristics.

Table 16: RTU electricity saving per hour and per ton by building site

\begin{tabular}{|c|c|c|c|c|c|c|c|}
\hline \multirow{2}{*}{$\begin{array}{l}\text { Site } \\
\text { ID }\end{array}$} & \multirow{2}{*}{$\begin{array}{l}\text { Climate } \\
\text { Zone }\end{array}$} & \multirow{2}{*}{$\begin{array}{l}\text { Number } \\
\text { of RTUs }\end{array}$} & \multirow{2}{*}{$\begin{array}{l}\text { RTU } \\
\text { Type }\end{array}$} & \multirow{2}{*}{$\begin{array}{l}\text { Cooling } \\
\text { Tons }\end{array}$} & \multirow{2}{*}{$\begin{array}{l}\text { Actual Savings } \\
\text { RTU Electricity } \\
\text { Savings (kWh/h) }\end{array}$} & \multicolumn{2}{|c|}{ Normalized Savings } \\
\hline & & & & & & $\begin{array}{c}\text { RTU Electricity } \\
\text { Savings (kWh/h) }\end{array}$ & $\begin{array}{c}\text { RTU Electricity } \\
\text { Savings (kWh/ton) }\end{array}$ \\
\hline 28 & $4 \mathrm{C}$ & 25 & $A C$ & 320 & 2.32 & 2.26 & 948 \\
\hline 39 & $5 \mathrm{~A}$ & 2 & $A C$ & 38 & 3.91 & 3.59 & 1,492 \\
\hline 40 & $4 \mathrm{~A}$ & 8 & $A C$ & 200 & 3.91 & 3.97 & 1,258 \\
\hline 41 & $4 C$ & 1 & HP & 12.5 & 2.87 & 2.13 & 744 \\
\hline 43 & $4 C$ & 6 & $\mathrm{HP}$ & 60 & 1.40 & 1.41 & 565 \\
\hline 44 & $4 C$ & 9 & $\mathrm{HP}$ & 140 & 1.98 & 1.72 & 932 \\
\hline 46 & $3 B$ & 5 & $A C$ & 82.5 & 1.95 & 1.78 & 942 \\
\hline 51 & $4 C$ & 5 & $A C$ & 50 & 1.94 & 1.92 & 848 \\
\hline
\end{tabular}

In addition to the total RTU electricity savings, the savings contributions from different months were investigated. This was conducted only for normalized savings because the actual measurements do not cover the same period for different building sites. Figure 30 shows the percentages of normalized annual electricity savings in each month. This figure led to the following observations:

- Monthly contribution ranged from approximately $6 \%$ to $12 \%$. A couple of building sites (e.g., Sites 46 and 40 ) had relatively even distribution of monthly savings across the whole year.

- Sites 43 and 44 had relatively higher savings in the heating season (December, January and February) because they used heat pumps. More comparisons between RTU types are reported later in Section 7.4. 


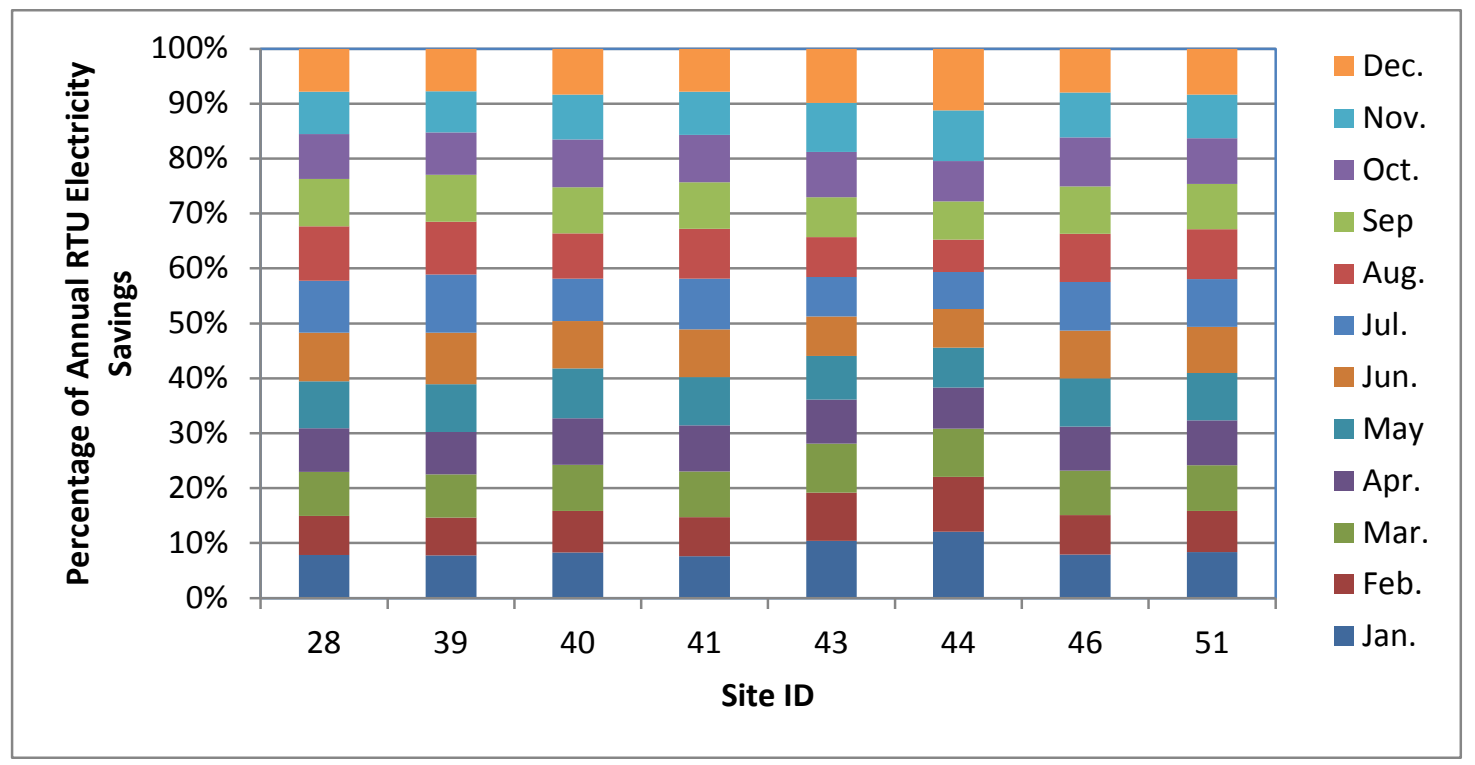

Figure 30: Monthly contribution to normalized annual electricity savings for different building sites

Figure 31 compares the percentage of runtime in different RTU operational modes between the preand the post-retrofit periods. This figure leads to similar findings as those from Table 14. At the building site level, the following changes can be observed after the controller retrofit:

- The reduction of runtime percentage in the heating mode ranged between $1 \%$ for site 40 and $6 \%$ for Site 28 . After the RTU controller retrofit, the runtime in heating mode decreased by $50 \%$ for sites 28,39 , and 51 . The runtime for space heating decreased because the advanced controller had DCV and thereby had decreased outdoor-air intake.

- The increase of runtime percentage in the economizing-only mode ranged between $2 \%$ for site 46 and $12 \%$ for Site 39 . RTUs operate more frequently in economizing mode because the economizer control was changed from fixed change-over point to differential dry-bulb control. In addition, enabling integrated economizer control led to between $2 \%$ and $4 \%$ more time running in the integrated economizer mode.

- Except for site 40, the percentage of runtime in the mechanical cooling only mode decreased after the controller retrofit.

\subsection{Results by RTU Size}

The RTUs were classified into three groups according to their nominal cooling capacities. The three groups had the following cooling capacity ranges: less than 10 tons, between 10 and 15 tons, and greater than 15 tons. Because the RTUs in each group may be located in different buildings or even different climate conditions, it was no longer meaningful to derive the percentage electricity savings by dividing the sum of electricity savings by the sum of projected baseline electricity consumption. Therefore, the percentage electricity savings for each group was calculated simply as the average of percentage savings for all units in that group. Table 17 shows the results of percentage savings together with the average of overall uncertainties. This table indicates that the middle and large group, with size 
ranges between 10 and 15 tons, had a higher percentage of electricity savings and lower uncertainty than the other two groups. However, it might be not reasonable to generalize the findings from this field test.

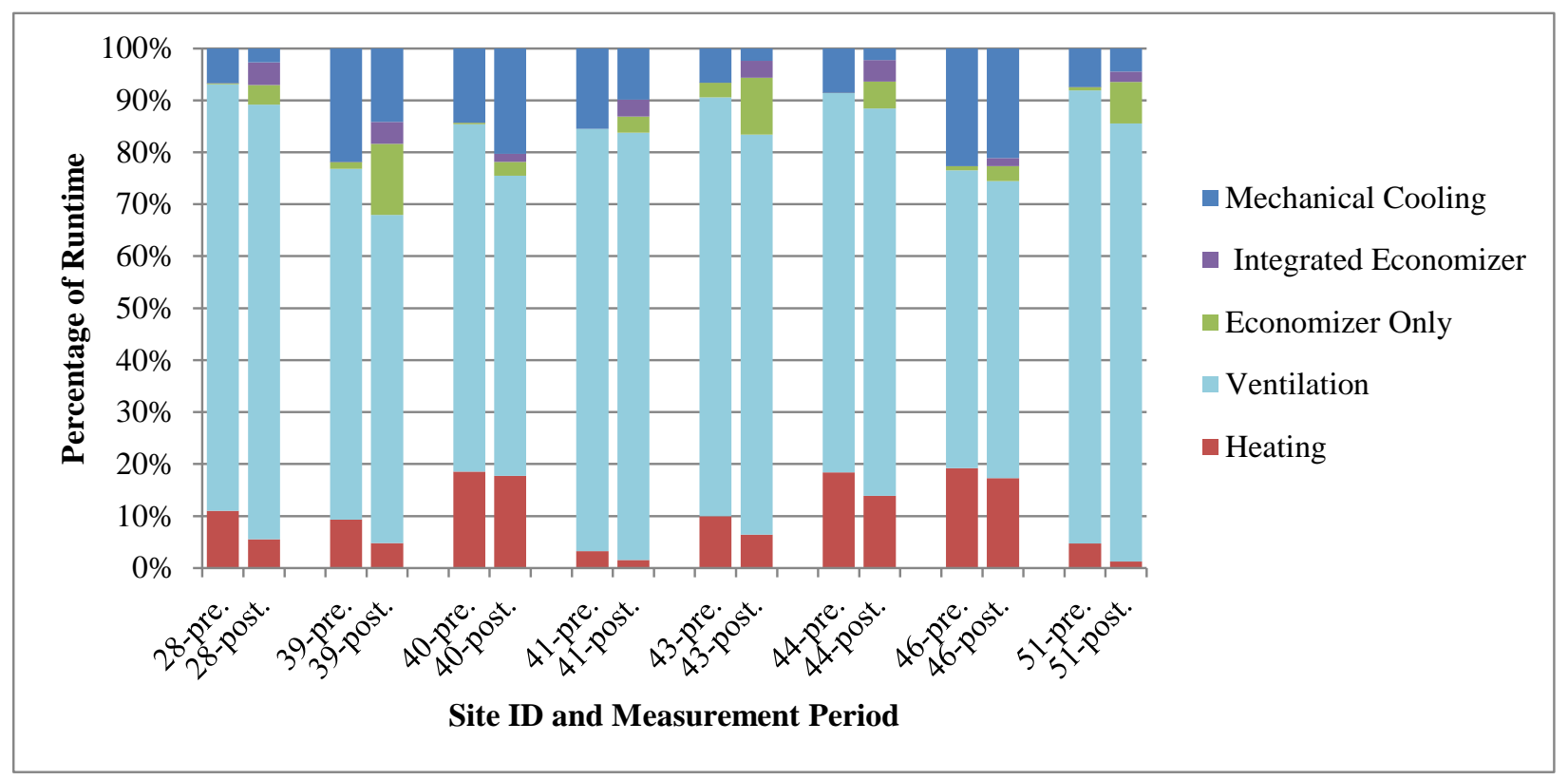

Figure 31: RTU runtime distribution across operational modes for different building sites

Table 17: Percentage of electricity savings and uncertainty by RTU size

\begin{tabular}{|c|c|c|c|c|c|}
\hline \multirow[b]{2}{*}{ Cooling Capacity } & \multirow{2}{*}{$\begin{array}{l}\text { Number } \\
\text { of RTUs }\end{array}$} & \multicolumn{2}{|c|}{ Actual Savings } & \multicolumn{2}{|c|}{ Normalized Savings } \\
\hline & & $\begin{array}{l}\text { RTU Electricity } \\
\text { Savings (\%) }\end{array}$ & $\begin{array}{c}\text { Uncertainty } \\
\text { (\%) }\end{array}$ & $\begin{array}{l}\text { RTU Electricity } \\
\text { Savings (\%) }\end{array}$ & $\begin{array}{c}\text { Uncertainty } \\
\text { (\%) }\end{array}$ \\
\hline$<10$ tons & 7 & 43 & 13 & 44 & 6 \\
\hline$\geq 10$ tons and $\leq 15$ tons & 38 & 59 & 5 & 60 & 3 \\
\hline$>15$ tons & 16 & 49 & 5 & 55 & 3 \\
\hline
\end{tabular}

Similarly, the RTU electricity savings per hour and savings per ton were calculated as the average of the corresponding entries for all units in each group, as shown in Table 18. Both actual and normalized savings increased from about $1.0 \mathrm{kWh} / \mathrm{h}$ for the group with the small RTU size, to $1.8 \mathrm{kWh} / \mathrm{h}$ for the group with the medium RTU size, and then to $4.2 \mathrm{kWh} / \mathrm{h}$ for the group with the large RTU size. On average, RTUs with large size had about $60 \%$ more normalized electricity savings per ton than those with medium and small sizes. Savings per ton were not calculated for actual savings to avoid misleading results, as explained earlier in Section 7.1. 
Table 18: Electricity saving per hour and per ton by RTU size

\begin{tabular}{|l|c|c|c|c|}
\hline \multirow{2}{*}{ Cooling Capacity } & \multirow{2}{*}{$\begin{array}{c}\text { Number } \\
\text { of RTUs }\end{array}$} & \begin{tabular}{c} 
Actual Savings \\
RTU Electricity \\
\cline { 3 - 5 }
\end{tabular} & $\begin{array}{c}\text { Savings (kWh/h) } \\
\text { RTU Electricity } \\
\text { Savings (kWh/h) }\end{array}$ & $\begin{array}{c}\text { RTU Electricity } \\
\text { Savings (kWh/ton) }\end{array}$ \\
\hline$<10$ tons & 7 & 1.03 & 0.99 & 790 \\
\hline$\geq 10$ tons and $\leq 15$ tons & 38 & 1.88 & 1.83 & 822 \\
\hline$>15$ tons & 16 & 4.23 & 4.27 & 1,266 \\
\hline
\end{tabular}

\subsection{RESUlTS BY RTU TyPE}

The RTUs were classified into two groups: one for AC units and the other for HP units. Following the same approach as used for RTU size, the percentage electricity savings for each group was calculated simply as the average of percentage savings for all units in that group. Table 19 shows the results of percentage savings together with the average of overall uncertainties. This table indicates that the AC group had higher percentage of electricity savings and lower uncertainty than the HP group. However, it might not be reasonable to generalize the findings from this field test.

Table 19: Percentage of electricity savings by RTU type

\begin{tabular}{|c|c|c|c|c|c|}
\hline \multirow{2}{*}{ RTU Type } & \multirow{2}{*}{$\begin{array}{c}\text { Number of } \\
\text { RTUs }\end{array}$} & \multicolumn{2}{|c|}{ Actual Savings } & \multicolumn{2}{c|}{ Normalized Savings } \\
\cline { 3 - 6 } & & $\begin{array}{c}\text { RTU Electricity } \\
\text { Savings (\%) }\end{array}$ & $\begin{array}{c}\text { Uncertainty } \\
\text { (\%) }\end{array}$ & $\begin{array}{c}\text { RTU Electricity } \\
\text { Savings (\%) }\end{array}$ & $\begin{array}{c}\text { Uncertainty } \\
\text { (\%) }\end{array}$ \\
\hline AC & 45 & 60 & 3 & 64 & 2 \\
\hline HP & 16 & 42 & 11 & 38 & 7 \\
\hline
\end{tabular}

RTU electricity savings per hour and per ton were calculated as the average of the corresponding entries for all units in each group, as provided in Table 20. Savings per ton were not calculated for actual savings to avoid misleading results, as explained earlier in Section 7.1. For both actual savings and normalized savings, the AC group saved about $2.6 \mathrm{kWh} / \mathrm{h}$, while the HP group saved about $1.8 \mathrm{kWh} / \mathrm{h}$. On average, AC units had about $25 \%$ more electricity savings per ton than HP units. Possible reasons for this include: 1) most HP units were smaller size than AC units; and 2) some HP units had simultaneous heating and cooling problem as illustrated in Figure 11.

Table 20: Electricity saving per hour and per ton by RTU type

\begin{tabular}{|c|c|c|c|c|}
\hline \multirow{2}{*}{ RTU Type } & \multirow{2}{*}{$\begin{array}{c}\text { Number } \\
\text { of RTUs }\end{array}$} & Actual Savings & \multicolumn{2}{|c|}{ Normalized Savings } \\
\cline { 3 - 5 } & & $\begin{array}{c}\text { RTU Electricity Savings } \\
\text { (kWh/h) }\end{array}$ & $\begin{array}{c}\text { RTU Electricity Savings } \\
\text { (kWh/h) }\end{array}$ & $\begin{array}{c}\text { RTU Electricity Savings } \\
\text { (kWh/ton) }\end{array}$ \\
\hline AC & 45 & 2.62 & 2.58 & 988 \\
\hline HP & 16 & 1.82 & 1.84 & 787 \\
\hline
\end{tabular}




\section{ECONOMIC ANALYSIS}

This section provides details on labor, metering and monitoring costs associated with the RTU advanced controller retrofits. Once these costs are determined, a simple payback period can be calculated for each RTU and each site. When analyzing each individual RTU, the payback period will be estimated without considering the metering and monitoring costs (just the installed cost of the controller). For site analysis, the payback period will be estimated with and without the metering and monitoring packages. The simple payback analysis helps building owners understand the financial impact of RTU controller retrofits and justify their investment. In addition, the tables provide guidance on the impact of adding the monitoring package and utility incentives on the payback period.

\subsection{RTU AdVANCEd Controller Cost BreaKdown}

Table 21 breaks down the costs associated with the advanced controller retrofit by metering and monitoring for a single RTU at varying capacities and corresponding supply-fan sizes. While the metering costs are fixed upfront, the monitoring is broken down into fixed and variable cost $(\$ /$ month for internet subscription and hosting fees).

Table 21: RTU advanced controller costs broken down by metering and monitoring

\begin{tabular}{|c|r|r|r|r|r|r|r|}
\hline $\begin{array}{c}\text { RTU Capacity } \\
\text { (tons) }\end{array}$ & $\begin{array}{c}\text { Supply Fan } \\
\text { Size (hp) }\end{array}$ & $\begin{array}{c}\text { Controller } \\
(\$)\end{array}$ & $\begin{array}{c}\text { Controller } \\
\text { Labor }(\$)\end{array}$ & $\begin{array}{c}\text { Metering }(\$) \\
\text { Labor }(\$)\end{array}$ & $\begin{array}{c}\text { Fixed } \\
\text { Monitoring (\$) }\end{array}$ & $\begin{array}{c}\text { Variable } \\
\text { Monitoring } \\
\text { (\$/Month) }\end{array}$ \\
\hline$\leq 5$ & 1 & 2,200 & 750 & 1,071 & 375 & 2,403 & 50 \\
\hline$>5$ and $\leq 10$ & 2 & 2,600 & 750 & 1,071 & 375 & 2,403 & 50 \\
\hline$>10$ and $\leq 15$ & 3 & 3,500 & 750 & 1,071 & 375 & 2,403 & 50 \\
\hline$>15$ and $\leq 20$ & 5 & 4,000 & 750 & 1,071 & 375 & 2,403 & 50 \\
\hline$>20$ and $\leq 25$ & 7.5 & 4,142 & 750 & 1,071 & 375 & 2,403 & 50 \\
\hline
\end{tabular}

- Controller cost varied because the size of the variable frequency drive (VFD) depended on the size of the supply fan motor, which was included in the controller cost.

- Labor rate was assumed to be $\$ 125 / \mathrm{h}$. This may vary based on market conditions.

- Metering included a total RTU power measurement device, a mixed-air sensor and cost to install the two sensors.

- Fixed monitoring cost included an elQ nSite center unit, cellular modem, radio, and wireless client transmitter. This cost is for one RTU, and each additional RTU at a site increased the monitoring cost by an additional $\$ 150$.

- Variable monitoring includes elQ hosting and internet access. 


\subsection{Advanced RTU Controller Payback Analysis}

Based on the costs outlined in Table 21, a simple payback period was calculated for the advanced controller, based on the projected normalized annual energy savings. Three utility rates were used: $0.05 \$ / \mathrm{kWh}, 0.10 \$ / \mathrm{kWh}$ and $0.15 \$ / \mathrm{kWh}$. This payback period is only for the controller and labor to install the controller. It did not include any of the metering packages. Table 22 gives the results for the payback analysis by unit, as well as the unit capacity, normalized annual energy savings and normalized runtime. Across all units, the annual average cost savings were $\$ 744, \$ 1,489$ and $\$ 2,233$ for the three considered utility rates, with a corresponding average installed cost of $\$ 4,172$, resulting in average payback period of 6,3 , and 2 years, respectively.

Table 22: Unit cost savings and payback period based on three different utility rates

\begin{tabular}{|c|c|c|c|c|c|c|c|c|c|}
\hline \multirow{3}{*}{$\begin{array}{l}\text { RTU } \\
\text { ID }\end{array}$} & \multirow{3}{*}{$\begin{array}{c}\text { RTU } \\
\text { Capacity } \\
\text { (tons) }\end{array}$} & \multirow{3}{*}{$\begin{array}{c}\text { Normalized } \\
\text { Annual } \\
\text { Energy } \\
\text { Savings } \\
\text { (kWh) }\end{array}$} & \multirow{3}{*}{$\begin{array}{c}\text { Normalized } \\
\text { Annual } \\
\text { Runtime } \\
\text { (hr) }\end{array}$} & \multicolumn{6}{|c|}{ Utility Rate $(\$ / \mathbf{k W h})$} \\
\hline & & & & \multicolumn{2}{|c|}{0.05} & \multicolumn{2}{|c|}{0.10} & \multicolumn{2}{|c|}{0.15} \\
\hline & & & & $\begin{array}{c}\text { Cost } \\
\text { Savings } \\
(\$ / y r)\end{array}$ & $\begin{array}{c}\text { Payback } \\
(y r)\end{array}$ & $\begin{array}{c}\text { Cost } \\
\text { Savings } \\
(\$ / y r)\end{array}$ & $\begin{array}{c}\text { Payback } \\
(\mathbf{y r})\end{array}$ & $\begin{array}{c}\text { Cost } \\
\text { Savings } \\
(\$ / y r)\end{array}$ & $\begin{array}{c}\text { Payback } \\
(y \mathbf{y})\end{array}$ \\
\hline 202 & 10 & 12,327 & 4,992 & 616 & 6.9 & 1,233 & 3.4 & 1,849 & 2.3 \\
\hline 203 & 10 & 6,913 & 4,992 & 346 & 12.3 & 691 & 6.1 & 1,037 & 4.1 \\
\hline 204 & 10 & 10,889 & 5,460 & 544 & 7.8 & 1,089 & 3.9 & 1,633 & 2.6 \\
\hline 205 & 15 & 8,611 & 5,460 & 431 & 9.9 & 861 & 4.9 & 1,292 & 3.3 \\
\hline 206 & 10 & 10,014 & 5,460 & 501 & 8.5 & 1,001 & 4.2 & 1,502 & 2.8 \\
\hline 207 & 25 & 36,876 & 5,460 & 1,844 & 2.7 & 3,688 & 1.3 & 5,531 & 0.9 \\
\hline 209 & 5 & 4,957 & 5,460 & 248 & 11.9 & 496 & 6.0 & 744 & 4.0 \\
\hline 210 & 25 & 37,919 & 5,460 & 1,896 & 2.6 & 3,792 & 1.3 & 5,688 & 0.9 \\
\hline 212 & 25 & 36,750 & 5,096 & 1,837 & 2.7 & 3,675 & 1.3 & 5,512 & 0.9 \\
\hline 213 & 15 & 13,720 & 5,096 & 686 & 6.2 & 1,372 & 3.1 & 2,058 & 2.1 \\
\hline 214 & 10 & 8,109 & 4,992 & 405 & 8.3 & 811 & 4.1 & 1,216 & 2.8 \\
\hline 215 & 10 & 6,293 & 4,992 & 315 & 13.5 & 629 & 6.8 & 944 & 4.5 \\
\hline 217 & 10 & 6,334 & 5,096 & 317 & 13.4 & 633 & 6.7 & 950 & 4.5 \\
\hline 218 & 10 & 10,383 & 5,460 & 519 & 8.2 & 1,038 & 4.1 & 1,557 & 2.7 \\
\hline 219 & 15 & 2,369 & 4,992 & 118 & 28.3 & 237 & 14.1 & 355 & 9.4 \\
\hline 220 & 15 & 7,121 & 4,992 & 356 & 9.4 & 712 & 4.7 & 1,068 & 3.1 \\
\hline 221 & 10 & 6,531 & 4,992 & 327 & 10.3 & 653 & 5.1 & 980 & 3.4 \\
\hline 222 & 15 & 6,736 & 4,992 & 337 & 9.9 & 674 & 5.0 & 1,010 & 3.3 \\
\hline 223 & 15 & 10,219 & 4,992 & 511 & 8.3 & 1,022 & 4.2 & 1,533 & 2.8 \\
\hline 224 & 10 & 8,465 & 5,200 & 423 & 7.9 & 847 & 4.0 & 1,270 & 2.6 \\
\hline 225 & 10 & 7,107 & 5,200 & 355 & 9.4 & 711 & 4.7 & 1,066 & 3.1 \\
\hline 226 & 12.5 & 13,105 & 4,992 & 655 & 6.5 & 1,311 & 3.2 & 1,966 & 2.2 \\
\hline 228 & 10 & 10,340 & 5,200 & 517 & 8.2 & 1,034 & 4.1 & 1,551 & 2.7 \\
\hline 229 & 10 & 15,232 & 4,888 & 762 & 6.2 & 1,523 & 3.1 & 2,285 & 2.1 \\
\hline 231 & 7.5 & 6,082 & 5,460 & 304 & 14.0 & 608 & 7.0 & 912 & 4.7 \\
\hline 362 & 18 & 15,457 & 7,904 & 773 & 5.5 & 1,546 & 2.7 & 2,319 & 1.8 \\
\hline 363 & 20 & 41,229 & 7,904 & 2,061 & 2.4 & 4,123 & 1.2 & 6,184 & 0.8 \\
\hline 364 & 25 & 25,034 & 5,460 & 1,252 & 3.9 & 2,503 & 2.0 & 3,755 & 1.3 \\
\hline
\end{tabular}




\begin{tabular}{|c|c|c|c|c|c|c|c|c|c|}
\hline \multirow{3}{*}{$\begin{array}{c}\text { RTU } \\
\text { ID }\end{array}$} & \multirow{3}{*}{$\begin{array}{c}\text { RTU } \\
\text { Capacity } \\
\text { (tons) }\end{array}$} & \multirow{3}{*}{$\begin{array}{c}\text { Normalized } \\
\text { Annual } \\
\text { Energy } \\
\text { Savings } \\
\text { (kWh) }\end{array}$} & \multirow{3}{*}{$\begin{array}{l}\text { Normalized } \\
\text { Annual } \\
\text { Runtime } \\
\text { (hr) }\end{array}$} & \multicolumn{6}{|c|}{ Utility Rate (\$/kWh) } \\
\hline & & & & \multicolumn{2}{|c|}{0.05} & \multicolumn{2}{|c|}{0.10} & \multicolumn{2}{|c|}{0.15} \\
\hline & & & & $\begin{array}{c}\text { Cost } \\
\text { Savings } \\
(\$ / y r)\end{array}$ & $\begin{array}{c}\text { Payback } \\
(\text { yr })\end{array}$ & $\begin{array}{c}\text { Cost } \\
\text { Savings } \\
(\$ / y r)\end{array}$ & $\begin{array}{c}\text { Payback } \\
(y r)\end{array}$ & $\begin{array}{c}\text { Cost } \\
\text { Savings } \\
(\$ / y r)\end{array}$ & $\begin{array}{c}\text { Payback } \\
(y r)\end{array}$ \\
\hline 365 & 25 & 24,357 & 5,460 & 1,218 & 4.0 & 2,436 & 2.0 & 3,653 & 1.3 \\
\hline 366 & 25 & 29,320 & 8,736 & 1,466 & 3.3 & 2,932 & 1.7 & 4,398 & 1.1 \\
\hline 367 & 25 & 27,892 & 8,736 & 1,395 & 3.5 & 2,789 & 1.8 & 4,184 & 1.2 \\
\hline 368 & 25 & 29,069 & 8,736 & 1,453 & 3.4 & 2,907 & 1.7 & 4,360 & 1.1 \\
\hline 369 & 25 & 38,168 & 8,736 & 1,908 & 2.6 & 3,817 & 1.3 & 5,725 & 0.9 \\
\hline 370 & 25 & 38,689 & 8,736 & 1,934 & 2.5 & 3,869 & 1.3 & 5,803 & 0.8 \\
\hline 371 & 25 & 39,081 & 8,736 & 1,954 & 2.5 & 3,908 & 1.3 & 5,862 & 0.8 \\
\hline 372 & 12.5 & 9,305 & 4,368 & 465 & 9.1 & 930 & 4.6 & 1,396 & 3.0 \\
\hline 375 & 15 & 12,198 & 4,004 & 610 & 7.0 & 1,220 & 3.5 & 1,830 & 2.3 \\
\hline 376 & 15 & 2,905 & 4,004 & 145 & 23.1 & 290 & 11.5 & 436 & 7.7 \\
\hline 377 & 7.5 & 4,677 & 4,004 & 234 & 14.3 & 468 & 7.2 & 702 & 4.8 \\
\hline 378 & 10 & 7,649 & 4,004 & 382 & 11.1 & 765 & 5.6 & 1,147 & 3.7 \\
\hline 379 & 5 & 2,038 & 4,004 & 102 & 29.0 & 204 & 14.5 & 306 & 9.7 \\
\hline 380 & 7.5 & 4,430 & 4,004 & 221 & 15.1 & 443 & 7.6 & 664 & 5.0 \\
\hline 381 & 15 & 13,940 & 6,916 & 697 & 6.1 & 1,394 & 3.0 & 2,091 & 2.0 \\
\hline 382 & 15 & 19,616 & 6,916 & 981 & 4.3 & 1,962 & 2.2 & 2,942 & 1.4 \\
\hline 383 & 15 & 12,181 & 6,916 & 609 & 7.0 & 1,218 & 3.5 & 1,827 & 2.3 \\
\hline 384 & 20 & 14,705 & 6,916 & 735 & 5.8 & 1,471 & 2.9 & 2,206 & 1.9 \\
\hline 385 & 15 & 16,511 & 6,916 & 826 & 5.1 & 1,651 & 2.6 & 2,477 & 1.7 \\
\hline 386 & 15 & 10,910 & 6,916 & 546 & 7.8 & 1,091 & 3.9 & 1,637 & 2.6 \\
\hline 387 & 15 & 12,671 & 6,916 & 634 & 6.7 & 1,267 & 3.4 & 1,901 & 2.2 \\
\hline 388 & 15 & 11,279 & 6,916 & 564 & 7.5 & 1,128 & 3.8 & 1,692 & 2.5 \\
\hline 389 & 15 & 18,732 & 6,916 & 937 & 4.5 & 1,873 & 2.3 & 2,810 & 1.5 \\
\hline 407 & 7.5 & 9,853 & 8,736 & 493 & 6.8 & 985 & 3.4 & 1,478 & 2.3 \\
\hline 408 & 10 & 9,441 & 8,736 & 472 & 7.1 & 944 & 3.5 & 1,416 & 2.4 \\
\hline 409 & 15 & 6,465 & 8,736 & 323 & 13.1 & 647 & 6.6 & 970 & 4.4 \\
\hline 410 & 25 & 30,264 & 8,736 & 1,513 & 2.8 & 3,026 & 1.4 & 4,540 & 0.9 \\
\hline 411 & 25 & 21,681 & 8,736 & 1,084 & 4.4 & 2,168 & 2.2 & 3,252 & 1.5 \\
\hline 423 & 10 & 7,592 & 4,420 & 380 & 11.2 & 759 & 5.6 & 1,139 & 3.7 \\
\hline 424 & 10 & 7,768 & 4,420 & 388 & 10.9 & 777 & 5.5 & 1,165 & 3.6 \\
\hline 425 & 10 & 9,205 & 4,420 & 460 & 9.2 & 920 & 4.6 & 1,381 & 3.1 \\
\hline 426 & 10 & 7,960 & 4,420 & 398 & 10.7 & 796 & 5.3 & 1,194 & 3.6 \\
\hline 427 & 10 & 9,867 & 4,420 & 493 & 8.6 & 987 & 4.3 & 1,480 & 2.9 \\
\hline
\end{tabular}

Table 22 shows that the simple payback period varied from 9 months to 10 years at a utility rate of $\$ 0.15 / \mathrm{kWh}$. This variation in payback period was largely dependent on RTU size and RTU runtime. The units with the shortest payback period were either large units (e.g., greater than 15 tons) or had the largest annual runtime (operating hours per year). The units with the shortest payback period were unit IDs 366 through 371 . All of these units had capacities of 25 tons, and the longest normalized runtime per year $(8,736$ hours) of all monitored units. One of the smallest monitored units, 379 , had the longest payback period of 9.7 years at $0.15 \$ / \mathrm{kWh}$. This unit also had a short annual runtimes $(4,004$ hours). 
Based on these observations, runtime and size were major factors that affected the calculated payback period for the advanced controller retrofit.

In addition to Table 22, Figure 32 shows the frequency of units at varying payback periods and capacity ranges for (a) all capacities at a $\$ 0.10 / \mathrm{kWh}$ utility rate; (b) all capacities at a $\$ 0.15 / \mathrm{kWh}$ utility rate; (c) two capacity ranges at a $\$ 0.10 / \mathrm{kWh}$ utility rate; and (d) two capacity ranges at a $\$ 0.15 / \mathrm{kWh}$ utility rate. Figure 32 shows that as the utility rate increased, the frequency of units with less than 3 years of payback period also increased, with the majority of the units with less than a 3 years of payback period having capacities greater than 20 tons.

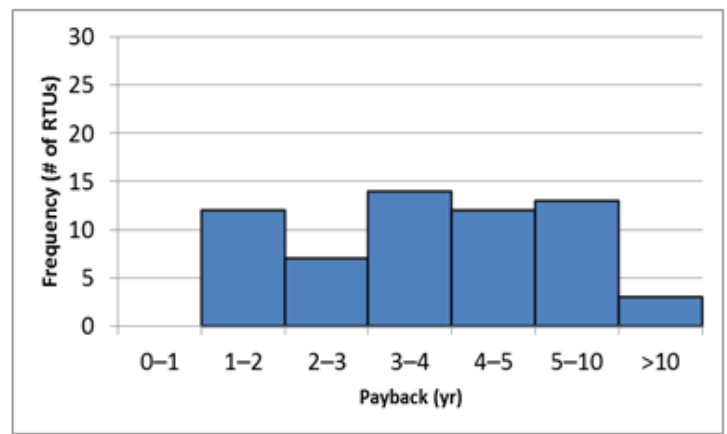

(a)

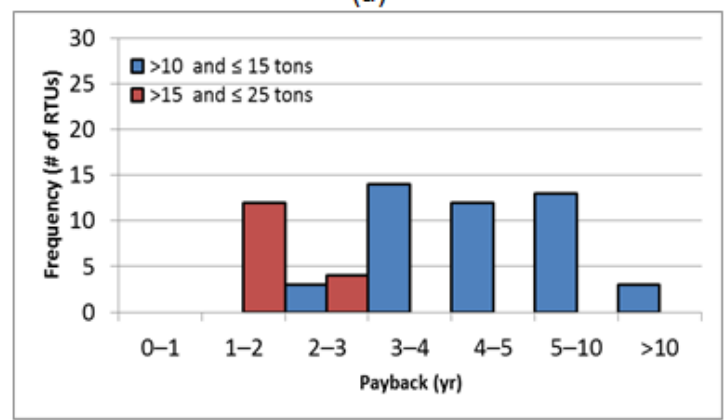

(c)

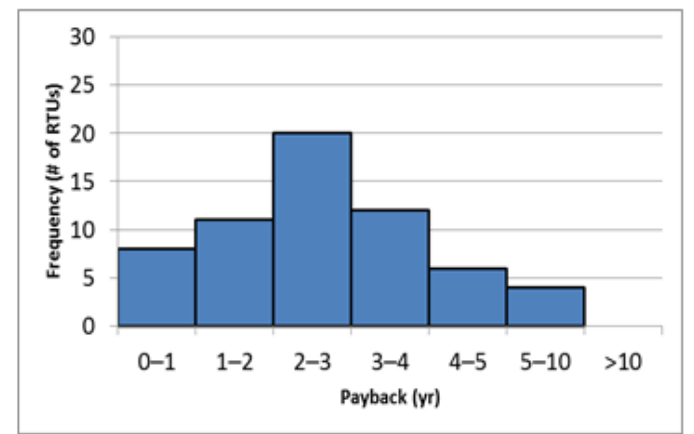

(b)

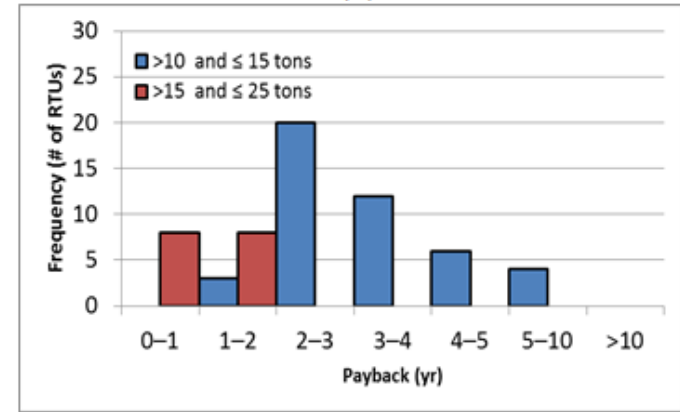

(d)

Figure 32: Histogram charts showing the frequency of units at varying payback periods for (a) all capacities at a $\$ 0.10 / \mathrm{kWh}$ utility rate; (b) all capacities at a $\$ 0.15 / \mathrm{kWh}$ utility rate; (c) 2 capacity ranges at a $\$ 0.10 / \mathrm{kWh}$ utility rate; and (d) 2 capacity ranges at a $\$ 0.15 / \mathrm{kWh}$ utility rate

Furthermore, the payback period for varying utility rates, unit capacity, and runtime can be seen in Figure 33 through Figure 36 . Figure 33 shows the average payback period for varying utility rates for units larger than 15 tons, annual runtimes larger than 7,904 hours, and with varying utility incentives $(0$, $25 \%$ and $50 \%$ ). Figure 33 shows that, for the units larger than 15 tons and runtimes larger than 7,904 hours, the average payback period without incentives will always be less than 3 years, independent of the utility rate. At a utility rate of $\$ 0.10 / \mathrm{kWh}$, the average payback period for these units is 1.4 years without incentives, 1 year with $25 \%$ incentives, and 8 months with $50 \%$ incentives. At a utility rate of $\$ 0.15 / \mathrm{kWh}$, the payback period was less than 1 year for all scenarios. 


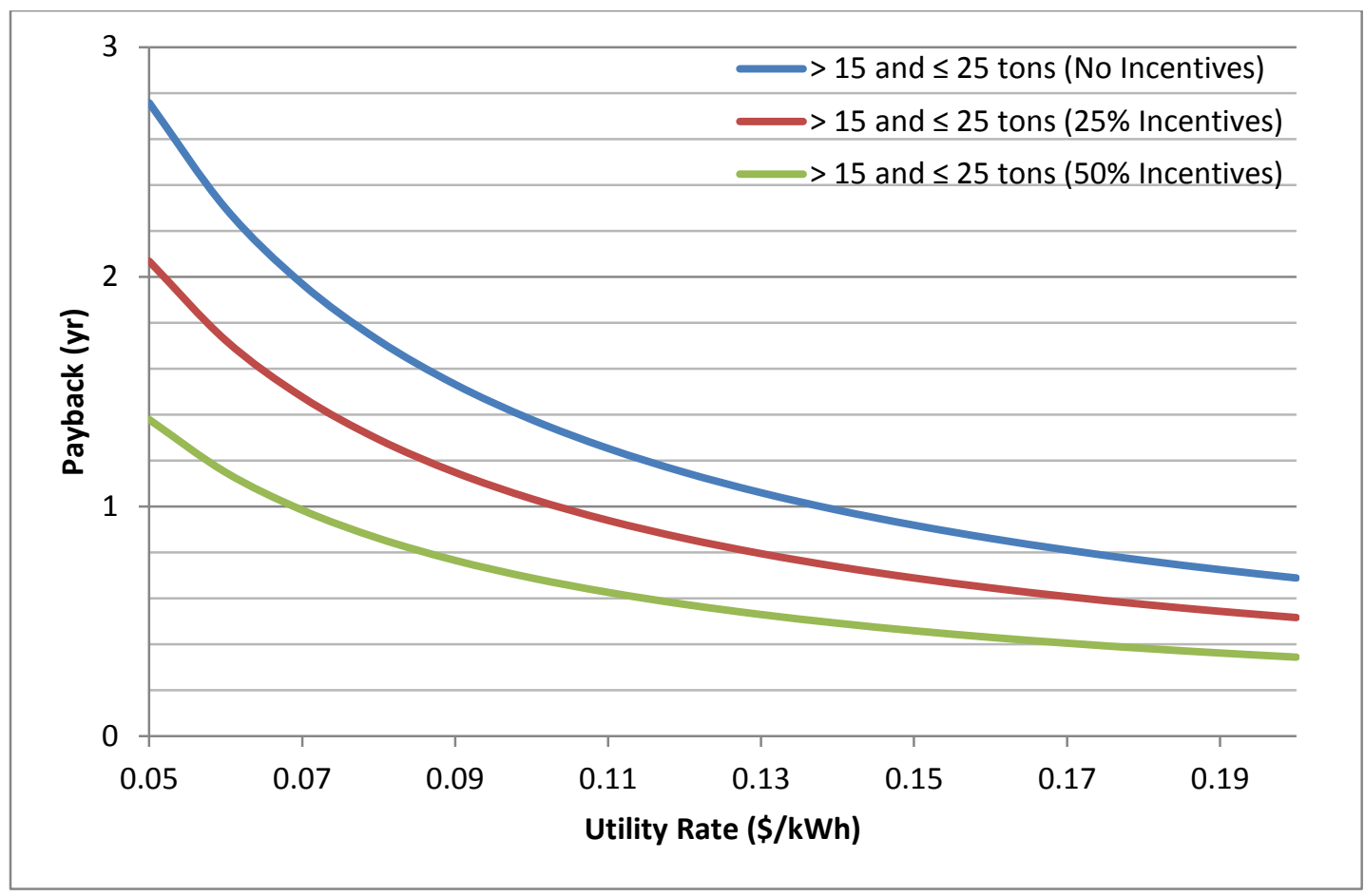

Figure 33: Average payback period for units with largest capacity (annual runtimes larger than 7,904 hours) for varying utility rates

Figure 34 through Figure 36, on the other hand, shows all other units not shown in Figure 33. These units have varying capacities (between 5 and 25 tons) and varying annual runtimes (between 4,004 and 8,736 hours). As you can see, for units smaller than 10 tons, the average payback period was 3 years or less for utility rates above $\$ 0.12 / \mathrm{kWh}$ when incentives were offered ( 3 years at $25 \%$ incentives and 2 years at $50 \%$ incentives, respectively), and $\$ 0.16 / \mathrm{kWh}$ without incentives. For units between 10 tons and 15 tons, the average payback period was 3 years or less for utility rates above $\$ .09 / \mathrm{kWh}$ when incentives were offered ( 3.1 years at $25 \%$ incentives and 2.1 years at $50 \%$ incentives, respectively), and $\$ 0.12 / \mathrm{kWh}$ without incentives. For units larger than 15 tons, the average payback period is always less than 3 years, with or without incentives.

Figure 33 through Figure 36 prove that, on average, a unit smaller than 15 tons will require some sort of incentive when installing the advanced controller to obtain a payback period of less than 3 years, or be located in a city with a utility rate of $\$ 0.12 / \mathrm{kWh}$ or greater. However, if the unit was larger than 15 tons, the payback period will always be less than 3 years, with or without incentives being offered. 


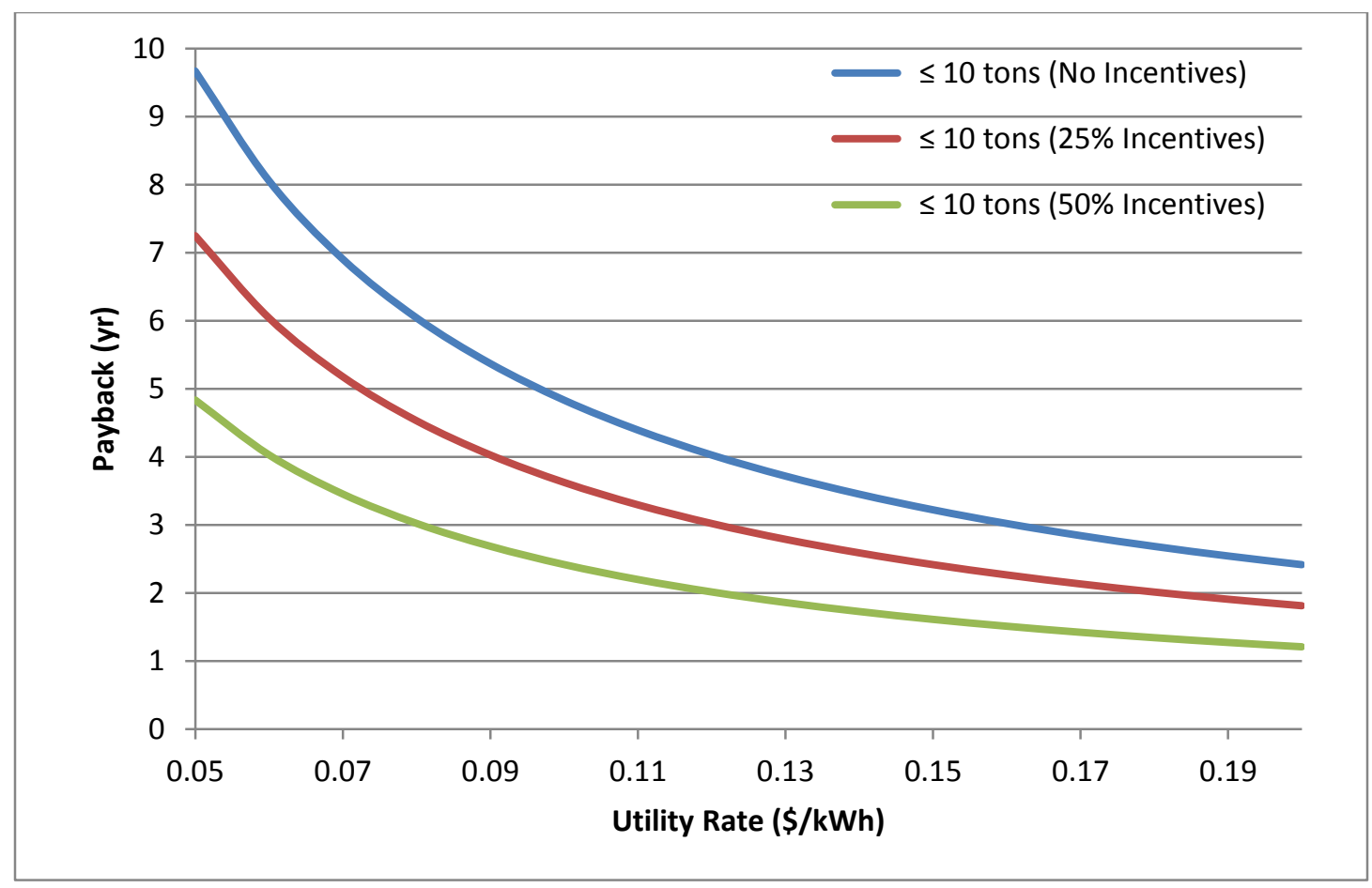

Figure 34: Average payback period for units with capacities less than 10 tons, for varying runtimes and utility rates

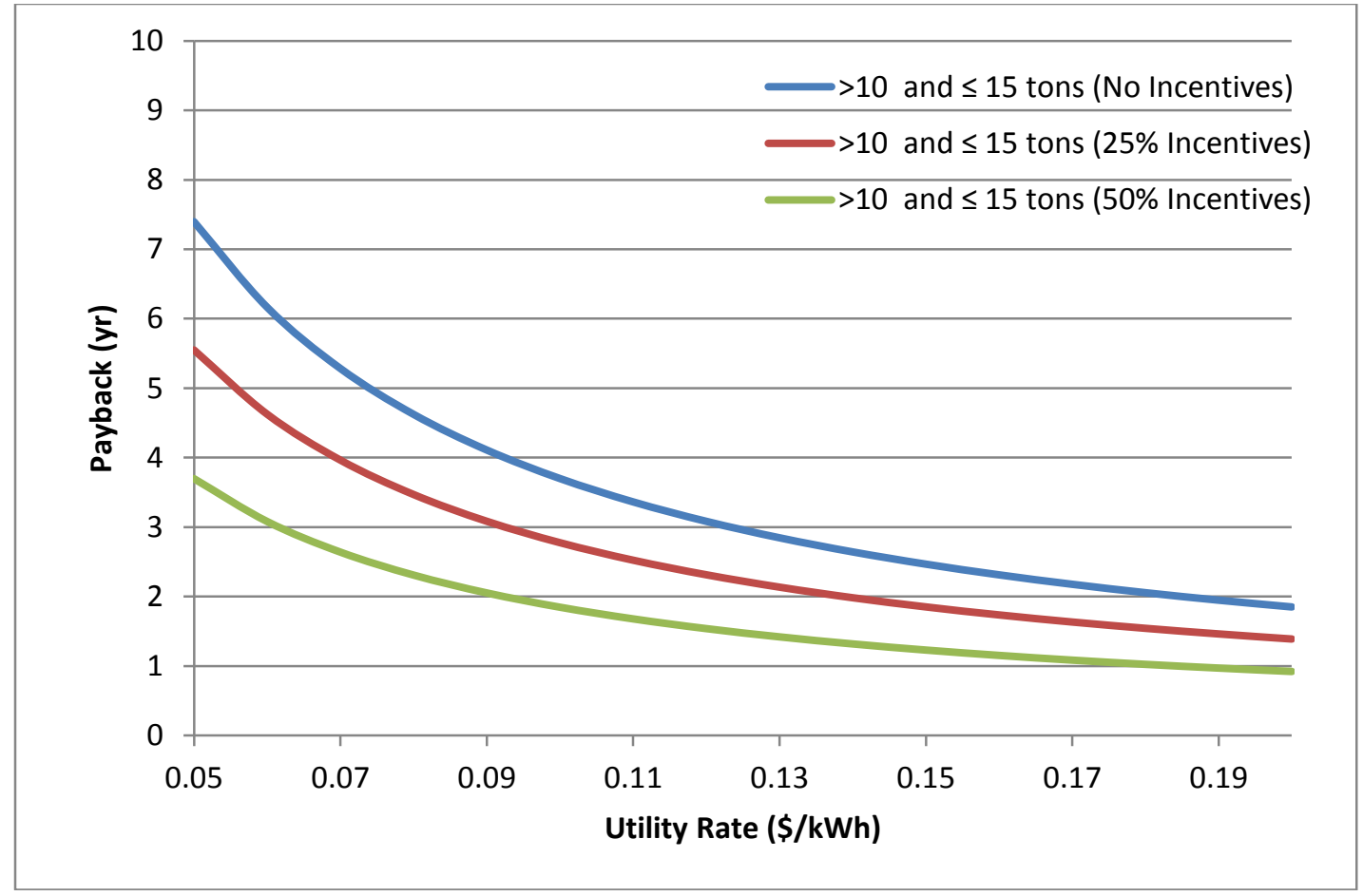

Figure 35: Average payback period for units with capacities between 10 tons and 15 tons, for varying runtimes and utility rates 


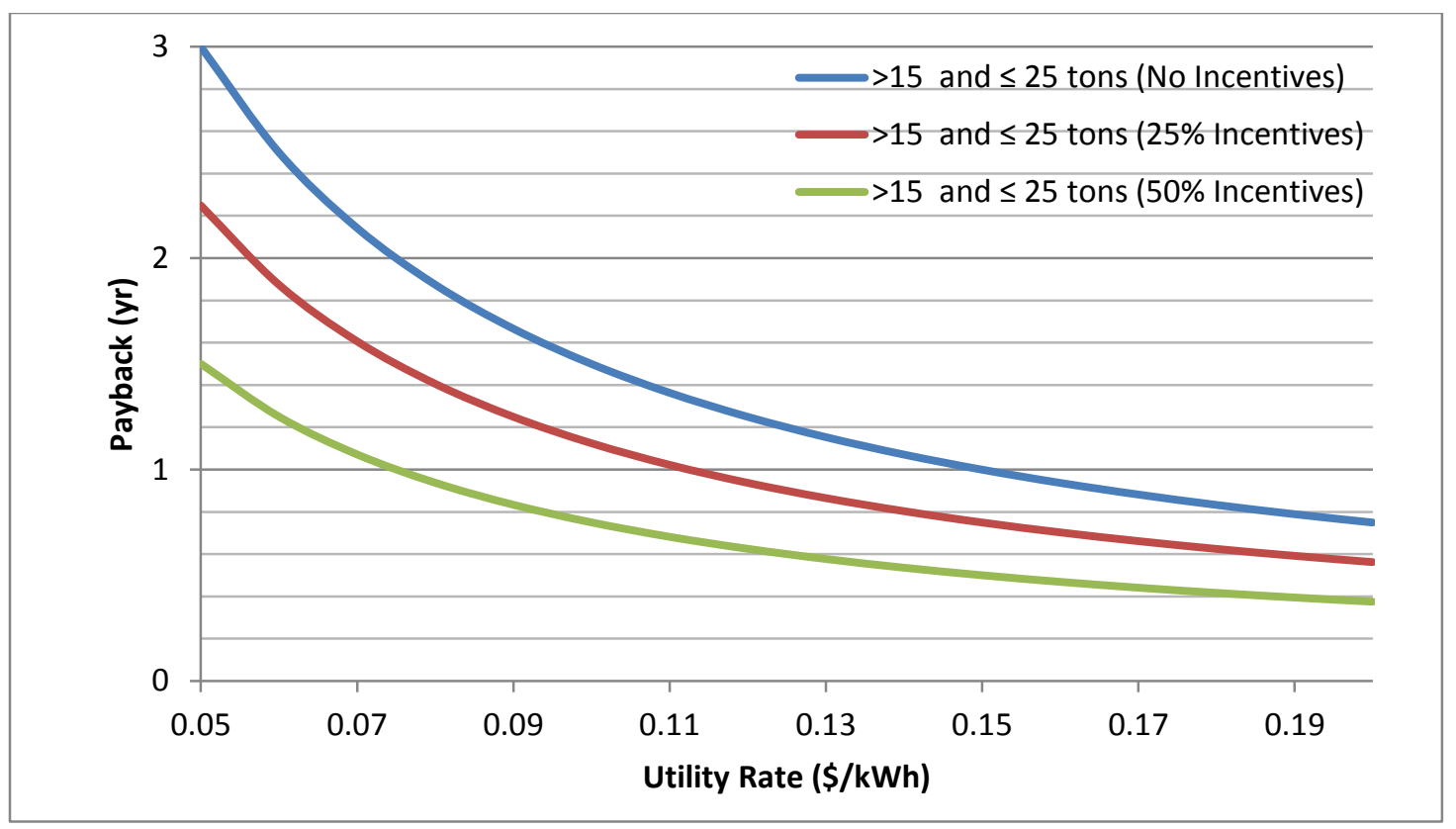

Figure 36: Average payback period for units with capacities between 15 and 25 tons, for varying runtimes and utility rates

In addition to the individual unit analysis, a total site payback period can be calculated based on the same three utility rates $(\$ 0.05 / \mathrm{kWh}, \$ 0.10 / \mathrm{kWh}$ and $\$ 0.15 / \mathrm{kWh})$, as can be seen in Table 23 . These payback periods are for the controller and labor costs only, and do not include any monitoring packages. For the utility rate of $0.15 \$ / \mathrm{kWh}$, the longest payback period is 4.2 years, while the shortest payback period is 1 year. Of all 8 sites, only 2 have payback periods longer than 3 years (sites 43 and 51) at a $\$ 0.15 / \mathrm{kWh}$ utility rate. At a utility rate of $\$ 0.10 / \mathrm{kWh}$, the longest payback period becomes 6.3 years, while the shortest payback period is 1.6 years. Of all 8 sites, 4 have payback periods longer than 3 years at a $\$ 0.10 / \mathrm{kWh}$ utility rate.

The payback period for both the controller and monitoring package can be seen by site in Table 24 for the same three utility rates. For the utility rate of $\$ 0.15 / \mathrm{kWh}$, the longest payback period is 10.2 years, and the shortest payback period is 1.5 years. When trying to determine if the monitoring package should be purchased in addition to the controller, the unit's runtime, size, and number of units at the site should be considered. The more units at the site, the lower the monitoring cost per unit and lower the payback periods.

Comparing the site payback period for just the controller and the controller and monitoring, at the utility rate of $\$ 0.15 / \mathrm{kWh}$, site 39 has a payback period increase from 13 months to 22 months, and site 40 has a payback period increase from 1 year to 18 months. On average, the payback period for a site where only the controller is installed is 2.3 years, while the payback period at a site where the controller and monitoring is installed is 4.4 years. 
Table 23: Cost savings and payback period by site for controller-only, based on three different utility rates

\begin{tabular}{|c|c|c|c|c|c|c|c|c|c|}
\hline \multirow{3}{*}{$\begin{array}{l}\text { Site } \\
\text { ID }\end{array}$} & \multirow{3}{*}{$\begin{array}{c}\text { Normalized } \\
\text { Annual } \\
\text { Energy } \\
\text { Savings } \\
\text { (kWh) }\end{array}$} & \multirow{3}{*}{$\begin{array}{c}\text { Normalized } \\
\text { Annual } \\
\text { Runtime } \\
\text { (hr) }\end{array}$} & \multirow{3}{*}{$\begin{array}{l}\text { Controller } \\
\text { Installed } \\
\text { Cost }(\$)\end{array}$} & \multicolumn{6}{|c|}{ Utility Rate $(\$ / \mathbf{k W h})$} \\
\hline & & & & \multicolumn{2}{|c|}{0.05} & \multicolumn{2}{|c|}{0.10} & \multicolumn{2}{|c|}{0.15} \\
\hline & & & & $\begin{array}{c}\text { Cost } \\
\text { Savings } \\
(\$ / y r)\end{array}$ & $\begin{array}{c}\text { Payback } \\
\text { (yr) }\end{array}$ & $\begin{array}{c}\text { Cost } \\
\text { Savings } \\
(\$ / y r)\end{array}$ & $\begin{array}{c}\text { Payback } \\
\text { (yr) }\end{array}$ & $\begin{array}{c}\text { Cost } \\
\text { Savings } \\
(\$ / y r)\end{array}$ & $\begin{array}{c}\text { Payback } \\
\text { (yr) }\end{array}$ \\
\hline 28 & 303,401 & 28 & 101,076 & 15,170 & 6.7 & 30,340 & 3.3 & 45,510 & 2.2 \\
\hline 39 & 56,686 & 39 & 9,142 & 2,834 & 3.2 & 5,669 & 1.6 & 8,503 & 1.1 \\
\hline 40 & 251,610 & 40 & 39,136 & 12,580 & 3.1 & 25,161 & 1.6 & 37,741 & 1.0 \\
\hline 41 & 9,305 & 41 & 4,250 & 465 & 9.1 & 930 & 4.6 & 1,396 & 3.0 \\
\hline 43 & 33,897 & 43 & 21,500 & 1,695 & 12.7 & 3,390 & 6.3 & 5,085 & 4.2 \\
\hline 44 & 130,545 & 44 & 38,250 & 6,527 & 5.9 & 13,055 & 2.9 & 19,582 & 2.0 \\
\hline 46 & 77,704 & 46 & 19,950 & 3,885 & 5.1 & 7,770 & 2.6 & 11,656 & 1.7 \\
\hline 51 & 42,392 & 51 & 21,250 & 2,120 & 10.0 & 4,239 & 5.0 & 6,359 & 3.3 \\
\hline
\end{tabular}

Table 24: Cost savings and payback period by site for controller and monitoring package based on three different utility rates

\begin{tabular}{|c|c|c|c|c|c|c|c|c|c|c|}
\hline \multirow{3}{*}{$\begin{array}{l}\text { Site } \\
\text { ID }\end{array}$} & \multirow{3}{*}{$\begin{array}{c}\text { Normalized } \\
\text { Annual } \\
\text { Energy } \\
\text { Savings } \\
\text { (kWh) }\end{array}$} & \multirow{3}{*}{$\begin{array}{c}\text { Normalized } \\
\text { Annual } \\
\text { Runtime } \\
\text { (hr) }\end{array}$} & \multirow{3}{*}{$\begin{array}{c}\text { Controller } \\
\text { Installed } \\
\text { Cost }(\$)\end{array}$} & \multirow{3}{*}{$\begin{array}{c}\text { Monitoring } \\
\text { Cost }(\$)\end{array}$} & \multicolumn{6}{|c|}{ Utility Rate $(\$ / \mathbf{k W h})$} \\
\hline & & & & & \multicolumn{2}{|c|}{0.05} & \multicolumn{2}{|c|}{0.10} & \multicolumn{2}{|c|}{0.15} \\
\hline & & & & & $\begin{array}{c}\text { Cost } \\
\text { Savings } \\
(\$ / y r)\end{array}$ & $\begin{array}{c}\text { Payback } \\
(y r)\end{array}$ & $\begin{array}{c}\text { Cost } \\
\text { Savings } \\
(\$ / y r)\end{array}$ & $\begin{array}{c}\text { Payback } \\
\text { (yr) }\end{array}$ & $\begin{array}{c}\text { Cost } \\
\text { Savings } \\
(\$ / y r)\end{array}$ & $\begin{array}{c}\text { Payback } \\
(\mathrm{yr})\end{array}$ \\
\hline 28 & 303,401 & 28 & 101,076 & 43,749 & 15,170 & 9.9 & 30,340 & 4.9 & 45,510 & 3.2 \\
\hline 39 & 56,686 & 39 & 9,142 & 5,445 & 2,834 & 6.5 & 5,669 & 2.9 & 8,503 & 1.8 \\
\hline 40 & 251,610 & 40 & 39,136 & 15,021 & 12,580 & 4.5 & 25,161 & 2.2 & 37,741 & 1.5 \\
\hline 41 & 9,305 & 41 & 4,250 & 3,849 & 465 & N/A* & 930 & 24.5 & 1,396 & 10.2 \\
\hline 43 & 33,897 & 43 & 21,500 & 11,829 & 1,695 & 30.4 & 3,390 & 11.9 & 5,085 & 7.4 \\
\hline 44 & 130,545 & 44 & 38,250 & 19,809 & 6,527 & 9.8 & 13,055 & 4.7 & 19,582 & 3.1 \\
\hline 46 & 77,704 & 46 & 19,950 & 10,233 & 3,885 & 9.2 & 7,770 & 4.2 & 11,656 & 2.7 \\
\hline 51 & 42,392 & 51 & 21,250 & 10,233 & 2,120 & 20.7 & 4,239 & 8.7 & 6,359 & 5.5 \\
\hline
\end{tabular}

*This site only had one unit, and the monitoring cost per year was more expensive than the cost savings per year 


\section{SUMMARY, DISCUSSION AND RECOMMENDATIONS}

This section summarizes the major findings of this research and demonstration project, discusses the caveats of applying the findings to RTU retrofits, provides some recommendations on potential improvement of the advanced controller and provides some rules-of-thumb for potential building owners on when to consider such a retrofit.

\subsection{Summary of Project Findings}

A total of 66 RTUs on 8 different buildings were retrofitted with a commercially available advanced controller for improving RTU operational efficiency. This product can be regarded as a representative of comparable RTU retrofit controllers in the market. The findings from this work are not limited to that specific product, but apply to all products with advanced RTU control strategies such as fan speed control, DCV, and enhanced economizer control.

Of the 66 tested RTUs, 17 were packaged heat pumps and the rest were packaged air conditioners with gas heat. The eight buildings covered four building types, including mercantile (both retail and shopping malls), office, food sales, and healthcare. These buildings were located in four different climate zones including $3 \mathrm{~B}$ for the warm and coastal climate, $4 \mathrm{~A}$ for the mixed and humid climate, $4 \mathrm{C}$ for the mixed and marine climate, and 5A for the cool and humid climate (ASHRAE 2010b). All RTUs were monitored for at least 1 year with alternative operations (standard vs. advanced). Field measurements included the unit's total electric power, the return-air $\mathrm{CO}_{2}$ concentration, and temperatures for the outdoor air, the return air, the mixed air, and the supply air. These field measurements were logged at 1-minute intervals, together with a number of other control signals such as the supply-fan speed, the outdoor-air damper signal and cooling and heating calls and commands. The 1-minute raw data were processed further to obtain daily energy consumption and average outdoor-air temperature. 3-P or 5-P changepoint regression models were developed for all units for standard and advanced control operations.

The measured actual savings, the normalized annual energy savings, and the savings uncertainties were calculated using the methods described in the ASHRAE Guideline 14. Major findings from this work are highlighted below:

- The advanced controller reduced both actual consumption and normalized consumption by between $22 \%$ and $90 \%$, with an average of $55 \%$ for all RTUs. The majority of RTUs had their electricity savings in the range between $40 \%$ and $90 \%$.

- On average, the fractional savings uncertainty was $25 \%$ for actual savings and $12 \%$ for normalized savings. This average uncertainty covered all RTUs with sufficient data collected for regression model development.

- For absolute savings, actual RTU electricity savings was in the range between 0.35 and $7.68 \mathrm{kWh}$ per hour of unit operation, with an average of $2.41 \mathrm{kWh} / \mathrm{h}$. Normalized annual electricity savings ranged between 0.47 and $7.21 \mathrm{kWh}$ per hour of unit operation, with an average of 2.39 $\mathrm{kWh} / \mathrm{h}$.

- Fan energy savings made a significant contribution to the total RTU electricity savings, while the heating and cooling energy savings varied with units and was relatively smaller in comparison 
with fan energy savings. In general, fan energy savings had much less uncertainty than heating and cooling energy savings.

- At the building level (total RTU electricity consumption), the percentage of RTU electricity savings ranged between $37 \%$ and $73 \%$ for both actual and normalized savings. Five of the eight building sites had no more than $5 \%$ difference between the actual savings and the normalized annual savings. The absolute electricity savings ranged between 1.4 and $3.9 \mathrm{kWh}$ per hour of unit operation.

- At the building level, monthly contribution to normalized annual energy savings ranged from approximately $6 \%$ to $12 \%$. Buildings using heat pumps had slightly higher savings in the heating season.

- As expected, both actual and normalized savings increased with the RTU size. The electricity savings increased from about $1.0 \mathrm{kWh} / \mathrm{h}$ for the group with RTU cooling capacity less than 10 tons, to $1.8 \mathrm{kWh} / \mathrm{h}$ for the group with RTU capacity between 10 and 15 tons, and then to 4.2 $\mathrm{kWh} / \mathrm{h}$ for the group with RTU capacity greater than 15 tons.

- On average, packaged air conditioners with gas heat (AC units) achieved more electricity savings than heat pumps (HP units). For both actual and normalized savings, the AC group saved 2.60 $\mathrm{kWh} / \mathrm{h}$ per running hour, while the HP group saved $1.75 \mathrm{kWh} / \mathrm{h}$. The reason for this was that the average size of HPs was smaller than the average size of the ACs.

- The variation of annual normalized RTU electricity savings were between 218 and 1086 $\mathrm{Wh} / \mathrm{h} / \mathrm{hp}$ with average savings approximately $695 \mathrm{Wh} / \mathrm{h} / \mathrm{hp}$ across all eight sites.

Based on the normalized annual electricity savings and the installed cost of the advanced controller, the simple payback period was calculated for three electricity rates including $0.05 \$ / \mathrm{kWh}, 0.10 \$ / \mathrm{kWh}$, and $0.15 \$ / \mathrm{kWh}$. Note that the gas energy savings were not considered in estimating the payback periods because gas consumption was not directly measured. Major findings from the economic analysis include the following:

- For all RTUs, the average payback period was 6, 3, and 2 years, respectively for the three utility rates. These payback periods account for the controller cost and labor to install the controller, but not the metering and monitoring packages. The simple payback period for individual units varies from 9 months to 10 years for the electricity rate of $0.15 \$ / \mathrm{kWh}$. The units with the shortest payback period were either large units (e.g., greater than 15 tons) or had the longest runtime (e.g., 24/7 operations).

- At the site level, the simple payback period from the advanced controller installation for all eight building sites ranged between 1 to 4.2 years for the utility rate of $0.15 \$ / \mathrm{kWh}$, between $11 / 2$ years and 6.3 years for the utility rate of $0.10 \$ / \mathrm{kWh}$, and between 3 years and 13 years for the utility rate of $0.05 \$ / \mathrm{kWh}$. The above payback periods did not account for the cost of metering and monitoring packages. On average (for $0.15 \$ / \mathrm{kWh}$ ), the payback period for a site where only the controller is installed is 2.3 years, while the payback period at a site where the controller and monitoring is installed is 4.4 years. 


\subsection{DiscuSSION}

When applying the project findings to a specific project, some factors not sufficiently considered in this work may affect the energy savings or the simple payback period. The following aspects need to be taken into account for RTU controller retrofits:

- Equipment maintenance and reparation should be an integrated part of the RTU controller retrofit. If some parts of the RTU do not function properly (e.g., the economizer operation discussed in Section 6.3), the potential of energy savings cannot be fully realized.

- Although significant demand reductions are not expected from advanced RTU controller retrofit, demand reduction and demand cost savings were not considered in the work. For many commercial buildings with demand cost (a big portion of the energy bills), demand reduction could have significant impact on the simple payback period. This may be a more salient feature for those advanced controllers capable of modulating the compressor speed.

- The simple payback period could be significantly reduced if utility incentives were available and considered in the economic analysis. In this respect, utility incentives are important to expand the market acceptance of the RTU advanced controller.

- Cost savings on natural gas were not considered in this work for simple payback period calculation. The gas cost savings are expected to become important in cold climates and buildings with high fluctuation of occupancy profiles.

\subsection{RECOMMENDATIONS FOR CONTROLLER IMPROVEMENT}

Based on the project team's experience, the following recommendations are made for possible improvement of the control algorithm:

- The advanced controller demonstrated in the field changed the supply-fan control from constant speed to multi-speed with use of a VFD. More savings could be achieved if the supplyfan speed was modulated continuously. For example, when RTU operates in the economizing mode, the controller might modulate the supply-fan speed based on the space temperature deviation from the cooling set point. This type of controls requires the knowledge of space temperature and the space temperature set point.

- The current control sequence implemented two-stage economizing when the outdoor-air temperature is $58^{\circ} \mathrm{F}$ and below. The supply fan ran at $75 \%$ or $90 \%$ of its full speed for the two stages of economizing. Although the intent was to reduce fan energy by running the supply fan at low speeds, a trade off exists between the fan running time and the fan running speed. Efforts are needed to compare the current approach with other alternative approaches such as running the supply fan at its full speed for economizing. Energy simulations may play an important role in optimizing the control sequence.

- When the outdoor-air temperature was above $70^{\circ} \mathrm{F}$, the current control sequence implemented two stages of DX cooling if the RTU had staged capacity controls. The supply fan ran at $75 \%$ or $90 \%$ of full speed for the two stages. To save more fan energy, it might be worthwhile to 
maintain the fan speed at $75 \%$ for the $2^{\text {nd }}$ stage cooling. Coil frosting or freezing should not be a concern because it has been considered with the low limit control of discharge-air temperature. However, additional work is needed to balance the reduction in fan energy with the impact of fan speed on DX cooling performance. Once the advantage of running the supply fan at low speed is verified, similar changes can be made for the DX cooling stage when the outdoor-air temperature is between $58^{\circ} \mathrm{F}$ and $70^{\circ} \mathrm{F}$.

- When the outdoor-air temperature was between $58^{\circ} \mathrm{F}$ and $70^{\circ} \mathrm{F}$ and there was a call for cooling, the current control sequence required that the $2^{\text {nd }}$ stage of DX cooling be initiated if the discharge-air temperature was above $58^{\circ} \mathrm{F}$ after the $1^{\text {st }}$ stage of DX cooling ran for 10 minutes. The motivation underlying this requirement was to ensure the space temperature reached the set point in a timely manner. However, this requirement may trigger the $2^{\text {nd }}$ stage DX cooling to come on unnecessarily. Because the anticipated temperature drop across the coil for the $1^{\text {st }}$ stage DX cooling is normally between $8^{\circ} \mathrm{F}$ and $12^{\circ} \mathrm{F}$, the discharge-air temperature is likely in the range between $56^{\circ} \mathrm{F}$ and $62^{\circ} \mathrm{F}$ when the outdoor-air temperature is less than $70^{\circ} \mathrm{F}$. Supplying air at that temperature range is usually sufficient to timely meeting the cooling load without causing comfort problems. In this respect, the current control sequence could be improved in several possible aspects: 1) consider using a time delay longer than 10 minutes; 2) consider raising the discharge-air temperature threshold value; 3 ) if the advanced controller has access to the space temperature, use the space temperature deviation from the cooling set point instead of the discharge-air temperature as the criterion to initiate the $2^{\text {nd }}$ stage of DX cooling; and 4) swap internally the $1^{\text {st }}$ and $2^{\text {nd }}$ stages of DX cooling and determine if the $2^{\text {nd }}$ stage is able to satisfy the internal requirements (discharge temperature and space set points).

- The discharge-air temperature sensor was used as a safety device to increase fan speeds when the discharge-air temperature was too high (discharge $>150^{\circ} \mathrm{F}$ ) or too low (discharge $<48^{\circ} \mathrm{F}$ ). If the discharge-air temperature sensor is reliable, it can be used to modulate the fan speed. Fan speeds could be based upon the target discharge set point (leaving air temperature) after the fan. Here are some concepts for heating and cooling:

- If the discharge temperature is less than the heating minimum target set point, slow the fan down incrementally until a threshold is reached. If the temperature continues to remain "stagnant", generate an alarm (heating failure). This may result in other actions such as activating the $2^{\text {nd }}$ stage heating coil or even making the $2^{\text {nd }}$ stage heating coil the $1^{\text {st }}$ stage heating coil.

- If the discharge temperature is greater than the cooling maximum target set point, slow the fan down incrementally until a threshold is reached. If the temperature continues to remain "stagnant", generate an alarm (cooling failure). This may result in other actions such as activating the $2^{\text {nd }}$ stage cooling coil or even making the $2^{\text {nd }}$ stage cooling coil the $1^{\text {st }}$ stage cooling coil.

- This control scheme enables "discharge-air temperature set point reset" possibilities for heating and cooling. Reset of the target discharge set point is based upon deviation (error) of room temperature from set point (heating or cooling). General reset values for heating would be $80^{\circ} \mathrm{F}$ to $140^{\circ} \mathrm{F}$ as the heating error grows from $0.1^{\circ} \mathrm{F}$ to $2.0^{\circ} \mathrm{F}$. General reset values for cooling would be $65^{\circ} \mathrm{F}$ to $50^{\circ} \mathrm{F}$, as the cooling error grows from $0.1^{\circ} \mathrm{F}$ to $2.0^{\circ} \mathrm{F}$. 
- The controller had heat pump lockouts that determined when compression heat was disabled (only electric heating is allowed) and when electric heat was disabled (only compression heat was allowed). The current sequence states: "Compressor heating is locked out when the Outside Air Temperature is below $35^{\circ} \mathrm{F}$ (adj.) and electric strip heat is locked out when the Outside Air Temperature is above $50^{\circ} \mathrm{F}$ (adj.)." Suggested improvements include lowering the electric strip lockout maximum value (it is still adjustable, but limit the maximum value to not exceed $42^{\circ} \mathrm{F}$ ); limit the minimum night set back temperature value that the space $(\mathrm{s})$ can be allowed to float. The idea is that the tradeoff for energy efficiency and savings is quickly lost when the RTU is a heat pump configuration with electric auxiliary heating. The kW demand costs from having to activate electric heating eliminates a significant portion of the kWh savings from extended night set back hours. This results in many owners putting their schedules to longer occupied periods. The solution is to have aggressive set back schedules (shorter occupancy periods), but limit the night set back temperature values $\left(65^{\circ} \mathrm{F}\right.$ would be the minimum setting allowed). This means that night time actions might show the RTU activating between 1 and 5 times to maintain the minimum setting, but the recovery period would be much shorter, and hopefully a short-lived use of the $2^{\text {nd }}$ stage auxiliary electric strip heater.

- The advanced controller can be enhanced by adding more capabilities, such as optimal start and stop, demand response strategies, and automatic fault diagnostics.

\subsection{ReCommendations on When to Consider THE AdVANCED RTU ConTROLleR RETROFIT}

Based on the analysis of the over 60 units in 4 different building types and 4 climate locations, it was clear that the building type, unit runtime and supply fan motor size are significant contributors to the energy savings potential. Although savings associated with DCV are expected to be high in extreme climate locations, most of the climate locations in the study were not extreme. Consider retrofitting an existing RTU with advanced controller under the following conditions, which will yield a 3-year payback period (Table 25):

Table 25: Recommendations on when to consider advanced RTU control retrofits that yield 3 year payback

\begin{tabular}{|l|l|l|}
\hline \multicolumn{1}{|c|}{ RTU Size } & Average Run Hours per Day & Utilities Rates and Incentives \\
\hline$>20$ tons & $>14$ & At any utility rates and with no incentive \\
\hline$>20$ tons & 12 to 14 & $\$ 0.10 / \mathrm{kWh}$ with no incentive \\
\hline$>20$ tons & $<10$ & $\$ 0.10 / \mathrm{kWh}$ with moderate $(25 \%)$ incentive \\
\hline 15 to 18 tons & $>14$ & $\$ 0.12 / \mathrm{kWh}$ with no incentive \\
\hline 15 to 18 tons & $<10$ & $\$ 0.10 / \mathrm{kWh}$ with high $(50 \%)$ incentive \\
\hline 7.5 to 12.5 tons & $>14$ & $\$ 0.15 / \mathrm{kWh}$ with no incentive \\
\hline 7.5 to 12.5 tons & $<10$ & $\$ 0.15 / \mathrm{kWh}$ with high $(50 \%)$ incentive \\
\hline$>7.5$ tons & $>14$ & $\$ 0.10 / \mathrm{kWh}$ with high $(50 \%)$ incentive \\
\hline$>7.5$ tons & $>14$ & $\$ 0.12 / \mathrm{kWh}$ with moderate $(25 \%)$ incentive \\
\hline$>7.5$ tons & $<10$ & $\$ 0.15 / \mathrm{kWh}$ with high $(50 \%)$ incentive \\
\hline
\end{tabular}


The above rules-of-thumb can be used for screening purposes, but a more thorough analysis based on site-specific conditions may be necessary. For units that are 5 tons and smaller, which typically use single-phase fan motors, this technology is not going to be cost-effective; however, there are other options for those units with single-phase motors that are cost-effective. Those options were not considered in this study. 


\section{REFERENCES}

ASHRAE 2002. ASHRAE Guideline 14-2002. Measurement of Energy and Demand Savings. American Society of Heating, Refrigerating and Air-Conditioning Engineers, Atlanta, GA.

ASHRAE. 2008. Handbook of HVAC Systems and Equipment. American Society of Heating, Refrigerating and Air-Conditioning Engineers, Atlanta, GA.

ASHRAE. 2010a. ASHRAE Standard 62.1-2010: Ventilation for Acceptable Indoor Air Quality. American Society of Heating, Refrigerating and Air-Conditioning Engineers Inc., Atlanta, GA.

ASHRAE. 2010b. ASHRAE Standard 90.1-2010: Energy Standard for Buildings Except Low-Rise Residential Buildings. American Society of Heating, Refrigerating and Air-Conditioning Engineers Inc. Atlanta, GA.

Brandemuel M.J. and J.E. Braun. 1999. "The impact of demand-controlled and economizer ventilation strategies on energy use in buildings." ASHRAE Transactions 105(2): 39-50.

Chan T. 2004. "Beyond the affinity laws." Engineered Systems, August, 2004.

Criscione P. 2011. "A dramatic boost for existing RTUs." E Source Research Brief, TAS-RB-47.

DOE (Department of Energy). 2010. EnergyPlus Energy Simulation Software, (version 6.0), US Department of Energy, Washington, DC.

Effinger M., J. Anthony, and L. Webster. 2009. "Case Studies in Using Whole Building Interval Data to Determine Annualized Electrical Savings." In Proceedings of the Ninth International Conference for Enhanced Building Operations, Austin, Texas, November, 2009, 13 pages, Texas A\&M University, College Station, TX.

EIA (Energy Information Administration). 2003. Commercial Buildings Energy Consumption Survey 2003. U.S. Department of Energy, Washington, D.C. Last accessed in July 2013 at http://www.eia.doe.gov/emeu/cbecs/contents.html.

Ford R.W. 2011. "Affinity Laws: Why They Work and When They Don't." ASHRAE Journal 53(3): 42-43.

Katipamula S., T.A. Reddy, and D.E. Claridge. 1995. "Effect of Time Resolution on Statistical Modeling of Cooling Energy Use in Large Commercial Buildings." ASHRAE Transactions, Vol. 101, Pt 2, pp. 172 185.

Katipamula S., R.G. Pratt, D.P. Chassin, Z.T. Taylor, K. Gowri, and M.R. Brambley. 1999. "Automated Fault Detection and Diagnostics for Outdoor-Air Ventilation Systems and Economizers: Methodology and Results from Field Testing." ASHRAE Transactions, Vol. 105 Pt. 1.

Katipamula S., M.R. Brambley, N.N. Bauman, and R.G. Pratt. 2003. "Enhancing Building Operations through Automated Diagnostics: Field Test Results." In Proceedings of the Third International Conference for Enhanced Building Operations (ICEBO), October 13-15, 2003. Berkeley, CA. Texas A\&M University, College Station, TX. 
Roth K.W., J. Dieckmann, and J. Brodrick. 2003. "Demand control ventilation." ASHRAE Journal 45(7): 9192.

Stanke D. 2006. “System Operation: Dynamic Reset Operations." ASHRAE Journal 48(12): 18-32.

Taasevigen D.J., S. Katipamula, and W. Koran. 2011. Interval Data Analysis with the Energy Charting and Metrics Tool (ECAM). PNNL-20495, Pacific Northwest National Laboratory, Richland, WA.

Taylor S.T. and C.H. Cheng. 2010. "Economizer High Limit Controls and Why Enthalpy Economizers Don't Work." ASHRAE Journal 52(11): 12-28

Wang W., S. Katipamula, Y. Huang, and M.R. Brambley. 2011. Energy Savings and Economics of Advanced Control Strategies for Packaged Air-Conditioning Units with Gas Heat. PNNL-20955, Pacific Northwest National Laboratory, Richland, WA

Wang W., Y. Huang, and S. Katipamula. 2012. Energy Savings and Economics of Advanced Control Strategies for Packaged Heat Pumps. PNNL-21944, Pacific Northwest National Laboratory, Richland, WA. 
APPENDIX A 
Table A - 1: Equipment characteristics of air conditioners with gas heat

\begin{tabular}{|c|c|c|c|c|c|c|c|c|c|c|c|c|c|c|}
\hline \multirow[t]{2}{*}{ ID } & \multirow[t]{2}{*}{ Make } & \multirow[t]{2}{*}{ Model } & \multirow{2}{*}{$\begin{array}{l}\text { Size } \\
\text { (ton) }\end{array}$} & \multirow[t]{2}{*}{ EER } & \multicolumn{2}{|c|}{$\begin{array}{l}\text { Burner } \\
\text { Capacity } \\
\text { (kBtu/h) }\end{array}$} & \multirow{2}{*}{$\begin{array}{c}\text { Economizer } \\
\text { changeover } \\
\left({ }^{\circ} \mathrm{F}\right)\end{array}$} & \multicolumn{2}{|c|}{$\begin{array}{l}\text { Min. Damper } \\
\text { Position }\end{array}$} & \multicolumn{2}{|c|}{$\begin{array}{l}\text { Occupied set } \\
\text { point }\left({ }^{\circ} \mathrm{F}\right)\end{array}$} & \multicolumn{2}{|c|}{$\begin{array}{c}\text { Unoccupied set } \\
\text { point }\left({ }^{\circ} \mathrm{F}\right)\end{array}$} & \multirow{2}{*}{$\begin{array}{l}\text { Repairs } \\
\text { needed }\end{array}$} \\
\hline & & & & & $\begin{array}{c}\text { 1st } \\
\text { stage }\end{array}$ & $\begin{array}{c}\text { 2nd } \\
\text { stage }\end{array}$ & & Pre- & Post-* & Heating & Cooling & Heating & Cooling & \\
\hline \multicolumn{15}{|l|}{$\begin{array}{l}\text { Site ID } \\
=28 \\
\end{array}$} \\
\hline 202 & Carrier & 48TJD012-611QA & 10 & 8.9 & 120 & 200 & 60 & $20 \%$ & & $\begin{array}{c}\text { No } \\
\text { access } \\
\text { to BMS }\end{array}$ & $\begin{array}{c}\text { No } \\
\text { access } \\
\text { to BMS }\end{array}$ & $\begin{array}{c}\text { No } \\
\text { access } \\
\text { to BMS }\end{array}$ & $\begin{array}{c}\text { No } \\
\text { access to } \\
\text { BMS }\end{array}$ & $\begin{array}{c}\text { replace } \\
\text { economizer } \\
\text { motor, clean } \\
\text { coils }\end{array}$ \\
\hline 203 & Carrier & 48TFD012-601GA & 10 & 9.0 & 120 & 180 & 60 & $0 \%$ & & $\begin{array}{c}\text { No } \\
\text { access } \\
\text { to BMS }\end{array}$ & $\begin{array}{c}\text { No } \\
\text { access } \\
\text { to BMS }\end{array}$ & $\begin{array}{c}\text { No } \\
\text { access } \\
\text { to BMS }\end{array}$ & $\begin{array}{c}\text { No } \\
\text { access to } \\
\text { BMS }\end{array}$ & $\begin{array}{c}\text { replaced } \\
\text { missing flue } \\
\text { hood, clean } \\
\text { coils }\end{array}$ \\
\hline 204 & Carrier & 48TJD012-611QA & 10 & 8.9 & 120 & 180 & 60 & $20 \%$ & & $\begin{array}{c}\text { No } \\
\text { access } \\
\text { to BMS }\end{array}$ & $\begin{array}{c}\text { No } \\
\text { access } \\
\text { to BMS }\end{array}$ & $\begin{array}{c}\text { No } \\
\text { access } \\
\text { to BMS }\end{array}$ & $\begin{array}{c}\text { No } \\
\text { access to } \\
\text { BMS } \\
\end{array}$ & clean coils \\
\hline 205 & Carrier & 48TJD016Z-650QA & 15 & 8.6 & 111 & 222 & 60 & $5 \%$ & & $\begin{array}{c}\text { No } \\
\text { access } \\
\text { to BMS }\end{array}$ & $\begin{array}{c}\text { No } \\
\text { access } \\
\text { to BMS }\end{array}$ & $\begin{array}{c}\text { No } \\
\text { access } \\
\text { to BMS }\end{array}$ & $\begin{array}{c}\text { No } \\
\text { access to } \\
\text { BMS } \\
\end{array}$ & clean coils \\
\hline 206 & Carrier & 48TFD012-601GA & 10 & 9.0 & 120 & 180 & 60 & $10 \%$ & & $\begin{array}{c}\text { No } \\
\text { access } \\
\text { to BMS }\end{array}$ & $\begin{array}{c}\text { No } \\
\text { access } \\
\text { to BMS }\end{array}$ & $\begin{array}{c}\text { No } \\
\text { access } \\
\text { to BMS }\end{array}$ & $\begin{array}{c}\text { No } \\
\text { access to } \\
\text { BMS } \\
\end{array}$ & clean coils \\
\hline 207 & Carrier & 48TJD028-600QA & 25 & 8.5 & 111 & 265 & 60 & $20 \%$ & & $\begin{array}{c}\text { No } \\
\text { access } \\
\text { to BMS }\end{array}$ & $\begin{array}{c}\text { No } \\
\text { access } \\
\text { to BMS }\end{array}$ & $\begin{array}{c}\text { No } \\
\text { access } \\
\text { to BMS }\end{array}$ & $\begin{array}{c}\text { No } \\
\text { access to } \\
\text { BMS }\end{array}$ & $\begin{array}{c}\text { replace LOR } \\
\text { board, free } \\
\text { up econ. } \\
\text { vanes, } \\
\text { replace } \\
\text { econ. motor, } \\
\text { clean coils }\end{array}$ \\
\hline
\end{tabular}




\begin{tabular}{|c|c|c|c|c|c|c|c|c|c|c|c|c|c|c|}
\hline \multirow[t]{2}{*}{ ID } & \multirow[t]{2}{*}{ Make } & \multirow[t]{2}{*}{ Model } & \multirow{2}{*}{$\begin{array}{l}\text { Size } \\
\text { (ton) }\end{array}$} & \multirow[t]{2}{*}{ EER } & \multicolumn{2}{|c|}{$\begin{array}{c}\text { Burner } \\
\text { Capacity } \\
\text { (kBtu/h) }\end{array}$} & \multirow{2}{*}{$\begin{array}{c}\text { Economizer } \\
\text { changeover } \\
\left({ }^{\circ} \mathrm{F}\right)\end{array}$} & \multicolumn{2}{|c|}{$\begin{array}{l}\text { Min. Damper } \\
\text { Position }\end{array}$} & \multicolumn{2}{|c|}{$\begin{array}{l}\text { Occupied set } \\
\text { point }\left({ }^{\circ} \mathrm{F}\right)\end{array}$} & \multicolumn{2}{|c|}{$\begin{array}{l}\text { Unoccupied set } \\
\left.\text { point ( }{ }^{\circ} \mathrm{F}\right)\end{array}$} & \multirow{2}{*}{$\begin{array}{l}\text { Repairs } \\
\text { needed }\end{array}$} \\
\hline & & & & & $\begin{array}{c}\text { 1st } \\
\text { stage }\end{array}$ & $\begin{array}{c}\text { 2nd } \\
\text { stage }\end{array}$ & & Pre- & Post-* & Heating & Cooling & Heating & Cooling & \\
\hline 209 & Carrier & 48TJD006-601QA & 5 & 8.5 & 74 & 74 & 60 & $20 \%$ & & $\begin{array}{c}\text { No } \\
\text { access } \\
\text { to BMS }\end{array}$ & $\begin{array}{c}\text { No } \\
\text { access } \\
\text { to BMS }\end{array}$ & $\begin{array}{c}\text { No } \\
\text { access } \\
\text { to BMS }\end{array}$ & $\begin{array}{c}\text { No } \\
\text { access to } \\
\text { BMS }\end{array}$ & $\begin{array}{c}\text { added } \\
\text { refrigerant, } \\
\text { replace } \\
\text { compressor, } \\
\text { replace heat } \\
\text { exchanger, } \\
\text { clean indoor } \\
\text { coils }\end{array}$ \\
\hline 210 & Carrier & 48TJD028-600QA & 25 & 8.5 & 111 & 265 & 60 & $20 \%$ & & $\begin{array}{c}\text { No } \\
\text { access } \\
\text { to BMS } \\
\end{array}$ & $\begin{array}{c}\text { No } \\
\text { access } \\
\text { to BMS }\end{array}$ & $\begin{array}{c}\text { No } \\
\text { access } \\
\text { to BMS } \\
\end{array}$ & $\begin{array}{c}\text { No } \\
\text { access to } \\
\text { BMS } \\
\end{array}$ & $\begin{array}{c}\text { clean incoor } \\
\text { coils }\end{array}$ \\
\hline 212 & Carrier & 48TJD028-600QA & 25 & 8.5 & 111 & 265 & 60 & $20 \%$ & & $\begin{array}{c}\text { No } \\
\text { access } \\
\text { to BMS }\end{array}$ & $\begin{array}{c}\text { No } \\
\text { access } \\
\text { to BMS }\end{array}$ & $\begin{array}{c}\text { No } \\
\text { access } \\
\text { to BMS }\end{array}$ & $\begin{array}{c}\text { No } \\
\text { access to } \\
\text { BMS }\end{array}$ & $\begin{array}{c}\text { replace LOR } \\
\text { board, } \\
\text { added } \\
\text { refrigerant, } \\
\text { clean coils }\end{array}$ \\
\hline 213 & Carrier & 48TJD016Z-650QA & 15 & 8.6 & 115 & 230 & 60 & $0 \%$ & & $\begin{array}{c}\text { No } \\
\text { access } \\
\text { to BMS }\end{array}$ & $\begin{array}{c}\text { No } \\
\text { access } \\
\text { to BMS }\end{array}$ & $\begin{array}{c}\text { No } \\
\text { access } \\
\text { to BMS }\end{array}$ & $\begin{array}{c}\text { No } \\
\text { access to } \\
\text { BMS }\end{array}$ & $\begin{array}{c}\text { replace fan } \\
\text { motor, clean } \\
\text { coils }\end{array}$ \\
\hline 214 & Carrier & 48TJD0122-611AA & 10 & 8.9 & 120 & 200 & 60 & $20 \%$ & & $\begin{array}{c}\text { No } \\
\text { access } \\
\text { to BMS }\end{array}$ & $\begin{array}{c}\text { No } \\
\text { access } \\
\text { to BMS }\end{array}$ & $\begin{array}{c}\text { No } \\
\text { access } \\
\text { to BMS }\end{array}$ & $\begin{array}{c}\text { No } \\
\text { access to } \\
\text { BMS }\end{array}$ & $\begin{array}{l}\text { replace fan } \\
\text { motor, } \\
\text { replace } \\
\text { sheave,clean } \\
\text { coils } \\
\end{array}$ \\
\hline 215 & Carrier & 48TJD012-611GA & 10 & 8.9 & 120 & 200 & 60 & $0 \%$ & & $\begin{array}{c}\text { No } \\
\text { access } \\
\text { to BMS }\end{array}$ & $\begin{array}{c}\text { No } \\
\text { access } \\
\text { to BMS }\end{array}$ & $\begin{array}{c}\text { No } \\
\text { access } \\
\text { to BMS }\end{array}$ & $\begin{array}{c}\text { No } \\
\text { access to } \\
\text { BMS }\end{array}$ & $\begin{array}{c}\text { replace fan } \\
\text { motor, clean } \\
\text { coils }\end{array}$ \\
\hline 216 & Carrier & 48TJD012-611QA & 10 & 8.9 & 120 & 200 & 60 & $0 \%$ & & $\begin{array}{c}\text { No } \\
\text { access } \\
\text { to BMS }\end{array}$ & $\begin{array}{c}\text { No } \\
\text { access } \\
\text { to BMS }\end{array}$ & $\begin{array}{c}\text { No } \\
\text { access } \\
\text { to BMS }\end{array}$ & $\begin{array}{c}\text { No } \\
\text { access to } \\
\text { BMS }\end{array}$ & $\begin{array}{c}\text { replaced } \\
\text { ignition } \\
\text { module, } \\
\text { flame sensor } \\
\& \text { ignitor, }\end{array}$ \\
\hline
\end{tabular}




\begin{tabular}{|c|c|c|c|c|c|c|c|c|c|c|c|c|c|c|}
\hline \multirow{2}{*}{ ID } & \multirow{2}{*}{ Make } & \multirow{2}{*}{ Model } & \multirow{2}{*}{$\begin{array}{l}\text { Size } \\
\text { (ton) }\end{array}$} & \multirow{2}{*}{ EER } & \multicolumn{2}{|c|}{$\begin{array}{l}\text { Burner } \\
\text { Capacity } \\
\text { (kBtu/h) }\end{array}$} & \multirow{2}{*}{$\begin{array}{c}\text { Economizer } \\
\text { changeover } \\
\left({ }^{\circ} \mathrm{F}\right)\end{array}$} & \multicolumn{2}{|c|}{$\begin{array}{l}\text { Min. Damper } \\
\text { Position }\end{array}$} & \multicolumn{2}{|c|}{$\begin{array}{l}\text { Occupied set } \\
\text { point }\left({ }^{\circ} \mathrm{F}\right)\end{array}$} & \multicolumn{2}{|c|}{$\begin{array}{l}\text { Unoccupied set } \\
\left.\text { point ( }{ }^{\circ} \mathrm{F}\right)\end{array}$} & \multirow{2}{*}{$\begin{array}{l}\text { Repairs } \\
\text { needed }\end{array}$} \\
\hline & & & & & $\begin{array}{c}\text { 1st } \\
\text { stage }\end{array}$ & $\begin{array}{l}\text { 2nd } \\
\text { stage }\end{array}$ & & Pre- & Post-* & Heating & Cooling & Heating & Cooling & \\
\hline & & & & & & & & & & & & & & clean coils \\
\hline 217 & Carrier & 48TJD012-611QA & 10 & 8.9 & 120 & 200 & 60 & $10 \%$ & & $\begin{array}{c}\text { No } \\
\text { access } \\
\text { to BMS }\end{array}$ & $\begin{array}{c}\text { No } \\
\text { access } \\
\text { to BMS }\end{array}$ & $\begin{array}{c}\text { No } \\
\text { access } \\
\text { to BMS }\end{array}$ & $\begin{array}{c}\text { No } \\
\text { access to } \\
\text { BMS }\end{array}$ & clean coils \\
\hline 218 & Carrier & 48TJD012-611GA & 10 & 8.9 & 120 & 200 & 60 & $5 \%$ & & $\begin{array}{c}\text { No } \\
\text { access } \\
\text { to BMS }\end{array}$ & $\begin{array}{c}\text { No } \\
\text { access } \\
\text { to BMS }\end{array}$ & $\begin{array}{c}\text { No } \\
\text { access } \\
\text { to BMS }\end{array}$ & $\begin{array}{c}\text { No } \\
\text { access to } \\
\text { BMS }\end{array}$ & clean coils \\
\hline 219 & Carrier & 48TJD016Z-650QA & 15 & 8.6 & 111 & 222 & 60 & $20 \%$ & & $\begin{array}{l}\text { No } \\
\text { access } \\
\text { to BMS }\end{array}$ & $\begin{array}{c}\text { No } \\
\text { access } \\
\text { to BMS }\end{array}$ & $\begin{array}{l}\text { No } \\
\text { access } \\
\text { to BMS }\end{array}$ & $\begin{array}{c}\text { No } \\
\text { access to } \\
\text { BMS }\end{array}$ & $\begin{array}{l}\text { replace fan } \\
\text { motor, } \\
\text { replace } \\
\text { econ. motor, } \\
\text { clean coils }\end{array}$ \\
\hline 220 & Carrier & 48tjd016-670QA & 15 & 8.6 & 111 & 222 & 60 & $20 \%$ & & $\begin{array}{c}\text { No } \\
\text { access } \\
\text { to BMS }\end{array}$ & $\begin{array}{c}\text { No } \\
\text { access } \\
\text { to BMS }\end{array}$ & $\begin{array}{c}\text { No } \\
\text { access } \\
\text { to BMS }\end{array}$ & $\begin{array}{c}\text { No } \\
\text { access to } \\
\text { BMS }\end{array}$ & clean coils \\
\hline 221 & Carrier & 48TJD012-611GA & 10 & 8.9 & 120 & 200 & 63 & $30 \%$ & & $\begin{array}{c}\text { No } \\
\text { access } \\
\text { to BMS }\end{array}$ & $\begin{array}{c}\text { No } \\
\text { access } \\
\text { to BMS }\end{array}$ & $\begin{array}{c}\text { No } \\
\text { access } \\
\text { to BMS }\end{array}$ & $\begin{array}{c}\text { No } \\
\text { access to } \\
\text { BMS }\end{array}$ & clean coils \\
\hline 222 & Carrier & 48TJD012-611QA & 10 & 8.6 & 111 & 222 & 60 & $0 \%$ & & $\begin{array}{c}\text { No } \\
\text { access } \\
\text { to BMS }\end{array}$ & $\begin{array}{c}\text { No } \\
\text { access } \\
\text { to BMS }\end{array}$ & $\begin{array}{c}\text { No } \\
\text { access } \\
\text { to BMS }\end{array}$ & $\begin{array}{c}\text { No } \\
\text { access to } \\
\text { BMS }\end{array}$ & clean coils \\
\hline 223 & Carrier & 48TJD016-671QA & 15 & 8.6 & 111 & 222 & 60 & $20 \%$ & & $\begin{array}{c}\text { No } \\
\text { access } \\
\text { to BMS }\end{array}$ & $\begin{array}{c}\text { No } \\
\text { access } \\
\text { to BMS }\end{array}$ & \begin{tabular}{|c|} 
No \\
access \\
to BMS \\
\end{tabular} & $\begin{array}{c}\text { No } \\
\text { access to } \\
\text { BMS }\end{array}$ & clean coils \\
\hline 224 & Carrier & 48TJD012-611QA & 10 & 8.9 & 120 & 200 & 60 & $15 \%$ & & $\begin{array}{c}\text { No } \\
\text { access } \\
\text { to BMS }\end{array}$ & $\begin{array}{c}\text { No } \\
\text { access } \\
\text { to BMS }\end{array}$ & $\begin{array}{c}\text { No } \\
\text { access } \\
\text { to BMS }\end{array}$ & $\begin{array}{c}\text { No } \\
\text { access to } \\
\text { BMS }\end{array}$ & clean coils \\
\hline 225 & Carrier & 48TFD012-601GA & 10 & 9.0 & 120 & 180 & 62 & $15 \%$ & & $\begin{array}{c}\text { No } \\
\text { access } \\
\text { to BMS }\end{array}$ & $\begin{array}{c}\text { No } \\
\text { access } \\
\text { to BMS }\end{array}$ & $\begin{array}{c}\text { No } \\
\text { access } \\
\text { to BMS }\end{array}$ & $\begin{array}{c}\text { No } \\
\text { access to } \\
\text { BMS }\end{array}$ & clean coils \\
\hline
\end{tabular}




\begin{tabular}{|c|c|c|c|c|c|c|c|c|c|c|c|c|c|c|}
\hline \multirow{2}{*}{ ID } & \multirow{2}{*}{ Make } & \multirow{2}{*}{ Model } & \multirow{2}{*}{$\begin{array}{l}\text { Size } \\
\text { (ton) }\end{array}$} & \multirow{2}{*}{ EER } & \multicolumn{2}{|c|}{$\begin{array}{l}\text { Burner } \\
\text { Capacity } \\
\text { (kBtu/h) }\end{array}$} & \multirow{2}{*}{$\begin{array}{c}\text { Economizer } \\
\text { changeover } \\
\left({ }^{\circ} \mathrm{F}\right)\end{array}$} & \multicolumn{2}{|c|}{$\begin{array}{l}\text { Min. Damper } \\
\text { Position }\end{array}$} & \multicolumn{2}{|c|}{$\begin{array}{l}\text { Occupied set } \\
\text { point }\left({ }^{\circ} \mathrm{F}\right)\end{array}$} & \multicolumn{2}{|c|}{$\begin{array}{l}\text { Unoccupied set } \\
\text { point }\left({ }^{\circ} \mathrm{F}\right)\end{array}$} & \multirow{2}{*}{$\begin{array}{l}\text { Repairs } \\
\text { needed }\end{array}$} \\
\hline & & & & & $\begin{array}{c}1 \text { st } \\
\text { stage }\end{array}$ & $\begin{array}{l}\text { 2nd } \\
\text { stage }\end{array}$ & & Pre- & Post-* & Heating & Cooling & Heating & Cooling & \\
\hline 226 & Carrier & 48TJD014621GA & 12.5 & 8.6 & 180 & 225 & 55 & $5 \%$ & & $\begin{array}{c}\text { No } \\
\text { access } \\
\text { to BMS }\end{array}$ & $\begin{array}{c}\text { No } \\
\text { access } \\
\text { to BMS }\end{array}$ & $\begin{array}{c}\text { No } \\
\text { access } \\
\text { to BMS }\end{array}$ & $\begin{array}{c}\text { No } \\
\text { access to } \\
\text { BMS }\end{array}$ & $\begin{array}{c}\text { replaced } \\
\text { rollout } \\
\text { switch with } \\
195 \text { degree } \\
\text { switch, clean } \\
\text { coils } \\
\end{array}$ \\
\hline 227 & Carrier & 48TFD012-601GA & 10 & 9.0 & 120 & 180 & 60 & $5 \%$ & & $\begin{array}{c}\text { No } \\
\text { access } \\
\text { to BMS }\end{array}$ & $\begin{array}{c}\text { No } \\
\text { access } \\
\text { to BMS }\end{array}$ & $\begin{array}{c}\text { No } \\
\text { access } \\
\text { to BMS }\end{array}$ & $\begin{array}{c}\text { No } \\
\text { access to } \\
\text { BMS }\end{array}$ & clean coils \\
\hline 228 & Carrier & 48TJD012-611QA & 10 & 8.9 & 120 & 200 & 58 & $10 \%$ & & $\begin{array}{c}\text { No } \\
\text { access } \\
\text { to BMS }\end{array}$ & $\begin{array}{c}\text { No } \\
\text { access } \\
\text { to BMS }\end{array}$ & $\begin{array}{c}\text { No } \\
\text { access } \\
\text { to BMS }\end{array}$ & $\begin{array}{c}\text { No } \\
\text { access to } \\
\text { BMS }\end{array}$ & $\begin{array}{c}\text { replace } \\
\text { economizer } \\
\text { motor, clean } \\
\text { coils } \\
\end{array}$ \\
\hline 229 & Trane & YSC120A4RA1401B & 10 & 10.2 & 175 & 250 & 60 & $15 \%$ & & $\begin{array}{c}\text { No } \\
\text { access } \\
\text { to BMS } \\
\end{array}$ & $\begin{array}{c}\text { No } \\
\text { access } \\
\text { to BMS }\end{array}$ & $\begin{array}{c}\text { No } \\
\text { access } \\
\text { to BMS } \\
\end{array}$ & $\begin{array}{c}\text { No } \\
\text { access to } \\
\text { BMS }\end{array}$ & clean coils \\
\hline 230 & Trane & YCD150D4LOBA & 12.5 & 10.3 & 100 & 150 & 58 & $5 \%$ & & $\begin{array}{c}\text { No } \\
\text { access } \\
\text { to BMS }\end{array}$ & $\begin{array}{c}\text { No } \\
\text { access } \\
\text { to BMS }\end{array}$ & $\begin{array}{c}\text { No } \\
\text { access } \\
\text { to BMS } \\
\end{array}$ & $\begin{array}{c}\text { No } \\
\text { access to } \\
\text { BMS }\end{array}$ & \\
\hline 231 & Trane & YSC090A4RHA1HC & 7.5 & 10.1 & 140 & 200 & 58 & $10 \%$ & & $\begin{array}{c}\text { No } \\
\text { access } \\
\text { to BMS }\end{array}$ & $\begin{array}{c}\text { No } \\
\text { access } \\
\text { to BMS }\end{array}$ & $\begin{array}{c}\text { No } \\
\text { access } \\
\text { to BMS }\end{array}$ & $\begin{array}{c}\text { No } \\
\text { access to } \\
\text { BMS }\end{array}$ & \\
\hline \multicolumn{15}{|l|}{$\begin{array}{l}\text { Site ID } \\
=39\end{array}$} \\
\hline 362 & Carrier & 48TJF020Z & 18 & 8.5 & 270 & 360 & $\begin{array}{l}\text { do not } \\
\text { have this } \\
\text { info }\end{array}$ & $10 \%$ & & 68 & 72 & 68 & 72 & $\begin{array}{c}\text { power } \\
\text { esxhaust } \\
\text { hooked up \& } \\
\text { fixed } \\
\text { actuators } \\
\text { that were } \\
\text { installed } \\
\text { backwards }\end{array}$ \\
\hline
\end{tabular}




\begin{tabular}{|c|c|c|c|c|c|c|c|c|c|c|c|c|c|c|}
\hline \multirow{2}{*}{ ID } & \multirow{2}{*}{ Make } & \multirow{2}{*}{ Model } & \multirow{2}{*}{$\begin{array}{l}\text { Size } \\
\text { (ton) }\end{array}$} & \multirow{2}{*}{ EER } & \multicolumn{2}{|c|}{$\begin{array}{l}\text { Burner } \\
\text { Capacity } \\
\text { (kBtu/h) }\end{array}$} & \multirow{2}{*}{$\begin{array}{c}\text { Economizer } \\
\text { changeover } \\
\left({ }^{\circ} \mathrm{F}\right)\end{array}$} & \multicolumn{2}{|c|}{$\begin{array}{l}\text { Min. Damper } \\
\text { Position }\end{array}$} & \multicolumn{2}{|c|}{$\begin{array}{l}\text { Occupied set } \\
\text { point }\left({ }^{\circ} \mathrm{F}\right)\end{array}$} & \multicolumn{2}{|c|}{$\begin{array}{l}\text { Unoccupied set } \\
\text { point }\left({ }^{\circ} \mathrm{F}\right)\end{array}$} & \multirow{2}{*}{$\begin{array}{l}\text { Repairs } \\
\text { needed }\end{array}$} \\
\hline & & & & & $\begin{array}{c}\text { 1st } \\
\text { stage }\end{array}$ & $\begin{array}{l}\text { 2nd } \\
\text { stage }\end{array}$ & & Pre- & Post-* & Heating & Cooling & Heating & Cooling & \\
\hline 363 & Carrier & 48TF024Z & 20 & 8.5 & 270 & 360 & $\begin{array}{l}\text { do not } \\
\text { have this } \\
\text { info }\end{array}$ & $10 \%$ & & 68 & 72 & 68 & 72 & $\begin{array}{c}\text { power } \\
\text { esxhaust } \\
\text { hooked up \& } \\
\text { fixed } \\
\text { actuators } \\
\text { that were } \\
\text { installed } \\
\text { backwards }\end{array}$ \\
\hline \multicolumn{15}{|c|}{$\begin{array}{l}\text { Site ID } \\
=40\end{array}$} \\
\hline 364 & Lennox & LGC300H4BH3G & 25 & 9.5 & 169 & 250 & N/A & $\begin{array}{c}0 \% \\
\text { (emulated } \\
\text { at } 20 \% \\
\text { prior to } \\
8 / 31 \text { ) } \\
\end{array}$ & & 68 & 74 & N/A & N/A & \\
\hline 365 & Lennox & LGC300H4BH3G & 25 & 11 & 169 & 250 & $\mathrm{~N} / \mathrm{A}$ & $\begin{array}{c}0 \% \\
\text { (emulated } \\
\text { at } 20 \% \\
\text { prior to } \\
8 / 31 \text { ) } \\
\end{array}$ & & 68 & 74 & N/A & N/A & \\
\hline 366 & Lennox & LGC300H4BH3G & 25 & 11 & 169 & 250 & N/A & $\begin{array}{c}0 \% \\
\text { (emulated } \\
\text { at } 20 \% \\
\text { prior to } \\
8 / 31 \text { ) } \\
\end{array}$ & & 68 & 74 & $\mathrm{~N} / \mathrm{A}$ & $\mathrm{N} / \mathrm{A}$ & \\
\hline 367 & Lennox & LGC300H4BH3G & 25 & 11 & 169 & 250 & N/A & $\begin{array}{c}0 \% \\
\text { (emulated } \\
\text { at } 20 \% \\
\text { prior to } \\
8 / 31 \text { ) } \\
\end{array}$ & & 68 & 74 & $\mathrm{~N} / \mathrm{A}$ & $\mathrm{N} / \mathrm{A}$ & \\
\hline
\end{tabular}




\begin{tabular}{|c|c|c|c|c|c|c|c|c|c|c|c|c|c|c|}
\hline \multirow{2}{*}{ ID } & \multirow{2}{*}{ Make } & \multirow{2}{*}{ Model } & \multirow{2}{*}{$\begin{array}{l}\text { Size } \\
\text { (ton) }\end{array}$} & \multirow{2}{*}{ EER } & \multicolumn{2}{|c|}{$\begin{array}{l}\text { Burner } \\
\text { Capacity } \\
\text { (kBtu/h) }\end{array}$} & \multirow{2}{*}{$\begin{array}{c}\text { Economizer } \\
\text { changeover } \\
\left({ }^{\circ} \mathrm{F}\right)\end{array}$} & \multicolumn{2}{|c|}{$\begin{array}{l}\text { Min. Damper } \\
\text { Position }\end{array}$} & \multicolumn{2}{|c|}{$\begin{array}{l}\text { Occupied set } \\
\text { point }\left({ }^{\circ} \mathrm{F}\right)\end{array}$} & \multicolumn{2}{|c|}{$\begin{array}{l}\text { Unoccupied set } \\
\text { point }\left({ }^{\circ} \mathrm{F}\right)\end{array}$} & \multirow{2}{*}{$\begin{array}{l}\text { Repairs } \\
\text { needed }\end{array}$} \\
\hline & & & & & $\begin{array}{c}\text { 1st } \\
\text { stage }\end{array}$ & $\begin{array}{l}\text { 2nd } \\
\text { stage }\end{array}$ & & Pre- & Post-* & Heating & Cooling & Heating & Cooling & \\
\hline 368 & Lennox & LGC300H4BH3G & 25 & 11 & 169 & 250 & N/A & $\begin{array}{c}0 \% \\
\text { (emulated } \\
\text { at } 20 \% \\
\text { prior to } \\
8 / 31 \text { ) } \\
\end{array}$ & & 68 & 74 & N/A & N/A & \\
\hline 369 & Lennox & LGC300H4BH3G & 25 & 11 & 169 & 250 & N/A & $\begin{array}{c}0 \% \\
\text { (emulated } \\
\text { at } 20 \% \\
\text { prior to } \\
8 / 31 \text { ) }\end{array}$ & & 68 & 74 & $\mathrm{~N} / \mathrm{A}$ & N/A & \\
\hline 370 & Lennox & LGC300H4BH3G & 25 & 11 & 169 & 250 & N/A & $\begin{array}{c}0 \% \\
\text { (emulated } \\
\text { at } 20 \% \\
\text { prior to } \\
8 / 31 \text { ) }\end{array}$ & & 68 & 74 & N/A & N/A & \\
\hline 371 & Lennox & LGC300H4BH3G & 25 & 11 & 169 & 250 & N/A & $\begin{array}{c}0 \% \\
\text { (emulated } \\
\text { at } 20 \% \\
\text { prior to } \\
8 / 31 \text { ) } \\
\end{array}$ & & 68 & 74 & N/A & N/A & $\begin{array}{l}\text { replaced } \\
\text { actuator }\end{array}$ \\
\hline \multicolumn{15}{|l|}{$\begin{array}{c}\text { Site ID } \\
=46\end{array}$} \\
\hline 407 & Carrier & 48HD008---541 & 7.5 & 11 & 72 & 179 & $\mathrm{~N} / \mathrm{A}$ & $20 \%$ & & N/A & $\mathrm{N} / \mathrm{A}$ & $\mathrm{N} / \mathrm{A}$ & N/A & none \\
\hline 408 & Carrier & 48HD012571 & 10 & 11 & 109 & 281 & N/A & $20 \%$ & & N/A & N/A & N/A & N/A & $\begin{array}{l}\text { bare high } \\
\text { voltage line } \\
\text { on top of } \\
\text { one } \\
\text { compressor } \\
\text { need to }\end{array}$ \\
\hline
\end{tabular}




\begin{tabular}{|c|c|c|c|c|c|c|c|c|c|c|c|c|c|c|}
\hline \multirow{2}{*}{ ID } & \multirow{2}{*}{ Make } & \multirow{2}{*}{ Model } & \multirow{2}{*}{$\begin{array}{l}\text { Size } \\
\text { (ton) }\end{array}$} & \multirow{2}{*}{ EER } & \multicolumn{2}{|c|}{$\begin{array}{l}\text { Burner } \\
\text { Capacity } \\
\text { (kBtu/h) }\end{array}$} & \multirow{2}{*}{$\begin{array}{c}\text { Economizer } \\
\text { changeover } \\
\left({ }^{\circ} \mathrm{F}\right)\end{array}$} & \multicolumn{2}{|c|}{$\begin{array}{l}\text { Min. Damper } \\
\text { Position }\end{array}$} & \multicolumn{2}{|c|}{$\begin{array}{l}\text { Occupied set } \\
\text { point }\left({ }^{\circ} \mathrm{F}\right)\end{array}$} & \multicolumn{2}{|c|}{$\begin{array}{l}\text { Unoccupied set } \\
\text { point }\left({ }^{\circ} \mathrm{F}\right)\end{array}$} & \multirow{2}{*}{$\begin{array}{l}\text { Repairs } \\
\text { needed }\end{array}$} \\
\hline & & & & & $\begin{array}{c}\text { 1st } \\
\text { stage }\end{array}$ & $\begin{array}{l}\text { 2nd } \\
\text { stage }\end{array}$ & & Pre- & Post-* & Heating & Cooling & Heating & Cooling & \\
\hline & & & & & & & & & & & & & & $\begin{array}{c}\text { replace } \\
\text { compressor, } \\
\text { wiring \& } \\
\text { contactor. }\end{array}$ \\
\hline 409 & Carrier & $\begin{array}{c}\text { 48HGD016--- } \\
\text { 591QA }\end{array}$ & 15 & 11.5 & 199 & 250 & $\mathrm{~N} / \mathrm{A}$ & $20 \%$ & & $\mathrm{~N} / \mathrm{A}$ & $\mathrm{N} / \mathrm{A}$ & N/A & N/A & $\begin{array}{c}\text { needs new } \\
\text { sheaves and } \\
\text { belts \& } \\
\text { economizer } \\
\text { needs full } \\
\text { service }\end{array}$ \\
\hline 410 & Carrier & $\begin{array}{c}\text { 48HGD028AC-- } \\
\text { 501AA }\end{array}$ & 25 & 10.4 & 199 & 250 & $\mathrm{~N} / \mathrm{A}$ & $20 \%$ & & N/A & $\mathrm{N} / \mathrm{A}$ & N/A & N/A & $\begin{array}{c}\text { needs new } \\
\text { sheaves, } \\
\text { belts \& } \\
\text { bearings }\end{array}$ \\
\hline 411 & Carrier & $\begin{array}{c}\text { 48HGD028AC-- } \\
\text { 501AA }\end{array}$ & 25 & 10.4 & 199 & 250 & $\mathrm{~N} / \mathrm{A}$ & $20 \%$ & & N/A & $\mathrm{N} / \mathrm{A}$ & N/A & N/A & $\begin{array}{c}\text { needs new } \\
\text { sheaves, } \\
\text { belts \& } \\
\text { bearings }\end{array}$ \\
\hline \multicolumn{15}{|c|}{$\begin{array}{l}\text { Site ID } \\
=51\end{array}$} \\
\hline 423 & Lennox & LGA120HH1Y & 10 & 10.0 & 152 & 205 & $\begin{array}{c}62 \\
\text { (emulated } \\
\text { at } 55 \text { prior } \\
\text { to } 8 / 31 \text { ) }\end{array}$ & $20 \%$ & & 68 & 73 & 55 & 85 & none \\
\hline 424 & Lennox & LGA120HH1Y & 10 & 10.0 & 133 & 205 & $\begin{array}{c}62 \\
\text { (emulated } \\
\text { at } 55 \text { prior } \\
\text { to } 8 / 31 \text { ) }\end{array}$ & $30 \%$ & & 68 & 73 & 55 & 85 & none \\
\hline
\end{tabular}




\begin{tabular}{|c|c|c|c|c|c|c|c|c|c|c|c|c|c|c|}
\hline \multirow{2}{*}{ ID } & \multirow{2}{*}{ Make } & \multirow{2}{*}{ Model } & \multirow{2}{*}{$\begin{array}{l}\text { Size } \\
\text { (ton) }\end{array}$} & \multirow{2}{*}{ EER } & \multicolumn{2}{|c|}{$\begin{array}{l}\text { Burner } \\
\text { Capacity } \\
\text { (kBtu/h) }\end{array}$} & \multirow{2}{*}{$\begin{array}{c}\text { Economizer } \\
\text { changeover } \\
\left({ }^{\circ} \mathrm{F}\right)\end{array}$} & \multicolumn{2}{|c|}{$\begin{array}{l}\text { Min. Damper } \\
\text { Position }\end{array}$} & \multicolumn{2}{|c|}{$\begin{array}{l}\text { Occupied set } \\
\text { point }\left({ }^{\circ} \mathrm{F}\right)\end{array}$} & \multicolumn{2}{|c|}{$\begin{array}{l}\text { Unoccupied set } \\
\text { point }\left({ }^{\circ} \mathrm{F}\right)\end{array}$} & \multirow{2}{*}{$\begin{array}{l}\text { Repairs } \\
\text { needed }\end{array}$} \\
\hline & & & & & $\begin{array}{c}\text { 1st } \\
\text { stage }\end{array}$ & $\begin{array}{l}\text { 2nd } \\
\text { stage }\end{array}$ & & Pre- & Post-* & Heating & Cooling & Heating & Cooling & \\
\hline 425 & Lennox & LGA120HH1Y & 10 & 10.0 & 133 & 205 & $\begin{array}{c}62 \\
\text { (emulated } \\
\text { at } 55 \text { prior } \\
\text { to } 8 / 31 \text { ) }\end{array}$ & $20 \%$ & & 68 & 73 & 55 & 85 & none \\
\hline 426 & Lennox & LGA120HH1Y & 10 & 10.0 & 133 & 205 & $\begin{array}{c}62 \\
\text { (emulated } \\
\text { at } 55 \text { prior } \\
\text { to } 8 / 31 \text { ) }\end{array}$ & $30 \%$ & & 68 & 73 & 55 & 85 & none \\
\hline 427 & Lennox & LGA120HH1Y & 10 & 10.0 & 133 & 205 & $\begin{array}{c}62 \\
\text { (emulated } \\
\text { at } 55 \text { prior } \\
\text { to } 8 / 31 \text { ) }\end{array}$ & $40 \%$ & & 68 & 73 & 55 & 85 & none \\
\hline
\end{tabular}

Note: During the post-retrofit period the minimum damper position varied with the supply-fan speed. For all units, the minimum amount of outdoor air (OA) for ventilation is $5 \%$ of the design supply-air flow when the supply fan runs at $100 \%$. At other fan speeds, the damper position is calculated as ( $5 \% /$ fan speed). For example, when the fan runs at $40 \%$ of its full speed, the OA damper position is set at $5 \% / 40 \%=12.5 \%$. 
Table A - 2: Equipment characteristics of heat pump units

\begin{tabular}{|c|c|c|c|c|c|c|c|c|c|c|c|c|c|c|}
\hline \multirow{2}{*}{ ID } & \multirow{2}{*}{ Make } & \multirow{2}{*}{ Model } & \multirow{2}{*}{$\begin{array}{l}\text { Size } \\
\text { (ton) }\end{array}$} & \multicolumn{2}{|c|}{ Efficiency } & \multirow{2}{*}{$\begin{array}{c}\text { Auxiliary } \\
\text { Heat } \\
\text { kW }\end{array}$} & \multirow{2}{*}{$\begin{array}{c}\text { Economizer } \\
\text { changeover } \\
\left({ }^{\circ} \mathbf{F}\right)\end{array}$} & \multicolumn{2}{|c|}{$\begin{array}{l}\text { Minimum } \\
\text { Damper } \\
\text { Position }\end{array}$} & \multicolumn{2}{|c|}{$\begin{array}{l}\text { Occupied set point } \\
\qquad\left({ }^{\circ} \mathrm{F}\right)\end{array}$} & \multicolumn{2}{|c|}{$\begin{array}{l}\text { Unoccupied set point } \\
\qquad\left({ }^{\circ} \mathrm{F}\right)\end{array}$} & \multirow{2}{*}{$\begin{array}{l}\text { Repairs } \\
\text { needed }\end{array}$} \\
\hline & & & & Cooling & Heating & & & Pre- & Post-* & Heating & Cooling & Heating & Cooling & \\
\hline \multicolumn{15}{|l|}{$\begin{array}{l}\text { Site } \\
\text { ID } \\
=41 \\
\end{array}$} \\
\hline 372 & Trane & WCD150B30AGB & 12.5 & 10.6 & $\begin{array}{l}\text { High=3.2 } \\
\text { Low=2.1 }\end{array}$ & 36 & N/A & $10 \%$ & $5 \%$ & 73 & 76 & 60 & 80 & none \\
\hline \multicolumn{15}{|l|}{$\begin{array}{c}\text { Site } \\
\text { ID = } \\
43 \\
\end{array}$} \\
\hline 375 & Trane & WCH180E40BAB & 15 & 10.6 & $\begin{array}{l}\text { High }=3.2 \\
\text { Low }=2.1\end{array}$ & 18 & 55 & $15 \%$ & $5 \%$ & 71 & 75 & 62 & 78 & none \\
\hline 376 & Trane & WSC090E4RGAOD & 7.5 & 11.1 & $\begin{array}{l}\text { High }=3.4 \\
\text { Low }=2.2\end{array}$ & 18 & 65 & $5 \%$ & $5 \%$ & 71 & 75 & 62 & 78 & none \\
\hline 377 & Trane & WSC090E4RGAO9D & 7.5 & 11.1 & $\begin{array}{l}\text { High }=3.4 \\
\text { Low }=2.2\end{array}$ & 18 & 65 & $5 \%$ & $5 \%$ & 71 & 75 & 62 & 78 & none \\
\hline 378 & Trane & WSC120E4RGA08D & 10 & 11.2 & $\begin{array}{l}\text { High }=3.6 \\
\text { Low }=2.40\end{array}$ & 18 & 65 & $5 \%$ & $5 \%$ & 71 & 75 & 62 & 78 & none \\
\hline 379 & Trane & WSC060E4BGA10D & 5 & $\begin{array}{c}13 \\
\text { SEER }\end{array}$ & $\begin{array}{c}\text { High }=3.5 \\
\text { Low }=2.3 \\
/ 8.0 \text { HSPF }\end{array}$ & 18 & 65 & $20 \%$ & $5 \%$ & 71 & 75 & 62 & 78 & none \\
\hline 380 & Trane & WSC090E4RGA0901B & 7.5 & 11.1 & $\begin{array}{l}\text { High }=3.4 \\
\text { Low }=2.2\end{array}$ & 18 & 65 & $10 \%$ & $5 \%$ & 71 & 75 & 62 & 78 & none \\
\hline
\end{tabular}




\begin{tabular}{|c|c|c|c|c|c|c|c|c|c|c|c|c|c|c|}
\hline $\begin{array}{l}\text { Site } \\
\text { ID } \\
=44\end{array}$ & & & & & & & & & & & & & & \\
\hline 381 & Trane & WCD180B400EA & 15 & 9.6 & $\begin{array}{l}\text { High }=3.2 \\
\text { Low }=2.1\end{array}$ & 18 & 65 & $20 \%$ & $5 \%$ & 74 & 74 & 60 & 85 & none \\
\hline 382 & Trane & WCD180B40GGA & 15 & 9.6 & $\begin{array}{l}\text { High }=3.2 \\
\text { Low }=2.1\end{array}$ & 18 & 55 & $10 \%$ & $5 \%$ & 68 & 74 & 60 & 85 & none \\
\hline 383 & Trane & WCD180B40GGA & 15 & 9.6 & $\begin{array}{l}\text { High }=3.2 \\
\text { Low }=2.1\end{array}$ & 18 & 65 & $20 \%$ & $5 \%$ & 68 & 74 & 60 & 85 & none \\
\hline 384 & Trane & WCD240B400EB & 20 & 9.8 & $\begin{array}{l}\text { High }=3.2 \\
\text { Low }=2.1\end{array}$ & 38 & 55 & $20 \%$ & $5 \%$ & 74 & 74 & 60 & 85 & $\begin{array}{c}\text { needs } 2 \\
\text { heat } \\
\text { contact } \\
\text { ors \& a } \\
\text { new } \\
\text { belt } \\
\end{array}$ \\
\hline 385 & Trane & WCD180B40GGA & 15 & 9.6 & $\begin{array}{l}\text { High }=3.2 \\
\text { Low }=2.1\end{array}$ & 18 & 65 & $20 \%$ & $5 \%$ & 68 & 74 & 60 & 85 & $\begin{array}{c}\text { circuit } \\
1 \text { low } \\
\text { on } \\
\text { charge }\end{array}$ \\
\hline 386 & Trane & WCD180B40GGA & 15 & 9.6 & $\begin{array}{l}\text { High }=3.2 \\
\text { Low }=2.1\end{array}$ & 18 & 55 & $20 \%$ & $5 \%$ & 68 & 74 & 60 & 85 & none \\
\hline 387 & Trane & WCD180B40GGA & 15 & 9.6 & $\begin{array}{l}\text { High }=3.2 \\
\text { Low }=2.1\end{array}$ & 18 & 60 & $20 \%$ & $5 \%$ & 68 & 74 & 60 & 85 & $\begin{array}{c}\text { needs } \\
\text { new } \\
\text { belt }\end{array}$ \\
\hline 388 & Trane & WCD180B400EA & 15 & 9.6 & $\begin{array}{l}\text { High }=3.2 \\
\text { Low }=2.1\end{array}$ & 18 & 65 & $0 \%$ & $5 \%$ & 74 & 74 & 60 & 85 & none \\
\hline 389 & Trane & WCD180B40GGA & 15 & 9.6 & $\begin{array}{l}\text { High }=3.2 \\
\text { Low }=2.1\end{array}$ & 18 & 55 & $10 \%$ & $5 \%$ & 68 & 74 & 60 & 85 & none \\
\hline 390 & Trane & WCD180B40GGA & 15 & 9.6 & $\begin{array}{l}\text { High }=3.2 \\
\text { Low }=2.1\end{array}$ & 18 & 55 & $30 \%$ & $5 \%$ & 68 & 74 & 60 & 85 & none \\
\hline 391 & Trane & WCD180B40GGA & 15 & 9.6 & $\begin{array}{l}\text { High }=3.2 \\
\text { Low }=2.1\end{array}$ & 18 & 55 & $20 \%$ & $5 \%$ & 68 & 74 & 60 & 85 & $\begin{array}{c}\text { needs } 1 \\
\text { heat } \\
\text { contact } \\
\text { or } \\
\text { (single }\end{array}$ \\
\hline
\end{tabular}




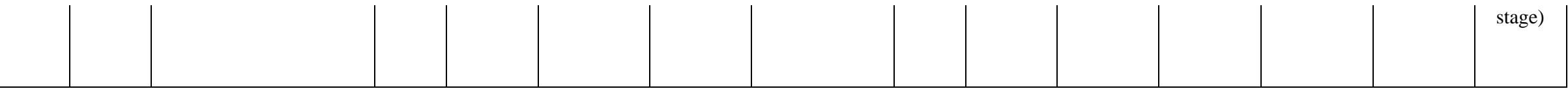

Note: During the post-retrofit period the minimum damper position varied with the supply-fan speed. For all units, the minimum amount of outdoor air (OA) for ventilation is $5 \%$ of the design supply-air flow when the supply fan runs at $100 \%$. At other fan speeds, the damper position is calculated as ( $5 \% /$ fan speed). For example, when the fan runs at $40 \%$ of its full speed, the OA damper position is set at $5 \% / 40 \%=12.5 \%$.

Table A - 3: Number of days in each operation mode ("standard" versus "advanced")

\begin{tabular}{|r|r|l|}
\hline RTU ID & $\begin{array}{l}\text { Number of Days } \\
\text { with “Standard” } \\
\text { (ESM Off) }\end{array}$ & $\begin{array}{l}\text { Number of Days } \\
\text { with “Advanced” } \\
\text { (ESM On) }\end{array}$ \\
\hline 202 & 67 & 220 \\
\hline 203 & 70 & 199 \\
\hline 204 & 74 & 238 \\
\hline 205 & 71 & 240 \\
\hline 206 & 82 & 194 \\
\hline 207 & 53 & 71 \\
\hline 209 & 80 & 241 \\
\hline 210 & 34 & 156 \\
\hline 212 & 92 & 266 \\
\hline 213 & 92 & 259 \\
\hline 214 & 80 & 198 \\
\hline 215 & 78 & 244 \\
\hline 216 & 4 & 7 \\
\hline 217 & 94 & 254 \\
\hline 218 & 80 & 246 \\
\hline 219 & 29 & 66 \\
\hline 220 & 82 & 240 \\
\hline 221 & 77 & 239 \\
\hline 222 & 95 & 250 \\
\hline 223 & 81 & 236 \\
\hline & & \\
\hline & &
\end{tabular}




\begin{tabular}{|c|c|c|}
\hline RTU ID & $\begin{array}{l}\text { Number of Days } \\
\text { with "Standard" } \\
\text { (ESM Off) }\end{array}$ & $\begin{array}{l}\text { Number of Days } \\
\text { with "Advanced" } \\
\text { (ESM On) }\end{array}$ \\
\hline 224 & 69 & 227 \\
\hline 225 & 79 & 191 \\
\hline 226 & 82 & 240 \\
\hline 227 & 30 & 130 \\
\hline 228 & 75 & 242 \\
\hline 229 & 81 & 246 \\
\hline 231 & 80 & 238 \\
\hline 362 & 145 & 166 \\
\hline 363 & 161 & 184 \\
\hline 364 & 163 & 173 \\
\hline 365 & 165 & 177 \\
\hline 366 & 158 & 171 \\
\hline 367 & 166 & 178 \\
\hline 368 & 127 & 141 \\
\hline 369 & 161 & 174 \\
\hline 370 & 166 & 177 \\
\hline 371 & 166 & 179 \\
\hline 372 & 88 & 92 \\
\hline 375 & 105 & 123 \\
\hline 376 & 108 & 127 \\
\hline 377 & 109 & 126 \\
\hline 378 & 114 & 121 \\
\hline 379 & 109 & 126 \\
\hline 380 & 109 & 125 \\
\hline 381 & 145 & 160 \\
\hline 382 & 145 & 160 \\
\hline 383 & 141 & 154 \\
\hline
\end{tabular}




\begin{tabular}{|c|c|c|}
\hline RTU ID & $\begin{array}{l}\text { Number of Days } \\
\text { with "Standard" } \\
\text { (ESM Off) }\end{array}$ & $\begin{array}{l}\text { Number of Days } \\
\text { with "Advanced" } \\
\text { (ESM On) }\end{array}$ \\
\hline 384 & 139 & 153 \\
\hline 385 & 144 & 159 \\
\hline 386 & 144 & 160 \\
\hline 387 & 144 & 158 \\
\hline 388 & 144 & 157 \\
\hline 389 & 140 & 151 \\
\hline 390 & 140 & 151 \\
\hline 391 & 139 & 151 \\
\hline 407 & 94 & 83 \\
\hline 408 & 137 & 153 \\
\hline 409 & 134 & 139 \\
\hline 410 & 137 & 153 \\
\hline 411 & 128 & 141 \\
\hline 423 & 126 & 142 \\
\hline 424 & 126 & 139 \\
\hline 425 & 126 & 142 \\
\hline 426 & 126 & 142 \\
\hline 427 & 126 & 142 \\
\hline
\end{tabular}




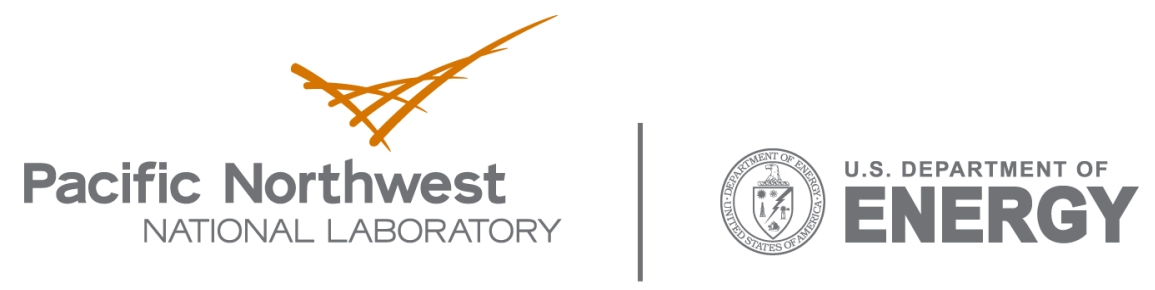

902 Battelle Boulevard

P.O. Box 999

Richland, WA 99352

1-888-375-PNNL (7665)

www.pnl.gov 